\title{
The ecological and immunological relationships between Salmonella and tuatara
}

\section{Danielle Mary Rose Lea Middleton}

A thesis submitted to

Victoria University of Wellington

in fulfilment of the requirements for the degree of

Doctor of Philosophy in Ecology and Biodiversity 


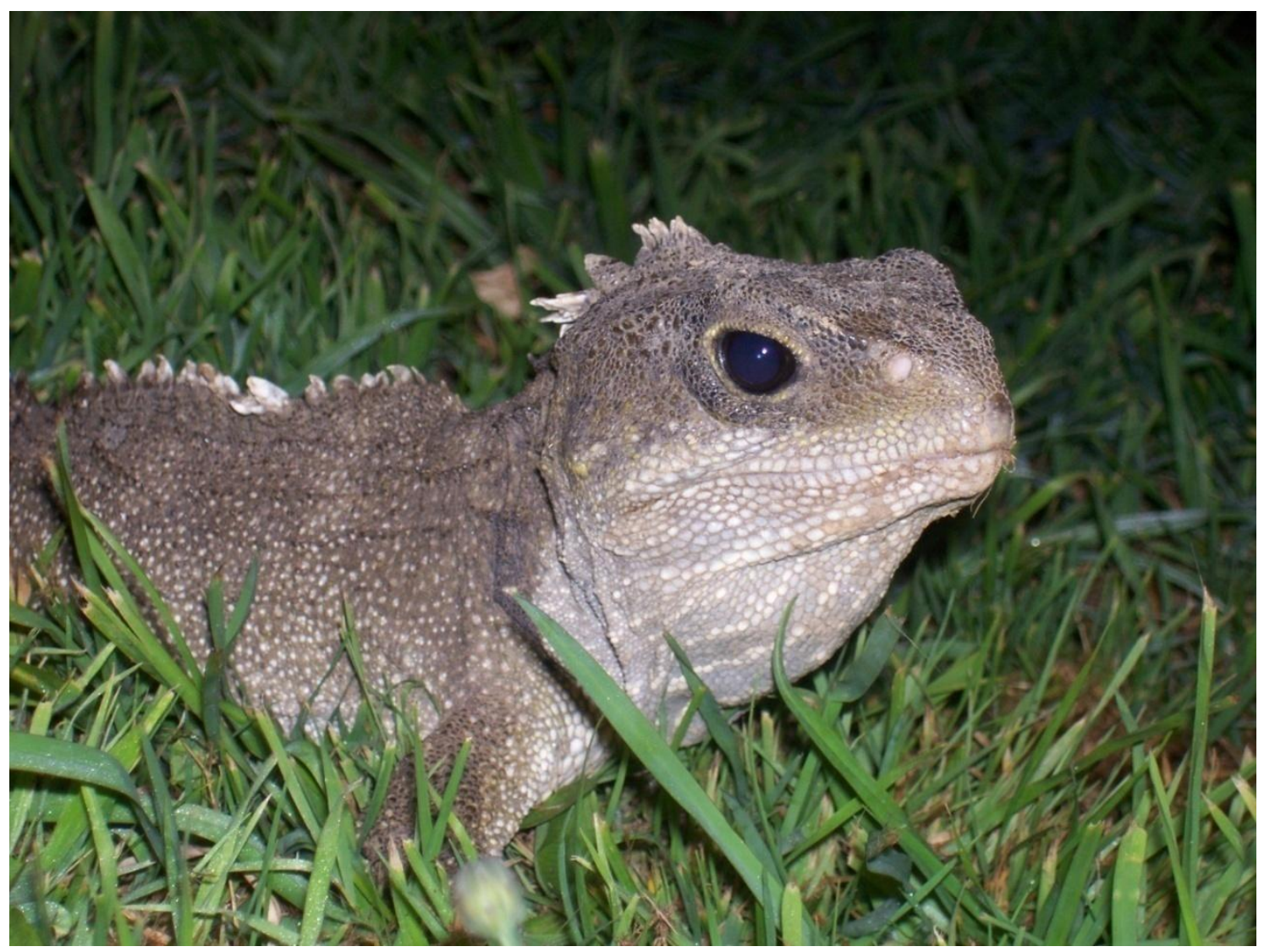

"Such is the adaptability and versatility of microorganisms as compared with humans and other so-called 'higher' organisms that they will doubtless continue to colonize and alter the face of the Earth long after we and the rest of our cohabitants have left the stage forever.

Microbes, not macrobes rule the world" 


\section{Abstract}

The transmission and expression of disease in wild animal populations is a complex interaction of host, pathogen and environmental factors. The individual fitness of a host may be negatively impacted by pathogenic bacteria in a number of ways including increased predation risk and reduced survival and reproductive output. Salmonellosis is an important zoonotic disease resulting in significant morbidity and mortality in populations of wild reptiles, birds and mammals throughout the world, and herpetofaunal species have often been implicated as shedders and transmitters of Salmonella globally. To better understand the unique threats to New Zealand native wildlife, I investigated spatio-temporal dynamics of Salmonella in an island ecosystem, and selected one species, tuatara (Sphenodon punctatus) (an endemic New Zealand reptile), for in-depth immunological analyses. I collected cloacal swabs and faecal samples from native wildlife on Stephens Island repeatedly between October 2009 and October 2011. While Salmonella was isolated from $6.5 \%$ of native skinks and $8 \%$ of the soil samples, intestinal carriage of Salmonella was not detected in the more than 600 cloacal swabs collected from wild tuatara, despite these tuatara living in close proximity to Salmonella-positive skinks or soil. In context, the lack of Salmonella detected in tuatara in this and other studies raises the question of whether tuatara are innately resistant to Salmonella.

To test this hypothesis I examined aspects of innate and adaptive immune responses in tuatara serum. Immune measurements included in vitro anti-microbial activity of serum and antibody recognition of bacterial antigens. Serum was tested against three closely related enteric pathogens, including Salmonella, in order to establish the importance of cross-reactivity in the strength of immune responses observed. I found that tuatara possess antibodies which recognise Salmonella antigens by Western blot and flow cytometry. I also determined that the anti-microbial activity of tuatara serum was approximately 6-fold higher than donkey or mouse sera, but showed similar activity to other reptilian species tested. These findings are the first report of both environmentally-induced anti-Salmonella antibodies and anti-microbial activity in tuatara serum. Taken together, these studies investigating the distribution and 
seasonality of Salmonella within the environment and evaluating anti-Salmonella immune responses in tuatara will help to inform decisions about disease screening and animal movements to maintain the health of native fauna. 


\section{Acknowledgements}

My $\mathrm{PhD}$ has been an amazing journey on which I have been aided and assisted by so many wonderful people. I would first like to thank my supervisors Nicola Nelson and Anne La Flamme. I am so grateful for the encouragement and inspiration they offered me both professionally and personally. They encouraged me to be the best I could be, to seize and make the most of every opportunity that came my way. I would also like to thank my secondary supervisors Brett Gartrell and Paul Rainey for their encouragement and advice.

I am very thankful for the financial support of the Allan Wilson Centre for Molecular Ecology and Evolution, Centre for Biodiversity and Restoration Ecology (CBRE) and Victoria University of Wellington, without whom this work would not have been possible. My work was also supported by Ngati Koata Iwi with permission from the New Zealand Department of Conservation (DoC; permit NM26339-FAU) and the Victoria University Animal Ethics committee (permit \#2009R12). This work was also made possible through the support of the many zoos and wildlife parks who allowed me to collect blood and cloacal swabs from their tuatara and exotic reptiles. All the staff at these parks were amazingly supportive throughout the research.

I would also like to acknowledge the support I received from a number of Department of Conservation staff. Thank you to Mike Aviss, Peter Gaze and all the team at Havelock who went above and beyond to provide assistance for this project, whether it was a prompt permit, transport to Stephens Island, or a ride back to Picton so that the weary, grubby scientists could make the last sailing of the day. I'd like to say a very big thank you to the DoC rangers on Stephens Island, Margie Grant-Caplan and Tim Bacon who went out of their way to help with every aspect of this project, but also made it fun!! Many a laugh was shared between Margie, Tim, Ilse and I. It would not have been possible to have sampled as many tuatara as I did without the help of some excellent field assistants. But a very special thank you must to go to my partner in crime, Ilse Corkery. Ilse made the cold nights, spent shivering on a hillside in 70knot winds more than tolerable, she made them fun. I'd also like to thank Heidy Kikillus who stepped up last minute and rescued a field trip after a rather unfortunate incident 
involving a $12 \mathrm{~kg}$ battery and my foot. A big thank you to Les Moran for not only sharing his vast skink and gecko knowledge with me but also for sharing many laughs during cold evenings in the house.

I have made some fantastic friends during my time at Victoria University. I'm very grateful to my office mates Helen Taylor, Lindsay Mickelson, Rosalynn AndersonLederer, Anna Carter and Elizabeth Heeg who meticulously edited endless drafts, drank many cups of tea and commiserated when things went wrong. I'd also like to thank everyone in labs KK601 and later AM312, especially Laura Green, Ariane Chan, Maddie White and Jenni Williams. Thanks for all the time you spent teaching me western blotting and FACsing, and thank you for letting me rant when they didn't work, it helped! A special thank you must go to Marie Kharkrang for all her help and advice with lab work and also for the many hours she spent reading my thesis. I am so grateful for the help that Steven Ritchie provided me with getting the genetic component of this research off the ground. It simply wouldn't have happened without him.

The final thanks belong to my wonderful family, their support was unwavering throughout this venture. My love goes to my family who have been incredibly understanding about the long hours and constant travels. A very special and sincere thank you to my mum, Julie, I would not have made it through this without her constant love and support and it is because of her strength of character and appreciation of the natural world that I am where I am today. I would also like to thank my uncle Darryl for the many hours he spent painstakingly editing my thesis. Finally, thank you to my partner Joel, who always managed to get me back-on-track with a word of encouragement and was my rock during the stressful times when nothing seemed to be working. I'm very grateful to my mum and Joel for their unwavering belief that I could do it.

"Progress lies not in enhancing what is, but in advancing toward what will be." - Kahlil Gibran 


\section{Table of Contents}

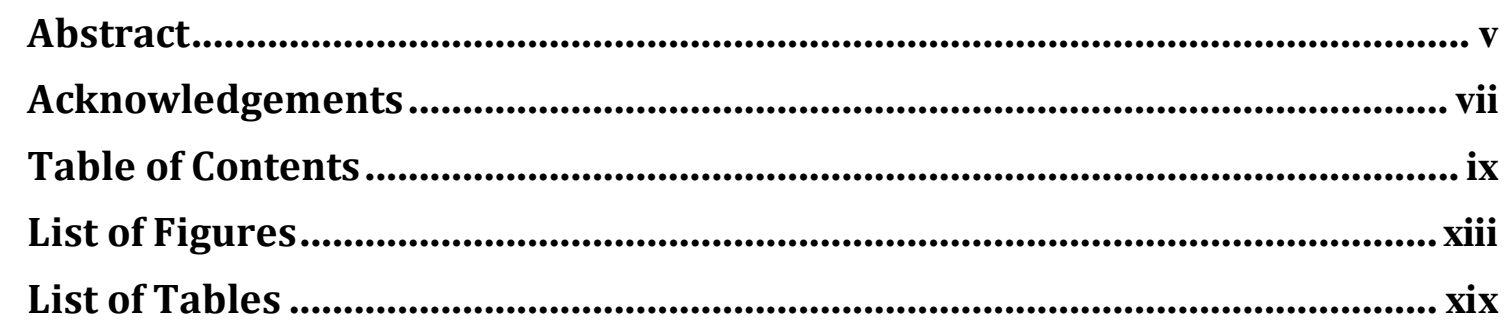

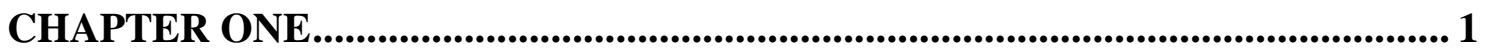

Salmonella disease ecology and immunology ........................................................ 1

$1.1 \quad$ Introduction.......................................................................................... 1

1.2 Salmonella, Escherichia and Citrobacter characteristics................................ 2

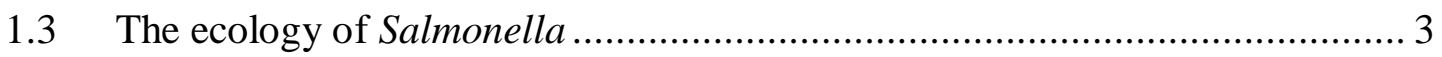

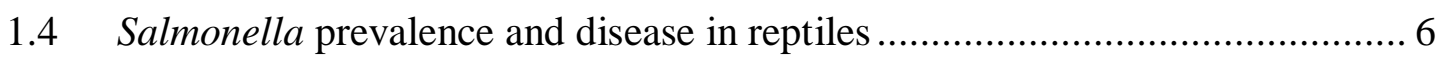

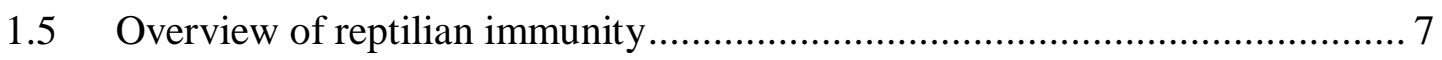

1.5.1 The innate immune response ……………….................................. 8

1.5.2 The adaptive immune response ......................................................... 9

1.5.3 Seasonal variation in reptilian immune responses .................................. 11

$1.6 \quad$ Tuatara ecology and immunity ................................................................. 12

1.8 Key questions, thesis outline and style....................................................... 16

1.8.1 Thesis outline and style .................................................................. 17

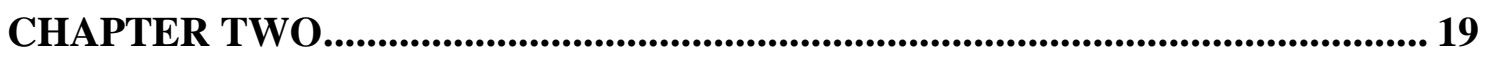

The abundance and spatio-temporal dynamics of Salmonella in an island

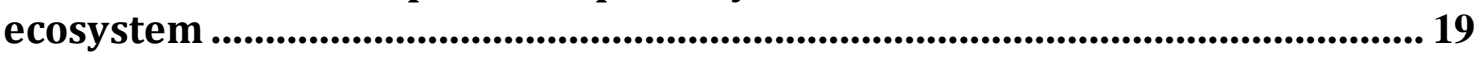

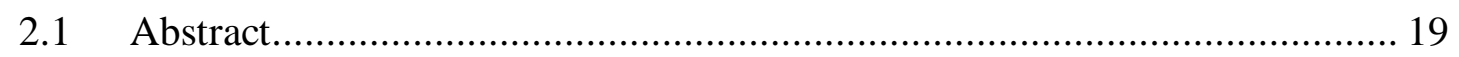

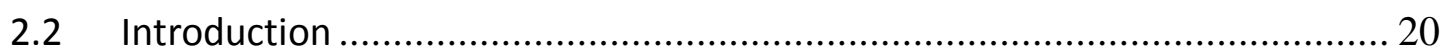

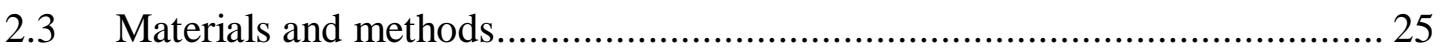

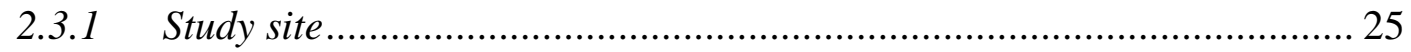

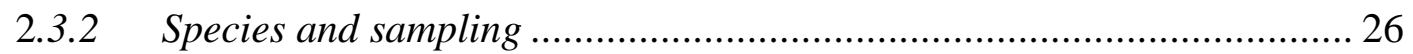

2.3.3 Laboratory isolation of Salmonella …………........................................ 30

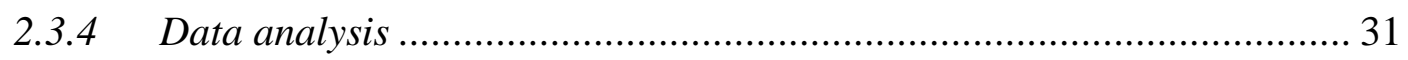

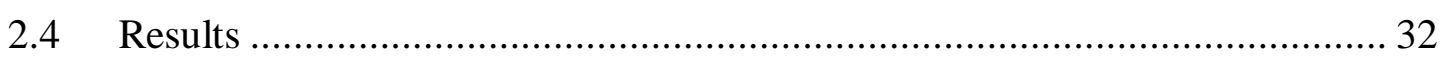

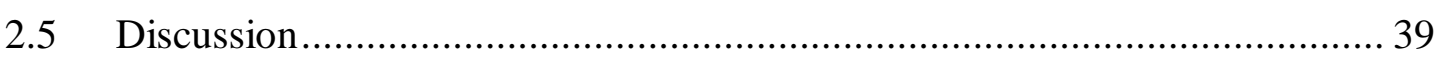


Presence of antibodies to Salmonella in tuatara sera ..........................................45

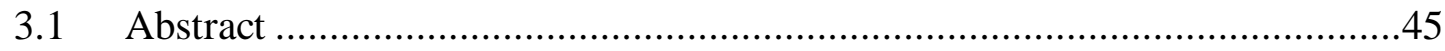

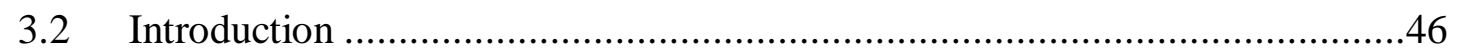

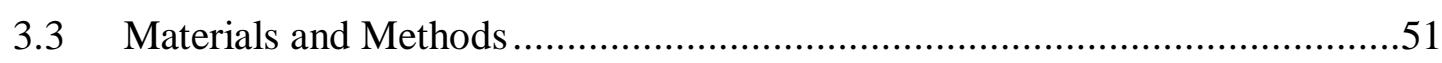

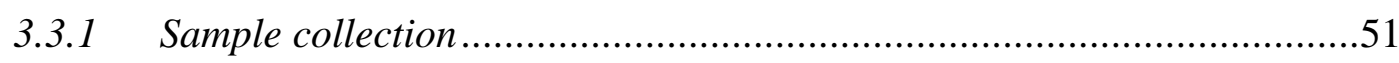

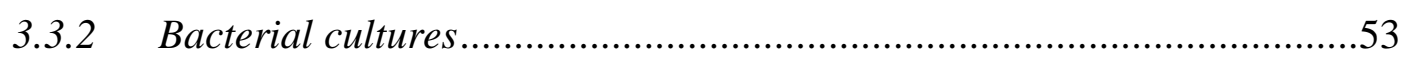

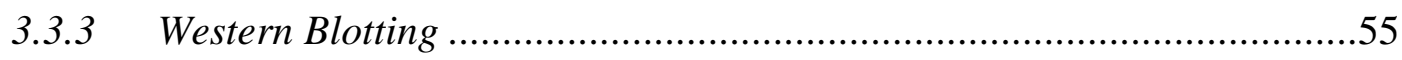

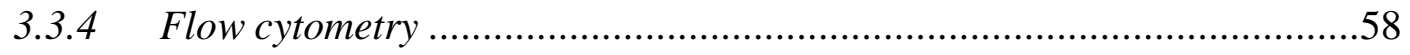

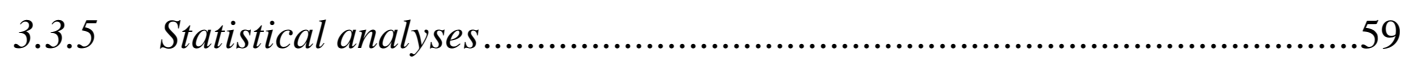

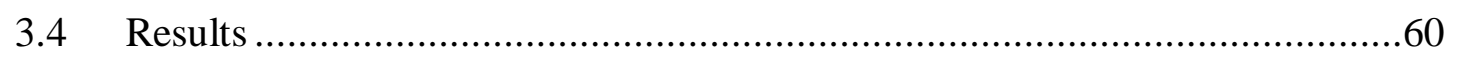

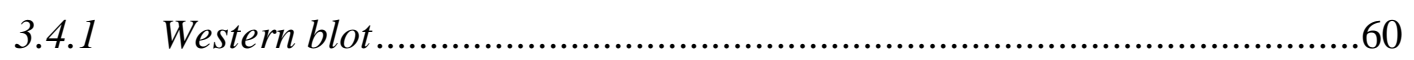

3.4.2 Optimisation of FCM ......................................................................65

3.4.3 Cross reactivity of tuatara sera antibodies to $S$. Saintpaul, E. coli and C. koseri .................................................................67

3.4.4 Seroprevalence of S. Saintpaul, E.coli and C. koseri among wild and

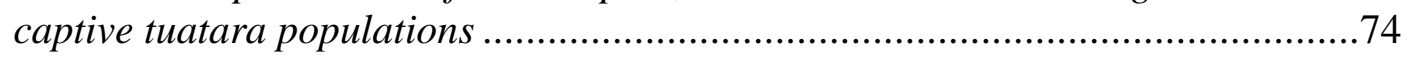

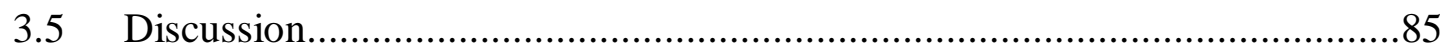

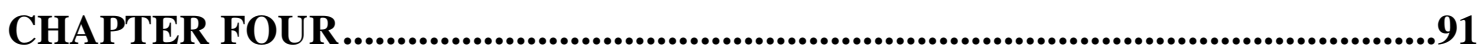

Anti-microbial activity of tuatara sera .....................................................................91

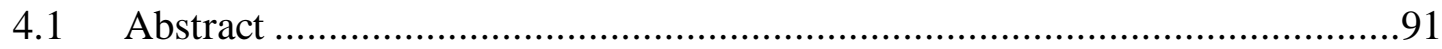

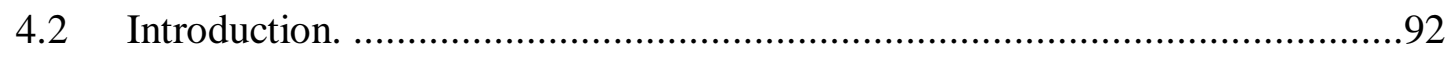

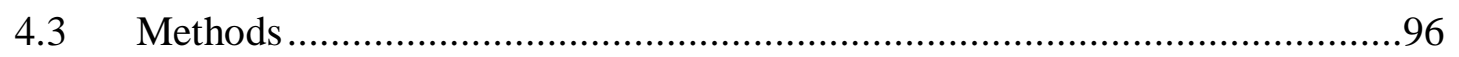

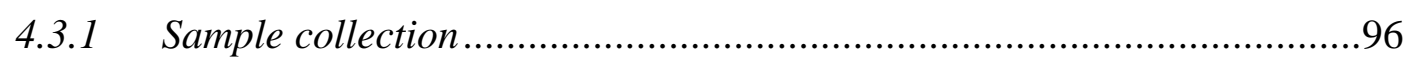

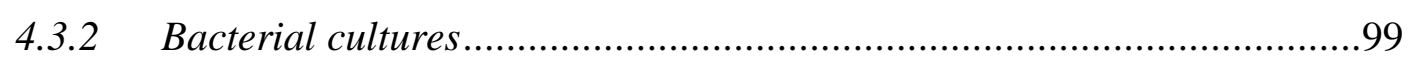

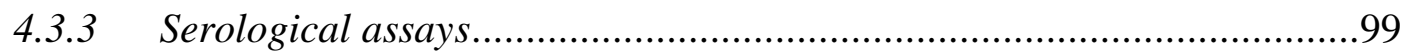

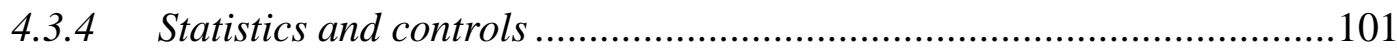

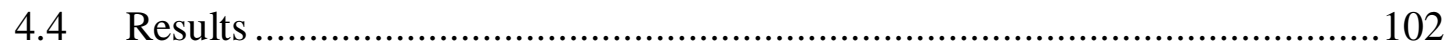

4.4.1 Tuatara anti-microbial activity against S. Saintpaul, E. coli and C. koseri

4.4.2 Concentration-dependent antibacterial properties of serum ..................102

4.4.3 Effects of decomplemented sera and protein size exclusion....................105

4.4.4 Effects of season, sex and body condition on the immune response of

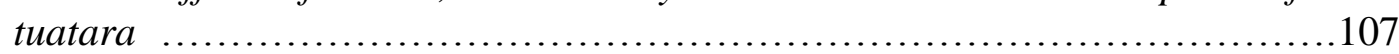

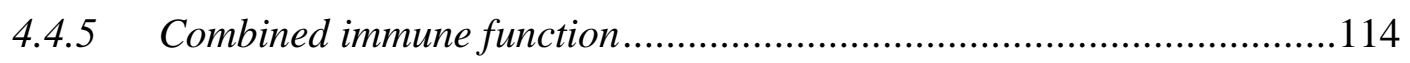

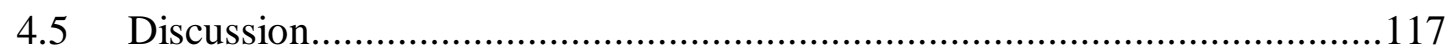


The population structure of Salmonella isolates from skinks and soil in New

Zealand

5.1 Abstract.

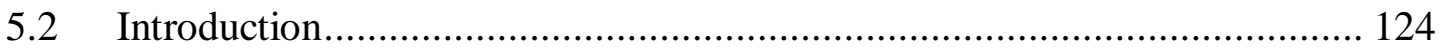

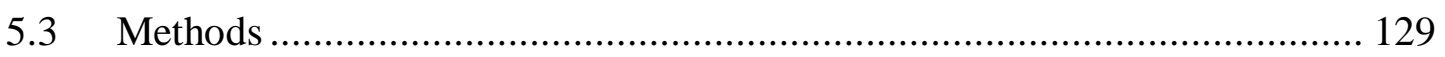

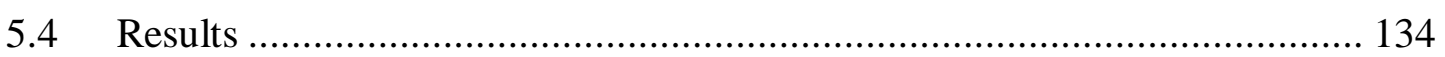

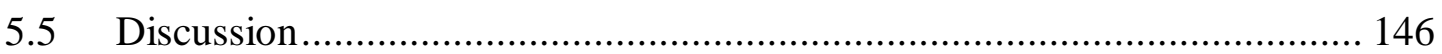

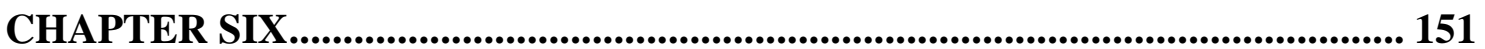

Understanding the ecological and immunological relationships between Salmonella and tuatara....................................................................................... 151

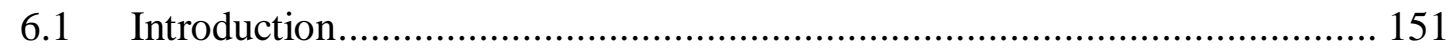

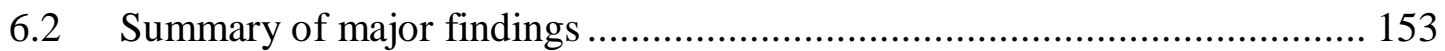

6.3 Ecological and immunological relationships between Salmonella and tuatara

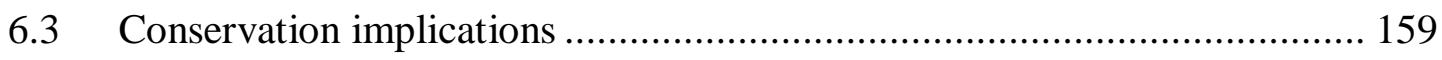

6.4 Directions for future research ......................................................... 161

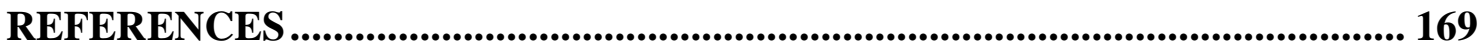

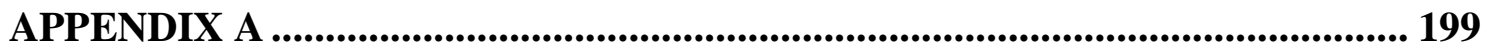

AIA calculations of tuatara sera antigen recognition ....................................... 199

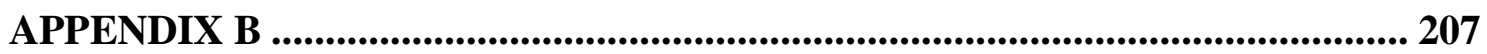

Comparison of colony forming units and optical density for anti-microbial assays ......................................................................................................................................... 207

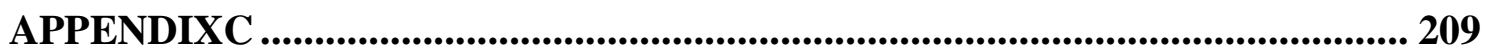

AIA calculations of tuatara sera anti-microbial activity .............................. 209

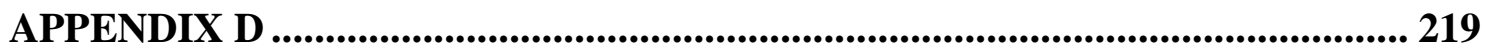

Individual maximum likelihood gene trees assigned by MLST ..................... 219 


\section{List of Figures}

Figure 2.1: Aerial photograph of Stephens Island (2000) showing location of field sites.

Figure 2.2: Skinks $(\bullet)$ living in paddock 2 have greater prevalence of Salmonella than those in the other two sites $\left(\chi_{(2)}^{2}=16.51, P \leq 0.0001\right)$. The prevalence of Salmonella in soil (ם) samples was not significantly different among habitat types on Stephens Island. Graph shows test prevalence and $95 \%$ confidence intervals of true prevalence. .35

Figure 2.3: The prevalence of Salmonella among skinks (•) and soil samples (घ) on Stephens Island varies seasonally. The graph shows test prevalence and 95\% confidence intervals of true prevalence for positive samples and the maximum possible prevalence at the $95 \%$ confidence level where no Salmonella was detected in October. .36

Figure 2.4: Mite prevalence (A) and mite load (B) do not affect the presence of Salmonella in skinks on Stephens Island, New Zealand. Figure 2.4A shows mean number of skinks which were host to mites $\pm 1 \mathrm{SE}$. Figure $2.4 \mathrm{~B}$ depicts the average number of mites per skink

Figure 3.1: Coomassie stained lysates of S. Saintpaul, E. coli and C. koseri...... .57

Figure 3.2: Western blots stained with secondary and tertiary antibodies only (a) and tertiary antibody only (b)

Figure 3.3: Western blots showing different patterns of antibody production for a captive tuatara (a), blue-tongue skink (b), wild tuatara (c) and coastal bearded dragon (d) when tested with $S$. Saintpaul, E.coli and C. koseri.

Figure 3.4: Examples of common bands occurring across $S$. Saintpaul, E. coli and $C$. koseri (A) and a single band only seen in E. coli (B) 
Figure 3.5: The majority of bands identified in S. Saintpaul, E. coli and C. koseri were shared across all three bacteria species. Small percentages of bands were identified in only one other bacterial species or were only identified in a single species of the test bacteria.

Figure 3.6: Dot plot analysis of a representative non-stained S. Saintpaul (a), E. coli (b) and $C$. koseri (c) distribution in FSC (size) versus SSC (granularity). Bacteria assume a characteristic distribution that allows selective analysis of live bacteria by creating a specific window over the bacteria region.

Figure 3.7: Dot plots representing S. Saintpaul, E. coli and C. koseri negative controls, positive controls and representative individual tuatara examples. .68

Figure 3.8: Wild and captive tuatara in this study have higher prevalences of antibodies which recognise E.coli than $S$. Saintpaul and C. koseri $\left(\mathrm{F}_{2,416}=10.332\right.$, $P<0.0001)$. $\mathrm{N}$ is shown in parentheses under $\mathrm{x}$-axis labels

Figure 3.9: Pre-absorbing serum samples with a bacteria of interest and removing antibodies which recognise that bacteria reduces antibody binding when that serum sample is exposed to a different bacterial species. The reduction in antibody binding by pre-absorbed sera suggests cross-reactivity between these species

Figure 3.10: Serum that is pre-absorbed against S. Saintpaul, E. coli and C. koseri demonstrates the large degree of cross-reactivity that occurs between antibodies which recognise these three antigens. Bars with different letters are statistically significantly different

Figure 3.11: Mean fluorescence index is strongly influenced by outliers and therefore does not accurately reflect the changes in positive events/antibody binding seen in the data 
Figure 3.12: Sera of male captive tuatara bound significantly higher numbers of $S$. Saintpaul $\left(\mathrm{F}_{1,77}=10.210, P=0.002\right)$ and $C$. koseri $\left(\mathrm{F}_{1,77}=4.350, P=0.041\right)$, but no significant difference in $E$. coli recognition was observed between the sexes $\left(\mathrm{F}_{1,77}=1.314, P=0.256\right) . \mathrm{N}$ is shown in parentheses under $\mathrm{x}$-axis labels

Figure 3.13: Sampling season does not significantly contribute to explaining the variation in antigen recognition of captive tuatara serum against $E$. coli $\left(\mathrm{F}_{3,77}=0.386\right.$, $P=0.764)$. Higher amounts of C. koseri recognition were observed in summer than in any other season $\left(\mathrm{F}_{3,77}=6.003, P=0.001\right)$ and $S$. Saintpaul recognition is higher in summer than in autumn or winter $\left(\mathrm{F}_{2,56}=4.136, P=0.023\right)$. Sample sizes are shown in parentheses below $\mathrm{x}$-axis label.

Figure 3.14: Box plot showing the recognition of captive (white, $\mathrm{N}=78$ ) and wild (grey, $\mathrm{N}=53$ ) tuatara serum to $S$. Saintpaul, E. coli and C. koseri. There was no significant difference in recognition of $S$. Saintpaul $\left(\mathrm{F}_{1,130}=1.648, P=0.202\right)$, E. coli $\left(\mathrm{F}_{1,130}=2.473\right.$, $P=0.119)$ and $C$. koseri $\left(\mathrm{F}_{1,130}=2.249, P=0.136\right)$ for captive or wild tuatara serum.

Figure 3.15: Tuatara sera showed significantly higher recognition of E. coli than did sera of blue-tongue skinks, coastal bearded dragons or Australian water dragons $\left(\mathrm{F}_{5,83}=2.832 . P=0.021\right)$. There was no significant difference in recognition of $S$. Saintpaul $\left(\mathrm{F}_{5,83}=1.335, P=0.288\right)$ or $C$. koseri $\left(\mathrm{F}_{5,83}=2.025, P=0.084\right)$ across reptilian species

Figure 3.16: A positive correlation between tuatara serum antigen recognition was found for a) $S$. Saintpaul and $C$. koseri $\left(\mathrm{R}^{2}=0.371, P<0.0001\right)$ and b) $C$. koseri and $E$. $\operatorname{coli}\left(\mathrm{R}^{2}=0.145, p<0.0001\right)$ and c) $S$. Saintpaul and $E$. coli $\left(\mathrm{R}^{2}=0.090, P=0.001\right)$. .84

Figure 4.1: Anti-microbial activity of captive and wild tuatara serum against three common gastrointestinal pathogens, S. Saintpaul, E. coli and C. koseri. Tuatara show higher AMA against $E$. coli than $S$. Saintpaul and have the lowest activity against $C$. koseri. $\mathrm{N}=115$. 
Figure 4.2: Concentration dependent increases in antibacterial activity of tuatara $(S$. punctatus; $\triangle)$, .coastal bearded dragon (P. barbata; $\times)$, Australian water dragon $(P$. lesuerii; $\mathbf{\square})$, donkey (๑) and mouse (M. musculus; $\bullet$ ) sera against $S$. Saintpaul(A), E. coli $(\mathbf{B})$ and $C$. koseri $(\mathbf{C})$. Each data point represents the mean bacterial killed in three replicates. $\mathrm{N}=1$ 104

Figure 4.3: Percentage of bacteria killed by normal (grey) and decomplemented (white; heated to $55^{\circ} \mathrm{C}$ for 30 minutes) serum of tuatara (S. punctatus), donkey (E. asinus), mouse (M. musculus), coastal bearded dragon (P. barbata) and Australian water dragon (P. lesuerii). The AMA of coastal bearded dragons and Australian water dragons was investigated against $S$. Saintpaul only .106

Figure 4.4: The anti-microbial activity of captive $(\mathrm{N}=2)$ and wild $(\mathrm{N}=1)$ tuatara serum. Each serum sample was separated into three and either left untreated, heat-treated to $55^{\circ} \mathrm{C}$ for 30 minutes (decomplemented), or filtered through a $10 \mathrm{kDa}$ size exclusion filter. There is no statistically significant difference in serum anti-microbial activity across the three treatments $\left(\mathrm{F}_{2,8}=2.414, P=0.170\right)$.

Figure 4.5: Body condition does not have a significant effect on the sera AMA of captive tuatara serum against $S$. Saintpaul $\left(\mathrm{R}^{2}=0.03, P=0.164\right)$, E. coli $\left(\mathrm{R}^{2}=0.0002\right.$, $P=0.908)$ or $C$. koseri $\left(\mathrm{R}^{2}=0.018, P=0.281\right)(\mathrm{N}=67)$. 109

Figure 4.6: Anti-microbial activity of captive tuatara serum is not significantly affected by sex and age. $\mathrm{N}$ is shown in parentheses under $\mathrm{x}$-axis labels.

Figure 4.7: The anti-microbial activity of captive (white) and wild (grey) tuatara serum against a) S. Saintpaul and b) E.coli was not significantly affected by season. Captive tuatara serum had higher anti-microbial activity against $C$. koseri during winter than during the other seasons. $\mathrm{N}$ is shown in parentheses under $\mathrm{x}$-axis labels

Figure 4.8: A very small amount of variation is shared between bacteria a) $S$. Saintpaul and $E$. coli $\left(\mathrm{R}^{2}=0.044, P=0.025\right)$, b) $S$. Saintpaul and $C$. koseri $\left(\mathrm{R}^{2}=0.159, P<0.001\right)$ and c) E. coli and C. koseri $\left(\mathrm{R}^{2}=0.121, P<0.001\right)$ was found in this study. 115 
Figure 4.9: Antigen recognition as a function of anti-microbial activity in individual captive and wild tuatara tested for both. A slight but significant correlation between antigen recognition and anti-microbial activity was seen for $S$. Saintpaul $\left(\mathrm{R}^{2}=0.173, P<\right.$ $0.001)$ and $C$. koseri $\left(\mathrm{R}^{2}=0.042, P=0.049\right)$, but not $E$. coli $\left(\mathrm{R}^{2}=0.006, P=0.481\right) \ldots \ldots . .116$

Figure 5.1: Phylogentic trees composed of nucleotides 1-1031 (a) and 1032-1503 (b), produced by determining recombination breakpoints in GARD, demonstrates evidence of recombination within the concatenated sequence as tree a varies in topology to tree b.

Figure 5.2: Likelihood mapping analysis of the sequence alignments of Salmonella present on Stephens Island. The regions of the corners of the triangles correspond to the three possible topologies of a quartet; the lateral regions to partly resolved trees and the central region to unresolved trees. The numbers indicate the percentage of quartets falling within each region. $52 \%$ of the trees in this study could not be resolved.....

Figure 5.3: A maximum likelihood neighbour-joining, bootstrapped tree of Salmonella samples from Stephens Island. The sample ID and whether the isolate came from skinks or soil are shown. The tree shows that $S$. Mississippi isolates (red) are in a different clade to $S$. Saintpaul (blue). The horizontal scale represents distances among strains, a scale of 0.002 means that the strains possess $99.8 \%$ nucleotide identity. The tree is rooted using $S$. Typhi as the out-group

Figure 5.4: Maximum likelihood tree of Salmonella concatenated sequences. Treepuzzling quartet support is shown at the nodes of each branch. Deep branches receive very low support. Isolates serotyped as $S$. Mississippi (red) are found in a different clade to $S$. Saintpaul (blue). The horizontal scale represents distances among strains. The tree is rooted using $S$. Typhi as the out group 
Figure 5.5: A Bayesian inference phylogenetic tree for all sequence types found among 38 Salmonella isolates based on sequencing of three genes. The phylogenetic tree was built using a Bayesian model using a concatenated alignment ThrA, dnaN and sucA. Posterior probabilities are shown above the branches and coloured from green (low support) to red (high support). The scale bar indicates relative sequence distance. Sequence ID (Table 5.1) is given at the end of branches, with isolates identified as $S$. Mississippi coloured red and S. Saintpaul blue

Figure 5.6: Non-metric multidimensional scaling (MDS) ordination of 38 isolates of Salmonella by serotype, host, location, month and year shows that serotype and host are the only factors significant in explaining diversity within the sequences. The figure shows the distribution isolates between the three ancestral populations. For example, $S$. Mississippi isolates are from one predominant population, in contrast the diversity within $S$. Saintpaul isolates arises from two main ancestral populations. 144

Figure 5.7: The posterior probabilities of the number of populations in Structure for admixture (a) and linkage models (b). The most likely value of $\mathrm{K}$ for the admixture model is 3 . The posterior probabilities vary over all values of $\mathrm{K}$ for the linage model and therefore this model was discarded in further analyses

Figure D1: Maximum likelihood of ThrA sequences. Isolates serotyped as $S$. Mississippi (red) and S. Saintpaul (black). Tree is rooted using S. Typhi as the outgroup

Figure D2: Maximum likelihood of SucA sequences. Isolates serotyped as $S$. Mississippi (red) and S. Saintpaul (black). Tree is rooted using S. Typhi as the outgroup. 220

Figure D3: Maximum likelihood of dnaN sequences. Isolates serotyped as $S$. Mississippi (red) and S. Saintpaul (black). Tree is rooted using S. Typhi as the outgroup. 


\section{List of Tables}

Table 2.1: Frequency of tuatara new captures and recaptures and the number of tuatara sharing burrows with other tuatara or fairy prions during trips to Stephens Island. The number of tuatara caught in the forest (B), paddock 1 (P1) and paddock 2 (P2) are shown. .29

Table 2.2: The prevalence of Salmonella isolated from New Zealand native species on Stephens Island, New Zealand

Table 2.3: Mean body condition, prevalence and species of skink caught at three different study sites on Stephens Island. Skinks in paddock 2 have a significantly higher prevalence of Salmonella. .38

Table 2.4: Summary of the prevalence (\%) and mean load of mites (Neotrombicula spp.) of tuatara (Sphenodon punctatus) and skinks within each study plot and sampling occasion.

Table 3.1: Frequency of tuatara new captures and recaptures in three habitat types; Remnant coastal forest (B), Pasture 1 (P1) and Pasture (P2) on Stephens Island, New Zealand

Table 3.2: Frequency of captive tuatara sampling at seven captive facilities (A-G) throughout New Zealand from October 2009-July 2011. The total number of tuatara sampled at any given facility is shown by $\mathrm{n}$ and the number of captures each season follows.

Table 3.3: Antibodies used for Western blotting..... .56 
Table 3.4: The mean number of bands identified by Western blot in blue-tongue skinks, coastal bearded dragons, captive and Stephens Island wild tuatara against $S$. Saintpaul, E. coli and C. koseri. Mean number of bands \pm SE, sample size (n), F-statistic and Pvalue is shown. F-statistic and $\mathrm{P}$ value show statistical significance in mean number of bands identified in each of the bacteria within reptile species

Table 3.5: Outcomes of wild tuatara serum candidate models for: (A) S. Saintpaul, (B) E. coli and (C) C. koseri. The top five models for each bacteria are shown. The variables included in each model, number of parameters $(\mathrm{K}), \mathrm{AIC}_{\mathrm{c}}$ values, $\mathrm{AIC}_{\mathrm{c}}$ differences $\left(\triangle \mathrm{AIC}_{\mathrm{c}}\right)$, and Akaike weight $\left(\omega_{\mathrm{i}}\right)$ are shown for each species of bacteria tested (S. Saintpaul, E. coli and C. koseri). Models are ranked from the smallest to largest $\mathrm{AIC}_{\mathrm{c}}$ value with the best supported models $\left(\Delta \mathrm{AIC}_{\mathrm{c}}<2.0\right)$ shown in bold.

Table 3.6: Two-way ANOVAs for the best models of wild tuatara against $S$. Saintpaul, E. coli and $C$. koseri show that the best model by AIC does not explain variation in the data. .76

Table 3.7: Outcomes of captive tuatara serum candidate for: (A) S. Saintpaul, (B) E. coli and (C) C. koseri. The top five models for each bacterium are shown (refer to Appendix A for the full model set). The variables included in each model, number of parameters $(\mathrm{K}), \mathrm{AIC}_{\mathrm{c}}$ values, $\mathrm{AIC}_{\mathrm{c}}$ differences $\left(\Delta \mathrm{AIC}_{\mathrm{c}}\right)$, and Akaike weight $\left(\omega_{\mathrm{i}}\right)$ are shown for each species of bacteria tested (S. Saintpaul, E. coli and C. koseri). Models are ranked from the smallest to largest $\mathrm{AIC}_{\mathrm{c}}$ value with the best supported model(s) (confidence set, i.e. $\Delta \mathrm{AIC}_{\mathrm{c}}<2.0$ ) shown in bold.

Table 3.8: Two-way ANOVAs for the best models of captive tuatara against $S$.

Saintpaul, E. coli and C. koseri. Significant predictors $(P=0.005)$ are shown in bold...79

Table 4.1: Frequency of tuatara new captures and recaptures in the three habitat types; Forest (F), Paddock 1 (P1) and Paddock 2 (P2) on Stephens Island, New Zealand. The total sample size per season is shown by $\mathrm{N}$.... 
Table 4.2: Frequency of captive tuatara sampling at seven captive facilities (A-G) throughout New Zealand from October 2009-July 2011. The total number of tuatara sampled at any given facility is shown by $\mathrm{N}$ and the number of re-captures each season follows

Table 4.3: The outcomes of candidate models for sera of captive tuatara within 10 Akaike units of the best model $(\triangle \mathrm{AICc}<10)$. Data on all models tested is shown in appendix B. The variables included in each model, number of parameters $(\mathrm{K}), \mathrm{AIC}_{\mathrm{c}}$ values, $\mathrm{AIC}_{\mathrm{c}}$ differences $\left(\Delta \mathrm{AIC} \mathrm{c}_{\mathrm{c}}\right)$, and Akaike weight $\left(\omega_{\mathrm{i}}\right)$ are shown for each species of bacteria tested (S. Saintpaul, E. coli and C. koseri). Models are ranked from the smallest to largest $\mathrm{AIC}_{\mathrm{c}}$ value with the best supported model (confidence set, i.e. $\sum \omega>$ $0.95)$ shown in bold.

Table 4.4.The outcomes of candidate models for the anti-microbial activity of sera from wild tuatara. The top five models are shown for: (A) S. Saintpaul, (B) E. coli and (C) C. koseri (for full models see Appendix C). The variables included in each model, number of parameters $(\mathrm{K}), \mathrm{AIC}_{\mathrm{c}}$ values, $\mathrm{AIC}_{\mathrm{c}}$ differences $\left(\Delta \mathrm{AIC}_{\mathrm{c}}\right)$, and Akaike weight $\left(\omega_{\mathrm{i}}\right)$ are shown. Models are ranked from the smallest to largest $\mathrm{AIC}_{\mathrm{c}}$ value

Table 5.1: Origin and characterisation of Salmonella isolates used in this study. The serotype, host, location and time of sampling are shown. Sequences were assigned allele types, from the MLST database, for each of three genes and these corresponded directly with serotype.

Table 5.2: Primers used to amplify the Salmonella genes $d n a N$, sucA and thrA by multilocus sequence typing. The forward and reverse primer sequences and the size of product (bp) are shown

Table 5.3: Genetic characteristics of MLST genes, dnaN, sucA, thrA and the concatenated sequences. The size of the product, GC content and number of alleles and polymorphic sites per gene are displayed. 
Table 5.4: Summary statistics of concatenated and individual genes of Salmonella. The number of segregating sites, measures of mutation $(\theta)$, recombination $(\rho)$ and the significance of recombination events (LPT) are shown. Recombination was found to be a significant evolutionary force in the diversity of Salmonella isolates on Stephens Island in $S u c A$ and the concatenated sequence $(\mathrm{LPT}<0.05)$

Table A1: Outcomes of wild tuatara serum candidate models for: (A) S. Saintpaul, (B) E. coli and (C) C. koseri. The variables included in each model, number of parameters $(\mathrm{K}), \mathrm{AIC}_{\mathrm{c}}$ values, $\mathrm{AIC}_{\mathrm{c}}$ differences $\left(\Delta \mathrm{AIC}_{\mathrm{c}}\right)$, and Akaike weight $\left(\omega_{\mathrm{i}}\right)$ are shown for each species of bacteria tested ( $S$. Saintpaul, E. coli and C. koseri). Models are ranked from the smallest to largest $\mathrm{AIC}_{\mathrm{c}}$ value with the best supported models $\left(\Delta \mathrm{AIC}_{\mathrm{c}}<3.0\right)$ shown in bold.

Table A2: Outcomes of captive tuatara serum candidate models for: (A) S. Saintpaul, (B) E. coli and (C) C. koseri. The variables included in each model, number of parameters $(\mathrm{K}), \mathrm{AIC}_{\mathrm{c}}$ values, $\mathrm{AIC}_{\mathrm{c}}$ differences $\left(\Delta \mathrm{AIC}_{\mathrm{c}}\right)$, and Akaike weight $\left(\omega_{\mathrm{i}}\right)$ are shown for each species of bacteria tested (S. Saintpaul, E. coli and C. koseri). Models are ranked from the smallest to largest $\mathrm{AIC}_{\mathrm{c}}$ value with the best supported models $\left(\Delta \mathrm{AIC}_{\mathrm{c}}<2.0\right)$ shown in bold

Table C1: Outcomes of captive tuatara serum candidate models for: (A) S. Saintpaul, (B) E. coli and (C) C. koseri. The variables included in each model, number of parameters $(\mathrm{K}), \mathrm{AIC}_{\mathrm{c}}$ values, $\mathrm{AIC}_{\mathrm{c}}$ differences $\left(\Delta \mathrm{AIC}_{\mathrm{c}}\right)$, and Akaike weight $\left(\omega_{\mathrm{i}}\right)$ are shown for each species of bacteria tested (S. Saintpaul, E. coli and C. koseri). Models are ranked from the smallest to largest $\mathrm{AIC}_{\mathrm{c}}$ value with the best supported models $\left(\Delta \mathrm{AIC}_{\mathrm{c}}<3.0\right)$ shown in bold. .209

Table C2: Outcomes of wild tuatara serum candidate models for: (A) S. Saintpaul, (B) E. coli and (C) C. koseri. The variables included in each model, number of parameters (K), $\mathrm{AIC}_{\mathrm{c}}$ values, $\mathrm{AIC}_{\mathrm{c}}$ differences $\left(\Delta \mathrm{AIC}_{\mathrm{c}}\right)$, and Akaike weight $\left(\omega_{\mathrm{i}}\right)$ are shown for each species of bacteria tested (S. Saintpaul, E. coli and C. koseri). Models are ranked from the smallest to largest $\mathrm{AIC}_{\mathrm{c}}$ value with the best supported models $\left(\Delta \mathrm{AIC}_{\mathrm{c}}<3.0\right)$ shown in bold. 


\section{CHAPTER ONE}

\section{Salmonella disease ecology and immunology}

\subsection{Introduction}

Patterns of disease transmission and expression in populations of wild animals are formed through complex interactions between hosts, pathogen and environmental factors. Pathogenic bacteria impact individual fitness in a number of ways including increasing predation risk, reducing survival and reducing reproductive output (Anderson and May 1979, Gulland 1995, Johnson et al. 2006, Moller and Nielsen 2007). Daphnia infected with the chytrid Polycaryum laeve are two to five times more susceptible to predation by fish predators than uninfected individuals (Johnson et al. 2006). Alternatively, disease infection may also reduce reproductive output either through increased mortality (of adults or juveniles) or, as is common in invertebrates, through castration (Schwanz 2008). For most wildlife species the data on prevalence and spatio-temporal distribution of pathogens are limited. It is also difficult to predict the complex nature of interactions that exist between host, pathogen and environment as well as the disturbances which may alter balances within these relationships. Understanding the abundance, distribution and dynamics of pathogen ecology is essential to our understanding of their ecological role in host populations, and in determining their threat to protected species.

Salmonellosis is an important zoonotic disease resulting in significant morbidity in populations of wild reptiles, birds and mammals throughout the world (Mader 2006). The prevalence and importance of this disease has been widely investigated overseas (Otokunefor et al. 2003, Mermin et al. 2004), but there has been little research into its importance in New Zealand. Salmonella has been identified in New Zealand native fauna including birds (Alley et al. 2002, Ewen et al. 2007) and lizards (Middleton et al. 2010), and also in a number of introduced and domestic species (Clark et al. 2002, Kikillus et al. 2011). A novel strain of Salmonella, S. Typhimurium DT195, introduced 
to New Zealand has resulted in mortality within wild populations of native birds (Ewen et al. 2007), hinting at the potential dangers unique serovars of this organism pose to native fauna. No Salmonella has been isolated from more than 130 cloacal swabs collected from live wild and captive tuatara (Gartrell et al. 2006, Gartrell et al. 2007). Gartrell et al. (2007) proposed that the lack of Salmonella detection in tuatara could be due to either an innate resistance, lack of exposure or human error in sampling. I investigated the ecology and evolution of Salmonella in New Zealand and examined the tuatara immune response for indications of an innate resistance to this widespread bacterium.

\subsection{Salmonella, Escherichia and Citrobacter characteristics}

The family Enterobacteriaceae is comprises Gram-negative facultative anaerobic rods and includes many common gastrointestinal pathogens such as Salmonella, Escherichia, Citrobacter and Klebsiella (Bergey et al. 2001). Many of the bacterial genera within this family are closely related, with significant DNA homology, biochemical similarity and serological cross-reactivity. In order to investigate the immune response of tuatara to Salmonella and the importance of cross-reactivity on this response, I investigated three members of the Enterobacteriaceae: Salmonella, Escherichia and Citrobacter, between which serological cross-reactivity has been shown to exist (Keleti et al. 1971).

Salmonella are zoonotic bacteria of significant public health and economic concern. This widespread bacterium has been isolated from many animal species including mammals, birds, reptiles and humans on every continent of the world (Mermin et al. 2004). Non-typhoidal Salmonella is one of the leading causes of human gastroenteritis globally with an estimated 93.8 million illnesses and 155,000 deaths per year (Majowicz et al. 2010). Many of the same serovars are isolated from both humans and animals indicating that animals are likely to act as important reservoirs of disease. Several serovars of Salmonella including $S$. Brandenburg and $S$. Abortusovis have also been linked to epidemic abortions in sheep and cattle resulting in huge economic losses (Clark et al. 2004, Habrun et al. 2006). In contrast, Escherichia coli are generally considered to be commensals of the lower gastrointestinal tract of mammals (Hartl and Dykhuizen 1984). The large majority of E. coli strains are harmless, but a small 
number are pathogenic resulting in diseases such as gastroenteritis and urinary tract infections. Citrobacter is recognized as an opportunistic pathogen, causing disease only when host resistance is low (Doran 1999). Unlike Salmonella and E. coli, clinical manifestation of $C$. koseri does not generally include gastroenteritis but is associated with infant meningitis, sepsis and urinary tract infections (Doran 1999).

Salmonella and Citrobacter species share many similar characteristics and Citrobacter was originally assigned to the genus Salmonella before being recognised as its own species. Several serovars of Salmonella, Citrobacter and E. coli have been shown to be cross-reactive, sharing homology within their O-antigens (Keleti et al. 1971).

Consequently I have included E. coli and C. koseri into this study in order to elucidate the importance of cross-reactivity among these bacteria on immune responses to the more commonly pathogenic bacterium, Salmonella. Both Citrobacter and Escherichia have been isolated from intestinal tracts of a wide variety of wildlife species worldwide; however, both genera are less commonly isolated from ectothermic species than from endothermic species and are rarely associated with disease in ectothermic hosts (Guentzel 1996).

\subsection{The ecology of Salmonella}

Salmonella enterica is a ubiquitous microorganism which is known to be an important zoonosis affecting animals across a broad taxonomic spectrum including humans, cattle, reptiles and birds (Woodward et al. 1997, Mermin et al. 2004, Carlson et al. 2011). Infection with Salmonella can result in a range of clinical outcomes depending on host immunity, the pathogenicity of the Salmonella serotype involved and environmental stressors. In most cases, after an initial period of gastroenteritis, infection is subclinical, and many animals act as asymptomatic carriers that shed the bacteria intermittently (Pfleger et al. 2003). However, when stressors result in a disruption of the host's normal intestinal flora Salmonella can establish and flourish in the gut resulting in septicaemic disease (Haraga et al. 2008). Individuals may be exposed to Salmonella via faeces, contaminated food or water, insect vectors or contaminated soils (Chiodini and Sundberg 1981). Salmonella serovars can remain viable outside of their hosts for extended periods of time; 89 days in tap water, 115 days in pond water, 280 days in soil, 
and 30 months in animal faeces (Johnson - Delaney 1996). This environmental stability allows for infection to occur via both direct and indirect exposure. The ease of transmission from an environmental source was highlighted by an outbreak of Salmonella Enteritidis in children (39 confirmed, 26 suspected cases) which was linked to environmental transmission via a wooden barrier at a Komodo dragon (Varanus komodoensis) exhibit (Friedman et al. 1998). Both endothermic and ectothermic vertebrates are important reservoirs of Salmonella serovars in nature (Chiodini and Sundberg 1981).

More than 2500 Salmonella enterica serovars have been identified but only a small proportion of these are regularly isolated from humans or animals (Mermin et al. 2004). Each of the 2500 distinct $S$. enterica serotypes varies in the antigenic specificities of their $\mathrm{O}, \mathrm{H}$ and $\mathrm{Vi}$ antigens. There is little or no correlation between the antigenic type of Salmonella and the pathogenicity of the organism. Salmonella serotypes have varying host specificities and virulences and can be divided into host-specific, hostrestricted and generalist serotypes (Uzzau et al. 2000, Hoelzer et al. 2011). Hostspecific species cause disease almost exclusively in one host, for example $S$.

Gallinarium, $S$. Typhi and $S$. Abortusovis infect only fowl (Barrow et al. 1994), humans (Forest et al. 2010) and ovines (Wirz-Dittus et al. 2010) respectively. Salmonella Cholarae suis is an example of a host-restricted serotype as it is adapted to swine (Gray et al. 1996) but may also infrequently cause disease in other mammalian hosts including humans (Saphra and Wassermann 1954). In contrast, generalist serotypes such as Salmonella Typhimurium will infect a wide range of hosts including humans, reptiles and mammals (Davies and Wray 1996, Aballay et al. 2000, Alley et al. 2002). The mechanisms through which Salmonella serovars infect their hosts and the reasons for varying host specificities and virulence is explained in detail in Haraga et al. (2008). It is thought that differences in receptor sites on the cell walls of host species are the cause of varying virulence between hosts (Haraga et al. 2008). Infection with generalist serotypes often result in high morbidity but low mortality compared with restricted or specific serotypes which generally present with low morbidity and high mortality (Hoelzer et al. 2011). Throughout this thesis all serovars of $S$. enterica will be assigned species nomenclature, but serotypes will not be italicised, so that Salmonella enterica subspecies enterica serovar Typhimurium will be written as $S$. Typhimurium. The 
nomenclature of Salmonella has varied throughout time but this is the accepted form at present (Heyndrickx et al. 2005).

Salmonella serotypes have been isolated from a variety of wild animal species worldwide, and salmonellosis of both human and production animals have been linked to wild animal carriers (Humphrey and Bygrave 1988, Handeland et al. 2002). S. Brandenburg causes widespread abortions and deaths in pregnant ewes in New Zealand (Clark 2001). Black-backed gulls (Larus dominicanus) are scavenging seabirds known to feed on a wide range of carrion including aborted sheep foetuses and membranes. These gulls have been shown to have high rates of intestinal carriage of $S$. Brandenburg during the abortive season and are therefore thought to play an important role in the spread of this disease among sheep farms in New Zealand (Clark 2001). Salmonellosis has also been demonstrated to be a significant cause of death in passerine birds, and many authors have demonstrated large scale mortality of birds by epidemic salmonellosis in Canada (Daoust et al. 2000), USA (Hall and Saito 2008), and Japan (Une et al. 2008). Similar large scale mortalities of passerines due to salmonellosis have been seen in New Zealand. During mid-2000 infection with a previously unreported strain of Salmonella in New Zealand, Salmonella Typhimurium DT160, resulted in the death of several hundred birds in Christchurch and the Manawatu (Alley et al. 2002). These mortalities predominantly involved sparrows (Passer domesticus) along with small numbers of greenfinches (Carduelis choloris), goldfinches (Cardeulis cardeulis), chaffinches (Fringilla coelebs) and occasionally blackbirds (Turdus merula) and native silvereyes (Zosterops lateralis) (Alley et al. 2002). The effect novel strains of Salmonella can have on indigenous wildlife in New Zealand is further highlighted by the S. Typhimurium DT195 outbreak which occurred amongst hihi (Notiomystis cincta) on Tiritiri Matangi Island. These birds are a well studied population and are closely monitored for disease, suggesting that this serovar was novel to this population of hihi. Whilst only nine hihi bodies were found, the authors estimate that the mortality rate could have been as high as 30\% (Ewen et al. 2007). S. Typhimurium DT195 was also isolated from three human patients in the years prior to the hihi outbreak; however the source of infection in hihi remains unclear (Ewen et al. 2007). 


\subsection{Salmonella prevalence and disease in reptiles}

Herpetofaunal species have often been implicated as transmitters of Salmonella, and reptile-associated salmonellosis is a significant threat to the health of humans, domestic animals and other wildlife (Mader 2006). The reported prevalence of Salmonella carriage in wild reptiles worldwide varies significantly. Richards et al. (2004) showed the frequency of isolation from essentially healthy reptiles in Virginia, USA to be $14 \%$, and Chamber and Hulse (2006) report a prevalence rate as high as 95\%. The squamates have the highest prevalence of Salmonella carriage of the reptiles investigated to date (Gopee et al. 2000). Furthermore, Salmonella is not continually shed from the gastrointestinal tract of reptiles but is often shed intermittently as a result of stress on the animals (Richards et al. 2004). This intermittence raises difficulty with the screening of reptiles for Salmonella, and repeated samples are often required in order to gain a true indication of the prevalence of this organism within a population (Gartrell et al. 2007).

Reptiles may initially become infected with Salmonella via faecally contaminated food and water, insect vectors or soil that contains the organism (Mermin et al. 2004). Reptiles may also become infected before birth while in the ovary, oviduct or cloaca (Mermin et al. 2004, Richards et al. 2004). The normal intestinal flora of reptiles and mammals generally inhibits the growth of Salmonella by producing volatile organic acids and blocking attachment sites required for Salmonella (Haraga et al. 2008). Stressors such as water deprivation, changes in diet, antibiotic therapy, transportation and overcrowding can disrupt the normal intestinal flora, therefore allowing Salmonella to establish in the gut (Quinn et al. 1994). In the instances where Salmonella colonisation results in disease, reptiles may present with depression, anorexia, vomiting, lethargy, wasting, respiratory distress, abortion, nervous signs and sudden death (Twentyman 1999).

Gartrell et al. (2006; 2007) did not detect Salmonella in 130 cloacal swabs from wild and captive tuatara. The absence of detectable Salmonella could be due to a lack of exposure, an innate resistance or a lack of sensitivity of the isolation methods. These findings are of interest due to the commonality of Salmonella in reptiles throughout the world. Recent research on geckos (Diplodactylidae) and skinks (Scincidae) in New 
Zealand found Salmonella at prevalences of up to 10\% (Middleton, 2008). On Stephens Island, where the tuatara population is extremely dense, the prevalence of Salmonella amongst geckos and skinks was found to be approximately $4 \%$.

Furthermore, many of the skinks sampled in this survey were caught in close proximity to tuatara (Middleton 2008).

\subsection{Overview of reptilian immunity}

Host immunity in most vertebrates occurs through an interplay between two separate but interrelated types of immunity: the innate and adaptive immune responses. The innate immune response is the most universal and rapidly acting type of immunity; it is also the sole source of immunity for most non-vertebrate species (Beutler 2004). Innate immunity comprises defences such as anatomical barriers (e.g. skin, mucous membranes), resident flora (e.g. commensal, non-pathogenic bacteria), humoral factors (e.g. anti-microbial peptides, lysozome and complement) and cellular components (e.g. macrophages, heterophils, eosinophils and natural killer cells) (Janeway and Medzhitov 2002). By contrast adaptive immunity is more specific, slower and generally only seen in vertebrate species (Zimmerman et al. 2010b).

Although current knowledge and understanding of mammalian immune responses is reasonably comprehensive, comparatively less is known about the immune systems of non-mammalian vertebrates. Reptiles are the only members of the amniotes that are ectothermic; consequently they have little physiological control over their body temperature, and exhibit seasonal changes in behaviour in response to environmental temperature. Collectively, these characteristics make reptiles a pivotal group to study in order to understand immune function and evolution in a wider context (Zimmerman et al. 2010b).

The tissues and organs of the reptilian immune system have been studied and investigated by a number of authors and reviewed by Zimmerman et al. (2010b). Briefly, the major organs and tissues of the reptilian immune response include the thymus, spleen, gut-associated lymphoid tissue (GALT) and bone marrow. Lymph nodes are absent in reptilian species and there is no formation of germinal centres. 
Seasonal variation in lymphoid tissue has been identified in a number of reptilian species, but the observed changes are species specific. In general, the thymus and the white pulp of the spleen are well developed in autumn and spring, become involuted in winter, and show species-specific differences in development during summer (Zimmerman et al. 2010b).

\subsubsection{The innate immune response}

Reptilian innate immunity is the most studied and consequently the best understood aspect of immunity in reptiles (Zimmerman et al. 2010b). Many of the same innate defences are found in reptiles as in other vertebrate groups, for example the complement system is considered a key component of mammalian immunity and has also been identified in reptilian species. However, in comparison to the extremely well characterized mammalian complement system in which all proteins have been purified to homogeneity, their functions in each pathway identified, and their genes isolated (Campbell et al. 1988), very little is known about the reptilian complement system. In mammals it is known that the complement cascade can be accomplished by three different pathways: classical, alternate and lectin pathways. Evidence of the classical and alternate pathways has been identified in reptilian species (Vogel and MüllerEberhard 1985, Vogel and Müller-Eberhard 1985b, Sunyer and Lambris 1998). Although, to date, there is no direct evident for a lectin pathway in reptiles, it is presumed to exist because of its presence in all other vertebrate species including amphibians, sharks and teleosts (Sunyer and Lambris 1998).

An effective reptilian complement system has been identified in the sera of the American alligator (Alligator mississippiensis) (Merchant et al. 2003, Merchant et al. 2004). The sera from this alligator species was effective at killing several strains of Gram-negative and Gram-positive bacteria and showed much higher anti-microbial activity against Gram-positive bacteria than human sera (Merchant et al. 2003). Complement activity was also observed by the sera of saltwater (Crocodylus porosus) and freshwater (Crocodylus johnstoni) crocodiles (Merchant and Britton 2006). Heating of both alligator and crocodile sera to $56^{\circ} \mathrm{C}$ for 30 minutes depleted the bactericidal activity. Human complement proteins are degraded at this temperature and 
consequently, this method is used to distinguish complement-mediated anti-microbial activity from anti-microbial peptide activity.

Anti-microbial peptides (AMPs) are small (<10kDa) multi-functional proteins. The primary biological function of these proteins appears to be the elimination of a suite of different pathogenic microorganisms, including Gram-positive and Gram-negative bacteria, fungi, and viruses (Diamond et al. 2009). A variety of AMPs have been uncovered in many vertebrate and non-vertebrate species including mammals (Carroll and Martinez 1981), fish, insects (Lemaitre and Hoffmann 2007), birds (van Dijk et al. 2008), plants (Castro and Fontes 2005), amphibians and reptiles (Pata et al. 2011).

AMPs are secreted by a number of different tissues and cells throughout the body (Diamond et al. 2009). Peptides similar in structure and function to the mammalian anti-microbial peptides, defensins, have been isolated from egg whites of loggerhead sea turtles (Caretta caretta) and these peptides exhibited strong anti-microbial activity against $E$. coli and $S$. Typhimurium (Chattopadhyay et al. 2006). Defensins have been isolated from all mammals investigated to date and in many bird species; however, their presence and importance in reptiles has only recently begun to be investigated (Ganz 2003, Zimmerman et al. 2010b). AMPs have also been identified in the sera of the Siamese crocodile (Crocodylus siamensis), and the small cationic protein exhibited strong activity against S. Typhi, E. coli, Staphylococcus aureus, Pseudomonas aeruginosa and Vibrio cholera (Preecharram et al. 2008). Finally, despite being strongly influenced by temperature, the complement and anti-microbial peptide responses of reptiles were frequently stronger than those of humans (Merchant et al. 2003, Preecharram et al. 2008).

\subsubsection{The adaptive immune response}

Cells and components of the innate immune response influence the adaptive immune system through the presentation of antigen and production of cytokines and mediators which interact with cells of the adaptive immune response (Vyas et al. 2008). The adaptive immune response can be divided into two components; cell-mediated immunity and humoral immunity. Cell-mediated immunity involves the class of lymphocytes known as $\mathrm{T}$ cells. While $\mathrm{T}$ cells regulate antibody production they do not 
produce antibodies. A number of reptilian species have been investigated for the presence of T cells, and functional $\mathrm{T}$ cells have been isolated in all species tested including lizards (Manickasundari et al. 1984) and tuatara (Burnham et al. 2005).

Humoral adaptive immunity is regulated by antibodies secreted by B cells. The general structure of the antibody appears to be highly conserved amongst the jawed vertebrates, with each antibody composed of two identical heavy chains and two identical light chains all held together by disulphide bonds (Zimmerman et al. 2010b). Despite this conservation in the general structure, reptile heavy chains have been shown to have a much higher level of genetic diversity as compared with birds, cattle and rabbits, which have limited combinatorial diversity and use gene conversion with a series of up-stream gene segments to increase antigen-binding diversity (Litman et al. 1999, Arakawa et al. 2002, Zimmerman et al. 2010b). The classes of antibody currently known to occur in reptiles are reviewed in Zimmerman et al. (2010b) and include IgY, IgD and an IgAlike immunoglobulin.

Reptilian antibody responses are generally slower than those seen in mammals and birds and often do not increase in titre upon a second exposure. After exposure to an antigen mammals typically have a latent period of around one week and antibody titres typically peak around two weeks post-immunisation, depending on the antigen and route of exposure. Reptiles also have a latent period of approximately one week following exposure, but their titres do not typically peak until six or eight weeks postimmunisation (Grey 1963, Marchalonis et al. 1969, Ingram and Molyneux 1983). In mammalian hosts IgG is the major antibody of the secondary response, the major isotype of the secondary response in reptiles has not yet been determined. The lack of increase in titer or in binding affinity during the secondary response may be attributed to the ectothermic nature of reptilian hosts. However, experiments demonstrating that the kinetics of the response in turtles held at $37^{\circ} \mathrm{C}$ did not differ from those held at $25^{\circ} \mathrm{C}$ suggest that the slow response may not be a function of temperature alone (Grey 1963). Less vigorous secondary responses have also been observed in amphibians and fishes and it has been hypothesised that the low responses may be due to the lack of germinal centres in these taxa (Hsu 1998; Zimmerman et al. 2010b). 
Despite the slower response, active adaptive immune responses have been observed in a number of reptilian species. Active cell-mediated and humoral responses have been observed in the red-eared slider (Trachemys scripta) (Zimmerman et al. 2010a) and antibodies against the wide-spread West Nile virus have been isolated from Furrowed wood turtles (Rhinoclemmys aerolata) and red-eared sliders (Farfan-Ale et al. 2006). Marchalonis et al. (1969) investigated antibody responses of tuatara to the Salmonella Adelaide flagellin and found antibody titres peaked six to eight weeks after exposure and found no increase in titre following a second exposure. These studies indicate that antibody production in reptiles is similar to that in mammals.

\subsubsection{Seasonal variation in reptilian immune responses}

For most reptile species both physiological and behavioural changes are observed seasonally. The ectothermic nature of reptiles means that environmental conditions control most aspects of their life histories, including reproduction, food intake and digestion, locomotor activity and immunity. The seasonal variation in immune responses among reptiles appears to be both species and aspect of immunity specific. Zimmerman et al. (2010b) found that different aspects of both the innate and adaptive immune responses produced different seasonal patterns in the red-eared slider.

Seasonal variation in innate, cell-mediated and humoral immunity was characterised in red-eared sliders across the active season (March to September). Serum bacterial killing capacity was found to peak in late May and June before dropping dramatically in August. In contrast, IgG levels increased gradually from March to September (Zimmerman et al. 2010a). This emphasises the complexity of the immune response and suggests a dynamic relationship in which different aspects of immunity are influenced by different biotic and abiotic factors.

In some species reduced immune function is observed during the winter months when body temperatures of the reptiles are often substantially decreased as compared with summer. Seasonal involutions in lymphoid organs, including the spleen, thymus and gut-associated lymphoid tissue, have been observed in a number of reptilian species (Hussein et al. 1979). Hussein et al. (1979) noted the thymus of the lizard Scincus scincus was involuted in winter and white pulp of the spleen was highly depleted as compared with summer and autumn. The changes in lymphoid tissues in winter were 
paralleled by a failure to form antibodies to rat erythrocytes in winter. Antibodies were produced slowly in spring and reached their most vigorous production in summer and winter (Hussein et al. 1979). For the large majority of studies temperature was found to be the most important factor affecting reptile immune function.

\subsection{Tuatara ecology and immunity}

Tuatara are medium-sized, long lived reptiles (c. 100 years; Gaze 2001) that are endemic to New Zealand. Predation by introduced mammals has reduced the once widespread distribution to small, predator-free offshore islands (Cree and Butler 1993). Tuatara are the only extant representative of the ancient reptilian order Rhynchocephalia (sensu Gauthier et al. 1988), and diverged from their sister group, the squamates, approximately 230 million years ago (Rest et al. 2003).

Tuatara are a diurno-nocturnal, burrowing species that exhibit varying degrees of day time activity depending on their habitat. Tuatara typically forage at night and can remain active in temperatures as low as $5.2^{\circ} \mathrm{C}$ (Thompson et al. 1996). Tuatara in closed-canopy forest areas will frequently bask and feed during the day. Day time body temperatures have been recorded as high as $30^{\circ} \mathrm{C}$ (Walls 1981, Barwick 1982).

Summer is the most active season for tuatara, and their courtship begins in late January and continues throughout February (Gillingham et al. 1995). Females migrate to rookeries in October-December (approximately 8-10months after mating) and lay eggs.

The largest (an estimated 30,000 to 50,000 individuals) and most well studied population of tuatara is found on Stephens Island (also known by its Māori name Takapourewa). Stephens Island is a 150 hectare (ha) island with a history of habitat modification (Brown 2000). An estimated $80 \%$ of the island's original forest was removed following the construction of a lighthouse in 1894 and to make room for the associated farming and grazing (Brown 2000). The modification has resulted in a number of different habitat types, and tuatara display different behaviour in the different habitats. My research was conducted in three sites, comprising two habitat types; open pasture and remnant coastal forest. The tuatara are present in very high densities in forests ( 2700 tuatara/ha), almost 10 fold higher than densities found in 
pastures and shrubland (<200 tuatara/ha) (Moore et al. 2007). Tuatara in pastures also lack any cover from natural predators and consequently are less active during the day than those found in the forests (Moore et al. 2007).

Stephens Island is also inhabited by an estimated one million fairy prions which use the island as a breeding ground during October to January (Falla 1993). Tuatara on Stephens Island will often share a burrow with fairy prions during the birds' breeding season (Markwell 1998) but tuatara will also prey on fairy prion eggs, chicks and occasionally adults (Walls 1981, Newman 1987). Tree weta (Hemideina crassidens) also occupy Stephens Island at an estimated density of 5300/ha (Moller 1985). Tree weta are much more abundant in areas of remnant coastal forest than in pasture areas. In areas such as Keepers Bush where tuatara and weta are abundant, weta form a primary part of the tuatara diet (Walls 1981). Four species of native skink (Oligosoma lineoocellatum, O. infrapunctatum, $O$. nigriplantare polychroma and $O$. zelandicum) are also found on Stephens Island at varying densities. Although these species are often abundant in areas of tuatara habitation, they only form a small part of the tuatara diet (Walls 1981). The agility and speed of most skink species is thought to be the primary reason they do not form a bigger part of the tuatara diet (Walls 1981). The skinks' speed does not exclude skinks as a potential reservoir of Salmonella for tuatara infection, as environmental contamination by skink faeces may also act as a potential route of infection. Several other species of seabird, such as sooty shearwater (Puffinus griseus) and little blue penguins (Eudyptula minor), as well as introduced and native passerines also inhabit the island, but none share the same degree of interaction with tuatara as the species previously mentioned.

Given that skinks are often found in close proximity to, and are potential prey items of tuatara I questioned whether the lack of detectable Salmonella seen in tuatara was due to a lack of exposure or whether it was due to an innate resistance. Consequently, I selected species known to have potential for high degrees of interaction with tuatara for Salmonella testing. Those species selected were tuatara, skinks, fairy prions and tree weta. I also performed environmental soil sampling of soil collected from inside tuatara burrows. Geckos on Stephens Island are also known carriers of Salmonella (Middleton 
et al. 2010) and are an occasional prey item of tuatara (Walls 1981). However, they were not included in this study because they are predominantly aboreal species and therefore do not share the same potential for high levels of interaction with tuatara as skinks. These cloacal and soil samples were collected in order to elucidate the probability of tuatara exposure to Salmonella. In contrast to lack of exposure, the lack of detectable Salmonella in tuatara may be due to strong immune defences against this bacterium. While there are several possible immune mechanisms, which could explain the absence of Salmonella in tuatara, I focussed on just two of the most likely mechanisms: 1) the presence of anti-Salmonella antibodies and 2) anti-microbial activity of tuatara sera.

Few studies have been conducted on the immune response of tuatara, and only one other study has investigated the immune response to specific bacterial pathogens. Marchalonis et al. (1969) demonstrated that tuatara respond to injection of $S$. Adelaide flagellin by producing antibodies which are structurally similar to the $\gamma \mathrm{M}$ immunoglobulins of higher vertebrates. Other studies on tuatara immune responses have considered the activity and seasonality of both innate and adaptive immune responses. Tuatara are among the few nocturnal reptiles adapted to live in cool temperate zones (Wilson and Lee 1970) and have preferred body temperatures of between $17-21^{\circ} \mathrm{C}$ (Besson and Cree 2011). It has therefore been proposed that seasonal variation in immune responses may be different to those of many other ectothermic vertebrates (Burnham et al. 2006). Previous research has indicated that the innate immunity of tuatara may be reduced in winter compared to summer (La Flamme et al. 2010). Investigation of toll-like receptor (TLR) responses in tuatara found a clear increase in TLR agonists in leukocytes isolated from tuatara in summer compared with winter (La Flamme et al. 2010). In contrast, Burnham et al. (2005) assessed T cell responses in captive tuatara and found no clear seasonal difference between winter and spring. Tuatara lymphocytes cannot be cultured in vitro at $37^{\circ} \mathrm{C}$ and are grown optimally at $26^{\circ} \mathrm{C}$ (Burnham et al. 2005). Therefore, it is possible that lymphocyte function may be less impaired by cold temperatures in tuatara than in other ectothermic vertebrates (Burnham et al. 2006). Conflicting results have been found in the limited studies on the effects of seasonality on tuatara peripheral blood cells. Desser (1978) observed a higher number of eosinophils and a lower number of neutrophils (i.e. heterophils) in summer than in winter. In contrast, Burnham et al. (2006) found an 
increase in heterophils from winter to spring. The sample sizes in both of these studies were small, comprising just one female in Desser (1978), and two males and two females in Burnham et al. (2006). Both of these studies were also conducted over just two seasons, winter and summer, and winter and spring respectively.

The presence of specific antibodies will provide evidence of immunological exposure of tuatara to Salmonella, and investigation of the bactericidal capacity of tuatara sera against Salmonella will provide some of the first evidence of the strength of an innate immune response against this bacterium. Having a baseline understanding of the prevalence and seasonal dynamics of disease in New Zealand native fauna provides wildlife managers with important information which can be utilised in management practices, such as translocations, by preventing disease spread among naïve populations. Understanding the seasonal differences in prevalence of Salmonella and tuatara immune responses to this pathogen further helps to assess threats to tuatara from the introduction of novel Salmonella serovars to New Zealand. Understanding the seasonal aspects of both prevalence and immunity also provides information as to the possible impacts a global change in climate may have on tuatara and other native fauna.

\subsection{Salmonella population genetics}

Understanding the epidemiology of infectious diseases is vital to the control of infections within populations. With the increased popularity and availability of molecular typing methods, molecular characterisation has begun to play a pivotal role in our epidemiological understanding of disease (Urwin and Maiden 2003).

Immunological typing methods, such as serotyping, have played an extremely important role in our understanding of Salmonella distributions within populations, allowing tracing of serovars involved in an epidemic, the emergence of new subtypes and historical trends in Salmonella distribution (Alcaine et al. 2006, Selander et al. 1990). However, there are recognised problems with immunological typing schemes such as the fact that immunological markers may not be representative of the genome as a whole, and they require a large number of costly reagents in order to test for the often high diversity of serotypes (Urwin and Maiden 2003, Gupta and Maiden 2001). 
Multi-locus sequence typing (MLST) was proposed in 1998 as a means of combating the problems associated with antigenic typing (Enright and Spratt 1998, Maiden et al. 1998). The MLST approach amplifies multiple house-keeping loci in order to cope with recombining populations such as bacteria (Urwin and Maiden 2003). Seven house-keeping genes, flanked by genes of similar function are typically chosen for the MLST scheme. Schemes which examine too few loci can encounter problems if high levels of recombination or selection disguise the phylogenetic signal (Urwin and Maiden 2003).

MLST schemes are commonly used to determine population structure by estimating recombination and mutation rates (Feil et al. 2001), and investigating evolutionary relationships among bacterial isolates (Godoy et al. 2003). MLST is also used as a routine typing tool enabling comparisons of isolates (Dicunzo et al. 2002, Johnson et al. 2003, and de Sousa et al. 2003) and for investigation of the global spread and disease caused by novel variants.

An MLST scheme allows investigation into the importance of recombination, selection, drift and mutation on the population structure of Salmonella on Stephens Island. To my knowledge this is the first investigation of Salmonella by MLST in New Zealand and will contribute to our understanding of the epidemiology of this bacterium in New Zealand wildlife.

\subsection{Key questions, thesis outline and style}

The aim of this thesis was to advance current understanding of the ecological and immunological relationships between tuatara and Salmonella, by answering the following questions:

-What is the prevalence and seasonal distribution of Salmonella in an island ecosystem?

- What are the contributions of mutation, selection, drift recombination and migration to patterns of Salmonella diversity in New Zealand native skinks?

- Do tuatara have antibodies against Salmonella? 
- Does tuatara serum exhibit anti-microbial activity against Salmonella?

- How are tuatara immune responses affected by season?

The findings enhance the current knowledge of disease ecology and eco-immunology, and improve conservation efforts by limiting disease spread during translocations and by providing important information on the likely threat novel serovars of Salmonella or global temperature changes may have on tuatara and other native fauna.

\subsubsection{Thesis outline and style}

This thesis is written as a series of stand-alone manuscripts formatted for publication in peer-reviewed journals. This style inevitably involves some replication, particularly in the introductory sections. Each chapter includes an introduction to the specific aims and hypotheses investigated in that chapter and a discussion which places the work in context with existing material.

Understanding the potential importance of Salmonella on New Zealand native wildlife, and in particular tuatara conservation, first requires knowledge of the underlying patterns of disease ecology in wildlife. Thus, Chapter Two investigates the abundance and seasonal dynamics of Salmonella within wildlife on Stephens Island. I explored the abundance and distribution of Salmonella serovars among species using cloacal swabs collected from a number of species on Stephens Island over two years. This chapter has been submitted to the Journal of Wildlife Disease with the following co-authors: A. La Flamme, B. Gartrell and N. Nelson. I conducted all the field and experimental work for this chapter and my supervisors provided input and advice on the experimental methods during the planning stages and provided comments and editing advice on the manuscript. However, for the sake of consistency with the following chapters I have written the chapter in a first person narrative.

The lack of Salmonella detected in tuatara in Chapter Two led me to investigate the antibody status of tuatara to this bacterium (Chapter Three). I developed Western blots and flow cytometry assays to investigate the recognition of Salmonella by antibodies in tuatara serum. I explored the relationships between the presence and abundance of 
tuatara antibodies with individual tuatara characteristics, and investigated seasonal effects on immune response. I also investigated the importance of cross-reactivity with two closely related bacteria, E. coli and C. koseri, on this response.

Chapter Four investigates the anti-microbial activity of tuatara sera to Salmonella. I developed anti-microbial assays with the sera of wild and captive tuatara obtained seasonally over two years. The anti-microbial activity of tuatara sera was compared with Australian water dragons and coastal bearded dragons, which are known carriers of Salmonella.

In Chapter Five, I examine the population structure of Salmonella in New Zealand wildlife using a multi-locus sequencing typing (MLST) scheme. This chapter investigates the genetic population structure of Salmonella obtained in Chapter Two. Thus, this chapter includes distribution and serovar typing information from Chapter Two and compares this information with the genetic information obtained from MLST.

Finally, Chapter Six provides a synthesis of the main findings of this thesis, and discusses implications for the conservation of tuatara and other native fauna. In this chapter I also outline potential directions for future research. 


\title{
CHAPTER TWO
}

\section{The abundance and spatio-temporal dynamics of}

\author{
Salmonella in an island ecosystem
}

\subsection{Abstract}

Salmonella are Gram-negative bacteria commonly encountered in reptiles, birds and mammals and are a serious concern to wildlife. A wide variety of Salmonella serotypes occur within reptilian hosts but the ecology of this organism and its relationships with its hosts are poorly understood. I collected cloacal swabs and faecal samples from tuatara (Sphenodon punctatus), fairy prions (Pachyptila turtur), skinks (Oligosoma spp.) and weta (Hemideina crassidens) in an island ecosystem to screen for Salmonella. Soil samples were also collected from inside burrows of tuatara and fairy prions and tested for Salmonella prevalence. I performed repeated sampling between October 2009 and October 2011. Cloacal swabs were collected from 620 tuatara and no intestinal shedding of Salmonella was detected. Similarly, no Salmonella was detected in the 190 fairy prions or 200 weta tested. In contrast, I isolated Salmonella from $6.5 \%$ of skinks $(\mathrm{n}=275)$ and $8.4 \%$ of soil samples $(\mathrm{n}=238)$. I identified two serovars of Salmonella from the 52 positive isolates, Salmonella Saintpaul and Salmonella Mississippi. S. Mississippi was isolated from skinks only and $S$. Saintpaul was found in both skinks and soil samples. A seasonal effect of Salmonella prevalence was observed in both skinks and soil, with no Salmonella isolation from either species during spring (October). A very high prevalence of Salmonella in soil was found in June 2010 but this was not observed again in June 2011. I tested species across three different sites representing two habitat types (bush and paddock), and found a higher prevalence of Salmonella among skinks caught in one of two paddock sites. Both serotypes of Salmonella isolated in this study were found in all seasons and across all habitat types. My findings indicate that Salmonella abundance on Stephens Island is influenced by species, season and habitat. Salmonella may be a persistent pathogen within the ecological network of Stephens Island, although not all species are affected. 
Establishing baseline measures of abundance and distribution of pathogens in wildlife populations and determining how infection varies at species, spatial and seasonal levels is essential to our understanding of the potential impacts of pathogens in host populations.

\subsection{Introduction}

The transmission and expression of disease in wild animal populations is a complex interaction of host, pathogen and environmental factors (Spurgin et al. 2012). In managed populations, human activities can increase transmission of these diseases by altering contact associations between hosts and consequently pathogen transmission patterns (Boggs et al. 1990, Daszak et al. 2001). In addition, anthropogenic factors may increase levels of host stress thereby increasing the severity and duration of infection by reducing immunocompetence (Alley et al. 1999, Amo et al. 2007).

Although pathogens play an important role in the evolution and ecology of their hosts, they can also pose a significant threat to the health and survival of endangered hosts and are increasingly cited as a major threat to positive outcomes of conservation efforts (Daszak et al. 2001). Pathogenic bacteria may impact individual fitness in a number of ways, such as by increasing predation risk and, reducing survival and reproductive output (Anderson and May 1979, Gulland 1995, Johnson et al. 2006, Moller and Nielsen 2007). For most wildlife species the data on prevalence and spatio-temporal distribution of pathogens are limited. It is also difficult to predict the complex nature of the interactions that exist between hosts, pathogens and the environment and the disturbances which may alter balances within these relationships. Understanding the abundance, distribution and dynamics of pathogen ecology is essential to our understanding of their ecological role in host populations, and in measuring their threat to protected species. Measuring the natural levels of infection in wildlife populations and determining how infection varies at species, spatial and temporal levels is a fundamental step in understanding the potential impacts of pathogens in host populations (Spurgin et al. 2012). 
Many factors are likely to influence the distribution of pathogens including host distribution, within-host factors and spatio-temporal dynamics (Spurgin et al. 2012). If pathogen distribution was determined solely by the range and distribution of the host, I would expect to see a homogenous distribution over the host's range (Apanius et al. 2000). However, in most cases within-host factors such as age, sex, life history and immune competence are also likely to affect pathogen distribution (McCurdy et al. 1998, Hosseini et al. 2004, Mougeot and Redpath 2004). Testosterone is generally considered immuno-suppressant and males of many species will often present with a greater prevalence or more severe clinical signs of disease when testosterone levels peak (Zuk and McKean 1996, Ferrari et al. 2004). In the house finch (Carpodacus mexicanus) increased testosterone has been demonstrated to accelerate the rate of coccidial infection (Duckworth et al. 2001). Pathogen diversity and abundance can also be strongly impacted by environmental conditions such as temperature. These conditions affect the prevalence of host infection by either favouring or limiting pathogen abundance (Bensch and Akesson 2003, Fallon et al. 2004, Cosgrove et al. 2008).

Previous investigations have shown that Salmonella infections can vary temporally. Salmonella are Gram-negative rods belonging to the phylum Enterobacteriaceae (Bergey et al. 2001). These bacteria are worldwide in distribution and affect animals across a broad taxonomic spectrum, including humans, cattle, reptiles and birds (Woodward et al. 1997, Mermin et al. 2004, Carlson et al. 2011). Infection with Salmonella can result in a broad range of clinical outcomes depending on host immunity, pathogenicity of the Salmonella serotype and environmental stressors. In most cases, after an initial period of gastroenteritis, infection is subclinical, and many animals act as asymptomatic carriers that shed the bacteria intermittently (Pfleger et al. 2003). However, when stressors result in a disruption of the host's normal intestinal flora, Salmonella can establish and flourish in the gut resulting in septicaemic disease (Haraga et al. 2008).

Effects of temperature on the prevalence of Salmonella have been investigated at different scales. Pollari and Powers (1998) investigated Salmonella serovars from nonhuman sources in 1995 and found a seasonal trend with higher rates detected in summer and autumn during this year. Many other authors have demonstrated a lack of distinct 
seasonal patterns in non-human isolates (Guerin et al. 2005). A very clear increase in Salmonella prevalence has been identified in isolates from human hosts during summer (Olsen et al. 2001), but it has been suggested that human behaviour such as increased outdoor dining, poor food handling and storage and increased water activity during summer months may contribute to this trend (Olsen et al. 2001).

There are more than 2500 Salmonella serovars which vary in their host specificity and virulence. For example, $S$. Gallinarium and $S$. Typhi infect only fowl (Barrow et al. 1994) and humans (Forest et al. 2010) respectively. In contrast, $S$. Typhimurium will infect a range of hosts including humans, reptiles and other mammals (Mills and Finlay 1994, Alley et al. 2002, Handeland et al. 2002, Kikillus et al. 2011). Disease attributed to Salmonella has been identified in many wildlife species, and there is concern about the impacts of wildlife reservoirs on both humans and production animals. Salmonella Brandenburg, the causative agent of epidemic abortions and deaths in pregnant ewes in New Zealand, is thought to be spread by black-backed gulls (Larus dominicanus) (Clark 2001). Black-backed gulls are scavenging seabirds known to feed on a wide range of carrion, including aborted sheep foetuses and membranes, and have high rates of intestinal carriage of $S$. Brandenburg during the abortive season (Clark 2001).

Many Salmonella serovars are capable of crossing host barriers and colonise a wide variety of macro-organisms. Herpetofaunal species have often been implicated as transmitters of Salmonella (Mermin et al. 2004), and reptile-associated salmonellosis is a significant threat to the health of humans (Chiodini and Sundberg 1981, Harris et al. 2009), domestic animals (McInnes 1971) and other wildlife (Clark et al. 2002). Wild geckos and skinks inhabiting the kitchens of homes in Otago, New Zealand were linked to an outbreak of human salmonellosis caused by Salmonella Saintpaul (Hamel and McInnes 1971). Given the often ubiquitous nature of Salmonella, Winfield and Groisman (2003) have suggested that non-host specific serovars may persist in a cyclic lifestyle consisting of passage through a host into the environment and back into a new host. Unlike other members of the family Enterobacteriaceae Salmonella are highly environmentally stable bacteria, capable of surviving for up to a year in water and soil (Davies and Wray 1996). 
Many birds and insects, including flies are important vectors for rapid, widespread dissemination of Salmonella in the environment (Davies and Wray 1996, Winfield and Groisman 2003). Infection of wild bird populations with Salmonella has been seen in a variety of seabirds including the black-backed gulls, shags (Phalacrocorax spp.) and red-billed gulls (Larus novaehollandiae scopulinus) (Robinson and Daniel 1968). Seabirds that feed around human rubbish dumps or sewage areas are particularly common carriers of Salmonella. Salmonellosis has also been demonstrated to be a significant cause of mortality in passerine birds, and authors have demonstrated largescale mortality of birds by epidemic salmonellosis in Canada (Daoust et al. 2000), USA (Hall and Saito 2008), and Japan (Une et al. 2008). Similar large-scale mortalities of passerines due to salmonellosis have been seen in New Zealand. During mid-2000 infection with a previously unreported strain of Salmonella in New Zealand, Salmonella Typhimurium DT160 resulted in the death of several hundred birds in Christchurch and the Manawatu (Alley et al. 2002). These mortalities predominantly involved sparrows (Passer domesticus) along with small numbers of greenfinches (Carduelis choloris), goldfinches (Cardeulis cardeulis), chaffinches (Fringilla coelebs) and occasionally blackbirds (Turdus merula) and native silvereyes (Zosterops lateralis) (Alley et al. 2002). The effect novel strains of Salmonella can have on indigenous wildlife in New Zealand is further highlighted by the Salmonella Typhimurium DT195 outbreak which occurred amongst hihi (Notiomystis cincta) on Tiritiri Matangi Island. Whilst only nine hihi bodies were found the authors estimate that the mortality rate could have been as high as 30\% (Ewen et al. 2007).

In New Zealand, Salmonella has been isolated from native and introduced lizards (Middleton et al. 2010, Kikillus et al. 2011), birds (Alley et al. 2002, Connolly et al. 2006) and domestic animals (Clark et al. 2002). However, there has been little research into the ecology and dynamics of this disease among natural populations. Investigating the ecology of Salmonella in an island ecosystem provides us with a measure of the natural levels of infection within species and allows investigation into the effects of species, spatio-temporal and within-host factors on Salmonella distribution. Stephens Island (also known by its Maori name, Takapourewa) is home to the largest density of the New Zealand endemic reptile, tuatara (Sphenodon punctatus) with total numbers estimated between 30,000 and 50,000 (Newman 1987), and an estimated one million fairy prions use the island as a breeding ground (Harper 1985). Both tuatara and fairy 
prion are burrowing species and are known to share burrows during the fairy prion breeding season (October-January), but tuatara will also prey on fairy prion eggs, chicks and occasionally adults (Walls 1981, Newman 1987). Tree weta (Hemideina crassidens) also occupy the island at an estimated density of 5300/ha (Moller 1985) and form a primary part of the tuatara diet (Walls 1981). The 150 hectare Stephens Island is also habitat for four species of native skink; Oligosoma lineoocellatum, $O$. infrapunctatum, O. nigriplantare polychroma and O. zelandicum. Stephens Island also provides habitat for three gecko species, Hoplodactylus stephensi, H. maculatus and Naultinus manukanus. Geckos throughout New Zealand and on Stephens Island are known carriers of Salmonella (Middleton et al. 2010). However, the gecko species on Stephens Island are not included in this survey because unlike the skinks they less commonly share burrows or live in very close proximity to tuatara burrows and therefore do not share the same level of interaction with tuatara as the skinks. Several other species of seabird, such as the sooty shearwater (Puffinus griseus) and little blue penguins (Eudyptula minor), as well as introduced and native passerines also inhabit the island, but like the geckos they are not included in this study because none share the same degree of interaction with tuatara as the species previously mentioned.

Consequently I selected tuatara, fairy prions, tree weta and skinks for investigation of their Salmonella carriage status due to their close interactions and potential for disease transmission.

Neotrombiculid mites (Neotrombicula naultini and Neotrombicula sphenodonti) infest tuatara, geckos and skinks on Stephens Island (Goff et al. 1987, Godfrey et al. 2010). Many species of arthropod have been shown to be effective transmitters of Salmonella (Letellier et al. 1999, Aballay et al. 2000, Olsen and Hammack 2000), and mites are known to effectively transmit Salmonella to chickens on poultry farms (Moro et al. 2009). Given that both lizards and tuatara are infested with the same species of Neotrombiculid mites on Stephens Island I investigated correlations between Neotrombiculid mite prevalence and loads as a possible source of Salmonella transmission on the island. Although skinks can be host to other species of mite the Neotrombiculid mites are the only ones that are also found on tuatara. Therefore I have investigated only Neotrombiculid mites and throughout this thesis the term 'mites' refers to Neotrombiculid mites only. 
Salmonella prevalence in populations of native skinks on Stephens Island has previously been investigated and was found at a test prevalence of $4.0 \%$ and an estimated true prevalence of $0-12 \%$ (Middleton et al. 2010). Three serotypes were isolated from skinks during this study, S. Saintpaul, $S$. Typhimurium DT135 and an unidentified serovar of antigen determination 4,12:-:1,2. Serovars $S$. Saintpaul and $S$. Typhimurium DT135 have been responsible for outbreaks of salmonellosis in humans and animals in New Zealand (Anonymous. 2010). Despite Salmonella being isolated from skinks living in close proximity to tuatara, no intestinal shedding of Salmonella has been detected in live tuatara (Gartrell et al. 2006, Gartrell et al. 2007). Intestinal carriage of Salmonella has not previously been investigated in fairy prions or tree weta.

I investigated the prevalence and distribution of Salmonella in native wildlife in an island ecosystem. Specifically, the following questions are addressed: (1) What is the prevalence of Salmonella among the species and soil tested? (2) Is there a seasonal pattern of Salmonella prevalence on Stephens Island? (3) Does habitat type affect Salmonella detection within species? (4) What is the spatial ecology of Salmonella serovars isolated on Stephens Island?

\subsection{Materials and methods}

\subsubsection{Study site}

I conducted sampling on Stephens Island (Cook Strait, New Zealand, $40^{\circ} 40^{\prime} \mathrm{S}, 174^{\circ} 0^{\prime} \mathrm{E}$ ) during eight trips from October 2009 to October 2011. Tuatara (Sphenodon punctatus), fairy prions (Pachyptila turtur), tree weta (H. crassidens) and lizards (Oligosoma spp.) were caught in three study sites; one closed canopy forest and two open pasture paddocks (Figure 2.1). These three sites represent two habitat types. The closed canopy 'forest' is dominated by trees up to $5 \mathrm{~m}$ tall, including ngaio (Myoporum laetum), mahoe (Melicytus ramiflorus), kohuhu (Pittosporum tennuifolium), kohekohe (Dysoxylum spectabile) and taupata (Coprosma repens) and shrubs, mainly kawakawa (Macropiper excelsum), which dominate the understory. The remaining two sites are in 'pastures' dominated by exotic grasses including wild oats (Avena sterilis), Yorkshire 
fog (Holcus lanatus) and perennial rye grass (Lolium perenne) (East et al. 1995, Brown 2000, Stephens 2007).

\subsubsection{Species and sampling}

The four species of skink were captured in all three study sites at varying abundances. Pitfall traps were used to catch lizards at the three sites; fifteen pitfall traps were placed at each site in October 2009. Pitfall traps were four-litre plastic paint buckets, with four drainage holes. The traps were dug into the ground with the top flush with the surface. A layer of grass or leaf litter, approximately $4 \mathrm{~cm}$ deep, was placed in the bottom of the buckets to provide protection for the skinks from weather and predators. Each trap was baited with jelly meat cat food and tinned pears. The traps were checked twice daily in the morning and evening. These traps were left in their position but securely sealed between trips. In January and March 2011 artificial cover objects (ACOs), made from corrugated bitumen roofing tiles one corrugation wide and $30 \mathrm{~cm}$ long were also used to catch skinks in the two paddock sites. ACOs were placed into each of the paddocks (60 at each site) on the first day I was on the island of each trip. They were also checked twice daily. Following capture, each skink was marked on the skin with a silver metallic marker (Artline 990XF) so that recaptures in a trip could be avoided. Snoutvent length (SVL) $( \pm 0.5 \mathrm{~mm})$, mass $( \pm 0.2 \mathrm{~g})$ and number of mites were recorded for each skink. A single cloacal swab was collected from each skink before it was released.

Tuatara (Sphenodon punctatus) are estimated to number between 30,000 to 50,000 on Stephens Island (Newman 1982). Tuatara in the remnant forest habitats reach much higher densities ( 2700 tuatara/ha) than in modified pastures ( 200 tuatara/ha) (Moore et al. 2009). The paddocks are commonly used by nesting females as sites to incubate their eggs (Thompson et al. 1996). Systematic surveys of the three study sites were conducted each night and all tuatara were captured by hand (Table 2.1). For each tuatara captured the capture location was recorded and morphological measurements were taken, including snout-to-vent length $(\mathrm{SVL} ; \pm 0.5 \mathrm{~mm})$, mass $( \pm 1.0 \mathrm{~g})$ and sex. The sex of individuals ( $\geq 170 \mathrm{~mm}$ ) was assessed using secondary sexual characteristics including crest development, spine shape, head size/shape, and shape of abdomen (Dawbin 1982, Cree et al. 1991). The total number of mites on the body surface was 
also noted. Mite loads above 100 were estimated by extrapolation of the area of the host that contained 100 mites (Godfrey et al. 2008).

Many of the tuatara caught in the forest had previously been marked with PIT (passive integrated transponder) tags as well as toe clippings and/or unique coloured beads inserted into the nuchal crest (Fisher and Muth 1989). Where present these were used as individual identifiers throughout the study. Tuatara in the paddock sites are less commonly marked with any permanent identifiers. For those tuatara in both the paddocks and forest that did not possess any identifiers a unique black number was written on the skin of each flank (with a non-toxic marker) to avoid recaptures during that sampling period. The tuatara were then observed over the duration of the field trip in order to locate their primary burrow at the time of the study. Tuatara occupied burrows were checked for co-habitation with fairy prions or other tuatara. If cohabitation with any species was noted I attempted to catch and sample the other animals also. Burrows with entrances $1 \mathrm{~m}$ or less from captured tuatara were also investigated for occupancy and any animals seen to be regularly using these burrows were also sampled.

Fairy prions are generally only present at their colonies during their breeding season, October to January. Therefore no fairy prions were caught during the March or June field trips. Fairy prions form relatively stable pair bonds and lay only one egg a season (Harper 1985). Both adults share in the incubation of the egg and the feeding of the chick. On Stephens Island it is common for fairy prions and tuatara to share their burrows. Newman (1987) found that $6.6 \%$ of burrows occupied by tuatara in Keepers Bush were shared with an adult bird and $10.3 \%$ with a fairy prion chick. The estimated number of fairy prions on Stephens Island during breeding season is 1,000,000 (Harper 1985). Fairy prions were caught as they came or left their burrows. The burrows were then observed over the duration of the trip and where possible the second bird of the pair was caught and also sampled. I also burrow-scoped the burrows to investigate occupancy and attempted to catch and sample any tuatara that were sharing the burrow. 


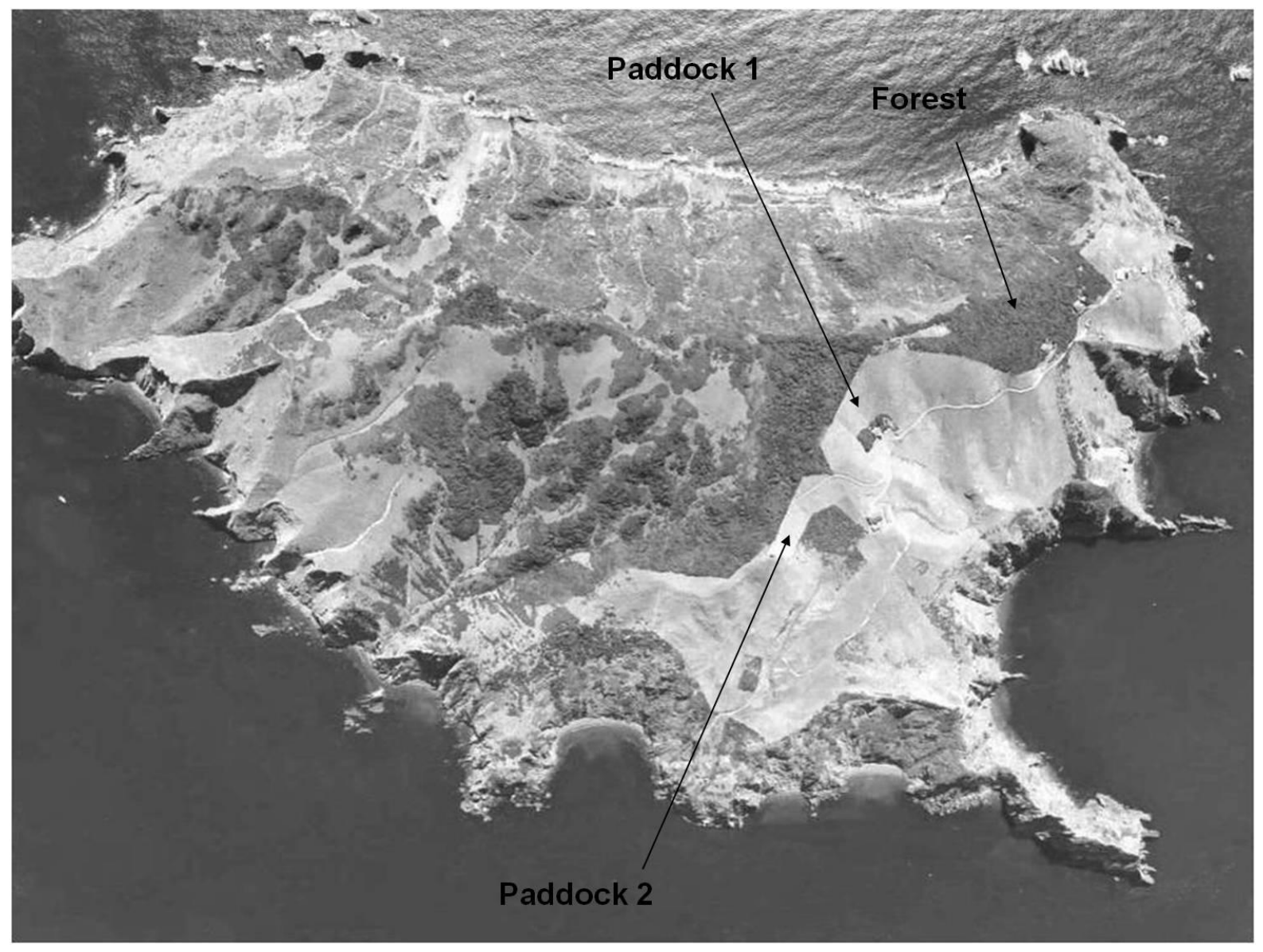

Figure 2.1: Aerial photograph of Stephens Island (2000) showing location of field sites. 
Table 2.1: Frequency of tuatara new captures and recaptures and the number of tuatara sharing burrows with other tuatara or fairy prions during trips to Stephens Island. The number of tuatara caught in the forest (B), paddock 1 (P1) and paddock 2 (P2) are shown.

\begin{tabular}{|c|c|c|c|c|c|c|c|c|c|c|}
\hline \multirow[b]{2}{*}{ Trip } & \multicolumn{4}{|c|}{ New captures } & \multicolumn{4}{|c|}{ Recaptures } & \multirow[b]{2}{*}{$\begin{array}{l}\mathbf{N} \\
\text { sharing } \\
\text { with } \\
\text { other } \\
\text { tuatara } \\
\end{array}$} & \multirow[b]{2}{*}{$\begin{array}{l}\mathbf{N} \\
\text { sharing } \\
\text { with } \\
\text { fairy } \\
\text { prions }\end{array}$} \\
\hline & B & $\mathbf{P 1}$ & $\mathbf{P 2}$ & $\mathbf{N}$ & B & P1 & $\mathbf{P 2}$ & $\mathbf{N}$ & & \\
\hline October 2009 & 77 & 58 & 55 & 190 & - & - & - & - & 2 & 27 \\
\hline January 2010 & 27 & 34 & 0 & 61 & 5 & 1 & 1 & 7 & 0 & 6 \\
\hline March 2010 & 47 & 52 & 54 & 153 & 22 & 9 & 5 & 36 & 6 & - \\
\hline June $2010 *$ & - & - & - & - & - & - & - & - & - & - \\
\hline January 2011 & 40 & 39 & 34 & 113 & 20 & 14 & 6 & 40 & 5 & 38 \\
\hline March 2011 & 15 & 49 & 38 & 102 & 28 & 3 & 6 & 37 & 6 & - \\
\hline June $2011^{*}$ & - & - & - & - & - & - & - & - & - & - \\
\hline October $2011 *$ & - & - & - & - & - & - & - & - & - & - \\
\hline Total & 206 & 232 & 181 & 619 & 75 & 27 & 18 & 120 & & \\
\hline
\end{tabular}

* Only soil samples tested during these periods

A single cloacal sample was collected from each animal caught. A sterile, dry Minitip swab was used and then placed into individual polypropylene tubes containing Aimes agar gel with charcoal (Copan Diagnostics Inc., Corona, California, USA). The swabs were immediately refrigerated on the island and stored for up to 20 days until transport to the laboratory where they were stored at $4{ }^{\circ} \mathrm{C}$ until culturing. A $70 \%$ ethanol solution was used to sterilise our hands, rulers and any other equipment coming into contact with the animals between each animal.

Soil samples were collected from tuatara or tuatara/fairy prion occupied burrows in the three study sites. In October 2009, 20 burrows were sampled from Keepers Bush and 
15 burrows were sampled in each of the paddocks. The same burrows were then resampled on each sampling occasion except June 2011 and October 2011 when random selections of burrows were tested in each location (Table 2.2). Where time permitted additional burrows were sampled each season at the different sites. Soil samples only were collected in three field trips (June 2010, June 2011 and October 2011). At each burrow one tablespoon of soil was collected from the end of the burrow or where the end of the burrow could not be reached, soil was collected at one arm's length into the burrows ( 1m from the entrance). Burrows were used as the experimental unit for soil, as soil samples were collected from inside burrows occupied by tuatara and/or fairy prions. The total number of burrows (tuatara and fairy prion) on Stephens Island has been conservatively estimated at 1,000,000 based on the number of tuatara ( 30-50000) and fairy prions $(\sim 1,000,000)$ which inhabit the island.

Tree weta were caught in Keepers Bush only. During each sampling occasion 50 tree weta were captured by hand by spotlighting at night. Weta were held overnight in clean 1 litre plastic ice-cream containers. Air holes were made in the top of the plastic container and a layer of leaf litter ( $2 \mathrm{~cm}$ deep) was placed at the bottom. A small $1 \mathrm{~cm}^{3}$ piece of carrot was provided to each weta. Faecal matter deposited over night was collected in $2 \mathrm{ml}$ eppendorfs and stored in the refrigerator. Weta were released back to their capture site the next evening. Faecal matter and soil samples were collected wearing sterile latex gloves.

\subsubsection{Laboratory isolation of Salmonella}

Salmonella isolation was achieved by inoculating selenite F enrichment broths (Fort Richard Laboratories, Otahuhu, Auckland, New Zealand) with either swabs, 1 teaspoon of soil or 1-2 weta faecal pellets roughly broken. The broths were incubated overnight at $35-37^{\circ} \mathrm{C}$ for 24 hours, they were then sub-cultured onto xylose lysine deoxycholate (XLD) plates (Fort Richard Laboratories, Otahuhu, Auckland, New Zealand) which were incubated in normal atmosphere at $35-37^{\circ} \mathrm{C}$ for a further 24 hours. Suspect colonies were used to inoculate triple sugar iron (TSI) agar slopes, urea agar slopes and lysine decarboxylase broths (Fort Richard Laboratories, Otahuhu, Auckland, New Zealand). These were incubated overnight at $35-37^{\circ} \mathrm{C}$. Colonies that resulted in glucose fermentation and hydrogen sulphide production on TSI slopes, acid (negative) 
urease tests and positive lysine decarboxylase tests were considered to be consistent with Salmonella. Each organism suspected of being Salmonella was tested for fermentation of glucose, mannitol and xylose; hydrolysis of o-nitriphenyl- $\beta$-dgalactopyranoside (ONPG); indole and acetoin production; citrate utilisation; and production of indole pyruvate and ornithine decarboxlase (Quinn et al. 1994). Samples positive for Salmonella were sent to Environmental Science and Research Services (ESR, Porirua, New Zealand) for confirmation and serotyping by antigenic determination, identifying the somatic ' $\mathrm{O}$ ' and flagellate ' $\mathrm{H}$ ' antigens present.

\subsubsection{Data analysis}

For the purpose of analyses the four species of skink (Oligosoma infrapunctatum, $O$. lineoocellatum, O. nigriplantare, O. zealandicum) have been pooled together to form the category 'skink'. This is due to the small number of each species obtained on each sampling trip.

Comparisons were made between the frequencies of Salmonella carriage by species, and by season using the Pearson's chi-square test. Where the frequencies involved were small, analyses were conducted using the Fisher's exact test (Crawley 2002). Statistical analyses were performed using SPSS (version 18) for Windows (SPSS, Inc., Chicago, IL) and R 2.9.2 (R Core Development Team, 2010).

The estimated true prevalence of Salmonella was calculated using test prevalence $\mathrm{P}^{\mathrm{T}}$ (Thrusfield 2005) and assuming that the Salmonella culture techniques were 50\% sensitive and 98\% specific (Bager and Petersen 1991). These sensitivities and specificities were determined using an animal model (pigs) and are therefore unlikely to be directly transferable to our soil samples. Unfortunately no data are available on the sensitivity and specificity of Salmonella isolation from environmental samples and we have consequently chosen to use these conservative measures for all samples. I calculated $95 \%$ confidence intervals of the true prevalence using the formulae described in Thrusfield (2005). In those cases where no Salmonella was detected the Detection of Disease component of WinEpiScope 2.0 (Facultad de Veterinaria Zaragoza, Spain; Wageningen University, The Netherlands; and University of Edinburgh, UK) was used to calculate the maximum possible prevalence at the $95 \%$ confidence level. Estimates 
of population sizes are required for this calculation and populations were estimated at 50,000 tuatara (Newman 1982), 1,000,000 fairy prion (Harper 1985), 800,000 tree weta (Moller 1985), 500,000 skinks (Stephens 2007) and 1,000,000 burrows.

Those graphs which show Salmonella and 95\% confidence intervals are built using the 95\% confidence intervals of true prevalence as calculated using the formula in Thrusfield (2005). Box plots portray the range, lower quartile, upper quartile and mean. Stars represent outliers in our data.

\subsection{Results}

Fifty-two Salmonella isolates were cultured during this study. All of these samples were fully serotyped and identified as $S$. Saintpaul (n=44) and $S$. Mississippi $(\mathrm{n}=8)$. Salmonella was detected in one of the four animal groups tested in this study (skinks) and in soil environmental sampling. S. Saintpaul was isolated from both soil and skink samples and $S$. Mississippi was isolated from skink samples only. Both serotypes were isolated from all three study sites and across all seasons.

Salmonella was not isolated from any of the 620 tuatara, 190 fairy prion or 200 tree weta samples investigated (Table 2.2). The estimated maximum possible prevalences for these species were calculated at $0.5 \%, 1.6 \%$ and $1.5 \%$ respectively. Of the 275 skinks tested Salmonella was detected in 18 hosts (6.5\%; 95\% CI 4.2-10.1\%). The prevalence of Salmonella in soil samples was not significantly higher in the 238 tuatara/fairy prion and random burrows sampled $(8.4 \% ; 5.5-12.6 \%)$ than in the skinks $\left(\chi_{(1)}^{2}=0.642, P<0.423\right)$ (Table 2.2). Among the skinks, Salmonella was isolated from three of the four endemic species (O. infrapunctatum $O$. zealandicum and $O$. lineoocellatum).

The likelihood of a skink testing positive for Salmonella on Stephens Island was, in part, determined by the location where the host was collected. Samples were collected from three sites on Stephens Island: remnant coastal forest (forest), and two pasture environments (paddock 1 and paddock 2). Skinks living in paddock $2(\mathrm{n}=26)$ were found to have the highest prevalence of Salmonella $\left(\mathrm{P}^{\mathrm{T}}=26.9 \%\right)$, compared with hosts 
living in forest $(\mathrm{n}=87)$ or paddock $1(\mathrm{n}=144)$ sites $\left(\mathrm{P}^{\mathrm{T}}=6.8 \%\right.$ and $3.5 \%$ respectively) $\left(\chi_{(2)}^{2}=18.6, P \leq 0.0001\right.$; Figure 2.2). A similar trend in environmental isolation of Salmonella from soil samples was not identified $\left(\chi_{(2)}^{2}=2.19, P=0.334\right.$; Figure 2.2).

The prevalence of Salmonella isolated from skinks varied from 0-19\% among the different sampling occasions. During the three study trips March 2010, January 2011 and March 2011, Salmonella prevalence in skinks was not significantly different, ranging from $8-19 \%\left(\chi_{(2)}^{2}=2.6, P=0.28\right)$ (Figure 2.3). A prevalence of $24 \%$ was obtained from soil samples collected in June 2010 (18/75, 95\%CI 15.8-34.8), which was significantly higher than from any other sampling occasion $\left(\chi_{(4)}^{2}=21.58, P<0.001\right)$ (Table 2.2). If the June 2010 outlier is excluded there is no difference in the prevalence of Salmonella between soil and skinks $\left(\chi_{(1)}^{2}=0.225, P=0.635\right)$ (Figure 2.3). Due to the surprising finding that Salmonella was not detected in any species or soil on Stephens Island during October 2009, a further collection of soil samples was made in October 2011 ( $\mathrm{n}=25)$, and again no Salmonella was detected. 
Table 2.2: The prevalence of Salmonella isolated from New Zealand native species on Stephens Island, New Zealand.

\begin{tabular}{|c|c|c|c|c|c|c|c|c|c|c|c|c|c|c|c|c|c|c|}
\hline \multirow[b]{2}{*}{ Species } & \multicolumn{2}{|c|}{$\begin{array}{c}\text { October } \\
2009\end{array}$} & \multicolumn{2}{|c|}{$\begin{array}{c}\text { January } \\
\text { 2010 }^{\mathbf{b}}\end{array}$} & \multicolumn{2}{|c|}{ March 2010 } & \multicolumn{2}{|c|}{ June $2010^{c}$} & \multicolumn{2}{|c|}{ January 2011} & \multicolumn{2}{|c|}{ March 2011 ${ }^{\mathrm{a}}$} & \multicolumn{2}{|c|}{ June $2011^{c}$} & \multicolumn{2}{|c|}{$\begin{array}{c}\text { October } \\
2011^{\text {c,d }}\end{array}$} & \multicolumn{2}{|c|}{$\begin{array}{c}\text { Totals } \\
\text { (ex. recaptures) }\end{array}$} \\
\hline & $\begin{array}{l}\mathbf{P}^{\mathrm{T}} \\
(\%) \\
(\mathbf{n}) \\
\end{array}$ & $\begin{array}{l}95 \% \\
\text { CI }\end{array}$ & $\begin{array}{l}\mathbf{P}^{\mathrm{T}} \\
(\%) \\
(\mathbf{n}) \\
\end{array}$ & $\begin{array}{l}95 \% \\
\text { CI }\end{array}$ & $\begin{array}{l}\mathbf{P}^{\mathbf{T}} \\
(\%) \\
(\mathbf{n}) \\
\end{array}$ & $95 \% \mathrm{CI}$ & $\begin{array}{l}\mathbf{P}^{\mathrm{T}} \\
(\%) \\
(\mathbf{n}) \\
\end{array}$ & $95 \%$ CI & $\begin{array}{l}\mathbf{P}^{\mathbf{T}} \\
(\%) \\
(\mathbf{n}) \\
\end{array}$ & $95 \% \mathrm{CI}$ & $\begin{array}{l}\mathbf{P}^{\mathrm{T}} \\
(\%) \\
(\mathbf{n}) \\
\end{array}$ & $95 \% \mathrm{CI}$ & $\begin{array}{l}\mathbf{P}^{\mathrm{T}} \\
(\%) \\
(\mathbf{n}) \\
\end{array}$ & $95 \% \mathrm{CI}$ & $\begin{array}{l}\mathbf{P}^{\mathrm{T}} \\
(\%)\end{array}$ & $\begin{array}{l}95 \% \\
\text { CI }\end{array}$ & $\begin{array}{l}\mathbf{P}^{\mathrm{T}} \\
(\%)\end{array}$ & $95 \% \mathrm{Cl}$ \\
\hline $\begin{array}{l}\text { Sphenodon } \\
\text { punctatus }\end{array}$ & $\begin{array}{l}0 \\
(190)\end{array}$ & $0-1.5$ & $0(68)$ & $0-4.5$ & $\begin{array}{l}0 \\
(189)\end{array}$ & $0-1.6$ & - & - & $\begin{array}{l}0 \\
(153)\end{array}$ & $0-1.9$ & $\begin{array}{l}0 \\
(139)\end{array}$ & $0-2.1$ & - & - & - & - & $\begin{array}{l}0 \\
(620)\end{array}$ & $0-0.5$ \\
\hline $\begin{array}{l}\text { Pachyptila } \\
\text { turtur }\end{array}$ & $\begin{array}{l}0 \\
(100)\end{array}$ & $0-3.0$ & $0(57)$ & $0-5.1$ & - & - & - & - & $\begin{array}{l}0 \\
(33)\end{array}$ & $0-8.7$ & - & - & - & - & - & - & $\begin{array}{l}0 \\
(190)\end{array}$ & $0-1.6$ \\
\hline $\begin{array}{l}\text { Oligosoma } \\
\text { spp. }\end{array}$ & $\begin{array}{l}0 \\
(109)\end{array}$ & $0-2.7$ & - & - & $\begin{array}{l}19 \\
(21)\end{array}$ & $7.7-40.0$ & - & - & $\begin{array}{l}8.3 \\
(103)\end{array}$ & $4.4-15.0$ & $\begin{array}{l}13.9 \\
(36)\end{array}$ & $2.9-21.8$ & - & - & - & - & $\begin{array}{l}6.5 \\
(275)\end{array}$ & $4.2-10.1$ \\
\hline $\begin{array}{l}\text { Hemideina } \\
\text { crassidens }\end{array}$ & $0(50)$ & $0-5.8$ & - & - & $\begin{array}{l}0 \\
(50)\end{array}$ & $0-5.8$ & - & - & $\begin{array}{l}0 \\
(50)\end{array}$ & $0-5.8$ & $\begin{array}{l}0 \\
(50)\end{array}$ & $0-5.8$ & - & - & - & - & $\begin{array}{l}0 \\
(200)\end{array}$ & $0-1.5$ \\
\hline Soil & $0(50)$ & $0-5.8$ & - & - & $\begin{array}{l}10 \\
(67)\end{array}$ & $5.2-20.0$ & $\begin{array}{l}24.0 \\
(75) \\
\end{array}$ & $15.8-34.8$ & $\begin{array}{l}10.7 \\
(75) \\
\end{array}$ & $5.5-19.7$ & $\begin{array}{l}6.9 \\
(58) \\
\end{array}$ & $2.7-16.4$ & $\begin{array}{l}7.4 \\
(68) \\
\end{array}$ & $3.2-16.1$ & $0(45)$ & $0-6.4$ & $\begin{array}{l}8.4 \\
(238)^{\mathrm{e}}\end{array}$ & $5.5-12.6$ \\
\hline
\end{tabular}

${ }^{a}$ No fairy prion samples were collected in March as fairy prions are only on the island during their breeding season October to January

${ }^{\mathrm{b}}$ Samples were collected from tuatara and fairy prion only during January 2010

${ }^{c}$ Soil samples only have been collected in these seasons

${ }^{\mathrm{d}}$ Soil collected from random collection of burrows

includes 50 burrows sampled repeatedly and 188 randomly sampled burrows 


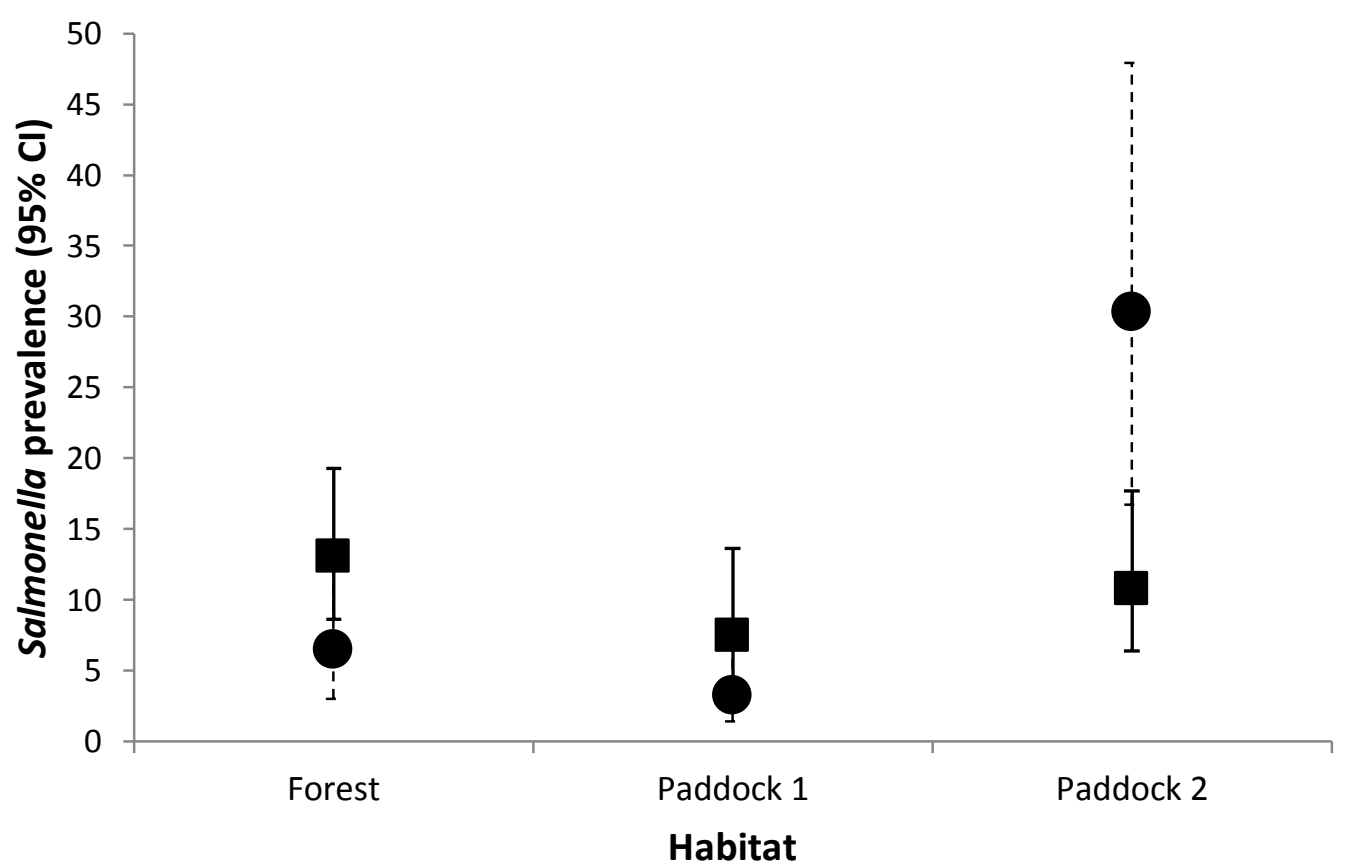

Figure 2.2: Skinks ( ) living in paddock 2 have greater prevalence of Salmonella than those in the other two sites $\left(\chi_{(2)}^{2}=16.51, P \leq 0.0001\right)$. The prevalence of Salmonella in soil (ם) samples was not significantly different among habitat types on Stephens Island. Graph shows test prevalence and 95\% confidence intervals of true prevalence. 
Neotrombiculid mites (Neotrombicula spp.) were found on both tuatara and skinks living in all study sites. The highest prevalence of mites on both species was found in Keepers Bush. This site also had the highest mite loads (Table 2. 4). The likelihood of a skink carrying Salmonella was not affected by either mite prevalence or mite load (Figure 2.4).

Contact associations between skinks and burrow soil samples appear to play a significant role in Salmonella prevalence and transmission on Stephens Island as 15 of the $18(83.3 \%)$ of Salmonella-positive skinks were captured within $1 \mathrm{~m}$ of a burrow which also tested positive for this bacterium. In contrast, only $32.3 \%$ of Salmonella negative skinks were caught less than a metre from a Salmonella-positive burrow $(32.3 \%)\left(\chi_{(1)}^{2}=19.1, P<0.0001\right)$.

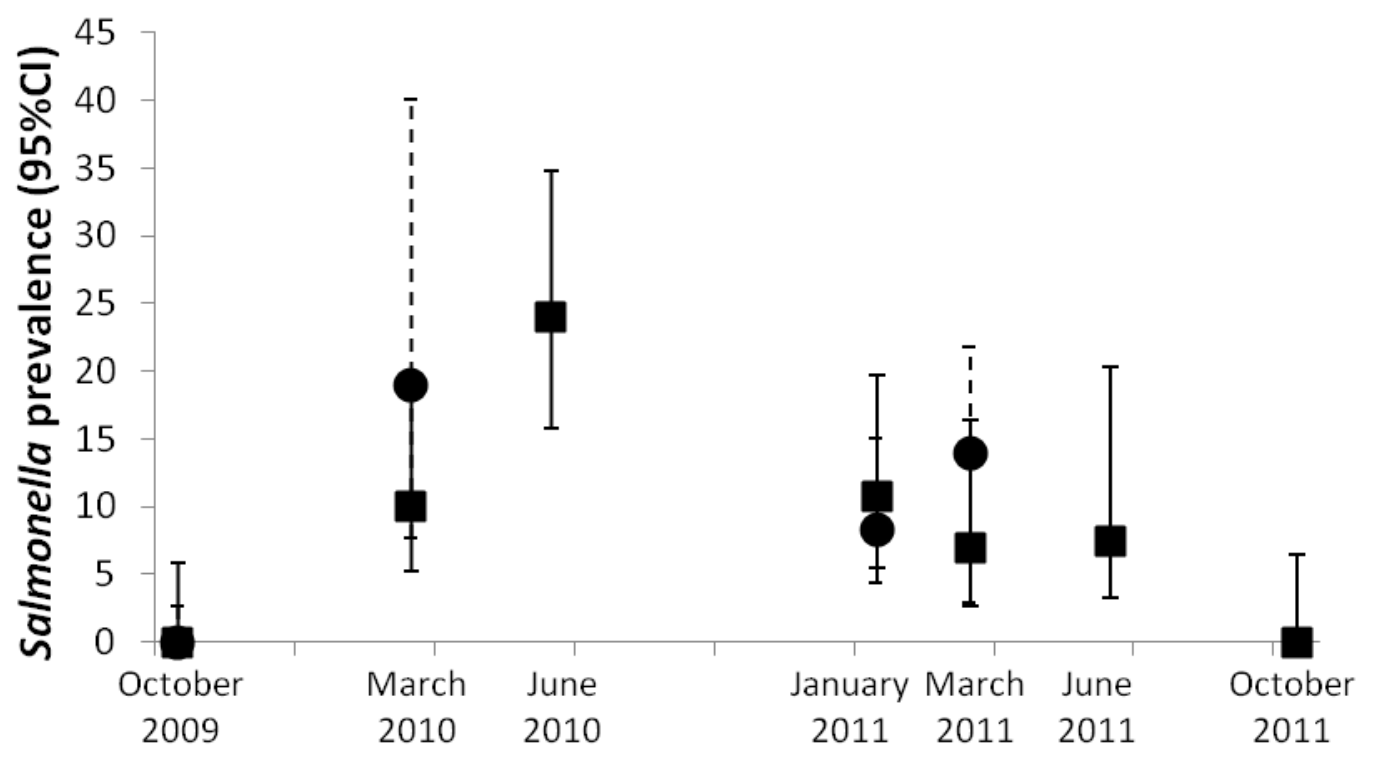

\section{sampling month}

Figure 2.3: The prevalence of Salmonella among skinks (•) and soil samples ( $\mathbf{\square})$ on Stephens Island varies seasonally. The graph shows test prevalence and 95\% confidence intervals of true prevalence for positive samples and the maximum possible prevalence at the 95\% confidence level where no Salmonella was detected in October. 

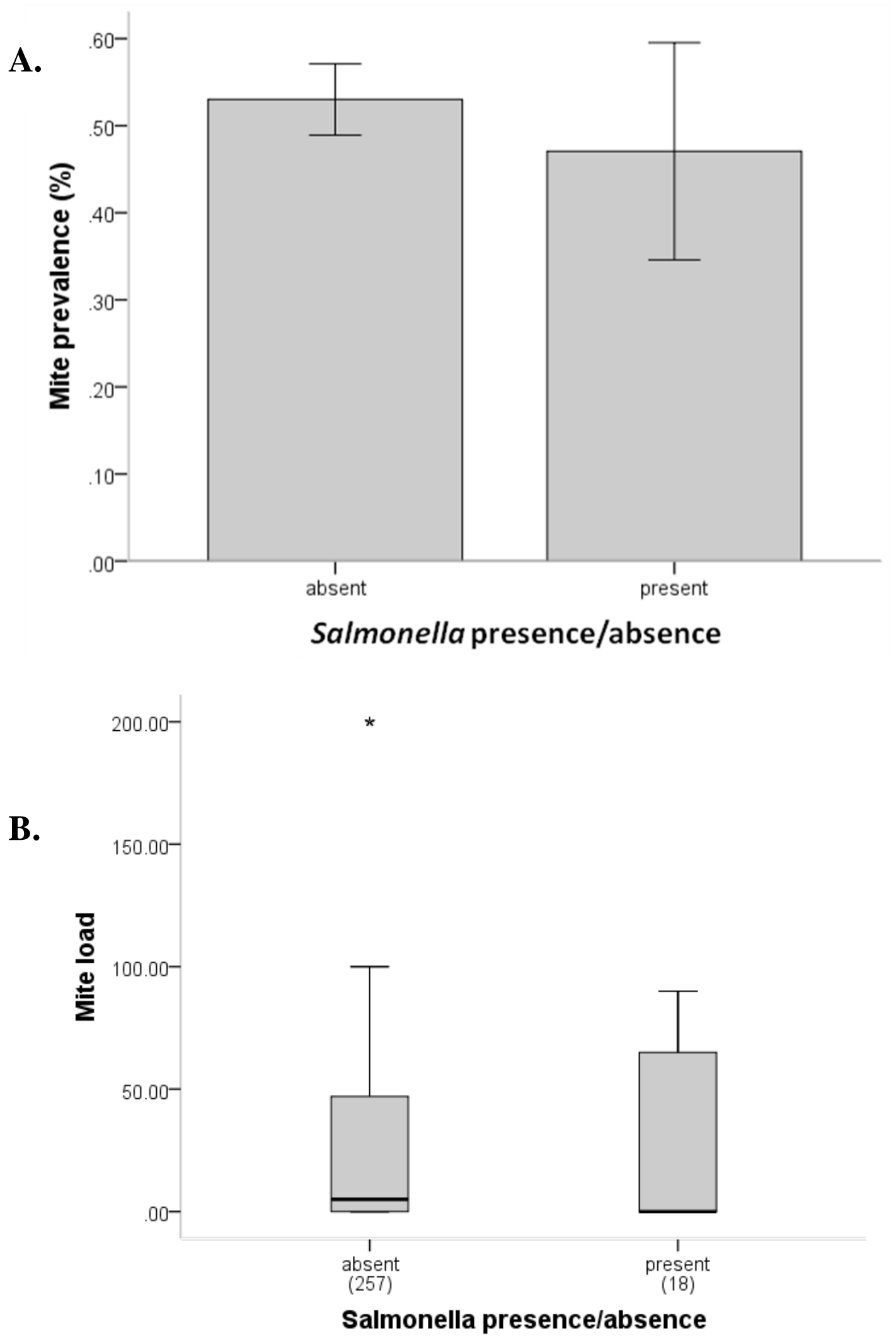

Figure 2.4: Neotrombiculid mite prevalence (A) and mite load (B) do not affect the presence of Salmonella in skinks on Stephens Island, New Zealand. Figure 2.4A shows mean number of skinks which were host to mites \pm 1 SE. Figure $2.4 \mathrm{~B}$ depicts the average number of mites per skink. 
Table 2.3: Mean body condition, prevalence and species of skink caught at three different study sites on Stephens Island. Skinks in paddock 2 have a significantly higher prevalence of Salmonella.

\begin{tabular}{|c|c|c|c|}
\hline Location & $\begin{array}{l}\text { Salmonella } \mathrm{P}^{\mathrm{T}}(\%) \\
(\mathrm{n})\end{array}$ & Species (n) & $\begin{array}{l}\text { Sample } \\
\text { size }\end{array}$ \\
\hline Forest & $6.8 \%(6)$ & $\begin{array}{l}\text { O. zealandicum }(2) \\
\text { O. lineoocellatum }(7) \\
\text { O. infrapunctatum }(32) \\
\text { O. nigriplantare }(46)\end{array}$ & 87 \\
\hline Paddock 1 & $3.5 \%(5)$ & $\begin{array}{l}\text { O. nigriplantare }(19) \\
\text { O. zealandicum }(23) \\
\text { O. infrapunctatum }(27) \\
\text { O. lineoocellatum }(75)\end{array}$ & 144 \\
\hline Paddock 2 & $26.9 \%(7)$ & $\begin{array}{l}\text { O. infrapunctatum }(5) \\
\text { O. zealandicum }(6) \\
\text { O. nigriplantare }(7) \\
\text { O. lineoocellatum }(8)\end{array}$ & 26 \\
\hline
\end{tabular}

Table 2.4: Summary of the prevalence (\%) and mean load of mites (Neotrombicula spp.) of tuatara (Sphenodon punctatus) and skinks within each study plot and sampling occasion

\begin{tabular}{|c|c|c|c|c|c|c|}
\hline \multirow{2}{*}{ Species } & \multicolumn{2}{|r|}{ B } & \multicolumn{2}{|r|}{ P1 } & \multicolumn{2}{|r|}{$\mathrm{P} 2$} \\
\hline & $\%$ & Load \pm SE & $\%$ & $\mathrm{Load} \pm \mathrm{SE}$ & $\%$ & Load \pm SE \\
\hline \multicolumn{7}{|l|}{ Tuatara } \\
\hline October 2009 & 0.0 & - & 0.0 & - & 0.0 & - \\
\hline January 2010 & 100.0 & $281.1 \pm 31.0$ & 82.1 & $303.5 \pm 62.4$ & 53.7 & $159.5 \pm 46.3$ \\
\hline March 2010 & 100.0 & $445.0 \pm 80.1$ & 8.2 & $4.1 \pm 2.5$ & 59.3 & $152.7 \pm 28.9$ \\
\hline January 2011 & 96.7 & $388.0 \pm 71.4$ & 9.6 & $8.6 \pm 4.6$ & 55.3 & $185.0 \pm 68.4$ \\
\hline March 2011 & 97.7 & $275.7 \pm 48.5$ & 17.3 & $52.0 \pm 39.4$ & 63.6 & $141.0 \pm 43.5$ \\
\hline \multicolumn{7}{|l|}{ Skinks } \\
\hline October 2009 & 0.0 & - & 0.0 & - & 0.0 & - \\
\hline January 2010 & - & - & - & - & - & - \\
\hline March 2010 & 58.3 & $39.8 \pm 16.6$ & 33.3 & $13.2 \pm 7.4$ & 38.4 & $6.8 \pm 5.5$ \\
\hline January 2011 & 72.4 & $43.7 \pm 9.8$ & 63.0 & $33.6 \pm 4.1$ & 28.6 & $3.7 \pm 3.6$ \\
\hline March 2011 & 50.0 & $3.2 \pm 1.9$ & 0.0 & - & 0.0 & - \\
\hline
\end{tabular}




\subsection{Discussion}

My study is one of the first to examine the distribution of Salmonella among multiple species over a range of temporal scales in an island ecosystem. The evidence indicates that Salmonella is a persistent pathogen existing within the ecological networks on Stephens Island, although not all species are carriers of the bacteria. Of the species I examined in this study Oligosoma skinks appear to be the most vulnerable to Salmonella infection.

Two serovars of Salmonella, S. Saintpaul and S. Mississippi, were isolated from skinks and soil on Stephens Island. I did not detect any seasonal or species differences in serovar distribution. S. Saintpaul is a common serovar isolated from humans, domestic animals and wildlife, both in New Zealand and overseas (Hamel and McInnes 1971, McInnes 1971, Taylor et al. 2010). Salmonella Saintpaul has been linked to an outbreak of human salmonellosis spread by lizards inhabiting kitchens (Hamel and McInnes 1971). S. Saintpaul was also previously isolated from geckos and skinks on Stephens Island (Middleton et al. 2010). Salmonella Mississippi has also been isolated from native reptiles in New Zealand, but was not previously isolated from skinks on Stephens Island (Middleton et al. 2010). Salmonella Mississippi is an uncommon cause of gastroenteritis in humans accounting for less than $1 \%$ of human cases of salmonellosis in the US (CDC 2001), but it is isolated from wild and domestic animals overseas including reptiles (Ashbolt and Kirk 2006). Given that the serovars of Salmonella found in this study are common multi-host pathogens infecting humans, domestic animals and wildlife both here and overseas, the lack of Salmonella detection seen in tuatara, fairy prions and weta cannot be attributed to host-adaption to the skinks, further implicating potential immunity as a factor in the lack of Salmonella infection.

Salmonella was found in Oligosoma skinks at a test prevalence of approximately $6.5 \%$ and a maximum estimated true prevalence of $10 \%$. This is similar to the previously reported Salmonella prevalence of $4.0 \%$ among skinks and geckos on this island (Middleton et al. 2010) and as identified in introduced exotic reptiles in New Zealand (Kikillus et al. 2011). It is also similar to the $11 \%$ prevalence which has been found in wild lizards of Australia (Parsons et al. 2010). Other studies have reported higher prevalences of Salmonella within members of the order Squamata. Salmonella was 
isolated from approximately $98 \%$ of a population of Land Iguana (Conolophus subcristatus) in the Galapagos Islands (Franco et al. 2011) and a similarly high prevalence $(100 \%)$ has been detected in tegu lizards (Tupinambis merianae) of South America and captive green iguanas (Iguana iguana) (Burnham et al. 1998, Maciel et al. 2010).

Soil samples collected from inside tuatara and fairy prion burrows were also positive for S. Saintpaul. Approximately $80 \%$ of Salmonella-positive skinks were captured within $1 \mathrm{~m}$ of a burrow which also tested positive for this bacterium. In contrast, only $30 \%$ of Salmonella-negative skinks were caught less than a metre from a Salmonellapositive burrow. I therefore propose that soil and environmental contamination likely play a role in the persistence of Salmonella on the island. Outside of the host environment Salmonella are exposed to fluctuating temperatures and $\mathrm{pH}$, limited nutrient availability and osmotic stress (Rozen and Belkin 2001, Winfield and Groisman 2003). In contrast to many enteric pathogens, Salmonella has been demonstrated to survive and multiply in these conditions for up to a year (Davies and Wray 1996, Winfield and Groisman 2003). Consequently, Salmonella may actively cycle through both host and non-host environments.

Surprisingly, Salmonella was not isolated from any of the test species or soil during October 2009 and 2011, suggesting another reservoir of Salmonella exists on the island, or the bacteria are being seasonally re-introduced by an unknown carrier. Stephens Island is inhabited and visited by a range of other species not investigated in this study. These species include natives, such as sooty shearwaters, little blue penguins and redbilled gulls, and introduced species e.g. passerines and includes a variety of insect fauna and humans. Any one or combination of these species may act as reservoirs of Salmonella on Stephens Island resulting in sporadic contamination of the environment. For example, red-billed gulls are known carriers of Salmonella in New Zealand and their propensity to feed around sites of human occupation, such as rubbish dumps and sewage plants, exposes them to a number of different serovars (Robinson and Daniel 1968). Large-scale mortalities of passerines have been attributed to Salmonella infection in New Zealand. A previously unreported strain of Salmonella in New Zealand, S. Typhimurium DT160, resulted in the death of several hundred native and introduced passerines in Christchurch and Manawatu (Alley et al. 2002). While there 
are no reports of Salmonella being transmitted to reptiles during this outbreak, it does highlight the potential for widespread dissemination of the bacteria by these passerine carriers.

Given the unfavourable conditions that Salmonella species are exposed to outside of the host, they may also cease reproducing or enter a viable but not culturable state (VBNC) in the soil during colder months and therefore become undetectable by current culture methods. Bacteria, including Salmonella, can enter this VBNC state in response to harsh environmental conditions such as temperature change or nutrient deprivation (Smith et al. 1994, Chmielewski and Frank 1995, Ravel et al. 1995, Winfield and Groisman 2003). Increasing temperature and nutrient availability has been demonstrated to support the growth of VBNC bacteria to a level detectable within the limitations of laboratory cultivation methods. Resuscitation of these bacteria will only occur when temperature and nutrient availability are increased and sustained for periods longer than normal culture methods (Ravel et al. 1995, Sinegani and Maghsoudi 2011). Salmonella on Stephens Island may therefore be present within the soil throughout the year, but during cold winter months reproduction may slow to such a level that bacteria are not detected by bacterial culture. Higher temperature results in increased bacteria reproduction and allows detection during January and March. The highest prevalence of Salmonella detected from soil in this study was obtained in June 2010 (24\%) and given that this is the start of winter in New Zealand I might have expected a lower prevalence given the VBNC hypothesis. The June soil samples were collected during the first few days of June, following a period of warm weather in summer, and may have been collected before temperatures became cold enough for a drop in bacteria reproduction or a VBNC state to occur. This finding may have important implications for the effects of a global change in climate. Prolonged periods of warm temperatures are likely to result in bacteria spending less time in VBNC states, and replicating faster and for longer periods, therefore, increasing infective doses present in the environment and within species.

I also found geographical differences in the prevalence of Salmonella among Oligosoma skinks on Stephens Island lending further support to the hypothesis that environmental factors affect the persistence of the bacteria on Stephens Island. I sampled species in three study sites, one closed canopy forest and two open pasture 
paddocks. I found a much greater prevalence of Salmonella within skinks in paddock 2 than in either of the other two sites (Figure 2.2). However, I did not find a detectable difference in Salmonella prevalence in soil samples across the three sites.

The increased prevalence of Salmonella seen in paddock 2 skinks could also be influenced by the differing species compositions obtained at the different sites. All four species of Oligosoma skink which inhabit Stephens Island were caught at all three study sites. However, the distribution of captures varied significantly between species. $O$. lineoocellatum was the most commonly caught skink in both paddock sites making up $52 \%$ of captures in paddock 1 and $31 \%$ of captures in paddock 2 . The most commonly captured skink in the forest site was $O$. nigriplantare making up 53\% of all captures. If some species of skink are more susceptible to Salmonella infection, due to diet or life history, this may affect the prevalence of Salmonella detected at the three sites. Due to the small sample sizes of each skink obtained in this study I am unable to test for species-specific differences in Salmonella carriage.

Given the often high prevalence of Salmonella isolated from soil collected from the interior of tuatara/fairy prion burrows and from skinks caught in close proximity to these burrows it was surprising to find that Salmonella was not isolated from tuatara, fairy prions or weta. In the case of tuatara and fairy prions I have clearly documented the potential for these species to be exposed to Salmonella within the burrow environment. The lack of detection of Salmonella in these species could be due to a number of factors including intermittent shedding resulting in false negatives, or overgrowth of Salmonella at the culture stage. I have taken these factors into account in the statistical analyses of the maximum possible prevalence in these species by using a low reported sensitivity (50\%) (Bager and Petersen 1991). This analysis suggests that the maximum rate of carriage of these bacteria in this population of tuatara is $0.5 \%$ and fairy prions $1.6 \%$. The lack of Salmonella carriage seen in tuatara and fairy prions despite the potential exposure through burrow soil contamination, and in the case of tuatara consumption through infected prey (skinks) may be due to an innate resistance to Salmonella in these species. Further research is therefore warranted on the innate and acquired immune response of these species to Salmonella. Previous research by Marchalonis et al. (1969) has shown that tuatara recognise Salmonella antigens; however, no further research has been conducted. 
Pathogen distribution in any given system is likely to be influenced by many different environmental, ecological and physiological variables (Spurgin et al. 2012).

Consequently, determining the causes and consequences of pathogen distribution is likely to be extremely difficult. I found that Salmonella is influenced by species, seasonal and habitat factors. Salmonella may be persistent within an ecological network but not all species will be affected. More research is needed to determine the causes of the lack of Salmonella in tuatara, fairy prions and weta which clearly have the potential to be exposed to this organism through the environment. Understanding the causes of Salmonella presence and absence in New Zealand wildlife may provide important indicators for understanding species which are at the greatest risk to this disease. 


\section{CHAPTER THREE}

\section{Presence of antibodies to Salmonella in tuatara sera}

\subsection{Abstract}

Colonisation by pathogenic microorganisms is a near constant threat to the health of all eukaryotic organisms. Most vertebrate species have evolved an efficient adaptive immune response which produces antibodies following exposure to a specific antigen. The strength of this response can be influenced by many factors including individual characteristics such as sex and body condition or by environmental factors including season and habitat type. Previous work has shown that tuatara are likely to be exposed to Salmonella through contact with infected skinks and soil; however, no gastrointestinal colonisation of tuatara with Salmonella has been found. Given that tuatara are a cold-adapted ectothermic reptile and are sexually dimorphic, I hypothesised that factors such as season and sex may play an important role in the strength of their immune defence. I used Western blots and flow cytometry to investigate Salmonella seroprevalence in captive and wild tuatara and to investigate the adaptive immune response of tuatara to this bacterium. Serum was tested against three closely related enteric pathogens, including Salmonella, in order to establish the importance of cross-reactivity in the strength of immune responses observed. I demonstrated that tuatara possess antibodies which recognise Salmonella antigens, but many of these antibodies are not specific and are cross-reactive with two closely related and ubiquitous bacteria, E. coli and C. koseri. Season contributed significantly to variation in the amount of $S$. Saintpaul and $C$. koseri antibodies within captive tuatara with much higher amounts observed in summer as compared with autumn and winter. Male captive tuatara also produced higher amounts of antibody against $S$. Saintpaul and C. koseri. I showed that the tuatara immune response against Salmonella is highest during summer when Salmonella is also most abundant in the environment. 


\subsection{Introduction}

The immune systems of eukaryotic organisms have evolved to combat the near constant threat of colonisation by pathogenic microorganisms (Zimmerman et al. 2010a). Adequate protection against pathogens requires an efficient innate and adaptive immune response (Abbas et al. 1996, Janeway and Medzhitov 2002, Zimmerman et al. 2010b). Innate immunity is a universal and ancient form of defence which does not require prior exposure to a specific antigen (Zimmerman et al. 2010a). In contrast, adaptive immunity is a specific response induced following antigen processing. The adaptive immune response is a slower form of defence than the initial, rapid response of the innate system (Medzhitov and Janeway 2000). However, in the event of re-exposure to the same pathogen, cells of the adaptive system can initiate a memory response which can be much quicker, stronger and more effective (Janeway and Medzhitov 2002, Goldsby et al. 2003).

Adaptive immunity involves both cell-mediated and humoral responses. The former is mediated by a class of lymphocytes known as T cells, and involves the activation of innate immune cells such as macrophages and natural killer cells (NK cells) as well as the release of cytokines. Whilst $\mathrm{T}$ cells regulate the production of antibodies, they are not actually responsible for antibody production (Zimmerman et al. 2010b). Instead, cytokines released by $\mathrm{T}$ cells can promote the proliferation and differentiation of $\mathrm{B}$ cells. $\mathrm{B}$ cells are components of the humoral immune system and produce antibodies when stimulated by antigens. B cells can recognise an antigen in its natural state and do not require intermediate cells to process the antigens (Goldsby et al. 2003).

B cells and antibodies have been isolated from fish, reptiles and mammals. The general structure of antibodies appears to be conserved among all jawed vertebrates, with each antibody composed of two identical heavy chains and two identical light chains held together by disulphide bonds (Goldsby et al. 2003). There is some variation within classes of organisms, with reptiles having high levels of genetic diversity within the heavy chain genes and multiple heavy chain variable regions (Turchin and Hsu 1996, Zimmerman et al. 2010b). In contrast, birds and mammals appear to have limited combinatorial diversity and instead generate higher amounts of antigen-binding 
diversity through gene conversion with a series of upstream gene segments (Litman et al. 1999, Arakawa et al. 2002, Zimmerman et al. 2010b).

Despite the similarities in the general structure of antibodies, studies have shown that reptile humoral responses are typically slower than those of birds or mammals (Zimmerman et al. 2010b). Post-immunisation in reptiles, there is typically a latent period of approximately one week after which antibodies can be detected; however antibody titres do not typically peak until six to eight weeks after infection (Grey 1963, Marchalonis et al. 1969, Ingram and Molyneux 1983, Work et al. 2000, Origgi et al. 2001, Pye et al. 2001). In contrast, although mammals also tend to have a latent period of approximately a week, peak titres are generally achieved approximately two weeks post-immunisation (Coico et al. 2003). Additionally, unlike mammals, reptiles do not show increased antibody titre or affinity following a second exposure as compared to the primary response (Grey 1963, Marchalonis et al. 1969). Marchalonis et al. (1969) immunised two tuatara (Sphenodon punctatus) with Salmonella Adelaide flagellin. In this study they showed that titres rose slowly and did not reach peak activity until two months post-immunisation. As found with similar studies in other reptiles, a second vaccination did not present any evidence for an enhanced secondary response (Grey 1963, Ingram and Molyneux 1983, Work et al 2000, Zimmerman et al. 2010b). I investigated antibody presence to the common bacterial pathogen Salmonella in tuatara. Using Western blots I tested recognition of lysed Salmonella cells by tuatara sera and investigated intact cells using flow cytometry. I investigated the strength of this recognition in tuatara sera collected in different seasons.

Salmonella enterica is a generalist pathogen which can result in significant morbidity and mortality within populations of reptiles, birds and mammals globally (Hoelzer et al. 2011). Reptiles are well documented as carriers and transmitters of Salmonella, acting as reservoirs for infection transmission to humans, domestic animals and other wildlife (Franco et al. 2011, Hoelzer et al. 2011). Reptilian carriers of Salmonella frequently do not express any negative symptoms of infection (Franco et al. 2011) and some authors have suggested that certain serovars may be part of the normal intestinal flora of reptiles (Mitchell and Shane 2001, Pasmans et al. 2008). Salmonella serovars may be induced to produce overt disease when the animals are exposed to stressors which can compromise the immune response and disrupt the normal intestinal flora (Franco et al. 
2011). Salmonella serovars are commonly recorded in a variety of reptiles globally with up to $90 \%$ of individuals in North American populations positive for Salmonella (Chambers and Hulse 2006). In New Zealand, Salmonella has been isolated from native and introduced species of reptiles (Middleton et al. 2010, Kikillus et al. 2011) and birds (Alley et al. 2002) and from many species of domestic animals (McInnes 1971). However, no Salmonella has been isolated from any live individuals of the endemic New Zealand reptile, the tuatara (Gartrell et al. 2006, Gartrell et al. 2007, Chapter Two). Surprisingly, soil samples collected from inside tuatara burrows and native lizards living in close proximity to these reptiles were positive for Salmonella (Chapter Two); therefore, a lack of exposure to Salmonella does not explain this finding.

Tuatara are medium sized, long lived reptiles (c. 100 years; Gaze 2001) and the only survivors of an ancient order of reptiles, Rhynchocephalia (sensu Gauthier et al. 1988, Benton 2000). Once widespread across New Zealand's mainland and offshore islands (Holdaway and Worthy 1997), predation by introduced mammals has restricted current populations to offshore islands around New Zealand. These evolutionarily distinct reptiles diverged from their sister group, the squamates, approximately 230 million years ago (Rest et al. 2003). Tuatara are a well studied species and much is known about their life history and development, but very little is known about their immune response. Previous studies have investigated different aspects of the adaptive immune system in tuatara and the effect of season on these responses. These studies have demonstrated that tuatara have functional $\mathrm{T}$ cell responses and that lymphocyte function in these reptiles is thought to be similar to those of mammals and other reptiles, mediating adaptive immunity through antibody production and antigen specific cellmediated immunity (Burnham et al. 2005). One of the earliest studies performed on tuatara immune responses showed that tuatara respond to injection with $S$. Adelaide flagellin by producing antibodies which are structurally similar to the $\mathrm{\gamma M}$ immunoglobulins of higher vertebrates (Marchalonis et al. 1969). This remains a very significant finding considering the apparent lack of detectable Salmonella in tuatara.

Hosts are expected to benefit from a constant strong defence against common invading pathogens. However, seasonal variation in immune response is observed in a variety of vertebrate species (Nelson and Demas 2004, Altizer et al. 2006, Zimmerman et al. 
2010a). Observed seasonal variation in immune responses may be attributed to factors such as sex steroids, reproductive state, age and seasonally occurring stressors (Nelson and Demas 2004). Tuatara are long-lived, cold-adapted ectotherms, and it has therefore been proposed that seasonal variation in immune responses among tuatara may be different to those of many other ectothermic vertebrates (Burnham et al. 2006). Burnham et al. (2005) assessed T cell responses in captive tuatara and found no clear seasonal effect between winter and spring. In contrast, La Flamme et al. (2010) investigated toll-like receptor (TLR) responses in tuatara and found a clear increase in the response to TLR agonists by leukocytes isolated from tuatara in summer compared with winter.

A number of approaches have been used in the diagnosis of Salmonella and other common enteric pathogens, including molecular detection methods and serological assays. Serological assays including Western blots, tube agglutination tests and enzyme-linked immunosorbent assays (ELISAs) have been described for the detection and diagnosis of Salmonella in wildlife (Aschfalk et al. 2002, Vicente et al. 2002, Wiuff et al. 2002, Aschfalk et al. 2003). Most of the assays require pathogen cells to be lysed prior to use in the assay. Flow cytometry (FCM) is becoming an increasingly common technique for studies on seroprevalence of a range of different pathogens. This increased popularity can partly be attributed to the increased specificity that is obtained from the use of intact pathogen cells (Shadomy et al. 2004, Julenius and Pederson 2006).

Flow cytometry in its present form has been extensively and effectively used to study mammalian cells since the 1960s (Steen 2000), but its capability to study microorganisms has only recently begun to be investigated (Steen 2000). New, highly developed generations of flow cytometry analysers have increased the range of microbial studies with the capability of observing diameters of cells as small as $0.5 \mu \mathrm{m}$ (within the range of many bacterial species) (Álvarez-Barrientos et al. 2000). FCM uses forward scatter (FSC) and side scatter (SSC) measurements to determine the granularity and size of cells. The size and optical refraction index of the outer membrane of the cell is measured by FSC, whilst SSC is related to the cell's granularity (Koch et al. 1996, Yitzhaki et al. 2004). These measurements allow one type of bacteria to be distinguished from another as well as to identify live bacteria from dead bacteria or debris. 
The aim of this study was to investigate whether antibodies in the serum of wild and captive tuatara specifically recognised Salmonella Saintpaul, Escherichia coli and Citrobacter koseri and if so, to examine seasonal variation in this response. I proposed that, given the ectothermic nature of tuatara, their immune function would be influenced by seasonal variations in temperature, because other reptiles have been shown to have strong seasonally influenced fluctuations in immune response (Saad and Ali 1992, Zimmerman et al. 2010a). I also hypothesised that, based on differences in sex steroids and activity patterns throughout the year, males and females would differ in their antibody recognition of the three test bacteria. There are many examples of sexually dimorphic mammalian and reptilian species that exhibit immunological sex differences. For the majority of species investigated males typically show an increased susceptibility to disease and higher rates of parasitism as compared to females (Klein 2000, Moore and Wilson 2002, Scantlebury et al. 2010). This sex bias in immune competence is often attributed to an inhibitory effect of testosterone on immune responses (Zuk 1996, Moller et al. 1998). Based on these hypotheses, if variation in immunity is driven by seasonal temperature differences alone, we would expect to see no differences in antigen recognition between the sexes.

Establishing baseline knowledge of the immune response of tuatara to some very common bacterial species has important implications for conservation and in particular, for movements among locations of these animals. The presence and possible spread of disease is an important consideration when translocating all animals to new areas. Animals born and bred in a captive breeding facility or captured from a wild population will have acquired local infections and may be symptomless carriers of disease. If these animals are translocated to new areas, they can introduce disease to other animals at the release site (Woodford and Rossiter 1994). Translocated animals will also inevitably lack the acquired immunity to disease found at the release site. Arabian oryx (Oryx leucoryx) that were bred in captivity in the US succumbed to botulism when they were released in Oman. Botulism is enzootic among sheep and goats of Oman and the Arabian oryx lacked acquired immunity, as they were naïve to botulism (Stanley-Price 1989). 
Understanding the immune response of these ectothermic vertebrates also provides us with valuable information for understanding the possible implications of climate change for tuatara. A warmer climate may permit the spread of animal and insect hosts of zoonotic disease, therefore increasing the risk of disease spread among humans, wildlife and domestic animals. Warmer climates may result in shorter and less severe winters which may prolong the transmission season for many diseases and allow previously exotic diseases that enter New Zealand to establish and disperse when they may previously have perished. Salmonella infections in humans are seasonally cyclic with the highest incidence of infection occurring during the summer months. This is in part due to direct effects on Salmonella reproduction and part due to indirect effects on eating habits (Zhang et al. 2010). The optimum temperature for the growth of Salmonella has been demonstrated to be between $35-37^{\circ} \mathrm{C}$, with growth rates greatly reduced at temperatures below $15^{\circ} \mathrm{C}$ (Zhang et al. 2010). Salmonella multiply within a host at rates directly proportional to the ambient temperature (at temperature range $7.5^{\circ} \mathrm{C}-37^{\circ} \mathrm{C}$ ), which often results in increased Salmonella reproduction at various stages of the food chain during warmer months, making the consequences of any ingestion by individuals further up the food chain more severe(Lake et al. 2009).

\subsection{Materials and Methods}

\subsubsection{Sample collection}

Serum samples were obtained from 46 wild tuatara captured by hand on Stephens Island (Takapourewa; $40^{\circ} 40^{\prime} \mathrm{S}, 174^{\circ} 00^{\prime} \mathrm{E}$ ) on three sampling occasions (Table 3.1). Samples were collected from wild tuatara during January and March as this is when tuatara are most active. Samples were also collected from 23 captive tuatara at seven captive facilities throughout New Zealand (Table 3.2). Captive tuatara were not resampled in every season, because in some cases the tuatara could not be captured during winter and in other instances throughout the year I was unable to obtain enough serum from an individual tuatara to perform the tests.. I acknowledge that captive animals will vary behaviourally and potentially physiologically (i.e. they may differ in their body mass and hormone cycles) as compared to their wild counterparts. However, I have included them to increase the opportunity for detection of Salmonella in tuatara. 
Captive tuatara are at facilities also housing native lizards known to be carriers of Salmonella. On occasion husbandry of these animals can increase the likelihood that tuatara will be exposed to Salmonella. Captive animals can also be more reliably sampled in every season and allow for repeated samples from known individuals. Four blue-tongue skinks (Tiliqua scincoides), four Australian water dragons (Physignathus lesuerii) and five coastal bearded dragons (Pogona barbata) were also bled during summer 2010 to provide positive controls. Some of these exotic reptiles were known to be carriers of Salmonella via cloacal swab at the time of sera collection. Coastal bearded dragons were the most frequent shedders of Salmonella with all five animals testing positive for $S$. Onderspoort. In contrast, only one of each of the blue-tongue skinks and Australian water dragons were found positive for Salmonella. Fourteen sera samples obtained from a second wild population of tuatara (North Brother Island; $41^{\circ} 07$ 'S; $174^{\circ} 27^{\prime} \mathrm{E}$ ) in spring (October) 2009 were included for comparison. All blood samples $(0.1-1 \mathrm{~mL})$ were drawn from the caudal vein/artery, and the serum was separated via centrifugation. Sera from all species were stored at $-20^{\circ} \mathrm{C}$ and thawed immediately before experiments. The serum samples were utilised in all Western blots and assays presented in this study as the primary antibody.

Tuatara were caught in three locations representing two habitat types; remnant coastal forest (B) and two open pasture sites (P1 and P2), in order to provide the largest coverage of tuatara and therefore provide the most opportunity for detecting Salmonella if it was present. For the purpose of analyses, the two pasture sites were combined to form the one habitat, paddock, due to low sample sizes in each site and the similar habitat type. From each tuatara I recorded a number of physical characteristics such as sex, mass, snout-to-vent length (SVL) and the number of mites and ticks on the body were counted. Mites and ticks are removed from captive populations of tuatara as part of captive management, so ectoparasites were not recorded in these populations and captive tuatara were not included in analyses which included mites and ticks. Individual tuatara were assessed for body condition by dividing the log mass ( $\mathrm{g}$ ) by the $\log$ SVL ( $\mathrm{mm}$ ) to correct for variation in length. In all cases the captive tuatara used in this study were housed outside and consequently exposed to daily photoperiod and temperature fluctuations. 
Table 3.1: Frequency of tuatara new captures and recaptures in three habitat types; Remnant coastal forest (B), Pasture 1 (P1) and Pasture (P2) on Stephens Island, New Zealand

\begin{tabular}{|c|c|c|c|c|c|c|c|c|c|c|}
\hline \multirow[b]{2}{*}{ Trip } & \multicolumn{4}{|c|}{ New captures } & \multicolumn{4}{|c|}{ Recaptures } & \multicolumn{2}{|c|}{ Sex } \\
\hline & B & P1 & $\mathbf{P 2}$ & $\mathbf{N}$ & B & P1 & $\mathbf{P 2}$ & $\mathbf{N}$ & Males & Females \\
\hline March 2010 & 12 & 5 & 0 & 17 & - & - & - & - & 12 & 5 \\
\hline January 2011 & 13 & 5 & 7 & 25 & 5 & 1 & 0 & 6 & 24 & 7 \\
\hline March 2011 & 2 & 0 & 2 & 4 & 1 & 0 & 0 & 1 & 3 & 2 \\
\hline Total & 27 & 10 & 9 & 46 & 6 & 1 & 0 & 7 & 39 & 14 \\
\hline
\end{tabular}

\subsubsection{Bacterial cultures}

E. coli, C. koseri and S. Saintpaul provided the antigens with which I analysed tuatara sera for antibodies. S. Saintpaul was selected as this serovar is commonly isolated from reptiles throughout the world and has been isolated from native skinks inhabiting Stephens Island (Middleton et al. 2010; Chapter Two). E. coli and C. koseri are closely related species to Salmonella, but do not share the pathogenicity of many Salmonella serovars. E. coli and C. koseri are also commonly isolated from the gastrointestinal tracts of reptiles and mammals and have been isolated from both wild and captive tuatara (Gartrell et al. 2006, personal observation). Stock cultures of these bacteria were maintained on slanted nutrient-agar and transferred fortnightly. 
Table 3.2: Frequency of captive tuatara sampling at seven captive facilities (A-G) throughout New Zealand from October 2009-July 2011. The total number of tuatara sampled at any given facility is shown by $\mathrm{n}$ and the number of captures each season follows.

\begin{tabular}{|c|c|c|c|c|c|c|c|c|c|c|c|}
\hline & & & & $\begin{array}{l}\text { October } \\
\text { (spring) }\end{array}$ & $\begin{array}{c}\text { January } \\
\text { (summer) }\end{array}$ & $\begin{array}{c}\text { April } \\
\text { (autumn) }\end{array}$ & $\begin{array}{c}\text { July } \\
\text { (winter) }\end{array}$ & $\begin{array}{l}\text { October } \\
\text { (spring) }\end{array}$ & $\begin{array}{c}\text { January } \\
\text { (summer) }\end{array}$ & $\begin{array}{c}\text { April } \\
\text { (autumn) }\end{array}$ & $\begin{array}{c}\text { July } \\
\text { (winter) }\end{array}$ \\
\hline Facility & Males & Females & $\mathrm{n}$ & 2009 & 2010 & 2010 & 2010 & 2010 & 2011 & 2011 & 2011 \\
\hline B & 1 & 1 & 2 & 0 & 2 & 0 & 0 & 2 & 0 & 0 & 0 \\
\hline $\mathbf{C}$ & 2 & 2 & 4 & 3 & 4 & 0 & 0 & 0 & 0 & 3 & 0 \\
\hline $\mathbf{E}$ & 1 & 0 & 1 & 0 & 1 & 0 & 0 & 0 & 0 & 0 & 0 \\
\hline $\mathbf{F}$ & 1 & 2 & 3 & 0 & 0 & 1 & 3 & 3 & 3 & 2 & 0 \\
\hline G & 1 & 3 & 4 & 3 & 3 & 3 & 4 & 3 & 0 & 0 & 2 \\
\hline Total & 10 & 13 & 23 & 13 & 17 & 6 & 7 & 8 & 3 & 10 & 2 \\
\hline
\end{tabular}




\subsubsection{Western Blotting}

Overnight cultures of $S$. Saintpaul, E.coli and C. koseri were grown in LB media at $37^{\circ} \mathrm{C}$ with agitation. Cell lysates were obtained by pelleting bacteria $(13,000 \mathrm{rpm}$ for 30 seconds) and re-suspending in 2\% SDS (Sodium Dodecyl Sulfate). The solution was then centrifuged at 13,000rpm for five minutes and the supernatant collected. Protein concentrations were assessed using a BCA kit (Pierce). The lysate was stored at $-20^{\circ} \mathrm{C}$ and thawed on ice immediately prior to use. Preparation of lysates for running in gels was carried out as follows; $80 \mu \mathrm{g}$ protein from each lysate were transferred into fresh tubes and incubated with $7 \mu \mathrm{L}$ of reducing buffer mix (1:10 dilution of 2mercaptoethanol [Sigma, St Louis, MO, USA] in 5x reducing buffer - containing bromophenol blue in running buffer), at $90^{\circ} \mathrm{C}$ for 10 minutes.

Bacterial lysates were run on 10-well SDS-PAGE (Sodium dodecyl sulfate polyacrylamide gel electrophoresis) gels with a $10 \%$ separating gel and a $4 \%$ stacking gel. Gels were prepared the day before the experiment and immersed in $1 \mathrm{x}$ running buffer (3.5mM SDS, $25 \mathrm{mM}$ Tris base, $190 \mathrm{mM}$ glycine) and stored at $4^{\circ} \mathrm{C}$. Lysate preparations and $3 \mu \mathrm{L}$ of dual colour MW ladder (Bio-Rad, Hercules, CA, USA) were then run at 200V for 45-60 minutes in 1x running buffer, or until the blue dye front had run off the gel. One gel was stained using coomassie blue to visualise the proteins (Figure 3.1).

Proteins were transferred onto a low background fluorescence, hydrophobic polyvinylidene diflouride (PVDF) membrane (GE Healthcare, Amersham). Each membrane was pre-soaked in methanol for one minute followed by transfer buffer (39mM glycine, $48 \mathrm{mM}$ Tris base, $0.037 \%$ (w/v) SDS, 20\% (v/v) methanol) for five minutes prior to transfer. Gels were then assembled with the membranes into a BioRad Tetracell transfer set (Bio-Rad) containing an ice-pack and transferred at 50V for four hours at $4^{\circ} \mathrm{C}$ in transfer buffer. Immunoblots were removed and blocked for one hour at room temperature using 5\% donkey serum (Sigma, St Louis, MO, USA) in Tween-Tris buffered saline (TTBS: $0.5 \mathrm{M}$ Tris, $1.5 \mathrm{M} \mathrm{NaCl}$, $0.1 \%$ Tween 20 (Sigma), $\mathrm{pH}$ 7.4). Membranes were then probed with primary, secondary and tertiary antibodies as detailed in Table 3.3. Antibodies were diluted in TTBS and membranes were incubated for either one hour at room temperature or overnight at $4^{\circ} \mathrm{C}$ on a rocker. Membranes 
were washed three times in TTBS between incubations and tertiary antibodies were incubated in the dark. The dilutions of all antibodies used to probe membranes were determined in the lab by optimisation. Images of the probed membranes were obtained on a Fuji Film FLA-5100 scanner (Fujifilm, Tokyo, Japan). Tertiary antibodies labelled with Cy5 were read using a $635 \mathrm{~nm}$ laser. Scanned images were analysed using Image J (version 1.46).

The secondary antibody was targeted anti-bird as no anti-reptile or the more specific anti-tuatara antibodies were commercially available. Previous research has shown that anti-bird antibody binds to components in reptile and bird serum but does not bind to components of mouse sera. This research has also demonstrated that the resulting bands correspond to heavy and light chains of Ig (La Flamme, personal communication). It was necessary to test that there were no significant interactions between secondary and tertiary antibodies and the bacterial lysates. Incubating the membrane in the absence of tuatara serum but with secondary and tertiary antibodies resulted in some non-specific binding (Figure 3.2). These bands were excluded from further analysis in the full Western blots performed later.

Table 3.3: Antibodies used for Western blotting

\begin{tabular}{llll}
\hline $\begin{array}{l}\text { Antibody } \\
\text { type }\end{array}$ & Antibody & $\begin{array}{l}\text { Dilution } \\
\text { factor }\end{array}$ & $\begin{array}{l}\text { Incubation } \\
\text { time }\end{array}$ \\
\hline Primary & Tuatara serum & $1: 10$ & $\begin{array}{l}\text { overnight } \\
\text { Secondary }\end{array}$ \\
& Goat anti-bird IgG polyclonal antibody & $1: 100$ & 1 hour \\
& (Bethyl laboratories, supplied by Global & & \\
& Science) & & 1 hour \\
Tertiary & Donkey anti-goat Cy5 (Abcam, & $1: 100$ & \\
& supplied by Sapphire Bioscience, & & \\
& Hamilton, NZ) & & \\
\hline
\end{tabular}




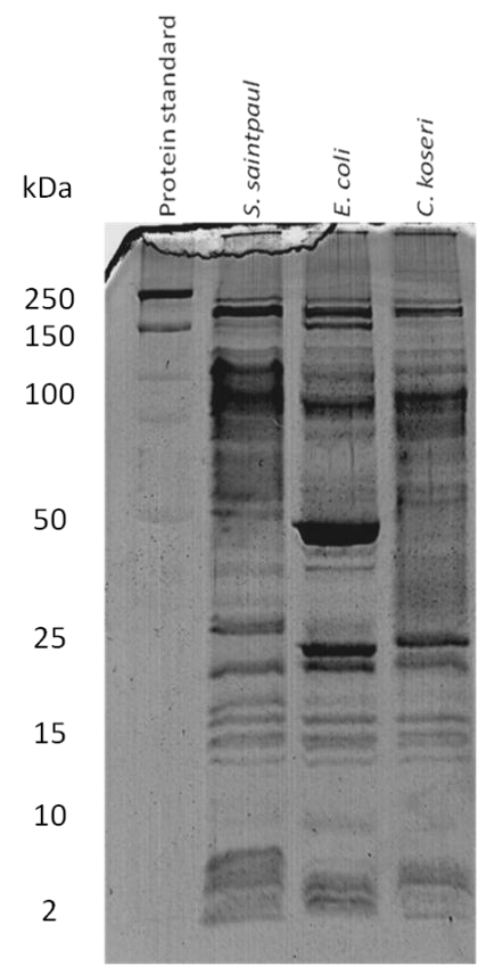

Figure 3.1: Coomassie stained lysates of S. Saintpaul, E. coli and C. koseri

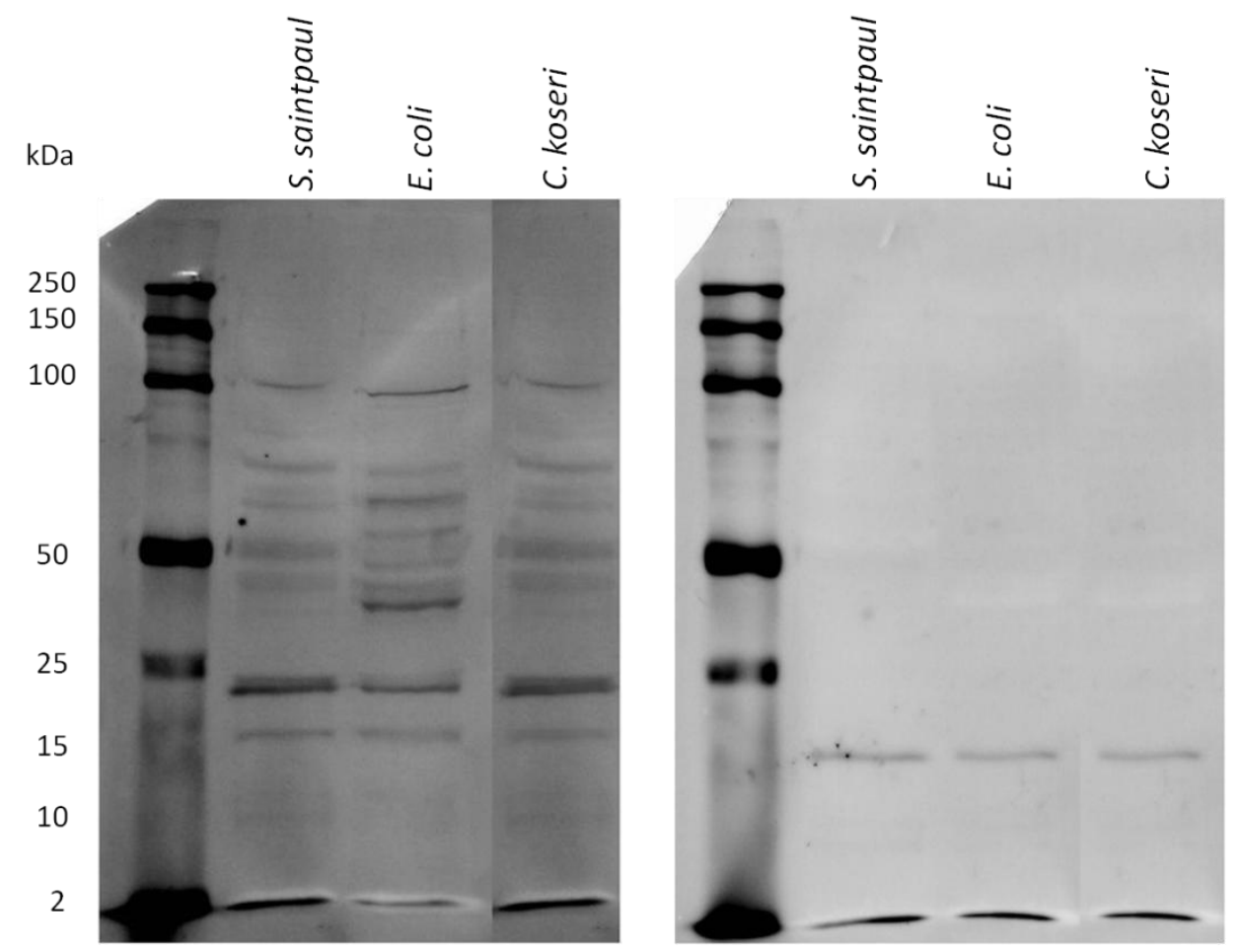

Figure 3.2: Western blots stained with secondary and tertiary antibodies only (a) and tertiary antibody only (b). 


\subsubsection{Flow cytometry}

Broth cultures of $S$. Saintpaul, E. coli and C. koseri were grown in LB media at $37^{\circ} \mathrm{C}$ for 17 hours to obtain early log-phase cultures. Bacteria were then diluted to approximately $1 \times 10^{6} \mathrm{CFU} / \mathrm{ml}$ in $1 \times \mathrm{xBS}$ and washed three times in $1 \mathrm{xPBS}$ to remove any residual LB media. Bacteria were pelleted by centrifugation at 4000rpm for 15 minutes and re-suspended with 1/50 dilutions of serum and incubated on ice for 30 minutes. Following incubation, the suspensions were centrifuged to isolate any bacteria-antibody complexes and the pellet was washed once with 1 xPBS to remove any excess serum. A secondary stain was then applied, fluorescein isothiocyanate (FITC) conjugated goat anti-bird IgG antibody (Bethyl laboratories), and incubated on ice in the dark for 30 minutes.

In order to investigate cross-reactivity of antibodies in tuatara serum against the three bacteria of interest, I pre-absorbed serum against each of the bacteria. Pre-absorption involved incubating serum in the presence of one of the three test bacteria. Antibodies which recognised this bacterium bound to the bacteria, and the antibody-bacterium complexes were removed by centrifugation. Using this technique I was able to obtain serum which had the majority of antibodies to a bacteria of interest removed. This serum was then incubated with one of the other test bacteria and recognition assessed using flow cytometry. The percentage of positive events obtained in comparison to serum that had not been pre-absorbed to any bacteria provided a measure of crossreactivity between bacterial species.

Tuatara are a protected species in New Zealand so it was not possible to obtain positive control sera by experimentally infecting individuals with the bacteria of interest. For this reason Salmonella cells stained with anti-Salmonella FITC (Abcam, Cambridge, MA, USA) were used as a positive control. I was also unable to obtain negative control sera due to the difficulty in conclusively ruling out prior exposure to these extremely common microorganisms. All antibodies were pre-titrated to optimise the identification of bacterial populations and minimise background fluorescence. Optimisation was performed using sera from a captive male tuatara bled during January 2010. 
After staining, cells were analysed using the BD FACS CANTO II flow cytometer (BD Bioscience, Franklin Lakes, NJ, USA) and 100,000 events were collected per sample. FlowJo v7 software (Tree Star Inc., Ashland, OR, USA) was used for both flow cytometry data storage and analysis.

\subsubsection{Statistical analyses}

The final percentage of positive bacteria was corrected for background fluorescence by subtracting the percentage positive when bacteria were incubated with secondary stain only. Pre-treated values are shown as a percentage of the maximum antibody, which was taken to be the percentage of positive bacteria when the bacteria were incubated with serum that had not been pre-absorbed.

Generalized linear mixed models (Lindstrom and Bates 1990) with procedure "glmer" within the statistical package $\mathrm{R}$ were applied to assess trends in tuatara serum antigen recognition of $S$. Saintpaul, E. coli and C. koseri. Linear mixed models (lme) with tuatara included as random effects (to account for re-sampling) were applied to the data. The dependent variable was percentage of positive bacteria. I included season, sex, habitat and external parasite loads (i.e. mites and ticks) as explanatory variables for wild tuatara, and season, sex and location for captive tuatara.

Model strength was assessed using Akaike's information criterion adjusted for small sample size (AICc; Akaike 1978, Anderson et al. 1998). $\mathrm{AIC}_{\mathrm{c}}$ is defined as $\mathrm{AIC}_{\mathrm{c}}=-2$ $\log$-likelihood $+\{2 \mathrm{~K}(\mathrm{~K}=1) /(\mathrm{n}-\mathrm{K}-1)\}$, where $\mathrm{K}$ is the number of parameters in the model and $\mathrm{n}$ is the number of observations. The model with the smallest $\mathrm{AIC}_{\mathrm{c}}$ value was selected as the best model among those being compared. Change in $\mathrm{AIC}_{\mathrm{c}}\left(\Delta \mathrm{AIC}_{\mathrm{c}}\right)$ is the difference in $\mathrm{AIC}_{\mathrm{c}}$ values between the best performing model and the model of interest, models within two units (i.e $\Delta \mathrm{AIC}_{\mathrm{c}}<2$ ) of the best model were considered equally and most substantially supported, models within four to seven units received considerably less support, and greater than ten units essentially no support (Burnham and Anderson 2002). Examining the Akaike weights further quantified the plausibility of each model as being the best model for the data (Burnham and Anderson 2002). Akaike weights $\left(\omega_{\mathrm{i}}\right)$ are defined as $\omega_{\mathrm{i}}=\exp \left(-0.5 \times \Delta \mathrm{AIC}_{\mathrm{c}} / \Sigma \exp \left(-0.5 \times \Delta \mathrm{AIC}_{\mathrm{c})}\right.\right.$. The use of $\mathrm{AIC}_{\mathrm{c}}$ in model selection provided not only a measure of the relative goodness-of-fit for each statistical 
model, but also included a penalty for the number of estimated parameters (K) to avoid over-fitting (Burnham and Anderson 2002).

For each species of bacteria (i.e. S. Saintpaul, E. coli and C. koseri)a number of models were tested including a global model which included sex, season, location, year and individual for captive tuatara, and season, location, sex, mites, ticks and individual for wild tuatara. Captive and wild tuatara were investigated in different models in order to deal with varying amounts of repeated sampling and the different parameters and seasons tested between the two populations.

A Pearson's correlation was used to investigate the importance of body condition on the prevalence of antibodies to the three bacteria of interest. Finally, I tested for a linear relationship between the percentages of bacteria killed for pairs of the three test bacteria. Pearson's correlation was used and statistical significance was set to 0.05. Analyses were carried out using the statistical program R (R Core Development Team, 2010) and SPSS version 18 (SPSS, Inc., Chicago, IL) for Windows. Box plots display the mean, inter-quartile range (IQR) and range. Outliers more than 1.5IQR or greater than $3 \mathrm{IQR}$ from the rest of the data are displayed as open circles or stars, respectively.

\subsection{Results}

\subsubsection{Western blot}

Western blots were performed using sera from ten tuatara (five captive and five wild), four blue-tongue skinks and two coastal bearded dragons to investigate sera recognition of S. Saintpaul, E. coli and C. koseri proteins. Results from the Western blot showed that all reptile species tested possessed antibodies which recognised the three test bacteria (Figure 3.3). The blue-tongue skink (Figure 3.3b) and coastal bearded dragon (Figure 3.3d) had previously been identified as carriers of Salmonella.

I did not identify a statistically significant difference in the mean number of bands identified among bacteria within reptile species or among reptile species within bacteria (Table 3.4). However, there was variation in the pattern of Western blot bands seen 
within individuals (examples see Figure 3.3). Some bands were found ubiquitously across the three test bacteria (Figure 3.4a), while other bands were only found within certain bacteria species (Figure 3.4b). Figure 3.5 shows that the large majority of bands (>70\%) in all reptile species were identified in S. Saintpaul, E. coli and C. koseri. In contrast, only a small percentage of bands were shared with only one other bacteria or were identified in only a single bacterial species (Figure 3.5).

The technique utilised in Western blotting investigates serum recognition of cell lysates. Consequently, I have investigated the recognition of reptile serum to all proteins in the test bacteria. Figure 3.5 shows the extremely high number of proteins of similar molecular weight, which are recognised in all three test bacteria. These similarities may be due to intracellular proteins, which are often much more highly conserved than outer cell surface proteins (Julenius and Pederson 2006). While some extracellular motifs on some of the antigens may also be highly conserved between species of bacteria, there is often much more diversity at the extracellular level (Julenius and Pederson 2006), for example three outer cell surface antigens are used in the identification of Salmonella serotypes. 
Table 3.4: The mean number of bands identified by Western blot in blue-tongue skinks, coastal bearded dragons, captive and Stephens Island wild tuatara against $S$. Saintpaul, E. coli and C. koseri. Mean number of bands \pm SE, sample size (n), F-statistic and Pvalue is shown. F-statistic and $\mathrm{P}$ value show statistical significance in mean number of bands identified in each of the bacteria within reptile species.

\section{Mean number of bands by WB \pm SE}

\begin{tabular}{lcccccc} 
Species & S. Saintpaul & E. coli & C. koseri & N & $\mathbf{F}_{2}$ & $P$ \\
\hline Blue-tongue skinks & $11.0 \pm 2.1$ & $11 \pm 1.2$ & $7.5 \pm 0.6$ & 4 & 3.585 & 0.072 \\
(T. scincoides) & & & & & &
\end{tabular}

$\begin{array}{lllllll}\text { Coastal bearded dragon } & 8.5 \pm 1.5 & 10.5 \pm 0.5 & 5.5 \pm 0.0 & 2 & 2.171 & 0.261 \\ \text { (P. barbata) } & & & & & & \end{array}$

$\begin{array}{lllllll}\text { Captive tuatara } & 11.4 \pm 2.5 & 15.4 \pm 1.9 & 10 \pm 2.1 & 5 & 1.623 & 0.238\end{array}$

(S. punctatus)

$\begin{array}{lllllll}\text { Wild tuatara (Stephens } & 11.2 \pm 4.0 & 12.2 \pm 2.0 & 8.6 \pm 2.4 & 5 & 0.398 & 0.680\end{array}$

Is.)(S. punctatus) 
$\mathbf{a}$

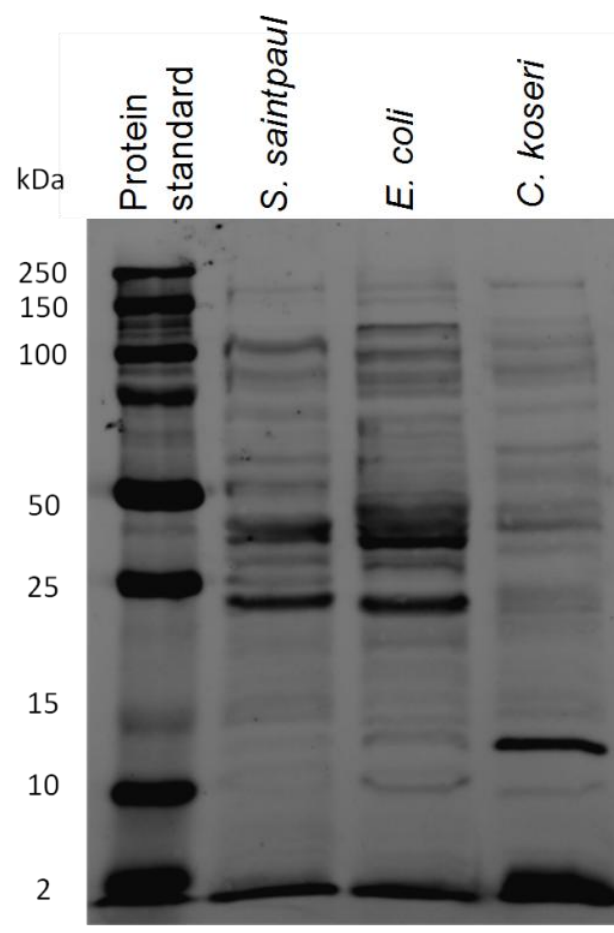

c

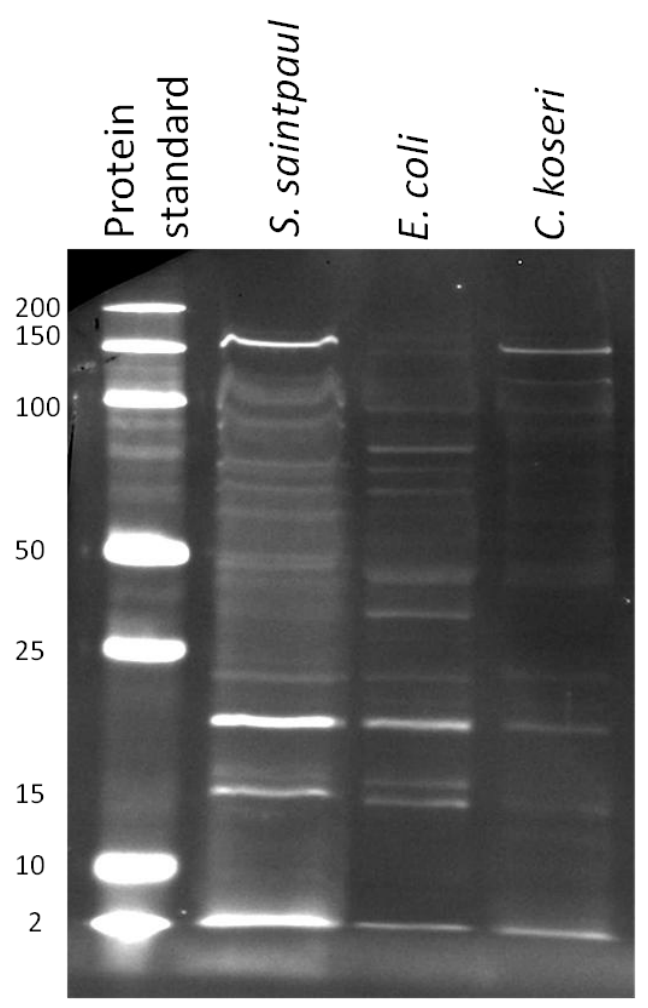

b
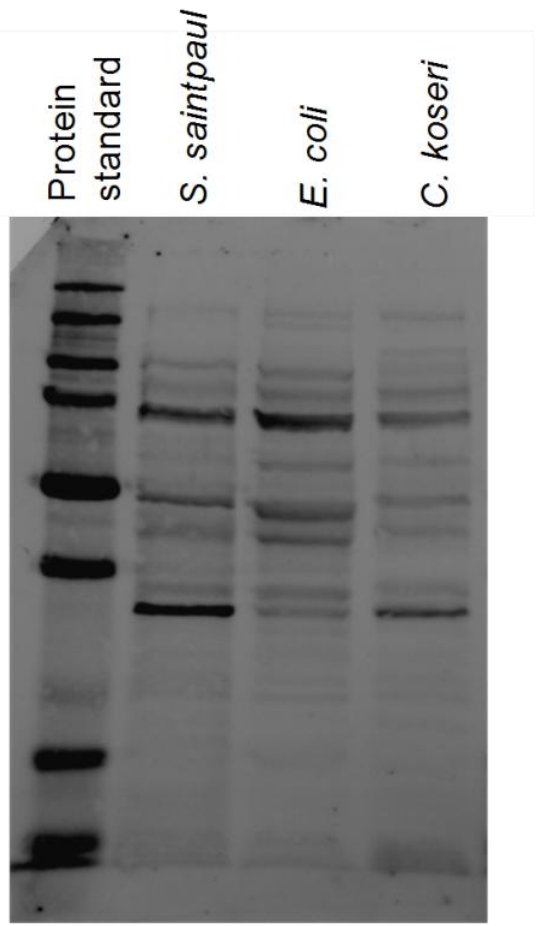

d

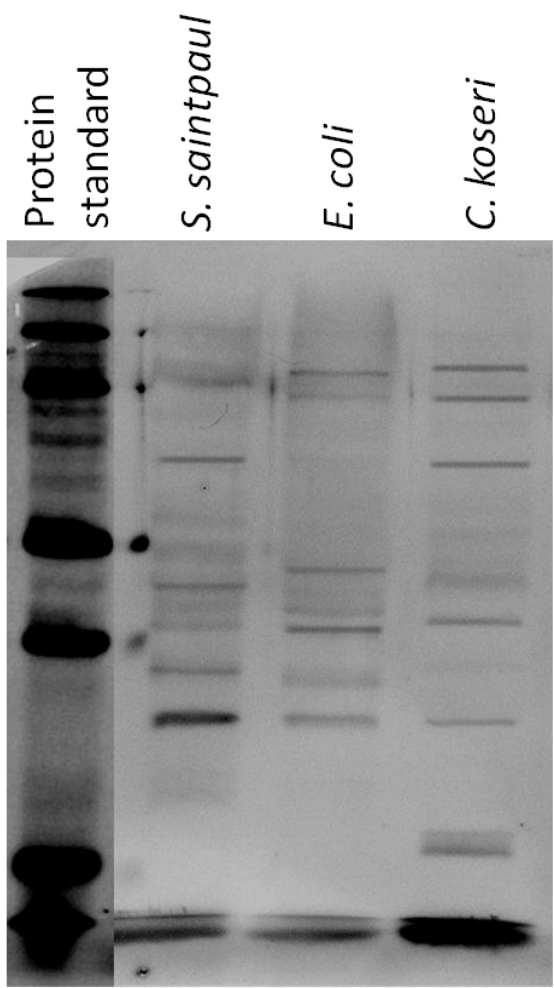

Figure 3.3: Western blots showing different patterns of antibody production for a captive tuatara (a), blue-tongue skink (b), wild tuatara (c) and coastal bearded dragon (d) when tested with S. Saintpaul, E.coli and C. koseri. 


\subsubsection{Optimisation of FCM}

Since a large amount of cross-reactivity seen in the Western blots may be due to conserved intracellular proteins shared between these closely related species of bacteria (S. Saintpaul, E. coli and C. koseri), a method which allowed investigation of outer cell surface proteins of live bacteria was devised to reduce this potential cross-reactivity. Flow cytometry provided a method to investigate the recognition of outer cell surface proteins of live bacteria by antibodies in serum samples.

Live bacteria were identified on the basis of specific forward (FSC) and side (SSC) light scattering properties. Following FSC and SSC gain adjustments and investigation of dot plots of control populations, bacteria were found by assuming a characteristic FSC x SSC dot plot distribution (Figure 3.6). The relative FITC fluorescence intensity of each event was analysed with SSC X FITC dotplot (Figure 3.7). A gate was set up on the dot plot representation and was used in all data analyses reported here to determine, for each serum sample, the relative percentage of positive fluorescent bacteria.

a)

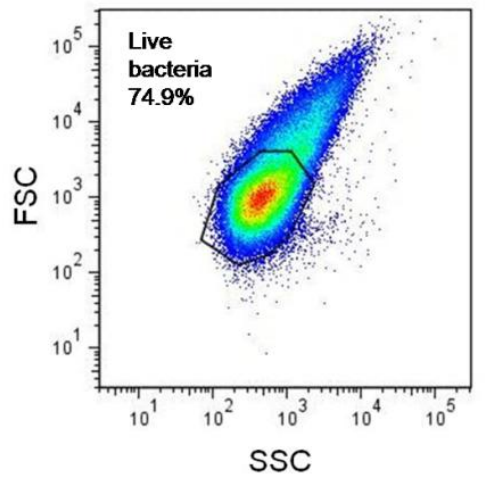

b)

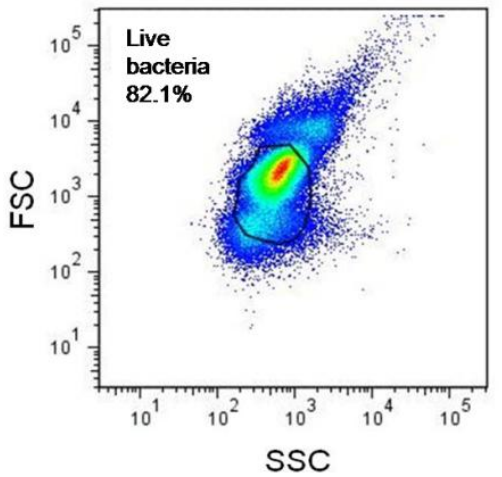

c)

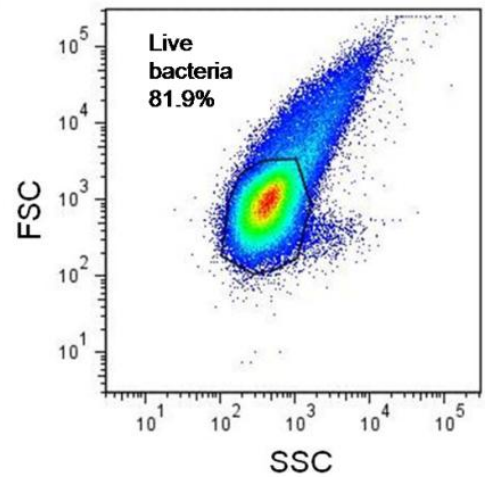

Figure 3.6: Dot plot analysis of a representative non-stained S. Saintpaul (a), E. coli (b) and C. koseri (c) distribution in FSC (size) versus SSC (granularity). Bacteria assume a characteristic distribution that allows selective analysis of live bacteria by creating a specific window over the bacteria region. 
Individual serum samples were analysed for the presence of antibodies to $S$. Saintpaul, E. coli and C. koseri, which bound to the bacteria. Flowjo data analyses showed that for 100,000 events acquired, an average of 80,000 live bacteria could be selected and gated for further analysis. Non-specific binding or the detection of secondary antibody was monitored by incubation of live bacteria with FITC conjugated goat-anti-bird IgG only. On the basis of this negative control, a gate for fluorescence positive bacteria was set up (Figure 3.7). This gate was established so that a maximum of $2 \%$ of negative control bacteria were fluorescence positive (Figure 3.7). For each test serum, percentage positive events were evaluated in the respective dot plots in relation to the same gate. Figure 3.7 shows dot plots representing S. Saintpaul, E. coli and C. koseri negative controls, positive controls and representative individual tuatara. The optimal growth time for bacteria used in the flow cytometry assays was determined by testing bacteria incubated for 9, 13 and 17 hours. Dot plots and mean fluorescent intensity (MFI) histograms were compared to determine the approach that best illustrated the recognition of bacteria with minimal background. An incubation period of 17 hours resulted in the optimal separation of populations and the lowest background fluorescence and was consequently used for all following assays.

From Figure 3.7 it is clear that the Salmonella-specific positive control recognises the culture bacteria. There are three distinct populations that vary in the level of their fluorescence with the majority (92.1\%) falling within the positive gate. The negative population is likely to include dying bacteria that may no longer express the epitope recognised by the antibody, and the population of bacteria that are highly positive are likely to be those that are rapidly dividing and thus may represent cellular doublets. A surprisingly similar pattern is observed when the Salmonella-specific antibody is tested against $C$. koseri. Three distinct populations are seen in the C. koseri positive control with the majority of bacteria (70\%) still falling into the positive gate. While this is less than the $92.1 \%$ seen in Salmonella it does suggest that a large number of epitopes are shared between these two species of bacteria. In contrast only $34.0 \%$ of E. coli cells fall inside the positive gate when stained with anti-Salmonella and rather than seeing three distinct populations of bacteria only one population is seen. Whereas in $S$. Saintpaul and C. koseri the positive population is a distinct and separate population, in $E$. coli we see an increase in the fluorescence of the whole population. 
Figure 3.7 also shows that tuatara serum recognises the culture bacteria. Unlike when Salmonella cells are stained with Salmonella-specific antibody there is no longer three separate populations but rather a shift towards greater fluorescence intensity of some cells. The greatest number of cells which fall within the positive gate are E. coli.

Using the flow cytometry technique designed and described above, I found a significant amount of individual variation in the recognition by tuatara sera to the three bacteria investigated in this study (Figure 3.8). However, within individuals there was a significant trend towards greater recognition of E. coli antigens than $S$. Saintpaul or $C$. koseri antigens. The antibody recognition and consequently percentage of positive events varies from approximately $18 \%$ in E.coli to $11 \%$ in S. Saintpaul and C. koseri $\left(\mathrm{F}_{2}=10.332, p<0.0001\right.$, Figure 3.8). I went on to assess how much of this antibody recognition was specific to the bacteria of interest and how much could be attributed to cross-reactivity between these closely related bacteria.

\subsubsection{Cross reactivity of tuatara sera antibodies to S. Saintpaul, E. coli and C. koseri}

I investigated the cross-reactivity of antibodies in tuatara sera to S. Saintpaul, E. coli and $C$. koseri using flow cytometry. The percentage of positive events obtained for each sera sample, when incubated with each of the three test bacteria independently, was taken to be $100 \%$, or the maximum available antibody to that bacterium (Figure 3.9). I then pre-absorbed each serum sample against one of the three test bacteria before incubating with the bacteria of interest. Pre-absorbing serum samples against $S$. Saintpaul and then re-incubating with $S$. Saintpaul did not result in a complete reduction of positive events, therefore indicating that I was not successful in removing all antibodies during the pre-absorption process (Figure 3.9). A similar result was seen for E. coli and C. koseri. Figure 3.10 shows that serum pre-absorbed against $S$. Saintpaul and then stained with $S$. Saintpaul results in an $80 \%$ reduction from maximum. This is likely to be due to individual variation in the amount of antibodies in tuatara. 


\section{S. saintpaul}

E. coli
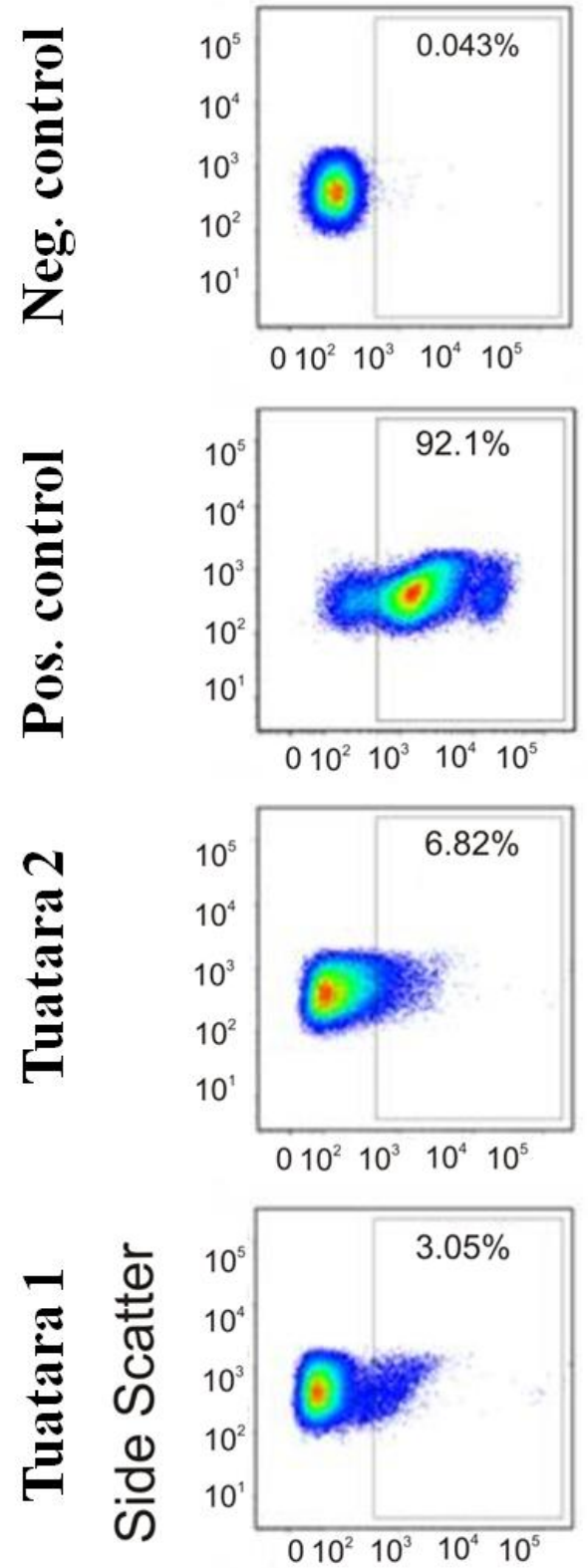
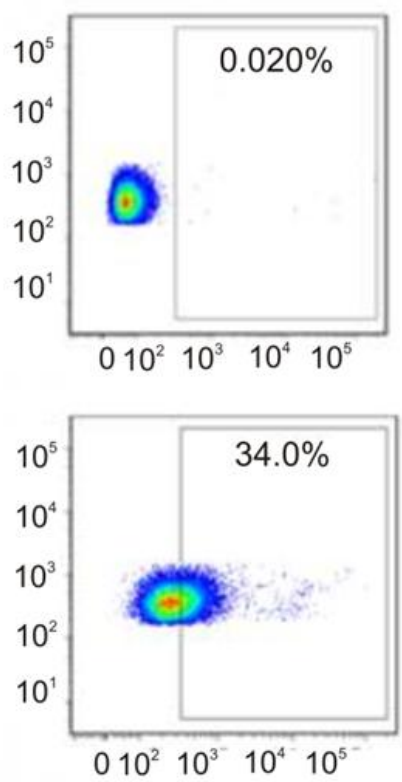

C. koseri
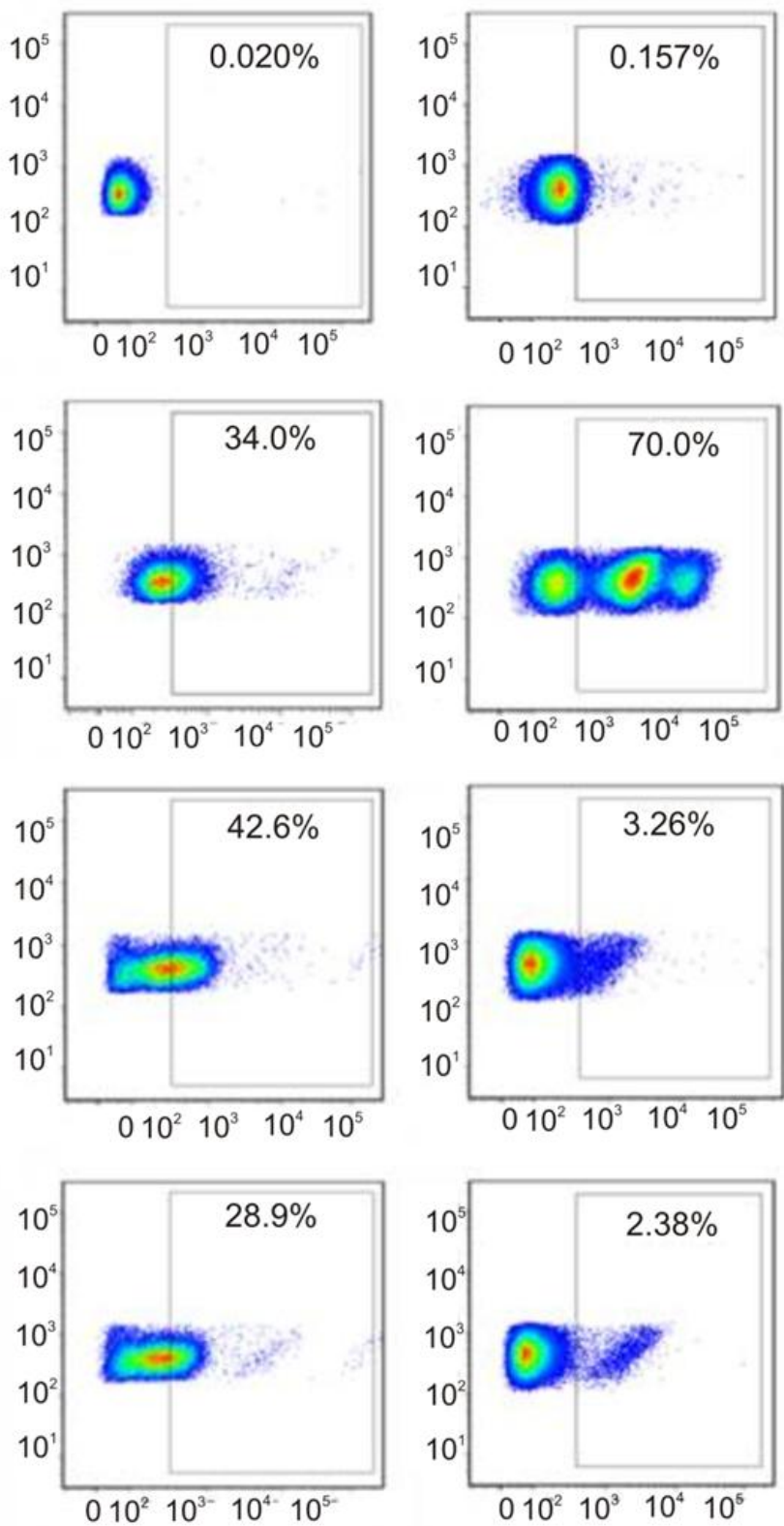

\section{Fluorescence intensity}

Figure 3.7: Dot plots representing S. Saintpaul, E. coli and C. koseri negative controls, positive controls and representative individual tuatara examples. 


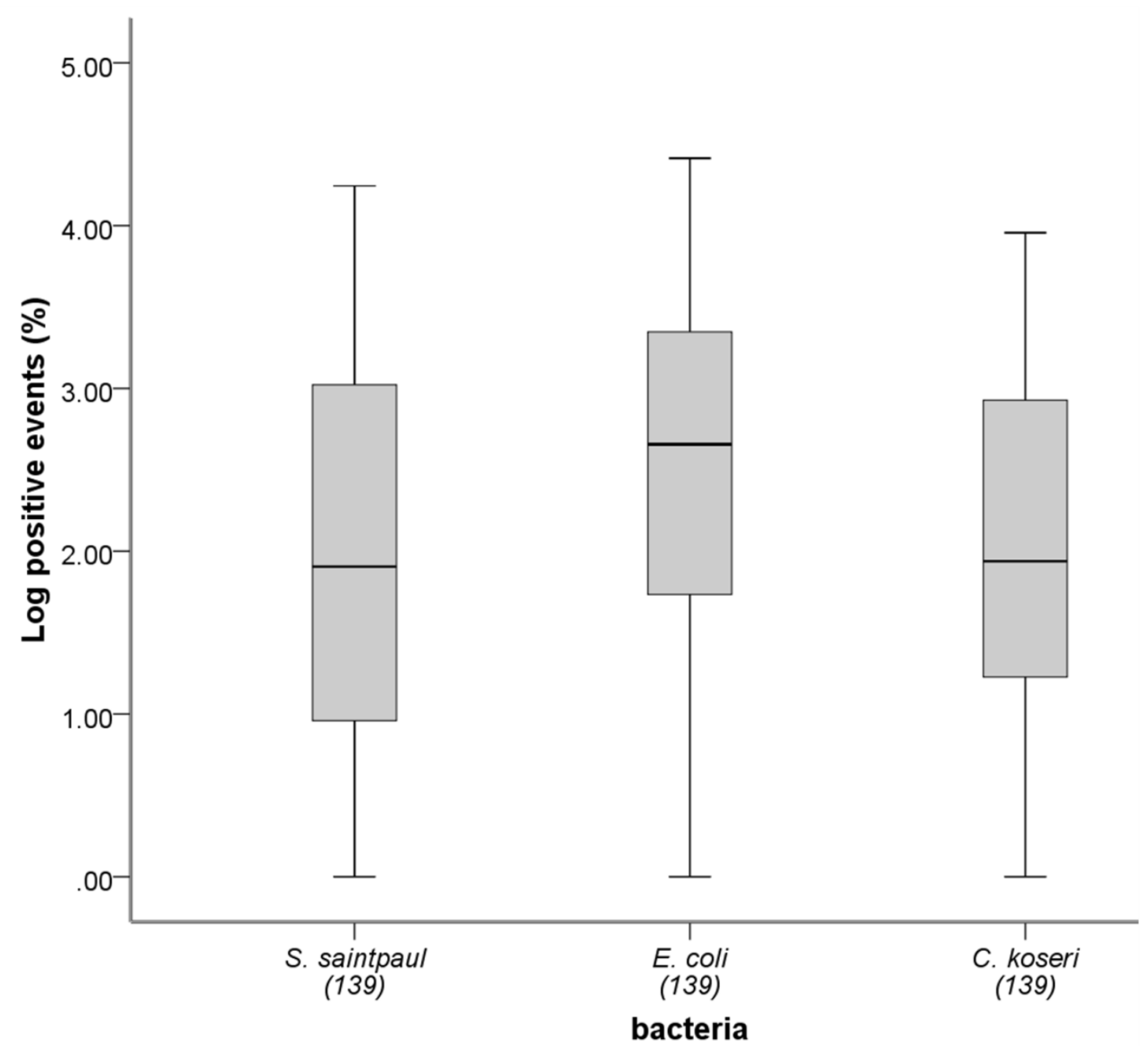

Figure 3.8: Wild and captive tuatara in this study have higher prevalences of antibodies which recognise E.coli than $S$. Saintpaul and C. koseri $\left(\mathrm{F}_{2,416}=10.332\right.$, $P<0.0001)$. $\mathrm{N}$ is shown in parentheses under $\mathrm{X}$-axis labels. 
Antibody binding can be assessed by calculating the percentage of positive events above a threshold fluorescence as discussed above or by calculating the mean fluorescence intensity (MFI) of the population. However, if the population is not normally distributed, MFI may not fairly depict the level of antibody binding in this assay (Figure 3.11). From Figure 3.9, it is evident that pre-absorption reduces the number of positive events but does not appear to reduce the MFI of the events that are positive. I have therefore selected to use the percentage of positive live bacteria to represent antigen binding in all further analyses.

Pre-absorbing serum samples with $C$. koseri before reacting the serum samples with $S$. Saintpaul results in a 70\% reduction in positive events as compared with non-preabsorbed serum. This reduction in positive events is significantly greater than when serum was pre-absorbed against $E$. coli (Figure 3.10). In contrast, there is no statistically significant difference in the percentage positive events when $C$. koseri is treated with serum pre-absorbed against $C$. koseri or $S$. Saintpaul. This finding suggests that many of the antibodies which recognise $S$. Saintpaul are cross-reactive with $C$. koseri. However, a small proportion of antibodies, which recognise $S$. Saintpaul, cannot be attributed to either $C$. koseri or E. coli cross-reactivity suggesting that they may be specific for Salmonella or cross-reactive with another closely related but untested bacterial species. In contrast, all C. koseri antibodies appear to be crossreactive with $S$. Saintpaul (Figure 3.10). Overall, Figure 3.10 shows that tuatara possess antibodies which recognise antigens of $S$. Saintpaul, E. coli and C. koseri, but the majority of these antibodies are cross-reactive with the three test bacteria.

Similar to the Western blot results, flow cytometry shows that the least cross-reactivity occurs between E. coli and either $C$. koseri or $S$. Saintpaul. This conclusion is supported by the finding that sera pre-absorbed to C. koseri or S. Saintpaul and then treated with $E$. coli only results in $\sim 55 \%$ reduction in positive events. Finally, despite the high level of cross-reactivity, there appear to be antibodies which recognise $S$. Saintpaul and E. coli antigens, which cannot be attributed to cross-reactivity with any of the bacteria tested in this study. 

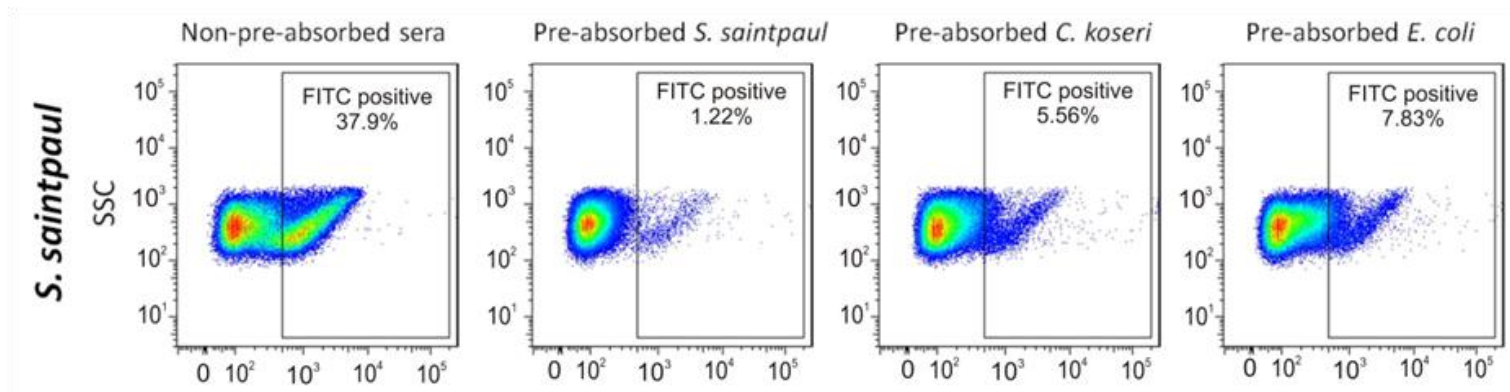

FITC
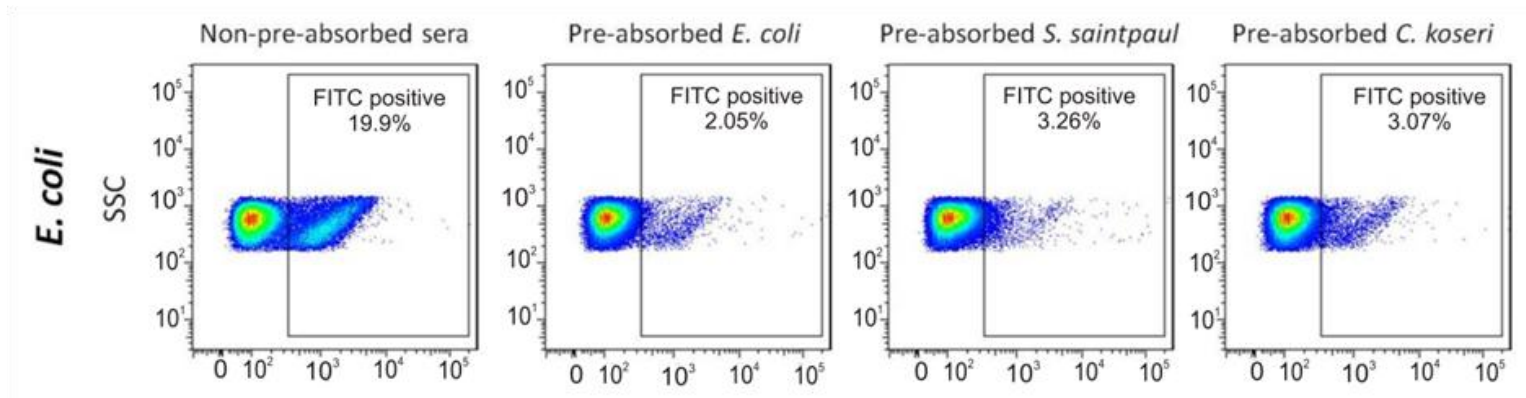

FITC
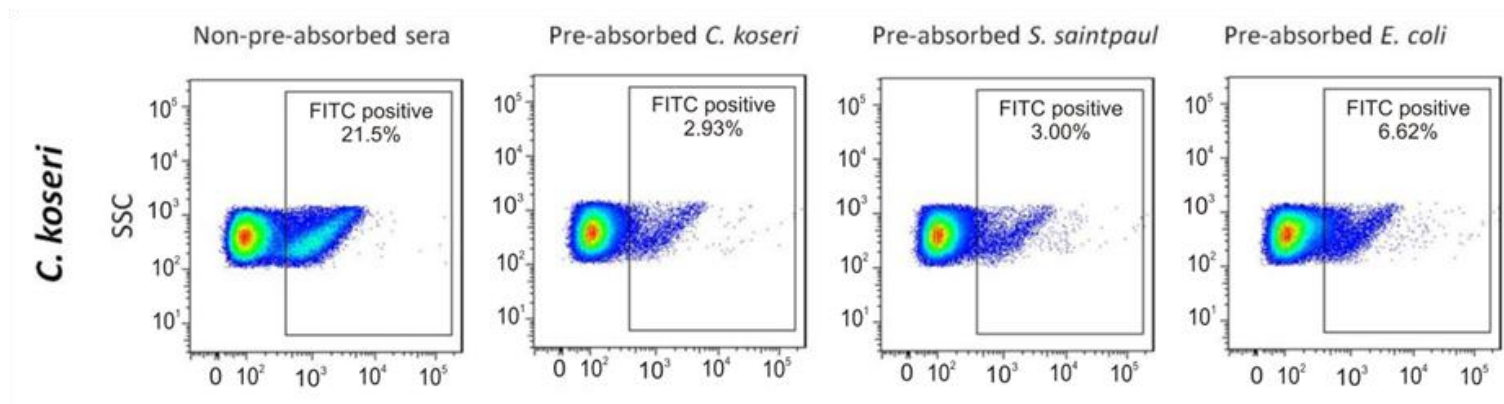

FITC

Figure 3.9: Pre-absorbing serum samples with a bacterium of interest and removing antibodies which recognise that bacteria reduces antibody binding when that serum sample is exposed to a different bacterial species. The reduction in antibody binding by pre-absorbed sera suggests cross-reactivity between these species. 

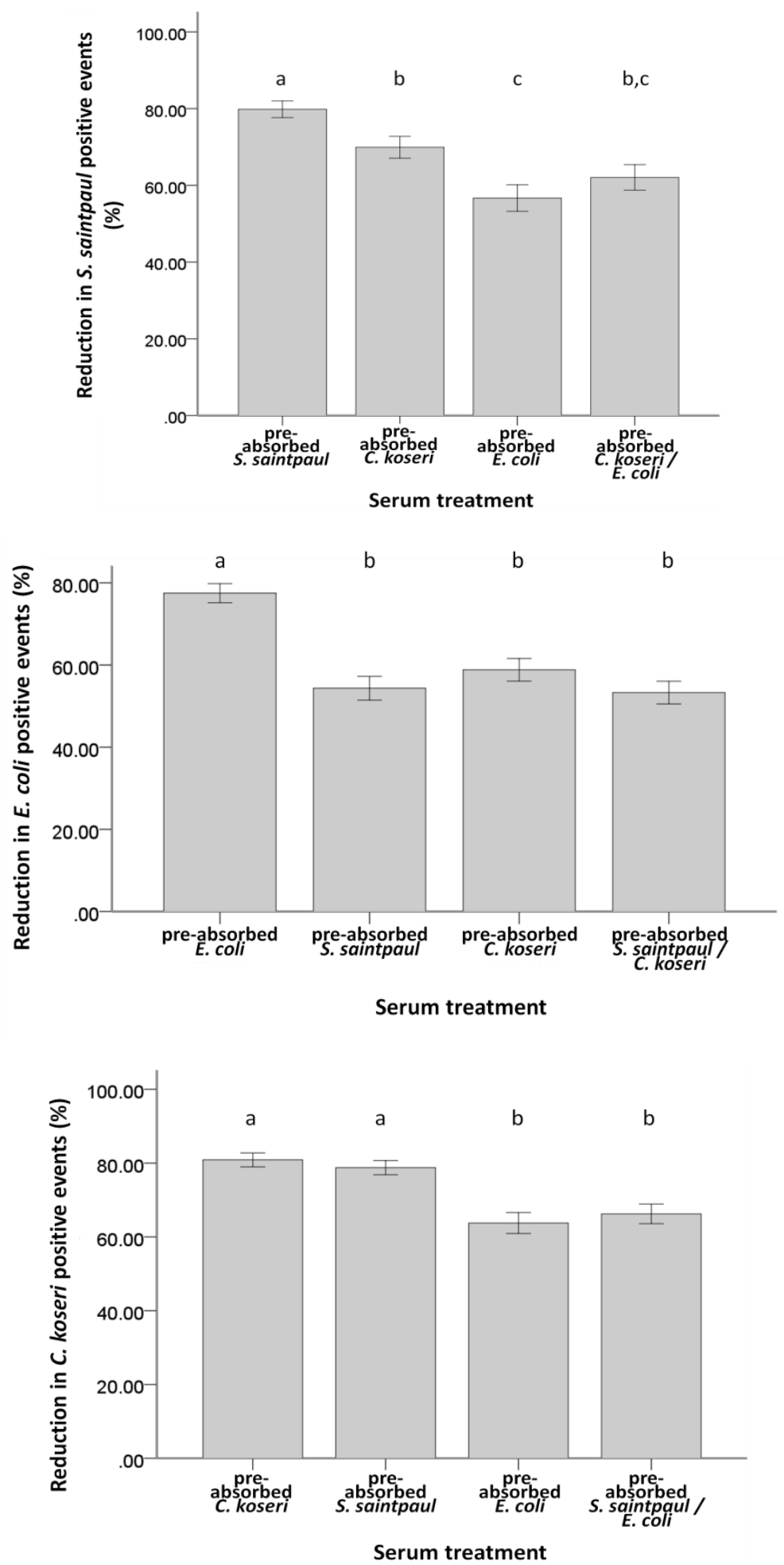

Figure 3.10: Serum that is pre-absorbed against S. Saintpaul, E. coli and C. koseri demonstrates the large degree of cross-reactivity that occurs between antibodies which recognise these three antigens. Bars with different letters are statistically significantly different. 

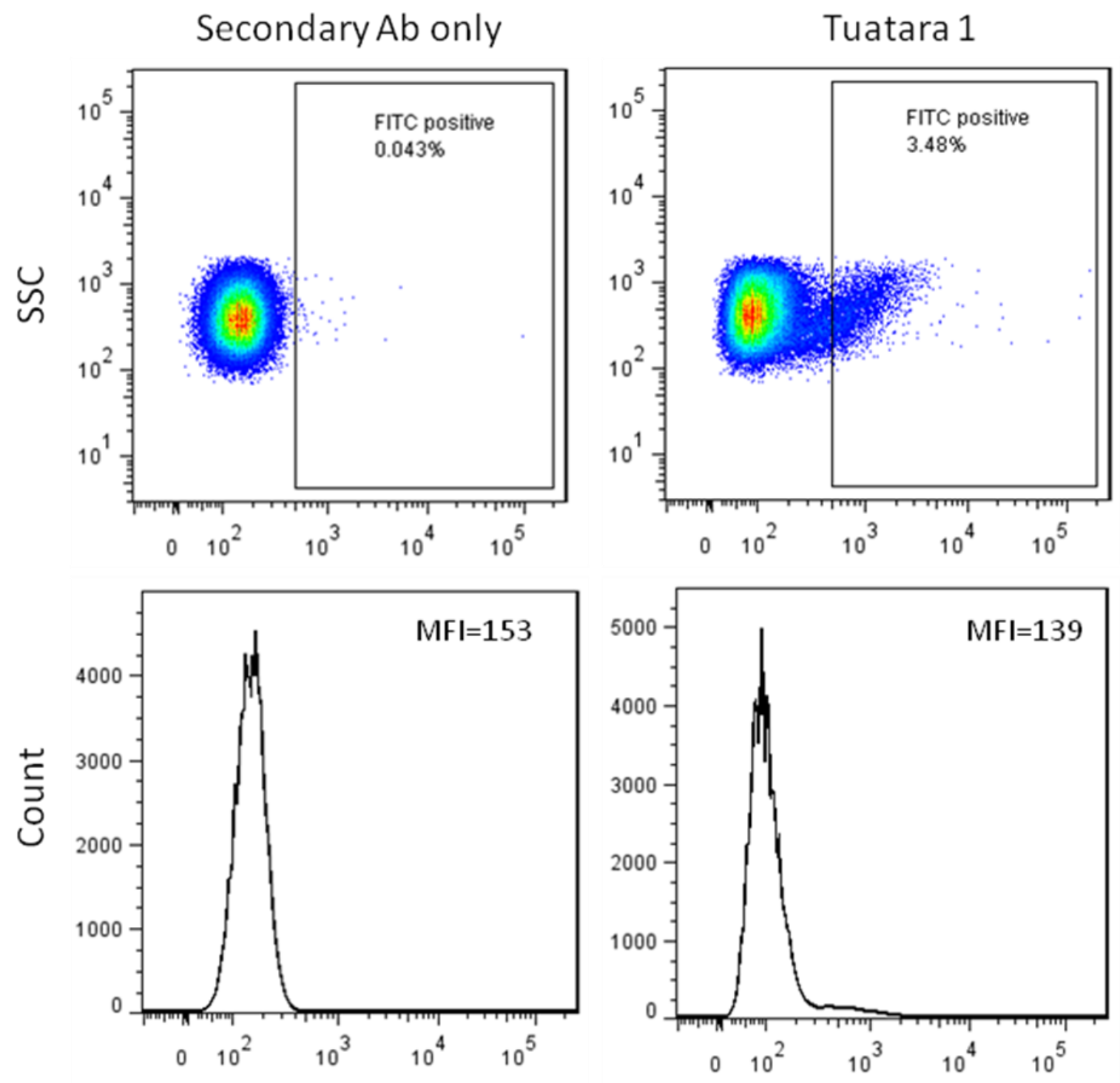

Figure 3.11: Mean fluorescence index is strongly influenced by outliers and therefore does not accurately reflect the changes in positive events/antibody binding seen in the data. 


\subsubsection{Seroprevalence of S. Saintpaul, E.coli and C. koseri among wild and captive tuatara populations}

For each species of bacteria a number of models were tested, according to the AIC model described in the methods. These models included a global model which included all the variables sex, season, location, year and an individual random effect of tuatara for captive tuatara and season, location, sex, mites, ticks and an individual random effect of tuatara in wild populations. Wild and captive populations of tuatara are analysed separately.

Models for all responses to all three species of bacteria were similar in wild tuatara serum (Table 3.5). The large majority of hypotheses tested were unsupported with $\Delta \mathrm{AIC}_{\mathrm{c}}>2$ (Appendix A). For each bacterial species the model which included sex, season and location together with an individual random effect of tuatara received the most support (i.e. had the lowest $\mathrm{AIC}_{\mathrm{c}}$ value) (Table 3.5). Other models which included various combinations of these four factors also received some support in explaining antigen recognition of each bacterial species $\left(\Delta \mathrm{AIC}_{\mathrm{c}}<2\right)($ Table 3.5).

Sex, season, location and tuatara are the best fitting models of the antigen binding ability of wild tuatara sera of those models investigated in this study. However, the weights for all these models are low $(<0.55)$, indicating these models do not effectively explain the variation within the data. Further investigation by two-way ANOVAs of main effects and interactions between sex, season, location and tuatara shows that no main effect or interaction is significant in explaining the variation in antigen binding observed in this study (Table 3.6).

Similar to the wild tuatara models, the top models for antigen binding of $S$. Saintpaul, E. coli and C. koseri only go part way to explaining the variation in the captive tuatara sera. Many of the factors in these models were found to be non-significant in further analyses. None of the variables tested by the models explain the variation observed in captive tuatara sera binding of E. coli. In contrast recognition of $C$. koseri and $S$. Saintpaul antigens by captive tuatara sera was influenced by season and sex (Table 3.8). 
Table 3.5: Outcomes of wild tuatara serum candidate models for: (A) S. Saintpaul, (B) E. coli and (C) C. koseri. The top five models for each bacteria are shown. The variables included in each model, number of parameters $(\mathrm{K}), \mathrm{AIC}_{\mathrm{c}}$ values, $\mathrm{AIC}_{\mathrm{c}}$ differences $\left(\triangle \mathrm{AIC}_{\mathrm{c}}\right)$, and Akaike weight $\left(\omega_{\mathrm{i}}\right)$ are shown for each species of bacteria tested (S. Saintpaul, E. coli and C. koseri). Models are ranked from the smallest to largest $\mathrm{AIC}_{\mathrm{c}}$ value with the best supported models $\left(\Delta \mathrm{AIC}_{\mathrm{c}}<2.0\right)$ shown in bold.

\begin{tabular}{lcccc}
\hline & & \multicolumn{3}{c}{$S$. Saintpaul } \\
Variables included in model & $\mathrm{K}$ & $\mathrm{AICc}$ & $\Delta \mathrm{AIC}_{\mathrm{c}}$ & $\omega_{\mathrm{i}}$ \\
\hline sex+season+location+(1|tuatara) & $\mathbf{6}$ & $\mathbf{4 2 9 . 5}$ & $\mathbf{0 . 0}$ & $\mathbf{0 . 5 2}$ \\
location+sex+(1|tuatara) & 5 & 431.6 & 2.1 & 0.19 \\
season+location+(1|tuatara) & 5 & 433.2 & 3.7 & 0.08 \\
season+sex+(1|tuatara) & 5 & 433.2 & 3.7 & 0.08 \\
season+location+sex+ticks+(1|tuatara) & 7 & 435.1 & 5.6 & 0.00 \\
\hline
\end{tabular}

A.

B.

\begin{tabular}{lccll}
\hline \multirow{2}{*}{ Variables included in model } & & \multicolumn{3}{c}{ E. coli } \\
\hline sex+season+location+(1|tuatara) & $\mathrm{K}$ & $\mathrm{AIC}_{\mathrm{c}}$ & $\Delta \mathrm{AIC}_{\mathrm{c}}$ & $\omega_{\mathrm{i}}$ \\
location+sex+(1|tuatara) & $\mathbf{6}$ & $\mathbf{4 5 3 . 9}$ & $\mathbf{0 . 0}$ & $\mathbf{0 . 4 8}$ \\
season+sex+(1|tuatara) & 5 & 456.6 & 2.7 & 0.13 \\
season+location+(1|tuatara) & 5 & 456.8 & 2.9 & 0.12 \\
season+location+sex+ticks+(1|tuatara) & 5 & 456.9 & 3.0 & 0.11 \\
\hline
\end{tabular}

C.

\begin{tabular}{lccll} 
Variables included in model & $\mathrm{K}$ & $\mathrm{AIC}_{\mathrm{c}}$ & $\Delta \mathrm{AIC}_{\mathrm{c}}$ & $\omega_{\mathrm{i}}$ \\
\hline sex+season+location+(1|tuatara) & $\mathbf{6}$ & $\mathbf{4 0 3 . 1}$ & $\mathbf{0 . 0}$ & $\mathbf{0 . 3 6}$ \\
location+sex+(1|tuatara) & $\mathbf{5}$ & $\mathbf{4 0 4 . 5}$ & $\mathbf{1 . 4}$ & $\mathbf{0 . 1 8}$ \\
season+sex+(1|tuatara) & $\mathbf{5}$ & $\mathbf{4 0 5 . 1}$ & $\mathbf{1 . 9 5}$ & $\mathbf{0 . 1 4}$ \\
season+location+(1|tuatara) & 5 & 405.9 & 2.75 & 0.09 \\
sex+(1|tuatara) & 4 & 406.4 & 3.30 & 0.07 \\
\hline
\end{tabular}


Table 3.6: Two-way ANOVAs for the best models of wild tuatara against $S$. Saintpaul, E. coli and C. koseri show that the best model by AIC does not explain variation in the data.

\begin{tabular}{|c|c|c|c|c|}
\hline Bacteria & Predictor & $F$ & df & $P$ \\
\hline \multirow[t]{7}{*}{ S. Saintpaul } & tuatara & 0.615 & 1,52 & 0.437 \\
\hline & season & 0.001 & 1,52 & 0.978 \\
\hline & sex & 2.429 & 1,52 & 0.126 \\
\hline & location & 1.535 & 1,52 & 0.222 \\
\hline & season*sex & 1.164 & 1,52 & 0.286 \\
\hline & season*location & 1.011 & 1,52 & 0.320 \\
\hline & sex*location & 0.207 & 1,52 & 0.651 \\
\hline \multirow[t]{7}{*}{ E. coli } & tuatara & 0.910 & 1,52 & 0.345 \\
\hline & season & 0.045 & 1,52 & 0.833 \\
\hline & sex & 0.135 & 1,52 & 0.715 \\
\hline & location & 0.137 & 1,52 & 0.713 \\
\hline & season*sex & 0.985 & 1,52 & 0.326 \\
\hline & season*location & 0.538 & 1,52 & 0.467 \\
\hline & sex*location & 0.058 & 1,52 & 0.810 \\
\hline \multirow[t]{7}{*}{ C. koseri } & tuatara & 2.698 & 1,52 & 0.107 \\
\hline & season & 0.452 & 1,52 & 0.505 \\
\hline & sex & 1.275 & 1,52 & 0.265 \\
\hline & location & 0.048 & 1,52 & 0.828 \\
\hline & season*sex & 1.386 & 1,52 & 0.245 \\
\hline & season*location & 0.097 & 1,52 & 0.757 \\
\hline & sex*location & 0.103 & 1,52 & 0.750 \\
\hline
\end{tabular}


Specifically, I found that sera from captive male tuatara bound a significantly higher number of $S$. Saintpaul $\left(\mathrm{F}_{1,77}=10.210, P=0.002\right)$ and $C$. koseri $\left(\mathrm{F}_{1,77}=5.337, P=0.025\right)$; Figure 3.12) than females. This same trend was not seen for E. coli antigens (Table 3.6, Figure 3.12). In contrast, a seasonal effect was seen in C. koseri recognition with captive tuatara sampled during summer having much higher antibody reactivity against C. koseri than those tested in any other season (Figure 3.13). There is a trend towards increased antibody numbers against $S$. Saintpaul during summer in captive tuatara (Figure 3.13) but this trend does not reach statistical significance $\left(\mathrm{F}_{3,77}=2.185, P=0.099\right)$. However, if spring data are removed from the analysis greater numbers of antibodies to $S$. Saintpaul are seen during summer as compared with autumn and winter $\left(\mathrm{F}_{2,56}=4.136\right.$, $P=0.023$; Figure 3.13).

Captive and wild tuatara sera were not found to differ in their recognition of $S$. Saintpaul $\left(\mathrm{F}_{1,130}=1.648, P=0.202\right)$, E. coli $\left(\mathrm{F}_{1,130}=2.473, P=0.119\right)$ or $C$. koseri $\left(\mathrm{F}_{1}\right.$, ${ }_{130}=2.249, P=0.136$ ) (Figure 3.14). I also compared the antigen recognition of captive and wild tuatara sera with three species of exotic reptiles (blue-tongue skink, coastal bearded dragon and Australian water dragon) and another population of wild tuatara from nearby North Brother Island (Figure 3.15). Blue-tongue skinks, coastal bearded dragons and Australian water dragons showed consistently lower antibody recognition than any of the tuatara populations for all three test bacteria, however this difference only reached statistical significance for $E$. $\operatorname{coli}\left(\mathrm{F}_{5,83}=2.832, P=0.021\right)$. Only tuatara tested in flow cytometry assays with exotic reptile species are included in this analysis. The lower recognition seen in the exotic reptile species is likely to be due in part to the lower sample sizes obtained for these species (four of each of blue-tongue skinks and Australian water dragons and five coastal bearded dragons) as compared to 71 tuatara. Very low binding was seen in exotic reptiles to E.coli, which is a fairly common bacteria in all species, a likely explanation may be that the anti-bird antibody has a lower affinity to exotic reptile antibodies than tuatara antibodies. 
Table 3.7: Outcomes of captive tuatara serum candidate for: (A) S. Saintpaul, (B) E. coli and (C) C. koseri. The top five models for each bacterium are shown (refer to Appendix A for the full model set). The variables included in each model, number of parameters $(\mathrm{K}), \mathrm{AIC}_{\mathrm{c}}$ values, $\mathrm{AIC}_{\mathrm{c}}$ differences $\left(\Delta \mathrm{AIC}_{\mathrm{c}}\right)$, and Akaike weight $\left(\omega_{\mathrm{i}}\right)$ are shown for each species of bacteria tested (S. Saintpaul, E. coli and C. koseri). Models are ranked from the smallest to largest $\mathrm{AIC}_{\mathrm{c}}$ value with the best supported model(s) (confidence set, i.e. $\Delta \mathrm{AIC}_{\mathrm{c}}<2.0$ ) shown in bold.

\begin{tabular}{llrrr}
\hline & \multicolumn{4}{c}{$S$. Saintpaul } \\
A. & $\mathrm{K}$ & $\mathrm{AIC}_{\mathrm{c}}$ & $\Delta \mathrm{AIC}_{\mathrm{c}}$ & $\omega_{\mathrm{i}}$ \\
\hline sex+season+location+year+(1|tuatara) & $\mathbf{1 4}$ & $\mathbf{4 7 5 . 1}$ & $\mathbf{0 . 0}$ & $\mathbf{0 . 7 5}$ \\
sex+season+location+(1|tuatara) & 13 & 477.4 & 2.3 & 0.23 \\
season+location+year+(1|tuatara) & 13 & 484.3 & 9.2 & 0.01 \\
season+location+(1|tuatara) & 12 & 486.5 & 11.4 & 0.00 \\
location+sex+year+(1|tuatara) & 11 & 486.6 & 11.5 & 0.00 \\
\hline & & & & \\
\hline & & $E . c o l i$ & & \\
B. & $\mathrm{K}$ & $\mathrm{AIC}$ & $\Delta \mathrm{AIC}$ & $\omega_{\mathrm{i}}$ \\
\hline Variables included in model & $\mathbf{1 4}$ & $\mathbf{5 0 7 . 3}$ & $\mathbf{0 . 0}$ & $\mathbf{0 . 6 7}$ \\
sex+season+location+year+(1|tuatara) & $\mathbf{1 3}$ & $\mathbf{5 0 9 . 2}$ & $\mathbf{1 . 9}$ & $\mathbf{0 . 2 5}$ \\
sex+season+location+(1|tuatara) & 13 & 513.5 & 6.2 & 0.03 \\
season+location+year+(1|tuatara) & 12 & 513.0 & 5.7 & 0.04 \\
season+location+(1|tuatara) & 11 & 516.0 & 8.7 & 0.01 \\
location+sex+year+(1|tuatara) & & & &
\end{tabular}

C. koseri

\begin{tabular}{llrrr} 
C. & $\mathrm{K}$ & $\mathrm{AIC}_{\mathrm{c}}$ & $\Delta \mathrm{AIC}_{\mathrm{c}}$ & $\omega_{\mathrm{i}}$ \\
\hline sex+season+location+year+(1|tuatara) & $\mathbf{1 4}$ & $\mathbf{4 7 0 . 4}$ & $\mathbf{0 . 0}$ & $\mathbf{0 . 6 2}$ \\
sex+season+location+(1|tuatara) & $\mathbf{1 3}$ & $\mathbf{4 7 1 . 6}$ & $\mathbf{1 . 2}$ & $\mathbf{0 . 3 3}$ \\
season+location+year+(1|tuatara) & 13 & 476.1 & 5.7 & 0.03 \\
season+location+(1|tuatara) & 12 & 477.5 & 7.1 & 0.02 \\
location+sex+year+(1|tuatara) & 11 & 493.3 & 22.9 & 0.00 \\
\hline
\end{tabular}


Table 3.8: Two-way ANOVAs for the best models of captive tuatara against $S$.

Saintpaul, E. coli and C. koseri. Significant predictors $(P=0.005)$ are shown in bold.

\begin{tabular}{lllll}
\hline Bacteria & Predictor & $\boldsymbol{F}$ & $\mathbf{d f}$ & $\boldsymbol{P}$ \\
\hline S. Saintpaul & season & 2.185 & 3,77 & 0.099 \\
& sex & $\mathbf{8 . 0 6 9}$ & $\mathbf{1 , 7 7}$ & $\mathbf{0 . 0 0 6}$ \\
& location & 0.497 & 6,77 & 0.808 \\
& year & 2.935 & 2,77 & 0.061 \\
\hline E. coli & season & 0.386 & 3,77 & 0.764 \\
& sex & 1.314 & 1,77 & 0.256 \\
& location & 0.299 & 6,77 & 0.935 \\
& year & 0.332 & 2,77 & 0.719 \\
\hline C. koseri & season & $\mathbf{6 . 0 0 3}$ & $\mathbf{3 , 7 7}$ & $\mathbf{0 . 0 0 1}$ \\
& sex & $\mathbf{4 . 3 5 0}$ & $\mathbf{1 , 7 7}$ & $\mathbf{0 . 0 4 1}$ \\
& location & 0.796 & 6,77 & 0.577 \\
& year & 1.022 & 2,77 & 0.366 \\
\hline
\end{tabular}

Within individuals I found a significant correlation between percentage recognition of the three bacterial species. Serum which showed high recognition of one bacteria species also tended to show higher recognition of the other two test bacteria (Figure 3.16). The highest correlation was seen between $S$. Saintpaul and $C$. koseri (Figure 3.16a). Salmonella and Citrobacter species are also the most closely related of the three bacteria investigated. 


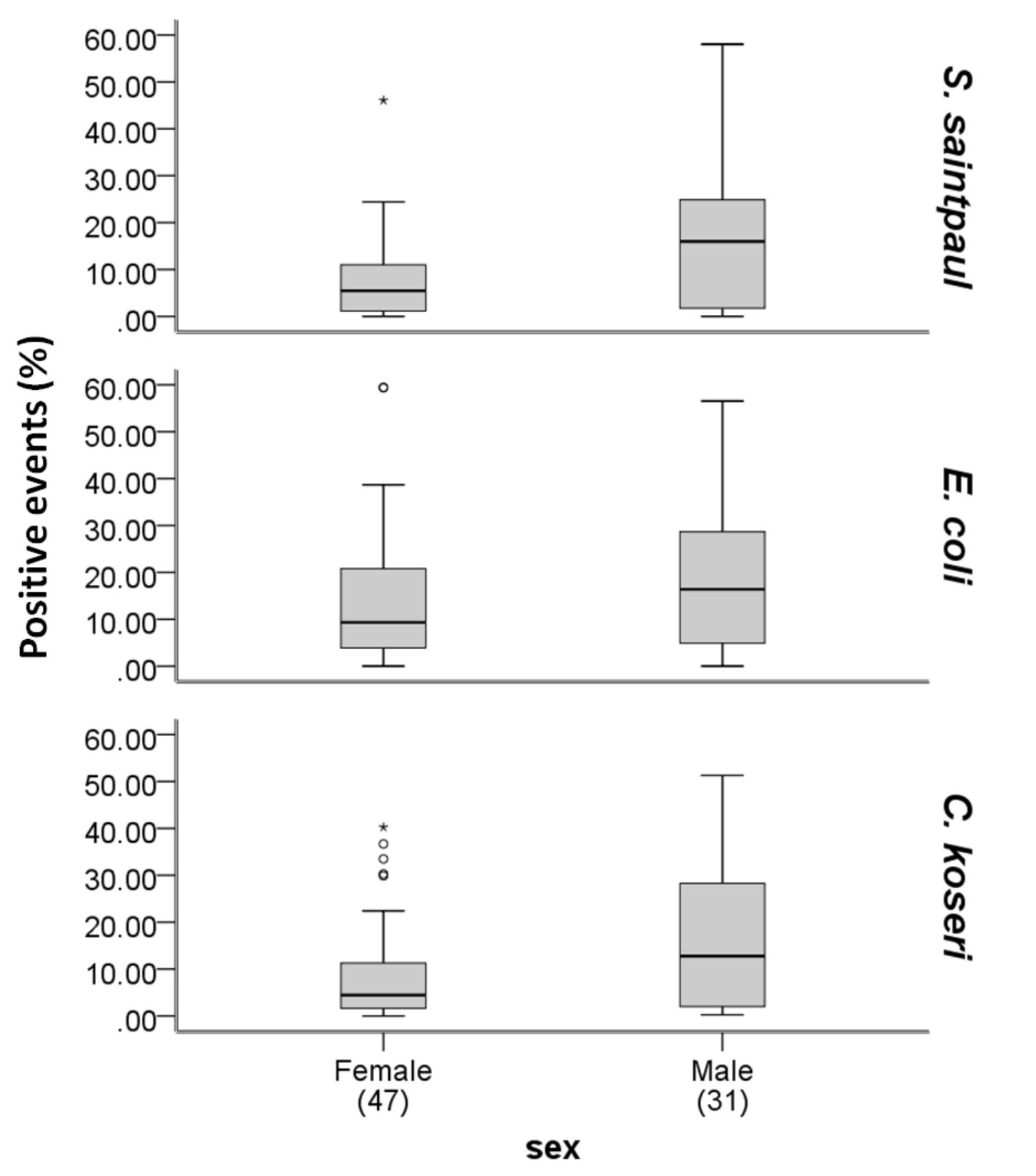

Figure 3.12: Sera of male captive tuatara bound significantly higher numbers of $S$. Saintpaul $\left(\mathrm{F}_{1,77}=10.210, P=0.002\right)$ and $C$. koseri $\left(\mathrm{F}_{1,77}=4.350, P=0.041\right)$, but no significant difference in $E$. coli recognition was observed between the sexes $\left(\mathrm{F}_{1,77}=1.314, P=0.256\right) . \mathrm{N}$ is shown in parentheses under $\mathrm{x}$-axis labels. 


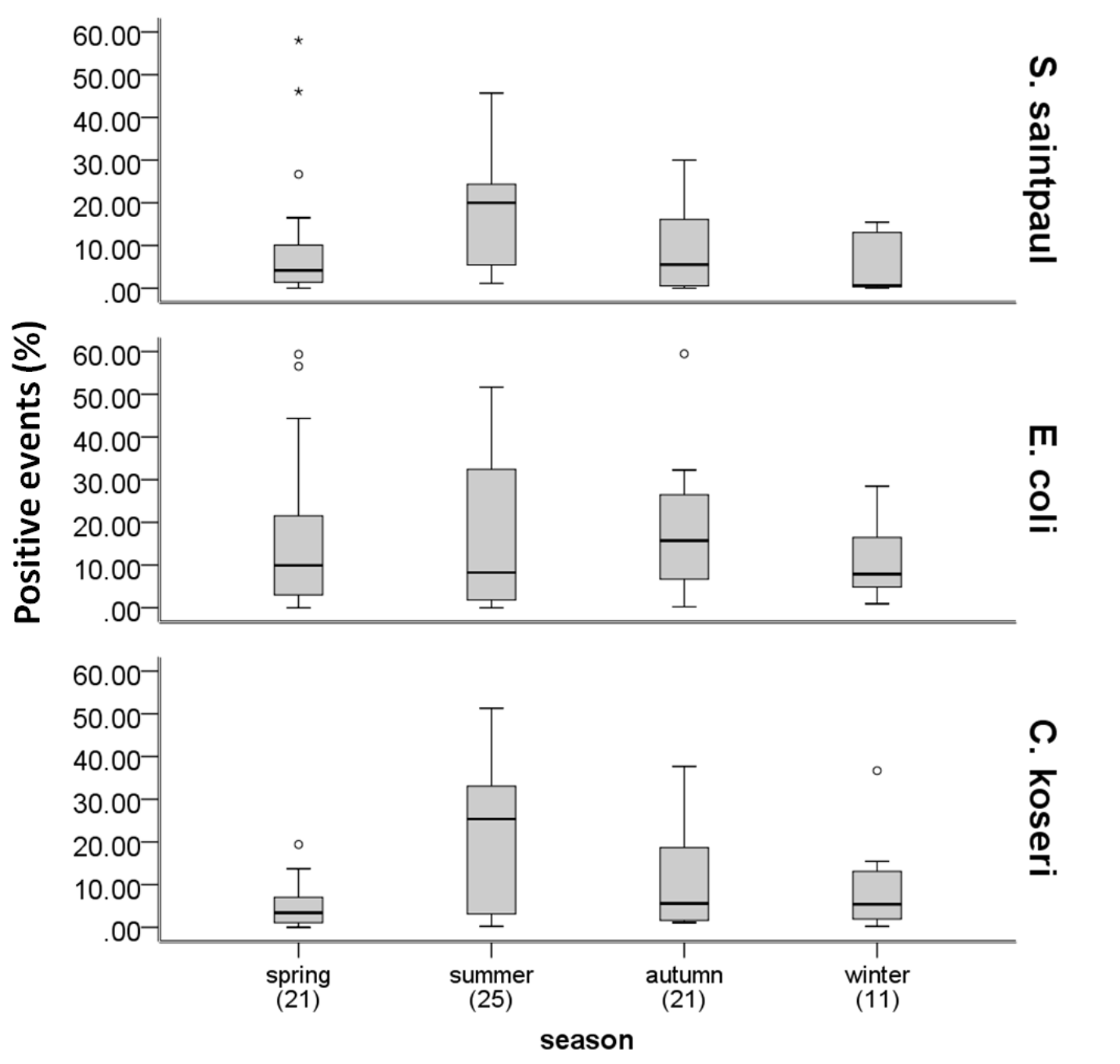

Figure 3.13: Sampling season does not significantly contribute to explaining the variation in antigen recognition of captive tuatara serum against $E$. coli $\left(\mathrm{F}_{3,77}=0.386\right.$, $P=0.764$ ). Higher amounts of C. koseri recognition were observed in summer than in any other season $\left(\mathrm{F}_{3,77}=6.003, P=0.001\right)$ and $S$. Saintpaul recognition is higher in summer than in autumn or winter $\left(\mathrm{F}_{2,56}=4.136, P=0.023\right)$. Sample sizes are shown in parentheses below x-axis label. 


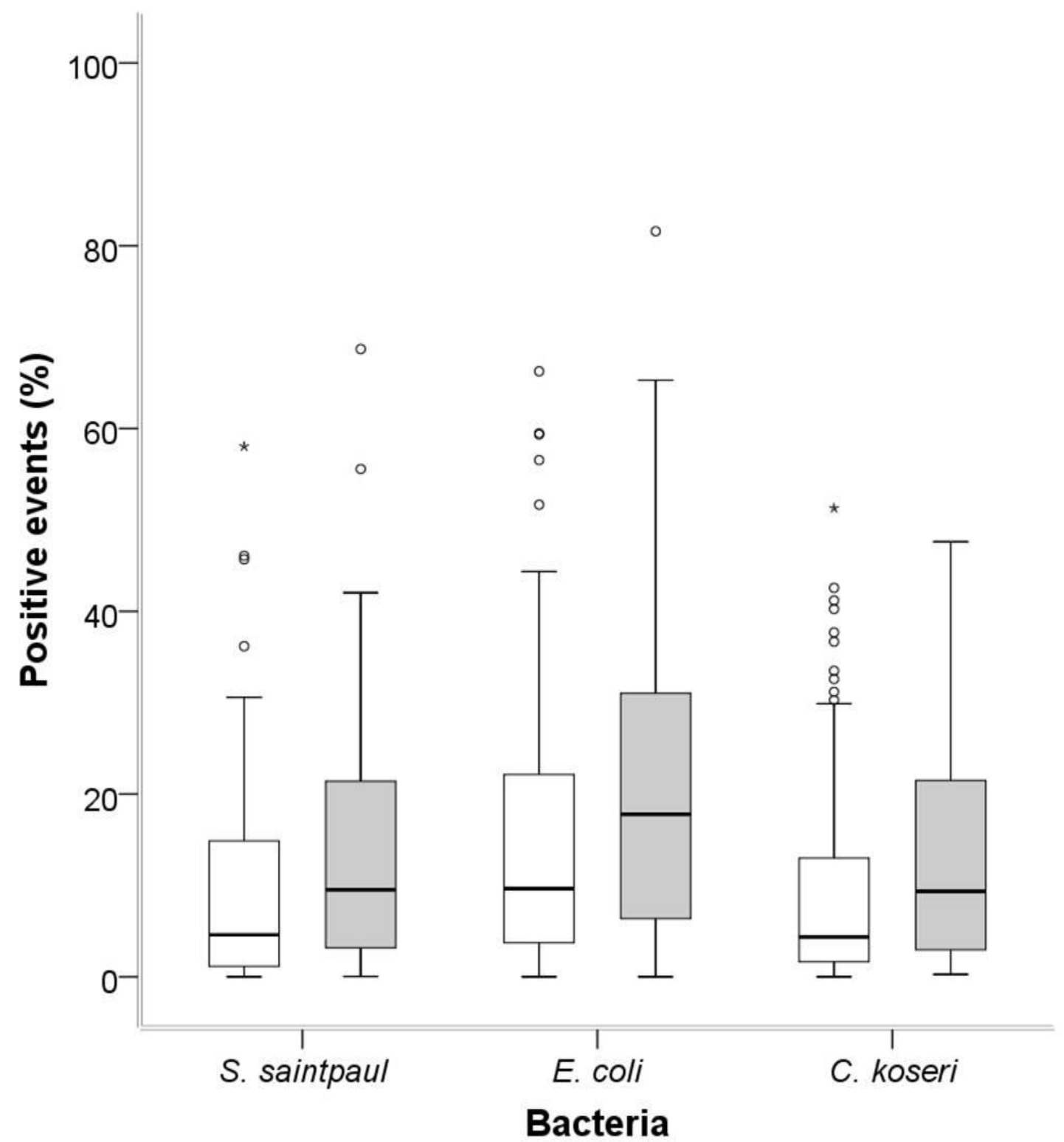

Figure 3.14: Box plot showing the recognition of captive (white, $\mathrm{N}=78$ ) and wild (grey, $\mathrm{N}=53$ ) tuatara serum to $S$. Saintpaul, E. coli and $C$. koseri. There was no significant difference in recognition of $S$. Saintpaul $\left(\mathrm{F}_{1,130}=1.648, P=0.202\right)$, E. coli $\left(\mathrm{F}_{1,130}=2.473\right.$, $P=0.119)$ and $C$. koseri $\left(F_{1,130}=2.249, P=0.136\right)$ for captive or wild tuatara serum. 


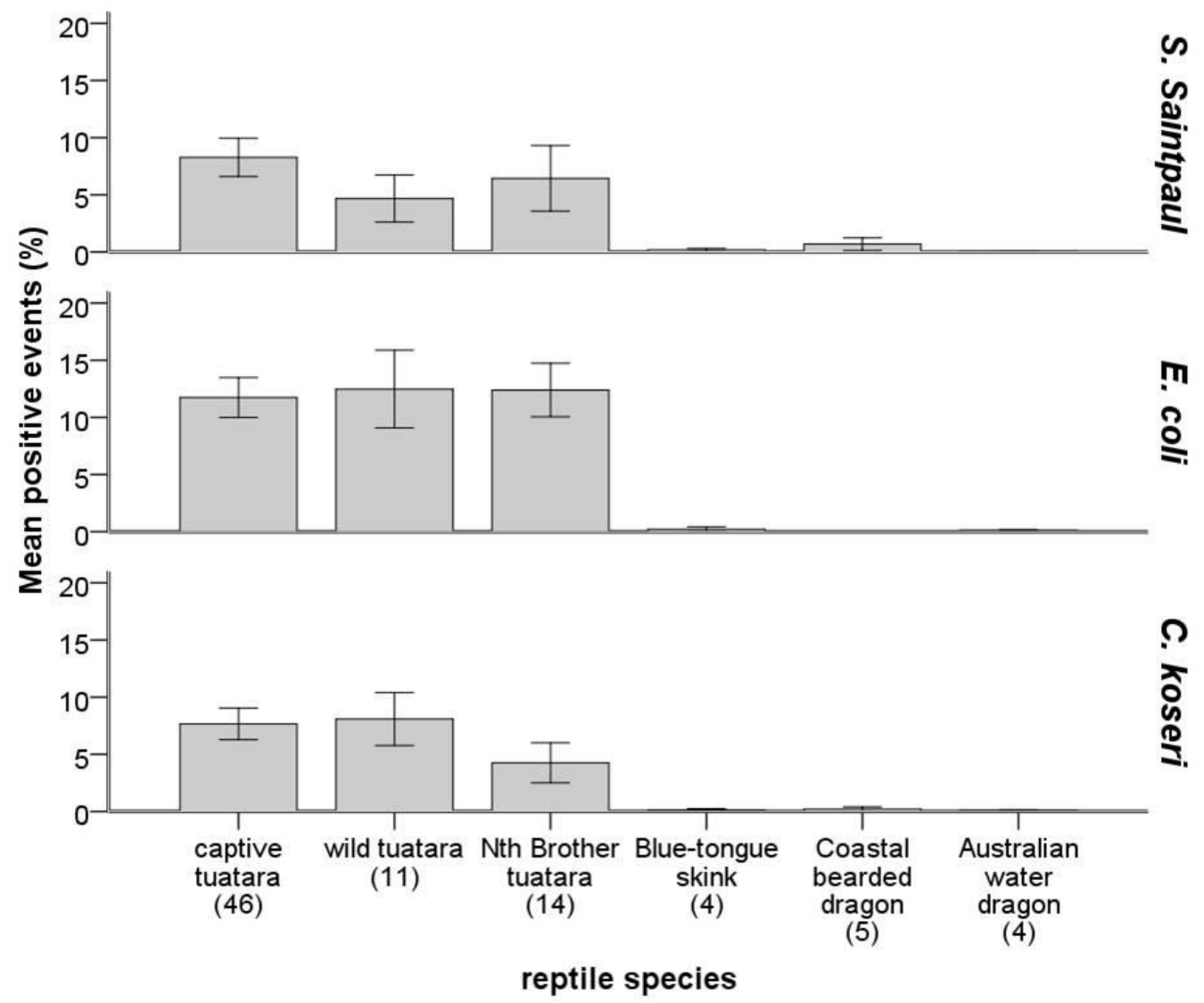

Figure 3.15: Tuatara sera showed significantly higher recognition of E. coli than did sera of blue-tongue skinks, coastal bearded dragons or Australian water dragons $\left(\mathrm{F}_{5,83}=2.832 . P=0.021\right)$. There was no significant difference in recognition of $S$. Saintpaul $\left(\mathrm{F}_{5,83}=1.335, P=0.288\right)$ or $C$. koseri $\left(\mathrm{F}_{5,83}=2.025, P=0.084\right)$ across reptilian species. 
A.

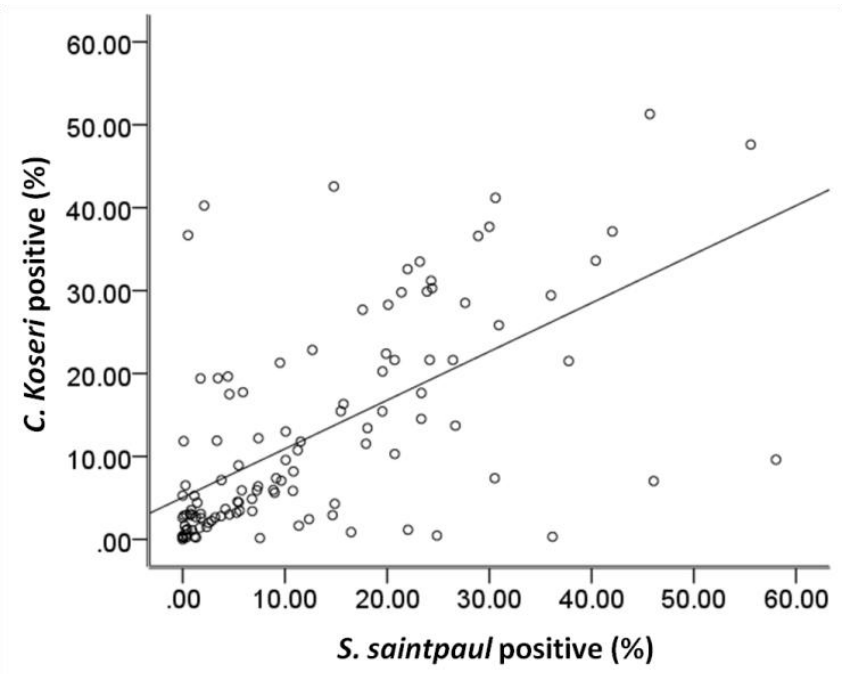

B.

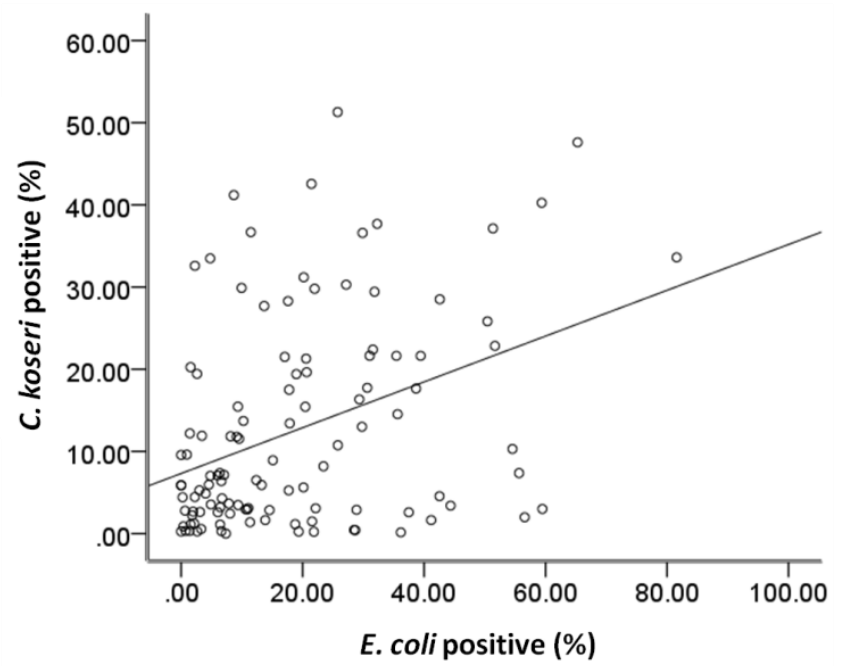

C.

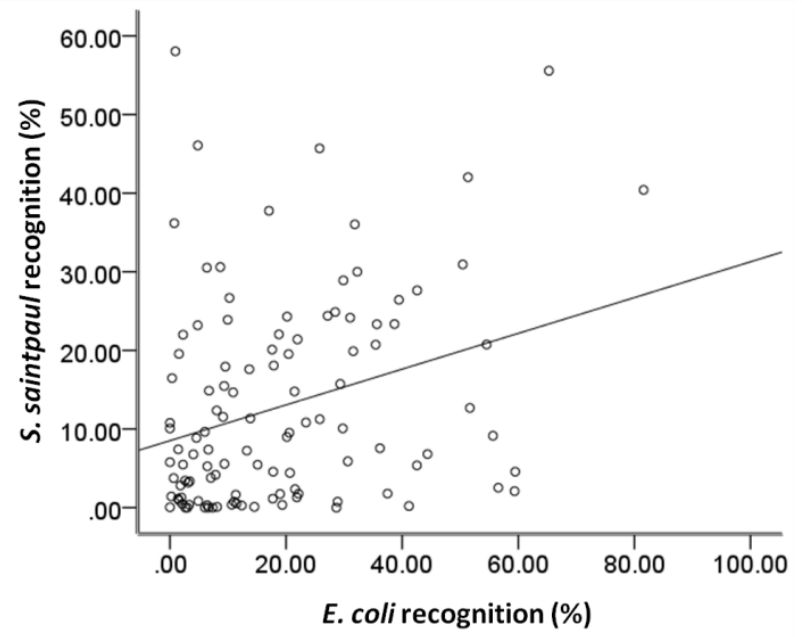

Figure 3.16: A positive correlation between tuatara serum antigen recognition was found for a) $S$. Saintpaul and $C$. koseri $\left(\mathrm{R}^{2}=0.371, P \leq 0.0001\right)$ and $\left.\mathbf{b}\right) C$. koseri and $E$. $\operatorname{coli}\left(\mathrm{R}^{2}=0.145, p \leq 0.0001\right)$ and c) $S$. Saintpaul and $E$. coli $\left(\mathrm{R}^{2}=0.090, P=0.001\right)$. 


\subsection{Discussion}

I demonstrated that tuatara have antibodies which recognise antigens of both intact and lysed Salmonella. While more than $90 \%$ of the observed recognition to lysed cells and more than $70 \%$ to intact cells can be attributed to cross-reactivity with either $E$. coli, $C$. koseri, or both, a small proportion $(<10 \%)$ of recognition appears to be Salmonella specific. However, because I have only investigated antibody cross-reactivity among three common and closely related enteric pathogens, I cannot exclude other bacterial species as the source of the remaining antibodies. Additionally, I found that captive tuatara produce higher amounts of antibody which recognise C. koseri and S. Saintpaul in summer than in autumn and winter, but the number of $E$. coli antibodies is not influenced by season. Male captive tuatara were also found to produce much higher amounts of antibody to $S$. Saintpaul and $C$. koseri than females, a similar trend was not observed for E. coli.

Tuatara are a long-lived ectothermic species that have adapted to live in a cool temperate zone. My hypothesis that the adaptive immune response of tuatara would be influenced by season was supported by this study, although the results should be interpreted with caution because of the small sample sizes obtained during some seasons such as winter. Although no seasonal effect on antigen recognition of wild tuatara sera was found to any of the three bacteria, it should be noted that the majority of captive tuatara were re-sampled each season, whereas in contrast very few of the wild tuatara $(n=7)$ were recaptured. The lack of re-sampling of the same individuals each season makes it difficult to compare findings among seasons in the wild population. Wild tuatara were also sampled only during summer and early autumn, therefore the time span between sampling periods may be too small to detect a difference in antibody production. A similar seasonality was observed in responses to toll-like receptor (TLR) agonists by leukocytes, with significantly greater responses observed in summer than in winter (La Flamme et al. 2010). In contrast, no seasonal effect on $\mathrm{T}$ cell responses was detected in captive tuatara tested during winter and spring (Burnham et al. 2005). In La Flamme et al. (2010) and the present study, summer was the period of increased immune function. Burnham et al. (2005) investigated $\mathrm{T}$ cell responses during winter and spring and consequently the time between sampling may have been too small to detect any difference in $\mathrm{T}$ cell response. 
On Stephens Island, Salmonella was detected in skinks and soil samples collected from inside tuatara burrows only in January, March and early June, but was not detected in October (Chapter Two). Consequently, the number of anti-Salmonella antibodies found in tuatara is highest during seasons when tuatara are most likely exposed to Salmonella in their environment.

Intrinsic biological factors such as sex may also play a role in modulating variation in immune response. Sex steroids have been implicated as a cause of sex differences in immune measures, with testosterone generally considered to reduce efficiency and duration of immune responses. Studies have proven that immunoglobulin production in female mice and hamsters is greater and more sustained than their male counterparts (Batchelor and Chapman 1965, Eidinger and Garrett 1972, Tartakovsky et al. 1981). The lessening of antibody production in male hamsters has been shown to coincide with an increase in sex steroids at maturity (Blazkovec and Orsini 1976). In contrast, I have demonstrated that sera from captive male tuatara are more reactive against $S$. Saintpaul and $C$. koseri than their female counterparts. A similar response was not seen in wild tuatara sera. It therefore seems likely that sex-dependent differences in immune response in captive populations of tuatara are not due to physiological factors such as sex steroids, but rather due to variation in pathogen exposure resulting from behavioural differences between the sexes. For example, if these pathogens are food bowl affiliated we might expect to see greater exposure in captive males through food bowl domination. Alternatively, any differences between the sexes in the wild population may be disguised by the small female sample size $(n=14)$ as compared with males $(n=39)$.

The present study lends further support to the possibility that variation in antibody production is due more to exposure than to physiological differences since other factors i.e. body condition, ectoparasite loads or location/habitat were not significant in explaining variation in immune responses. Captive and wild tuatara did not differ in their recognition of the three test bacteria (Figure 3.14). This suggests that both groups have produced antibodies to the bacteria at similar levels. All of the captive tuatara investigated in this study were housed in outdoor enclosures with an open mesh roof. Consequently, the enclosures are open to contamination by bird faecal matter. Previous studies have shown that a number of bird species in New Zealand are carriers and spreaders of Salmonella serovars, in particular, red-billed gulls (Chroicocephalus 
scopulinus), black-backed gulls (Larus dominicanus) and house sparrows (Passer domesticus) (Robinson and Daniel 1968, Clark 2001, Connolly et al. 2006). Many of these avian species are common around zoological and wildlife parks, feeding on food scraps left behind by visitors. Sparrows and other birds may provide a potential source of contact with Salmonella and other pathogens for captive tuatara. Captive animals have previously been infected with Salmonella serovars by free-ranging wild animals for example, during a Salmonella Typhimurium DT195 outbreak in New Zealand, which resulted in the mortality of several hundred sparrows. This same serovar was isolated from a captive kaka (Nestor meridionalis) at a zoological park frequented by sparrows (Alley et al. 2002).

Captive blue-tongue skinks, coastal bearded dragons and Australian water dragons were also tested for antibodies to $S$. Saintpaul, E. coli and C. koseri. These reptiles showed significantly lower antibody levels than either captive or wild tuatara for $E$. coli but no significant difference in S. Saintpaul or C. koseri recognition. Surprisingly, $80 \%$ of these reptiles were known carriers of Salmonella. The lower recognition seen in these exotic reptiles may be in part attributed to the lower sample sizes obtained for these species. I may also be observing reduced affinity by the sera of these three exotic reptiles to the secondary antibody (anti-bird). I also observed a lower number of bands in exotic reptiles by Western blot when compared with the tuatara populations, further lending support to the hypothesis that the Australian water dragon, coastal bearded dragon and blue-tongue skink sera are not as effectively bound by the anti-bird sera as tuatara. The reduced fluorescence seen among the exotic reptile species tested in this study may therefore not reflect fewer antibodies within these species.

Within individuals there is a significant correlation between antibody recognition of the three bacteria, with individuals possessing high levels of antibodies against $S$. Saintpaul also having high levels against $E$. coli and $C$. koseri and likewise for the other bacteria. The highest correlation was seen between antibodies against $S$. Saintpaul and $C$. koseri. This correlation may indicate that individuals with robust, efficient immune responses against one pathogen, also produce efficient responses against all other pathogens. Alternatively, it could allude to potential cross-reactivity of antibodies against these three very common pathogens. I have demonstrated that wild and captive populations of tuatara have antibody responses against $S$. Saintpaul, E. coli and C. koseri. By pre- 
absorbing sera against specific antigens and therefore removing antibodies which recognise that antigen I have demonstrated that a large proportion of antigen recognition of the three test bacteria can be attributed to cross-reactivity. This technique has also shown a higher level of cross-reactivity between antibodies which recognise $S$. Saintpaul and $C$. koseri than those which recognise E. coli. This finding is not surprising given that Salmonella and Citrobacter share many similar traits. Not all antibodies which recognise $E$. coli can be attributed to cross-reactivity with $S$. Saintpaul or $C$. koseri but this does not rule out reactivity with other bacterial species not tested here. However, E. coli and C. koseri were selected as the most likely candidates for cross-reactivity with Salmonella based on the findings of other studies which have shown that these species share homology within their $\mathrm{O}$ antigens which results in a large degree of cross-reactivity (Keleti et al. 1971). E. coli and C. koseri are also commonly isolated from both wild and captive tuatara (Gartrell et al. 2010, personal observation).

Recognition of S. Saintpaul, E. coli and C. koseri antigens by tuatara serum does not necessarily infer previous exposure to these pathogens. As I have demonstrated, recognition can in part be attributed to cross-reactivity with other closely related enteric pathogens, but antigen recognition may also be attributed to natural antibodies (NAbs). Natural antibodies are antigen-specific antibodies which have been isolated from animals that have not been immunised or otherwise exposed to a source of those antigens (Hunter Jr et al. 2008). NAbs are evolutionarily conserved and represent an important component of the innate immune response (Ochsenbein and Zinkernagel 2000, Baumgarth et al. 2005). NAbs have been found and shown to bind to a variety of antigens in fish, reptiles, birds and mammals (Adelman et al. 2004, Whiteman et al. 2006, Hunter Jr et al. 2008). The importance of natural antibodies in pathogen defence has been considered in earlier studies. NAbs against the bacterium Aeromonas salmonicida have been isolated from unexposed goldfish. Sinyakov et al. (2002) divided unexposed goldfish into high and low natural antibody groups, and when challenged with $A$. salmonicida, the high natural antibody group was largely protected while infections in the low natural antibody group resulted in $100 \%$ morbidity. Some authors have even hypothesised that a NAb response will predict the strength of the adaptive immune response (Kohler et al. 2003). Thereby, NAbs form a link between adaptive and innate immunity. NAbs can play an important role in protection against 
pathogenic bacteria, and therefore may play a part in antigen recognition of the three bacteria species tested in this study.

The present study appears to be the first to describe the use of flow cytometry detection in the testing of wildlife for antibodies to common bacterial pathogens. Flow cytometry has been shown to have increased specificity as compared to other serological assays in studies of infection with the parasite Trypanosoma cruzi (Cordeiro et al. 2001, Araújo et al. 2002). Other assays are likely to have similar sensitivities but specificities may be lower due to the use of pathogen lysates. In contrast, the antigens I have used in this study were intact bacteria cells; therefore reactivity was limited to surface proteins on the outside membrane. Using live intact cells avoids the binding of IgG to intracellular components which are often widely conserved among other bacteria species. This intracellular binding is thought to cause much of the cross-reactivity that occurs when bacterial lysates are used.

The findings of this study indicate that tuatara have antibodies which recognise the common bacteria $S$. Saintpaul despite this bacterium never having been isolated from any living tuatara. I have also found that tuatara have antibodies which recognise the closely related bacteria species E. coli and C. koseri. While there is a high degree of cross-reactivity between these three bacterial species not all antibodies to $S$. Saintpaul or $E$. coli can be attributed to cross-reactivity with any of the three species tested in this study. I have found no difference in the recognition of wild or captive tuatara sera to the three test bacteria, suggesting most populations are exposed to or have natural antibodies against these pathogens at similar levels. 


\section{CHAPTER FOUR}

\section{Anti-microbial activity of tuatara sera}

\subsection{Abstract}

The innate immune system provides vertebrates with a rapid, non-specific first line of defence against colonisation by microorganisms. Very little is known about the immune response of New Zealand's endemic reptile, the tuatara (Sphenodon punctatus) against environmental pathogens. This study investigates the innate immune response of tuatara against a common pathogen, Salmonella Saintpaul, and two common enteric bacteria, Escherichia coli and Citrobacter koseri. Using anti-microbial assays to determine the in vitro anti-microbial activity in serum, I compared the activity in tuatara sera to that in mouse (Mus musculus), donkey (Equus asinus), coastal bearded dragon (Pogona barbata) and Australian water dragon (Physignathus lesuerii) sera and found that the anti-microbial activity of tuatara serum was approximately 6-fold higher than donkey or mouse sera, but showed similar activity to coastal bearded dragons and Australian water dragons. Moderate heat treatment $\left(55^{\circ} \mathrm{C}\right.$ for 30 minutes $)$ did not inhibit the anti-microbial activity of tuatara serum indicating the activity was not due to complement but rather to heat-stable factors such as anti-microbial peptides. The antimicrobial activity of tuatara serum against $S$. Saintpaul and E. coli did not alter with season, sex or body condition, whereas serum samples obtained from captive tuatara during winter showed higher anti-microbial activity against C. koseri. This study is the first report of active peptide-mediated innate immunity in tuatara and suggests that peptide-mediated anti-microbial activity may play a significant role in the prevention of systemic infections of tuatara by Salmonella. 


\subsection{Introduction.}

All eukaryotic organisms fight a continual battle against colonisation by pathogenic microorganisms (Reddy et al. 2004). Adequate host protection against pathogens requires two separate, but interrelated, types of responses: acquired immunity and innate immunity (Ferronato et al. 2009). Acquired immunity elicits targeted responses against specific antigens to which the host was previously exposed and against which specific receptors have been assembled to (Janeway and Medzhitov 2002). Cells of the acquired immune response include CD4 T cells, regulatory $\mathrm{T}$ cells and B cells, collectively known as lymphocytes, whereas the innate immune response comprises a variety of cells, including macrophages (MØ), dendritic cells (DC), basophils and neutrophils (in reptiles neutrophils are replaced with heterophils). These cells express receptors such as toll-like receptors which lack the degree of specificity seen in acquired immunity, and unlike lymphocytes, each cell expresses a wide variety of different receptors. Innate immunity acts as a rapid, non-specific first line of defence in contrast to the slower, more specific response of adaptive immunity (Diamond et al. 2009). Innate immune defence is an ancient and ubiquitous defence system that is described in almost all classes of organism including plants (Castro and Fontes 2005), fungi and insects (Hultmark et al. 1980; Lemaitre and Hoffmann 2007), and almost every species of vertebrate (van Dijk et al. 2008).

Anti-microbial properties have been documented in the blood of many taxa including horseshoe crabs (Nachum et al. 1979), crocodilians (Merchant et al. 2006), birds (Matson et al. 2006) and mammals (Carroll and Martinez 1981). Anti-microbial activity (AMA) can arise as a result of anti-microbial peptides (AMPs) or the serum complement system. The potent activity of AMPs arises from their cationic charge and amphipathicity, which causes the peptide to be attracted to the bacterial membrane. The AMP then attaches to the membrane of the microorganism where killing typically occurs via membrane permeation (Diamond et al. 2009). In contrast to anti-microbial peptides which act alone, serum complement activity requires a large number of proteins that circulate as inactive precursor proteins. When stimulated by one of several triggers, the complement system can be activated to initiate the inflammatory response, recruit immune cells to the site of infection, mediate opsonisation of pathogens and activate cell killing through the formation of the membrane attack complex (MAC) in 
the outer membrane of microorganisms (Merchant and Britton 2006). Both mechanisms have been described and shown to be very well developed in organisms from reptiles to birds and mammals (Beck and Habicht 1996; Diamond et al. 2009; Treffers et al. 2005). Serum complement is composed of proteins which are heat-labile and can be inactivated by moderate heat treatment $\left(55^{\circ} \mathrm{C}\right.$ for 30 minutes $)$. In contrast, AMPs are generally heat-stable at moderate temperatures, allowing for an in vitro method of differentiating between the two mechanisms of serum AMA.

Salmonellosis is an important zoonotic disease resulting in significant morbidity in populations of wild reptiles, birds and mammals throughout the world. Herpetofaunal species have often been implicated as transmitters of Salmonella, and reptile-associated salmonellosis is a significant threat to the health of humans, domestic animals and other wildlife (Mader 2006). Salmonella has been isolated from the intestinal flora of a wide variety of reptiles including, broad-snouted caiman (Caiman latirostris) (Uhart et al. 2011), crocodiles (Manolis et al. 1991), coastal bearded dragons (Pogona barbata) and blue-tongue skinks (Tiliqua scincoides) (Kikillus et al. 2011). Clinical signs of infection are uncommon in reptiles, and most infected animals act as asymptomatic carriers of the disease (Johnson - Delaney 1996). However, stressors resulting from environmental changes such as pollution and dietary changes or from management practices such as translocations, which require periods of transportation and captivity, can compromise the immune response and induce clinical disease (Quinn et al. 1994).

Many species have innate immune responses that demonstrate AMA against Grampositive and Gram-negative bacteria including Salmonella. Members of the Crocodilia order have been studied extensively and most show efficient AMA (Ferronato et al. 2009; Merchant and Britton 2006; Merchant et al. 2003). For example, blood from the American alligator (Alligator mississippiensis) has shown resistance activity against bacteria (Merchant et al. 2003), amoebae (Merchant et al. 2004), viruses (Merchant et al. 2005) and fungi (Merchant and Britton 2006). It is unclear whether other species of reptiles possess a similar defence arsenal, as studies to date have been limited (Major et al. 2011). Much of the AMA seen in these species has been attributed to complementmediated immunity as moderate heat treatment results in a significant reduction if not complete loss of activity (Merchant and Britton 2006). 
In addition to complement-mediated immunity AMPs play an important role in immune defence against Salmonella. A small, cationic protein similar in structure to the antimicrobial peptide $\beta$-defensin has been isolated from the egg white of loggerhead sea turtle (Caretta caretta) eggs. This protein exhibited strong AMA against Escherichia coli and Salmonella Typhimurium as well as antiviral activity against the Chandipura virus (Chattopadhyay et al. 2006). A small protein with antibacterial activity against Gram-negative and Gram-positive bacteria, including S. Typhi and E. coli, has also been isolated from the serum of the Siamese crocodile (Crocodylus siamensis) (Preecharram et al. 2008). In this study I include two common enteric bacterial species, Citrobacter koseri and E. coli. Although these species are extremely closely related to Salmonella, they do not share the same pathogenicity and are far more ubiquitous within the environment. Both E.coli and C. koseri have been observed in bacterial growth from tuatara cloacal swabs (personal observation; Gartrell et al. 2006).

Tuatara (Sphenodon punctatus) are medium sized reptiles and the only survivors of an ancient order of reptiles, Rhynchocephalia (Benton 2000). Once widespread across New Zealand (Holdaway and Worthy 1997) their range has declined since the arrival of humans circa 800 years ago. They are now restricted to offshore islands around New Zealand. Tuatara are evolutionarily distinct reptiles that diverged from their sister group, the squamates, approximately 230 million years ago (Rest et al., 2003). Very little is known about the immune response of this species. A number of studies have been conducted on their acquired immunity (Burnham et al. 2005; Marchalonis et al. 1969) but considerably less is known about innate immunity in this species (La Flamme et al. 2010). Despite these long-lived reptiles (>80yrs) being extensively tested, there has only been one reported case of Salmonella in a wild tuatara (tuatara was found deceased and Salmonella identified post-mortem; K. McInnes, Department of Conservation, personal communication) and it has never been isolated from captive tuatara (Gartrell et al. 2006; Gartrell et al. 2007). Salmonella has however been isolated from native lizards found living in close proximity to this species (Middleton et al. 2010) and in soil samples collected from inside tuatara burrows (Chapter Two). These findings raise the question of whether tuatara are innately resistant to Salmonella.

Seasonal variation in immune response is seen in a variety of vertebrate species (Nelson and Demas 2004, Altizer et al. 2006; Zimmerman et al. 2010). Previous studies have 
found that seasonal variation in the distribution and function of leukocytes is greater in reptiles than in any other animal group, but the significance of these changes is clouded by the uncertainty concerning their functions in reptiles (Nelson and Demas 2004). Tuatara are cold-adapted ectotherms that prefer lower temperatures $\left(17-21^{\circ} \mathrm{C}\right)$ than many other extant reptilian orders (Wilson and Lee 1970, Saint Girons 1980, Besson and Cree 2011). They are also amongst the few nocturnal reptiles adapted to live in cool temperate zones. It has therefore been proposed that seasonal variation in immune response among tuatara may be different to those of many other ectothermic vertebrates (Burnham et al. 2006). Burnham et al. (2005) assessed T cell responses in captive tuatara and found no clear seasonal effect between winter and spring. In contrast La Flamme et al. (2010) investigated the response of tuatara leukocytes to toll-like receptor agonists and found a clear increase in the responses of leukocytes isolated in summer compared to winter.

The study of wildlife immunology is of major importance since many diseases can arise secondarily as a result of a compromised immune system. Environmental contamination has been associated with increased incidence of immuno-suppression on birds, reptiles and marine mammals (Ferronato et al. 2009). Translocations are a common management strategy employed to increase the numbers and genetic diversity within species. Translocations require animals to be exposed to such stressors as handling, transportation and captivity, before being released at the new site. These stressors may compromise the immune response and potentially expose the animals to novel pathogens arising from the human handlers, other animals held in the captive facilities or to novel pathogens present at the release site. Likewise, translocated animals can introduce novel pathogens to their release site (Woodford and Rossiter 1994).

The aim of this study was to investigate the antibacterial properties of tuatara serum against S. Saintpaul, E. coli and C. koseri, and these properties were compared with the sera of coastal bearded dragon (Pogona barbata), Australian water dragon (Physignathus lesuerii), mouse (Mus musculus) and donkey (Equus asinus).

Additionally, I examined the effects of season and sex on the innate immune response of captive and wild populations of these ectothermic, sexually dimorphic species. Investigating the immune function of tuatara allows us to understand the potential 
impacts that common reptilian pathogens may have on this organism. Because tuatara are the last survivors of an ancient lineage, elucidating their immune function also provides us with a greater understanding of the evolution and functionality of innate immunity in higher vertebrates.

\subsection{Methods}

\subsubsection{Sample collection}

Serum samples were obtained from 37 wild tuatara on Stephens Island, New Zealand. Samples were collected on three sampling occasions (March 2010, January 2011 and March 2011) and 11 of the 37 individuals were recaptured on more than one of these occasions (Table 4.1). Ideally samples would have been collected in every season (spring-winter) and the same wild tuatara would have been caught in each sampling trip. However, previous research has found that low numbers of tuatara are caught on Stephens Island during winter ( $\mathrm{n}=8$ in June) (Godfrey et al. 2008) and therefore in order to maximise the opportunity for detecting Salmonella if it was present I sampled only during the warmer seasons when tuatara are more easily captured. In order to further maximise the potential for identifying Salmonella in tuatara I collected samples from 29 tuatara at seven captive facilities throughout New Zealand (Table 4.2). Due to difficulties catching tuatara during winter, serum samples were collected from five captive tuatara in July 2010 and from two captive tuatara in July 2011 (Table 4.2). When comparing wild and captive tuatara sera samples it should be noted that captive tuatara may differ from their wild counterparts in body mass, hormonal cycles and routes of exposure to Salmonella, all of which could influence the likelihood and potential patterns of Salmonella carriage. Serum was also collected from captive coastal bearded dragons and Australian water dragons in summer 2010. Many of these dragons had been identified as carriers of Salmonella by microbial culture of cloacal swabs. Blood samples $(0.1-1 \mathrm{~mL})$ were drawn from the caudal vein/artery and the serum was separated via centrifugation. Blood was also collected from normal male $\mathrm{BALB} / \mathrm{c}$ mice aged 18-21 weeks via cardiac puncture. Commercially available donkey serum was obtained from Sigma (St Louis, MO, USA). Sera from all species were stored at $-20^{\circ} \mathrm{C}$ and thawed immediately before experiments. 
A number of physical characteristics such as sex, mass and snout-to-vent length (SVL) were recorded from each tuatara sampled, and the number of mites and ticks on the body were counted. Mites and ticks are removed from captive tuatara as part of management protocols, therefore ectoparasites were not recorded in these populations. Individual tuatara were assessed for body condition by dividing the log mass ( $\mathrm{g}$ ) by the $\log$ SVL $(\mathrm{mm})$ to correct for variation in length.

Table 4.1: Frequency of tuatara new captures and recaptures in the three habitat types; Forest (F), Paddock 1 (P1) and Paddock 2 (P2) on Stephens Island, New Zealand. The total sample size per season is shown by $\mathrm{N}$

\begin{tabular}{|c|c|c|c|c|c|c|c|c|c|c|}
\hline \multirow[b]{2}{*}{ Trip } & \multicolumn{4}{|c|}{ New captures } & \multicolumn{4}{|c|}{ Recaptures } & \multirow[b]{2}{*}{ Males } & \multirow[b]{2}{*}{ Females } \\
\hline & $\mathbf{F}$ & P1 & $\mathbf{P 2}$ & $\mathbf{N}$ & $\mathbf{B}$ & P1 & $\mathbf{P 2}$ & $\mathbf{N}$ & & \\
\hline March 2010 & 9 & 3 & 1 & 13 & 0 & 0 & 0 & 0 & 8 & 5 \\
\hline January 2011 & 6 & 3 & 0 & 9 & 4 & 1 & 2 & 7 & 9 & 7 \\
\hline March 2011 & 9 & 3 & 3 & 15 & 3 & 1 & 0 & 4 & 17 & 2 \\
\hline Total & 24 & 9 & 4 & 37 & 7 & 2 & 3 & 11 & 34 & 14 \\
\hline
\end{tabular}


Table 4.2: Frequency of captive tuatara sampling at seven captive facilities (A-G) throughout New Zealand from October 2009-July 2011. The total number of tuatara sampled at any given facility is shown by $\mathrm{N}$ and the number of re-captures each season follows.

\begin{tabular}{lcccclllllllll}
\hline & & & & & October & January & April & July & October & January & April & July \\
Facilities & Males & Females & SA $^{1}$ & N & 2009 & 2010 & 2010 & 2010 & 2010 & 2011 & 2011 & 2011 \\
\hline A & 0 & 4 & 0 & 4 & 0 & 0 & 0 & 0 & 4 & 0 & 0 & 0 \\
B & 1 & 1 & 1 & 3 & 0 & 2 & 0 & 0 & 3 & 1 & 0 & 0 \\
C & 3 & 4 & 0 & 7 & 2 & 4 & 4 & 0 & 1 & 3 & 2 & 0 \\
D & 1 & 2 & 0 & 3 & 3 & 2 & 2 & 3 & 2 & 3 & 3 & 2 \\
E & 1 & 1 & 2 & 4 & 4 & 2 & 4 & 2 & 3 & 3 & 2 & 0 \\
F & 2 & 1 & 0 & 3 & 2 & 1 & 3 & 0 & 1 & 0 & 1 & 0 \\
G & 1 & 0 & 3 & 4 & 0 & 4 & 0 & 0 & 0 & 0 & 0 & 0 \\
Total & 9 & 13 & 6 & 28 & 11 & 15 & 13 & 5 & 14 & 10 & 8 & 2 \\
\hline
\end{tabular}

${ }^{1}$ Sub-adult. 


\subsubsection{Bacterial cultures}

Cultures of $S$. Saintpaul, E. coli and C. koseri were maintained on nutrient agar slants at $4^{\circ} \mathrm{C}$ and transferred fortnightly. The day before an experiment, a $4 \mathrm{ml}$ Luria-Bertani (LB) liquid culture was inoculated from the slant and grown in triplicate overnight at $37^{\circ} \mathrm{C}$. Fifty micro-litres of this early $\log$-phase culture were removed and transferred to $3 \mathrm{ml}$ of fresh LB media. The culture was allowed to recover at $37^{\circ} \mathrm{C}$ for one hour in a shaking incubator. After incubation the cells were centrifuged (4000rpm for 20minutes at $4^{\circ} \mathrm{C}$ ) and re-suspended in fresh LB media (Bugla-Płoskońska et al. 2009); optical density (OD) was measured at 600nm and samples were diluted to approximately 0.2 OD.

In 96-well non-treated tissue culture plates (BD Bioscience, Franklin Lakes, NJ, USA) $100 \mu \mathrm{L}$ of the $0.2 \mathrm{OD}$ bacterial cultures were added to $100 \mu \mathrm{L}$ of sterile physiological saline $(0.9 \% \mathrm{NaCl})$. These samples were set-up in triplicate with each replicate being made up of a different overnight broth of the given bacteria and grown at both $25^{\circ} \mathrm{C}$ and $37^{\circ} \mathrm{C}$ with gentle rotation. Samples were checked and optical density was measured at $9,12,15,17$ and 19 hours. Incubation periods that resulted in a mean optical density of approximately 0.6 OD across the three replicates were chosen as the incubation period for all future experiments. Tuatara samples were incubated at $25^{\circ} \mathrm{C}$ (as this is within the normal body temperature range of this species), and samples were incubated for 17 hours to achieve a mean optical density of 0.6. Donkey and mouse samples were incubated at the normal mammalian body temperature of $37^{\circ} \mathrm{C}$ for 15 hours. The preferred body temperatures of Australian water dragons and coastal bearded dragons are $30^{\circ} \mathrm{C}$ (Dawson 1975) and $33^{\circ} \mathrm{C}$ (Melville and Schulte II 2001) respectively, consequently sera from these two species were incubated at $30^{\circ} \mathrm{C}$ for 15 hours.

\subsubsection{Serological assays}

All assays were carried out in 96-well non-tissue culture plates. Samples of bacteria were set-up in triplicate using three overnight broths per bacterium. In each assay 100 $\mu \mathrm{L}$ of bacterial suspension was added to $100 \mu \mathrm{L}$ of serum diluted to the requirements of the assay (diluted with $0.9 \% \mathrm{NaCl}$ ). Control wells containing $100 \mu \mathrm{L}$ of bacteria and $100 \mu \mathrm{l}$ of $0.9 \% \mathrm{NaCl}$ were also included in triplicate. Plates were incubated at $25^{\circ} \mathrm{C}, 30^{\circ}$ 
and $37^{\circ} \mathrm{C}$ depending on the species of interest. The optical density of each assay was measured at 0 and 19 hours of incubation. Percentage of bacteria killed was calculated

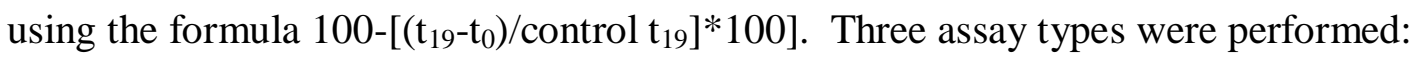

\section{Colony forming units and optical densities}

Ten tuatara samples were selected at random and colony forming units per $\mathrm{ml}(\mathrm{CFU} / \mathrm{ml})$ were calculated alongside optical density for comparison of techniques. An aliquot was collected from each sample at 0 and 19 hours, diluted and cultured on nutrient agar plates overnight at $25^{\circ} \mathrm{C}$. I did not find any statistically significant difference in the AMA of tuatara serum against $S$. Saintpaul $\left(\mathrm{F}_{1}=1.409, P=0.251\right)$, E. coli $\left(\mathrm{F}_{1}=3.119\right.$, $P=0.094)$ or $C$. koseri $\left(\mathrm{F}_{1}=2.582, P=0.129\right)$ when tested using CFU or OD (Appendix B). Therefore, optical densities are recorded for all remaining tests.

\section{Concentration-dependent anti-microbial properties}

Sera from mouse, donkey, coastal bearded dragon, Australian water dragon and one captive adult male tuatara were tested at concentrations of $12.5 \%, 25 \%, 50 \%, 75 \%$ and $100 \%$ serum. Due to low quantities of available sera from coastal bearded dragons and Australian water dragons the concentration dependent AMA of these species were only tested against $S$. Saintpaul. The male tuatara was selected as previous studies had shown the serum from this male recognised Salmonella antigen in vitro (Chapter Three). From this study a serum dilution of $25 \%$ was chosen for all future assays as it was a mid-range point on the graph and would allow me to see deviation from this point in either direction. This dilution also optimised the amount of available sera for testing.

\section{Effects of de-complemented sera and protein size exclusion}

Thirty tuatara sera samples (15 captive and 15 wild) were diluted to $25 \%$ and analysed using both decomplemented $\left(55^{\circ} \mathrm{C}\right.$ for 30 minutes) and non-heat-treated sera. Sera from five male mice, five coastal bearded dragons and four Australian water dragons were tested with both heat-treated and non-heat-treated sera. Pooled commercially available donkey serum was also analysed.

Sera samples from three tuatara (one captive and two wild) were diluted to $25 \%$ and filtered through a $10 \mathrm{kDa}$ Nanosep centrifugal filter (Pall Corporation, Port Washington, 
New York 1150, USA). Assays were set up using normal sera, heat-treated sera and size-filtered sera. Size exclusion assays were performed for S. Saintpaul only.

\section{Assay of individual tuatara}

All available captive $(n=67)$ and wild tuatara $(n=48)$ sera samples (Table 4.1 and 4.2) were thawed and diluted to $25 \%$. Sera samples were added to bacterial preparations and incubated with gentle rotation. The percentage of bacteria killed was calculated.

\subsubsection{Statistics and controls}

Linear regression models within the package lme 4 of the statistical programme $\mathrm{R}$ were used to assess trends in tuatara serum AMA against $S$. Saintpaul, E. coli and C. koseri. Individual tuatara were included as random effects in each model to account for resampling of tuatara. Akaike's information criterion adjusted for small sample size (AICc; Burnham and Anderson 2002), defined as $\mathrm{AIC}_{\mathrm{c}}=-2 \mathrm{x} \log$-likelihood $+\{2 \mathrm{~K}(\mathrm{~K}=1)$ / (n-K-1)\}, where $\mathrm{K}$ is the number of parameters in the model and $\mathrm{n}$ the number of observations, was used to contrast and assess strength of evidence for competing models. The use of AIC in model selection provided a measure of the relative goodness-of-fit for each statistical model, and also included a penalty for the number of estimated parameters to avoid over-fitting (Burnham and Anderson 2002). The model with the smallest $\mathrm{AIC}_{\mathrm{c}}$ value was selected as the best model among those being compared. Models within two units (i.e. $\Delta \mathrm{AIC}_{\mathrm{c}}<2$ ) of the best model were considered equally and most substantially supported, while models within four to seven units received considerably less support, and greater than ten units essentially no support (Burnham and Anderson 2002). Examining the Akaike weights $\left(\omega_{\mathrm{i}}\right)\left[\omega_{\mathrm{i}}=\exp (-0.5 \mathrm{x}\right.$ $\left.\Delta \mathrm{AIC}_{\mathrm{c}} / \Sigma \exp \left(-0.5 \mathrm{x} \Delta \mathrm{AIC}_{\mathrm{c}}\right)\right)$, where $\Delta \mathrm{AIC}_{\mathrm{c}}$ is the difference in $\mathrm{AIC}_{\mathrm{c}}$ values between the best performing model and the model of interest] further quantified the plausibility of each model as being the best model given the data (Burnham and Anderson 2002). Eighty three models were tested for wild tuatara and 37 were tested for captive tuatara (Appendix C). A number of individual characteristics were included as variables in the model including sex, body condition, SVL and mite and tick loads. The habitat or captive facility where the tuatara were sampled and season captured were also included as factors in the models. Body condition and SVL are nested measurements and were therefore not tested within the same model. Mite and tick loads were only included in the wild tuatara models as these ectoparasites are not found on captive tuatara due to 
management practices. Power within the top model was insufficient to be able to investigate interaction effects between the factors. Interaction effects are therefore investigated using generalised linear models and Pearson's correlation tests.

I tested for a linear relationship between the percentages of bacteria killed for pairs of the three test bacteria. Pearson's correlation was used and statistical significance was set to 0.05 . Finally I tested for a linear association between anti-microbial activity and antibody recognition data, obtained in Chapter Three, within individuals subjected to both assays $(n=94)$. Analyses were carried out using the statistical program R (R Core Development Team, 2010) and SPSS (SPSS, Inc., Chicago, IL). Box plots portray the range, lower quartile, upper quartile and mean and stars represent outliers in the data. Bar graphs represent means \pm 1 standard error (SE).

\subsection{Results}

\subsubsection{Tuatara anti-microbial activity against S. Saintpaul, E. coli and $C$. koseri}

I investigated the anti-microbial activity of 115 wild and captive tuatara sera samples against S. Saintpaul, E. coli and C. koseri and compared the strength of their response against these three common gastrointestinal pathogens. This comparison included tuatara captured and sampled in differing seasons. Tuatara serum shows AMA against the three bacterial species tested in this study. The highest anti-microbial activity is seen against $E$. coli with a mean of $60.4 \%(\mathrm{SE} \pm 26.03)$ of bacteria killed $\left(\mathrm{F}_{2}=3.1\right.$, $P<0.001)$. Serum AMA against $S$. Saintpaul shows an average of $45.1 \%(\mathrm{SE} \pm 2.6)$ of bacteria killed, higher than the 34.2\% (SE \pm 2.2$)$ of $C$. koseri $\left(\mathrm{F}_{1}=6.9, P=0.009\right)$ (Figure 4.1).

\subsubsection{Concentration-dependent antibacterial properties of serum}

In order to understand the dose dependence of the serum anti-microbial activity I investigated the bacterial killing capacity of tuatara, coastal bearded dragon, Australian water dragon, mouse and donkey sera at concentrations ranging from $12.5 \%$ to $100 \%$. Tuatara serum showed concentration-dependent increases in AMA against the three 
bacterial strains investigated (Figure 4.2). For all three test bacteria the AMA of tuatara serum ranged from approximately $40 \%$ of bacteria killed with the lowest concentration of serum $(12.5 \%)$ through to $80-90 \%$ of bacteria killed with $100 \%$ serum. Antimicrobial activity of tuatara serum against $S$. Saintpaul was similar to that of coastal bearded dragons and Australian water dragons when used neat; however, the activity in tuatara serum lost potency more quickly upon dilution than the other two reptilian species tested. Overall the three reptilian species investigated showed markedly higher sera AMA against $S$. Saintpaul than the mammalian species investigated $\left(\mathrm{F}_{4}=930.68\right.$, $p<0.001$; Figure 4.2A).

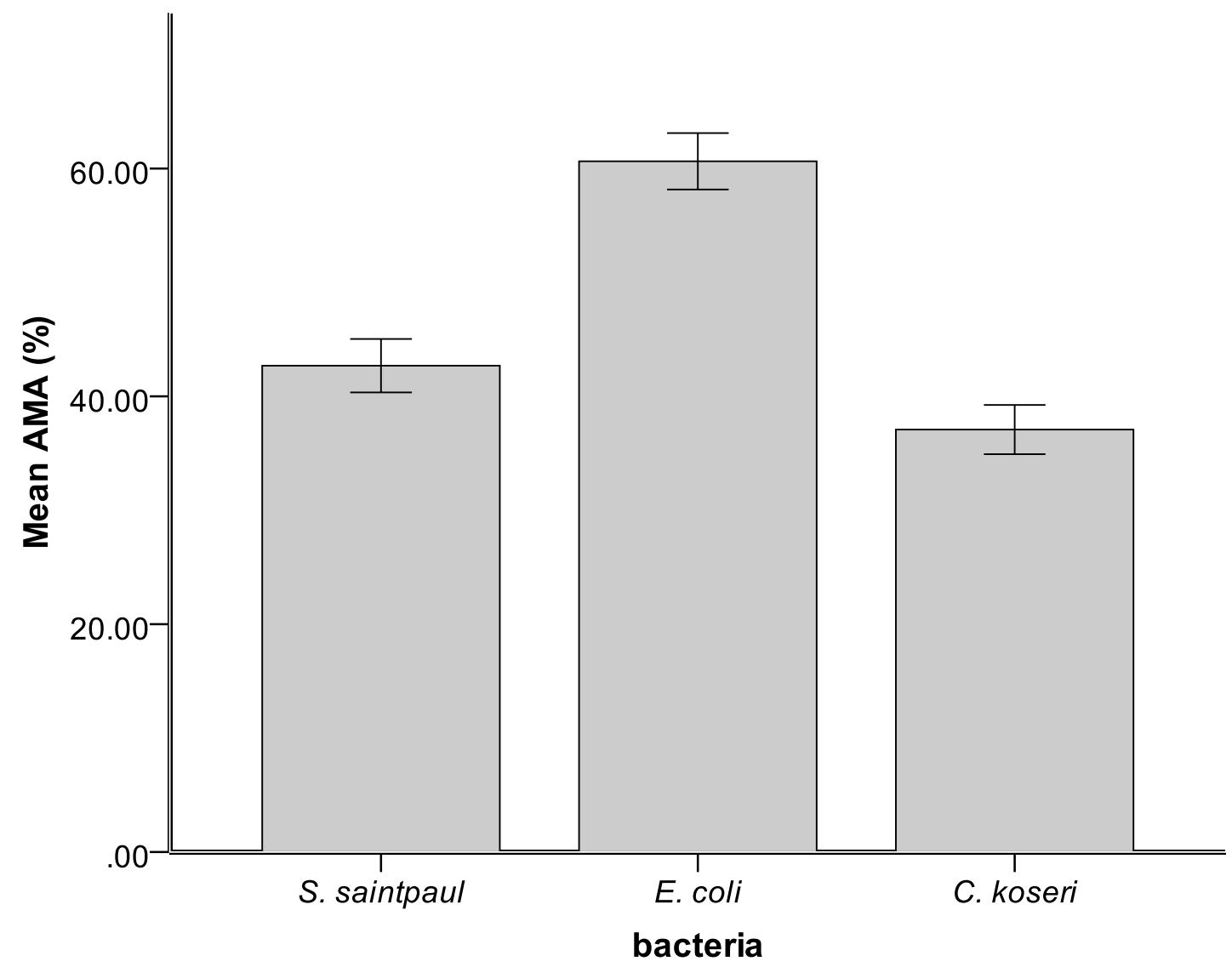

Figure 4.1: Anti-microbial activity of captive and wild tuatara serum against three common gastrointestinal pathogens, S. Saintpaul, E. coli and C. koseri. Tuatara show higher AMA against $E$. coli than $S$. Saintpaul and have the lowest activity against $C$. koseri. $\mathrm{N}=115$. 
A.

B.

C.
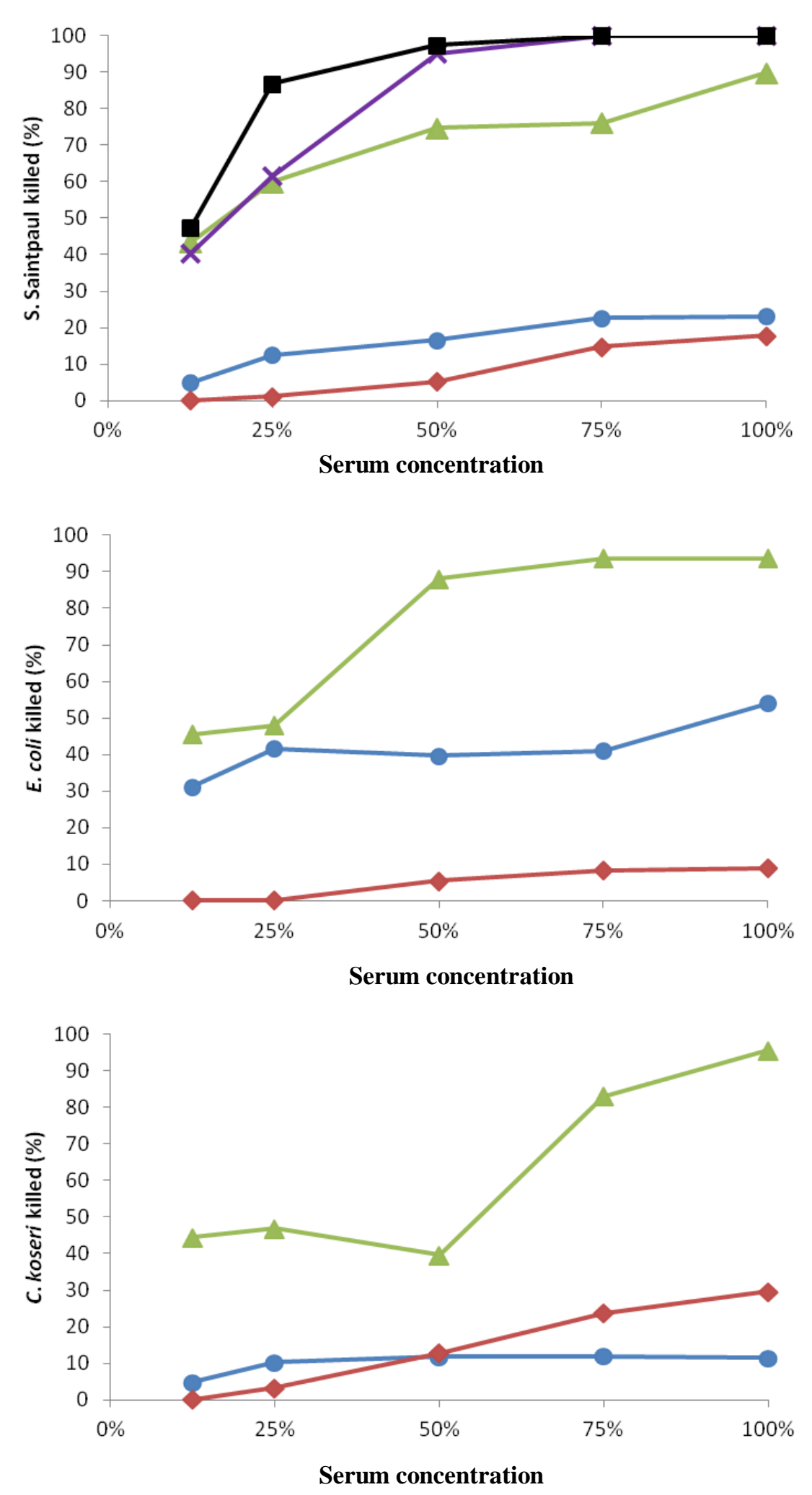

Figure 4.2: Concentration-dependent increases in antibacterial activity of tuatara $(S$. punctatus; $\triangle)$, coastal bearded dragon (P. barbata; $\times)$, Australian water dragon $(P$. lesuerii; - ), donkey (๑) and mouse (M. musculus; $\bullet$ ) sera against $S$. Saintpaul(A), E. coli $(\mathbf{B})$ and $C$. koseri $(\mathbf{C})$. Each data point represents the mean bacteria killed in three replicates. $\mathrm{N}=3$. 


\subsubsection{Effects of decomplemented sera and protein size exclusion}

Because serum anti-microbial activity may be mediated by anti-microbial peptides such as defensins or by complement, the serum samples were heat-treated, which has been shown to abolish complement activity but not that of anti-microbial peptides. No significant effect was found when tuatara samples were heat-treated to $55^{\circ} \mathrm{C}$ as compared to non-heat-treated samples. Decomplemented serum killed $28.9 \%$ of $S$. Saintpaul (SE \pm 27.1 ), 52.2\% (SE \pm 27.6 ) of E. coli and 21.3\% (SE \pm 22.8 ) of C . koseri, and non-heat-treated serum killed 32.7\% (SE \pm 24.1 ), 60.9\% (SE \pm 25.1$)$ and 29.9\% $(\mathrm{SE} \pm 22.8)$ of these bacteria respectively. Moderate heat treatment of donkey and mouse serum also caused no significant reduction in AMA for any of the three test species (Figure 4.4). In contrast, heat treating serum from coastal bearded dragons caused a significant reduction in anti-microbial activity $\left(S\right.$. Saintpaul $\mathrm{F}_{1,4}=19.5$, $P=0.002)$ and heat-treating Australian water dragon sera resulted in the complete loss of AMA ( $S$. Saintpaul $F_{1,3}=2543, P<0.001$; Figure 4.3) suggesting that the AMA of coastal bearded dragon and Australian water dragon sera is complement mediated while the AMA of tuatara, mouse and donkey serum appears to be mediated by heat stable proteins such as anti-microbial peptides.

To more fully determine if the anti-microbial activity exhibited by tuatara sera was due to the presence of small peptides $(<10 \mathrm{kDa})$, the serum samples were filtered through a $10 \mathrm{kDa}$ membrane to remove all proteins greater than $10 \mathrm{kDa}$. Because tuatara serum showed high levels of anti-microbial activity against $S$. Saintpaul even when filtered through a $10 \mathrm{kDa}$ size exclusion filter my results suggest that the anti-microbial activity of tuatara serum is peptide-mediated (Figure 4.4). While filtering did reduce the antimicrobial activity of tuatara serum as compared with untreated or decomplemented serum, this reduction was not statistically significant $\left(\mathrm{F}_{2,8}=2.414, P=0.170\right.$, Figure 4.4). Together these results indicate that tuatara have significant anti-microbial defences in their blood and this anti-microbial activity appears to be in large part peptide-mediated although the possibility of a larger (> $10 \mathrm{kDa})$, non heat-labile protein contributing cannot be ruled out. 

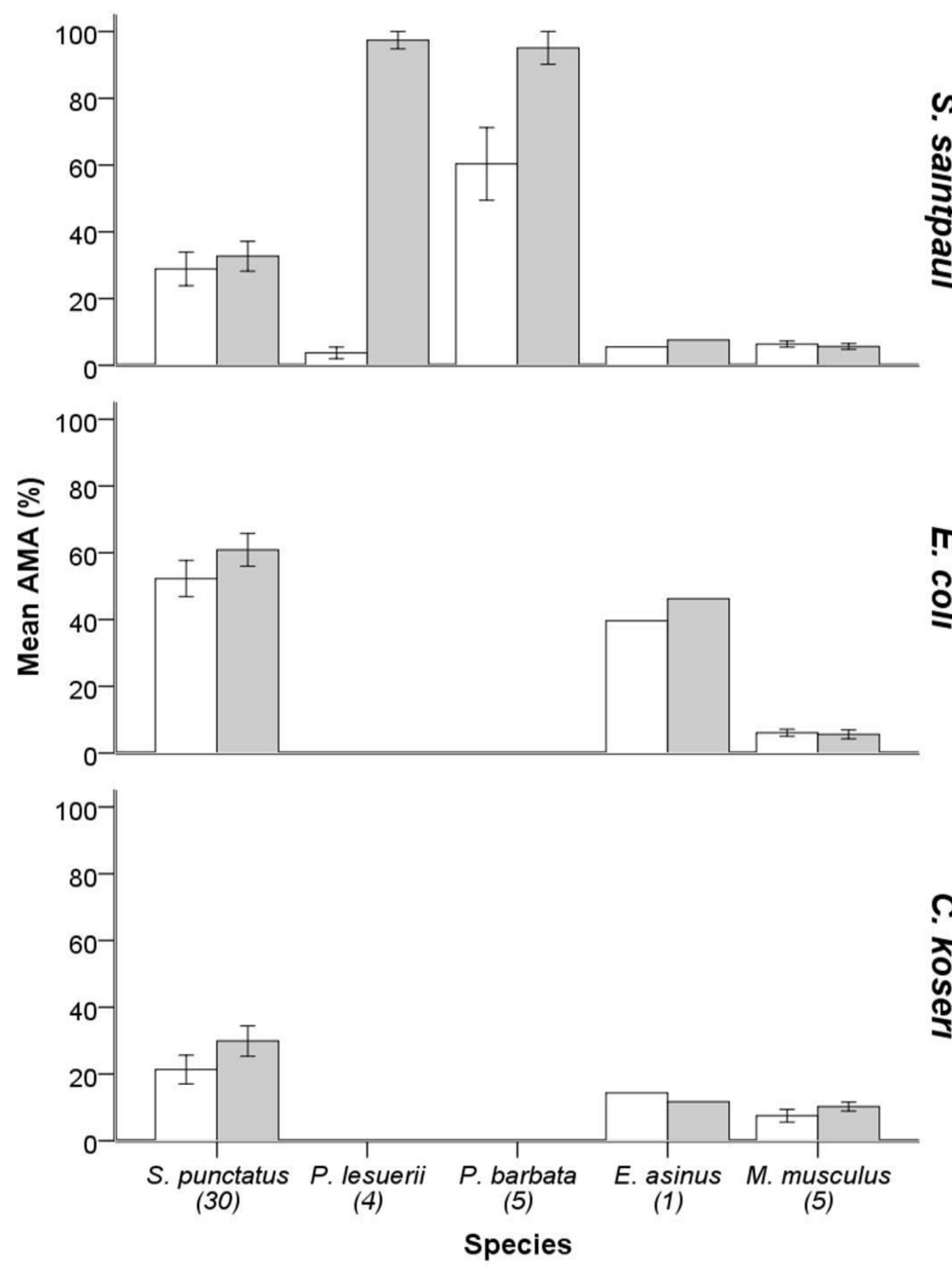

Figure 4.3: Percentage of bacteria killed by normal (grey) and decomplemented (white; heated to $55^{\circ} \mathrm{C}$ for 30 minutes) serum of tuatara (S. punctatus), donkey (E. asinus), mouse (M. musculus), coastal bearded dragon (P. barbata) and Australian water dragon (P. lesuerii). The AMA of coastal bearded dragons and Australian water dragons was investigated against $S$. Saintpaul only. 


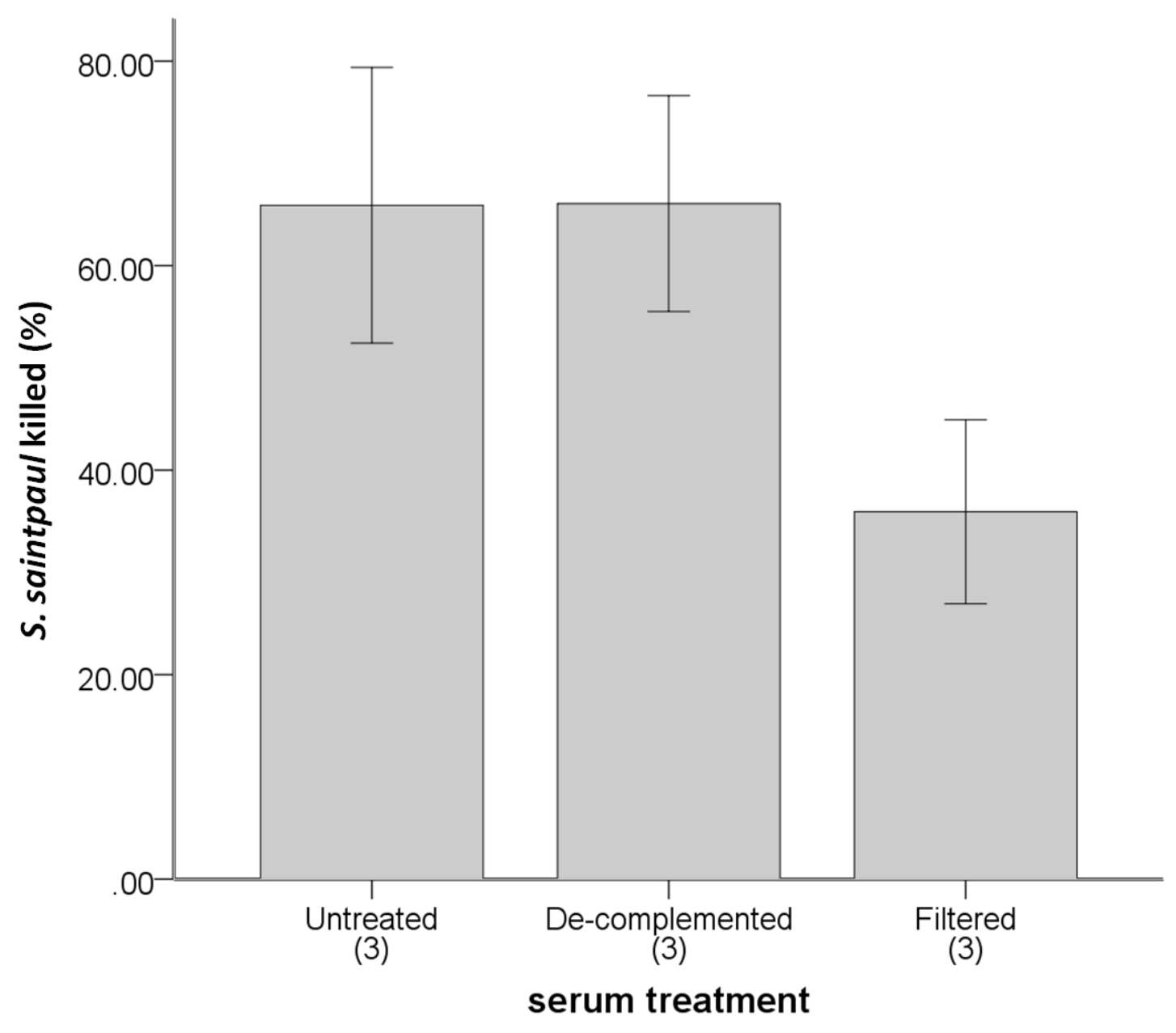

Figure 4.4: The anti-microbial activity of captive $(\mathrm{N}=2)$ and wild $(\mathrm{N}=1)$ tuatara serum. Each serum sample was separated into three and either left untreated, heat-treated to $55^{\circ} \mathrm{C}$ for 30 minutes (decomplemented), or filtered through a $10 \mathrm{kDa}$ size exclusion filter. There is no statistically significant difference in serum anti-microbial activity across the three treatments $\left(\mathrm{F}_{2,8}=2.414, P=0.170\right)$.

4.4.4 Effects of season, sex and body condition on the immune response of tuatara

Season, location, sex and condition were significant main effects identified by AIC model selection for the three bacterial species tested $\left(S\right.$. Saintpaul $\triangle \mathrm{AIC}_{\mathrm{c}}=0, \omega_{\mathrm{i}}=0.97 ; E$. coli $\Delta \mathrm{AIC}_{\mathrm{c}}=0, \omega_{\mathrm{i}}=0.97 ;$ C. koseri $\Delta \mathrm{AIC}_{\mathrm{c}}=0, \omega_{\mathrm{i}}=0.97$; Table 4.3). Models for $S$.

Saintpaul, E. coli and C. koseri tested against serum from captive tuatara revealed very similar results (Table 4.3). Most hypotheses under examination for the AMA of the 
three bacterial species were not supported (i.e. $\Delta \mathrm{AIC}_{\mathrm{c}}>10$; Appendix C). Those models of serum activity from captive animals which incorporated only a single variable performed particularly poorly (Appendix C). Models within 10 units of the best model $\left(\Delta \mathrm{AIC}_{\mathrm{c}}<10\right)$ are displayed (Table 4.3). Closer examination showed that, despite being the most supported models the variables do not significantly affect the AMA of captive tuatara serum against $S$. Saintpaul or E. coli (Figures 4.5-4.7). Season was shown to significantly affect anti-microbial activity of captive tuatara serum against $C$. koseri with samples obtained during winter showing much higher activity than those collected during other seasons (Figure 4.7).

The majority of models for the AMA of serum from wild tuatara were also not supported (i.e. $\Delta \mathrm{AIC}_{\mathrm{c}}>10$; Appendix $\mathrm{C}$ ). As I found with the captive models, wild models which included the variables season, location, sex and condition received the most support $\left(S\right.$. Saintpaul, $\Delta \mathrm{AIC}_{\mathrm{c}}=0, \omega_{\mathrm{i}}=0.66 ;$ E. coli $\Delta \mathrm{AIC}_{\mathrm{c}}=0, \omega_{\mathrm{i}}=0.75 ;$ C. koseri $\Delta \mathrm{AIC}_{\mathrm{c}}=0, \omega_{\mathrm{i}}=0.59$; table 4.4). However, the weights for these models were low for all three test bacteria indicating that they explain only a small amount of the variation within the data. Those models which included the factors mites and ticks in the same model generally received very little support as did models which included a single variable (Appendix C).

The mean AMA of captive and wild tuatara serum was not significantly different for $S$. Saintpaul $\left(\mathrm{F}_{1}=1.5, P=0.226\right)$ or $E$. coli $\left(\mathrm{F}_{1}=0.1, P=0.752\right)$. In contrast, captive tuatara serum killed significantly more $C$. koseri (44.6\% S.E. \pm 22.5$)$ than wild tuatara serum $(27.1 \%$ S.E. \pm 20.5$)\left(\mathrm{F}_{1}=18.1, P=0.001\right)$. A very small amount of variation is shared between bacterial species $(<15 \%)\left(\mathrm{R}^{2}=0.044, P=0.025\right.$; Figure 4.8A) and $C$. koseri $\left(\mathrm{R}^{2}=0.159, P<0.001\right.$; Figure $\left.4.8 \mathrm{~B}\right)$. Likewise those tuatara with serum that killed higher amounts of $E$. coli also killed high levels of $C$. koseri $\left(\mathrm{R}^{2}=0.123, P<0.001\right.$; Figure 4.8C). 


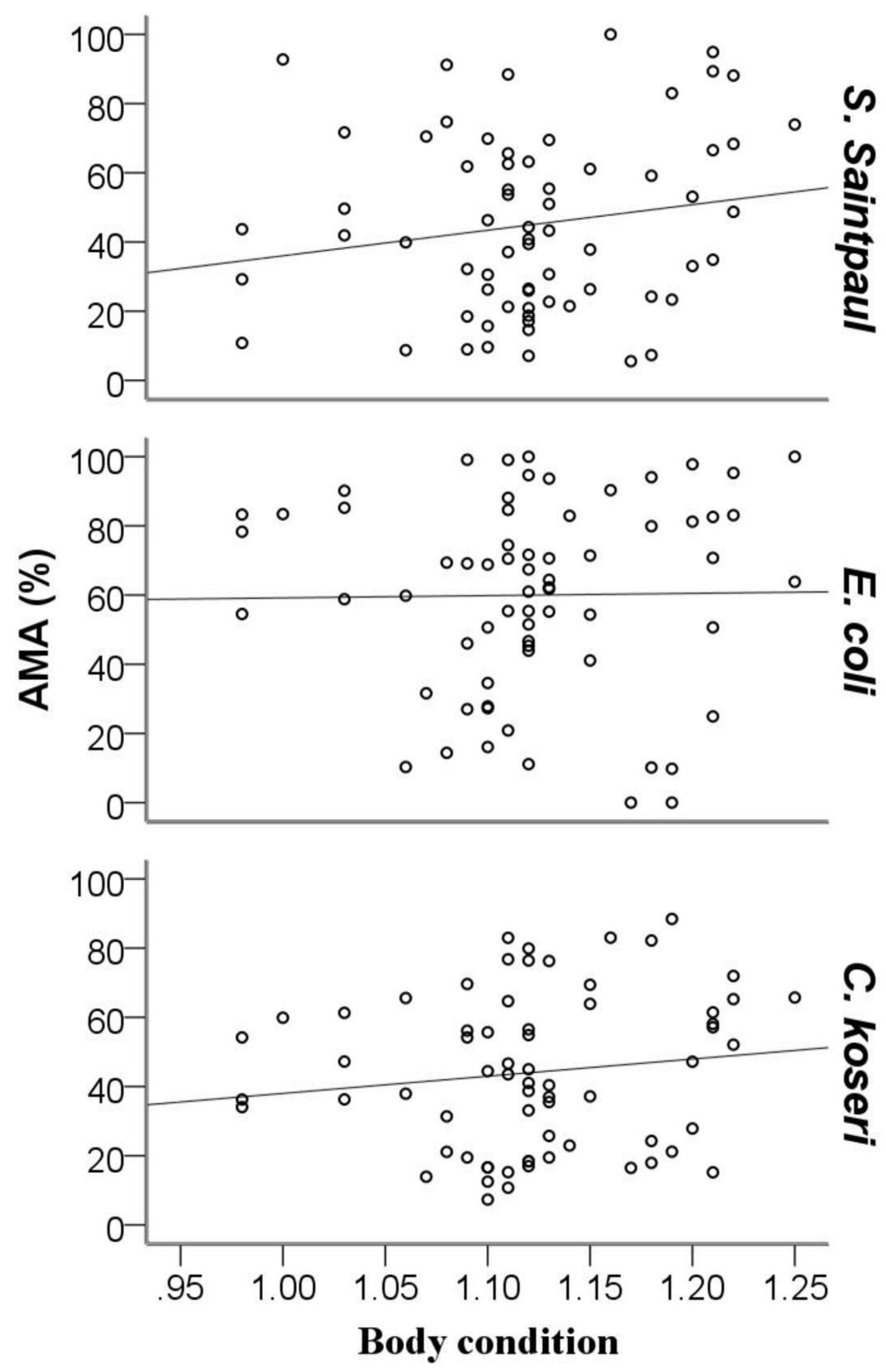

Figure 4.5: Body condition does not have a significant effect on the sera AMA of captive tuatara serum against $S$. Saintpaul $\left(\mathrm{R}^{2}=0.03, P=0.164\right)$, E. coli $\left(\mathrm{R}^{2}=0.0002\right.$, $P=0.908)$ or $C$. koseri $\left(\mathrm{R}^{2}=0.018, P=0.281\right)(\mathrm{N}=67)$. 
Table 4.3: The outcomes of candidate models for sera of captive tuatara within 10 Akaike units of the best model $(\Delta$ AICc $<10)$. Data on all models tested is shown in appendix $\mathrm{C}$. The variables included in each model, number of parameters $(\mathrm{K}), \mathrm{AIC}_{\mathrm{c}} \mathrm{values}, \mathrm{AIC}_{\mathrm{c}}$ differences $(\Delta \mathrm{AIC})$, and Akaike weight $\left(\omega_{\mathrm{i}}\right)$ are shown for each species of bacteria tested (S. Saintpaul, E. coli and C. koseri). Models are ranked from the smallest to largest $\mathrm{AIC}_{\mathrm{c}}$ value with the best supported model (confidence set, i.e. $\sum \omega>0.95$ ) shown in bold.

\begin{tabular}{lcrrrrrrrrr}
\hline & \multicolumn{4}{c}{ S. Saintpaul } & \multicolumn{3}{c}{ E. coli } & \multicolumn{3}{c}{ C. koseri } \\
Variables included in model & $\mathrm{K}$ & $\mathrm{AIC}_{\mathrm{c}}$ & $\Delta \mathrm{AIC}_{\mathrm{c}}$ & $\omega_{\mathrm{i}}$ & $\mathrm{AIC}_{\mathrm{c}}$ & $\Delta \mathrm{AIC}_{\mathrm{c}}$ & $\omega_{\mathrm{i}}$ & $\mathrm{AIC}_{\mathrm{c}}$ & $\Delta \mathrm{AIC}_{\mathrm{c}}$ & $\omega_{\mathrm{i}}$ \\
\hline Season, location, sex, condition & $\mathbf{1 5}$ & $\mathbf{5 6 3 . 4}$ & $\mathbf{0 . 0}$ & $\mathbf{0 . 9 6}$ & $\mathbf{5 0 3 . 5}$ & $\mathbf{0 . 0}$ & $\mathbf{0 . 9 7}$ & $\mathbf{5 3 8 . 4}$ & $\mathbf{0 . 0}$ & $\mathbf{0 . 9 7}$ \\
Sex, season, location & 14 & 570.9 & 7.5 & 0.02 & 511.8 & 8.3 & 0.02 & 546.0 & 7.6 & 0.02 \\
Condition, season, location & 13 & 572.6 & 9.2 & 0.01 & & & & 548.3 & 9.9 & 0.01 \\
\hline
\end{tabular}




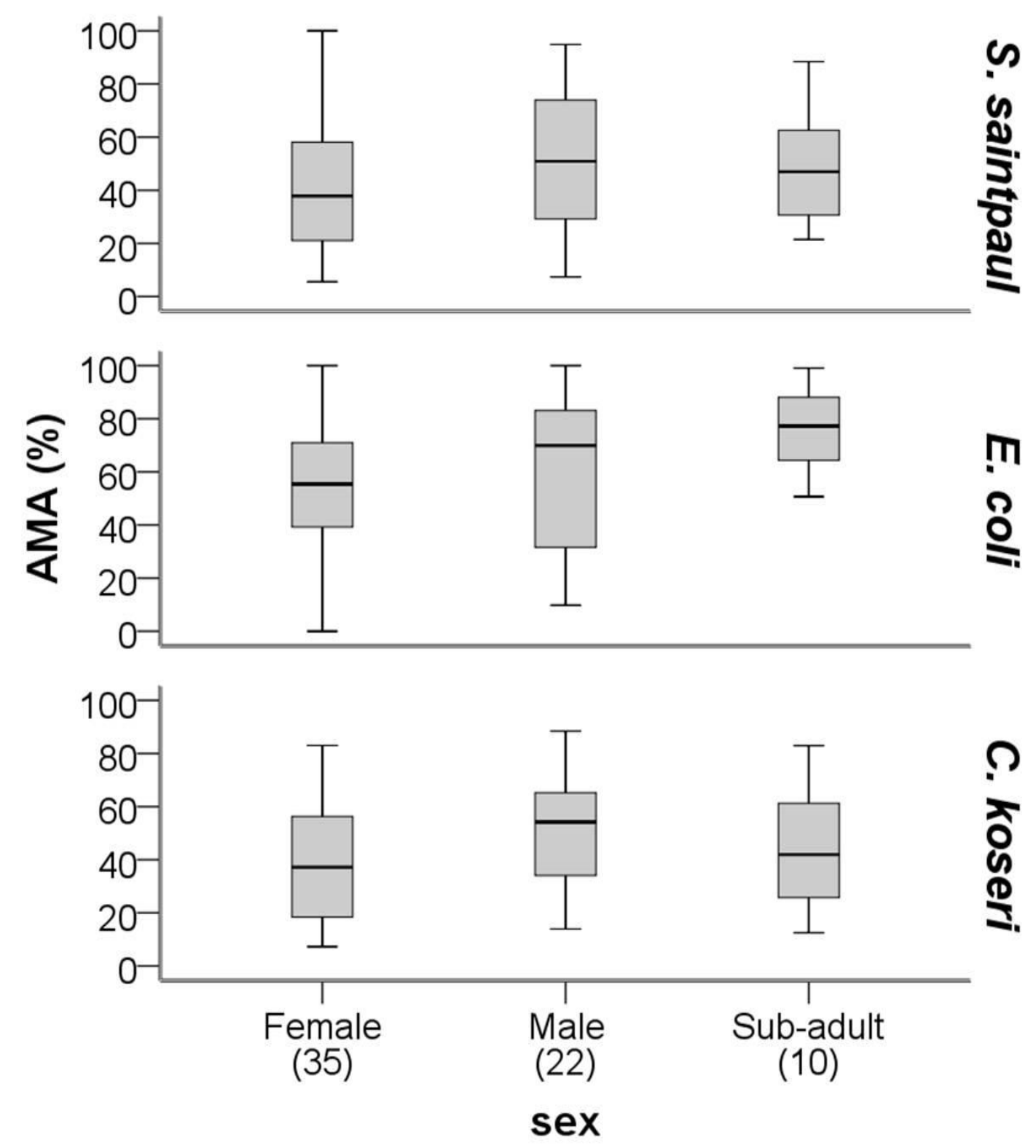

Figure 4.6: Anti-microbial activity of captive tuatara serum is not significantly affected by sex and age. $\mathrm{N}$ is shown in parentheses under $\mathrm{X}$-axis labels. 


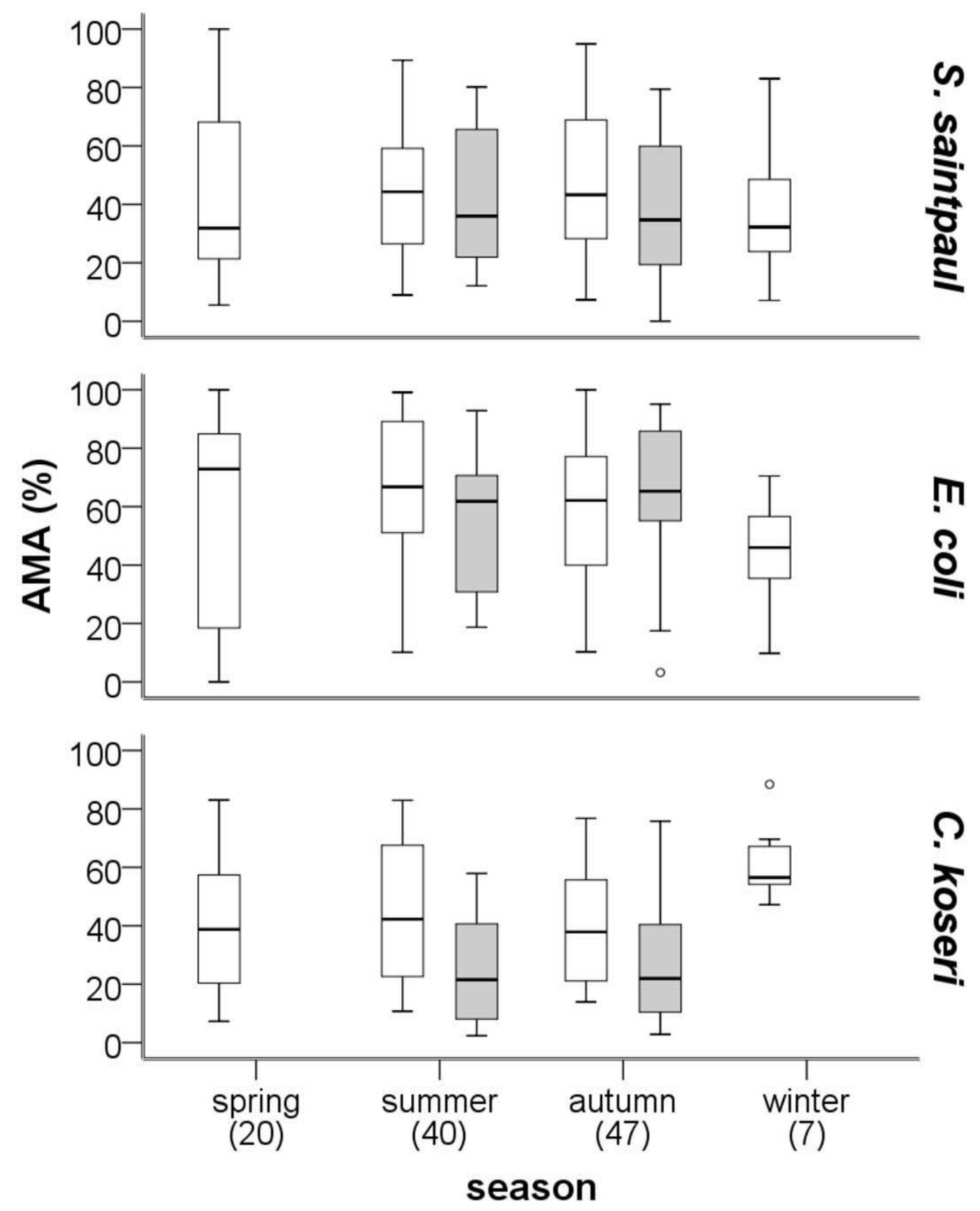

Figure 4.7: The anti-microbial activity of captive (white) and wild (grey) tuatara serum against a) $S$. Saintpaul and b) E.coli was not significantly affected by season. Captive tuatara serum had higher anti-microbial activity against $C$. koseri during winter than during the other seasons. $\mathrm{N}$ is shown in parentheses under $\mathrm{X}$-axis labels. 
Table 4.4. The outcomes of candidate models for the anti-microbial activity of sera from wild tuatara. The top five models are shown for: (A) S. Saintpaul, (B) E. coli and (C).C. koseri (for full models see Appendix C). The variables included in each model, number of parameters $(\mathrm{K}), \mathrm{AIC}_{\mathrm{c}}$ values, $\mathrm{AIC}_{\mathrm{c}}$ differences $(\Delta \mathrm{AIC})$, and Akaike weight $\left(\omega_{\mathrm{i}}\right)$ are shown. Models are ranked from the smallest to largest $\mathrm{AIC}_{\mathrm{c}}$ value.

\begin{tabular}{lllll}
\hline & & \multicolumn{3}{c}{$S$. Saintpaul } \\
Variables included in model & $\mathrm{K}$ & $\mathrm{AIC}_{\mathrm{c}}$ & $\Delta \mathrm{AIC}_{\mathrm{c}}$ & $\omega_{\mathrm{i}}$ \\
\hline Season, location, sex, condition & 7 & 413.1 & 0.0 & 0.48 \\
Season, location, sex, condition, ticks & 8 & 414.6 & 1.5 & 0.22 \\
Location, sex, condition & 6 & 416.5 & 3.4 & 0.09 \\
Condition, season, location & 6 & 417.3 & 4.2 & 0.06 \\
Location, sex, condition, ticks & 7 & 417.6 & 4.5 & 0.05 \\
\hline
\end{tabular}

\begin{tabular}{lllll}
\hline & & \multicolumn{3}{c}{ E. coli } \\
V. & $\mathrm{K}$ & $\mathrm{AIC}_{\mathrm{c}}$ & $\Delta \mathrm{AIC}_{\mathrm{c}}$ & $\omega_{\mathrm{i}}$ \\
\hline Season, location, sex, condition & 7 & 413.8 & 0.0 & 0.68 \\
Condition, season, location & 6 & 417.3 & 3.5 & 0.12 \\
Season, sex, condition & 6 & 418.7 & 4.9 & 0.06 \\
Season, location, sex, condition, ticks & 8 & 419.4 & 5.6 & 0.04 \\
Location, sex, condition & 6 & 419.4 & 5.6 & 0.04 \\
\hline
\end{tabular}

C.

\begin{tabular}{lllll}
\hline \multicolumn{1}{l}{ C. koseri } \\
Variables included in model & $\mathrm{K}$ & $\mathrm{AIC}_{\mathrm{c}}$ & $\Delta \mathrm{AIC}_{\mathrm{c}}$ & $\omega_{\mathrm{i}}$ \\
\hline Season, location, sex, condition & 7 & 399.1 & 0.0 & 0.51 \\
Location, sex, condition & 6 & 401.4 & 2.3 & 0.16 \\
Condition, season, location & 6 & 402.4 & 3.3 & 0.10 \\
Season, sex, condition & 6 & 402.6 & 3.5 & 0.09 \\
Location, condition & 5 & 404.8 & 5.7 & 0.03 \\
\hline
\end{tabular}




\subsubsection{Combined immune function}

In order to properly characterise and understand the tuatara immune response I have compared the innate immune function determined in this chapter with the adaptive immune response measured in Chapter Three. I compared each individual tuatara which had been measured in both assays $(\mathrm{N}=94)$; this included both captive and wild tuatara. Within individual tuatara there was no significant correlation between antimicrobial activity and antigen recognition in $S$. Saintpaul $\left(\mathrm{R}^{2}=0.173, P<0.001\right)$, E. coli $\left(\mathrm{R}^{2}=0.006, P=0.481\right)$ or $C$. koseri $\left(\mathrm{R}^{2}=0.042, P=0.049\right)$ (Figure 4.9$)$, suggesting that tuatara do not maximally activate several aspects of immunity simultaneously. 
A.

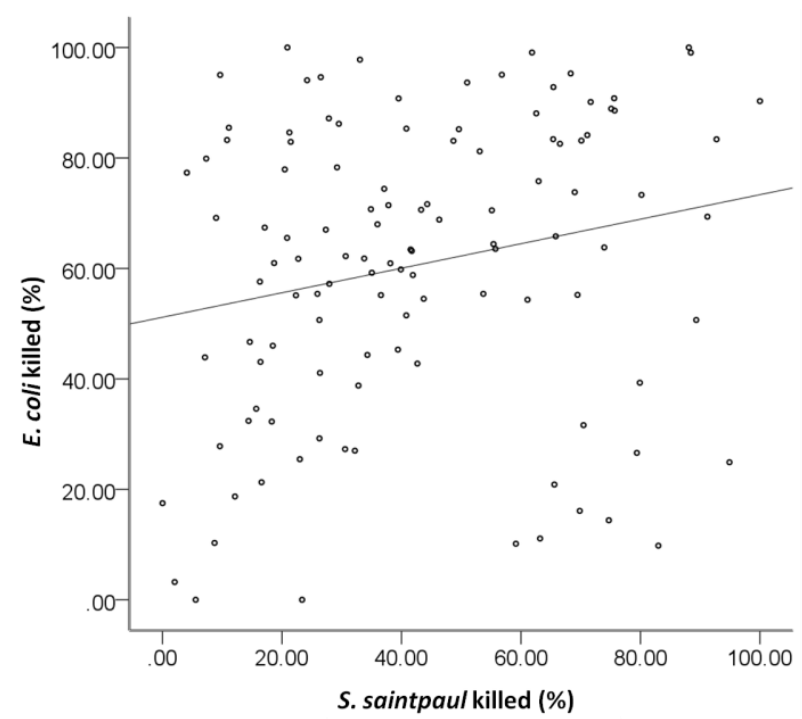

B.
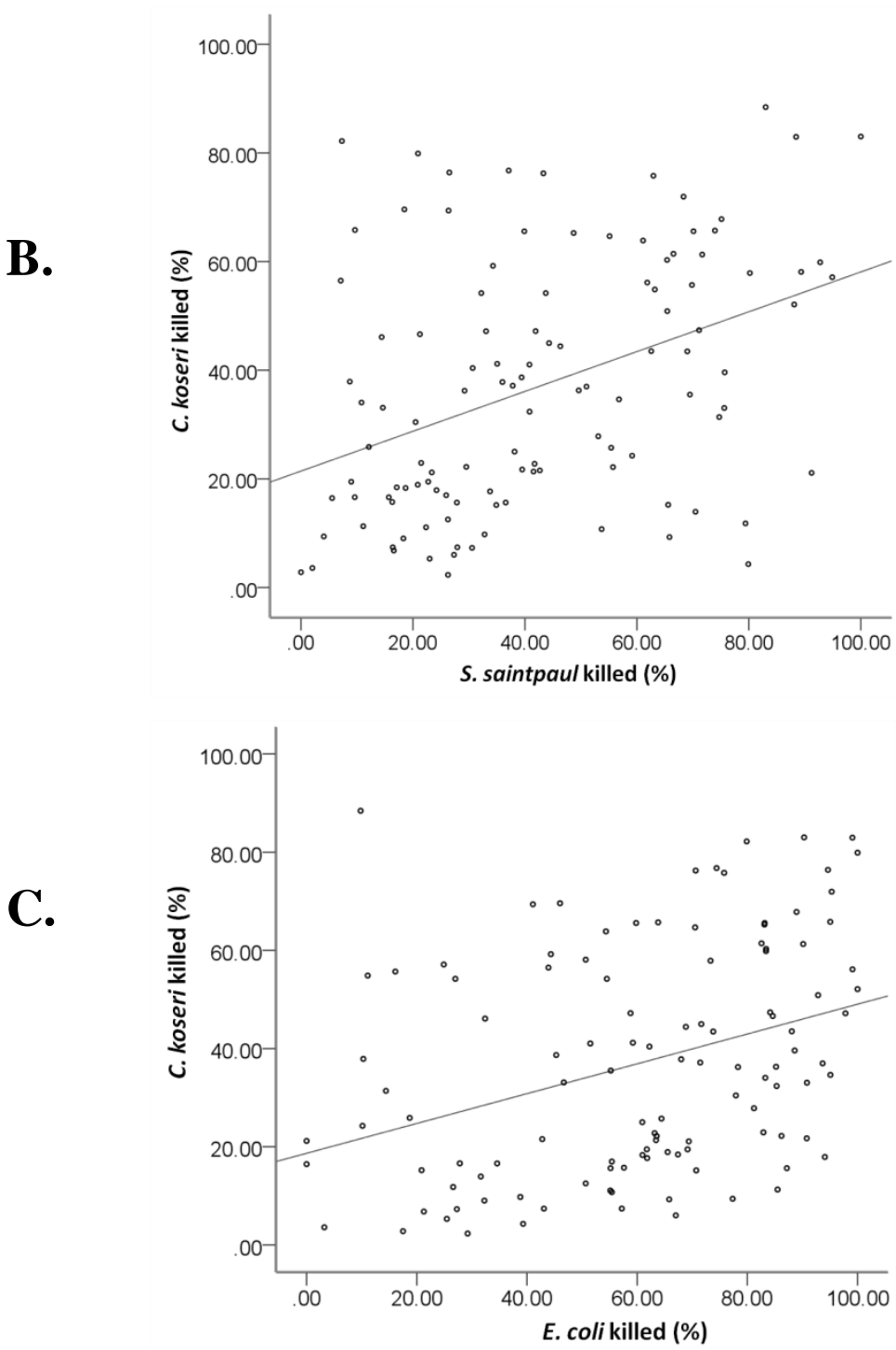

Figure 4.8: A very small amount of variation is shared between bacteria a) $S$. Saintpaul and $E$. coli $\left(\mathrm{R}^{2}=0.044, P=0.025\right)$, b) $S$. Saintpaul and $C$. koseri $\left(\mathrm{R}^{2}=0.159, P<0.001\right)$ and c) E. coli and $C$. koseri $\left(\mathrm{R}^{2}=0.121, P<0.001\right)$ was found in this study. 

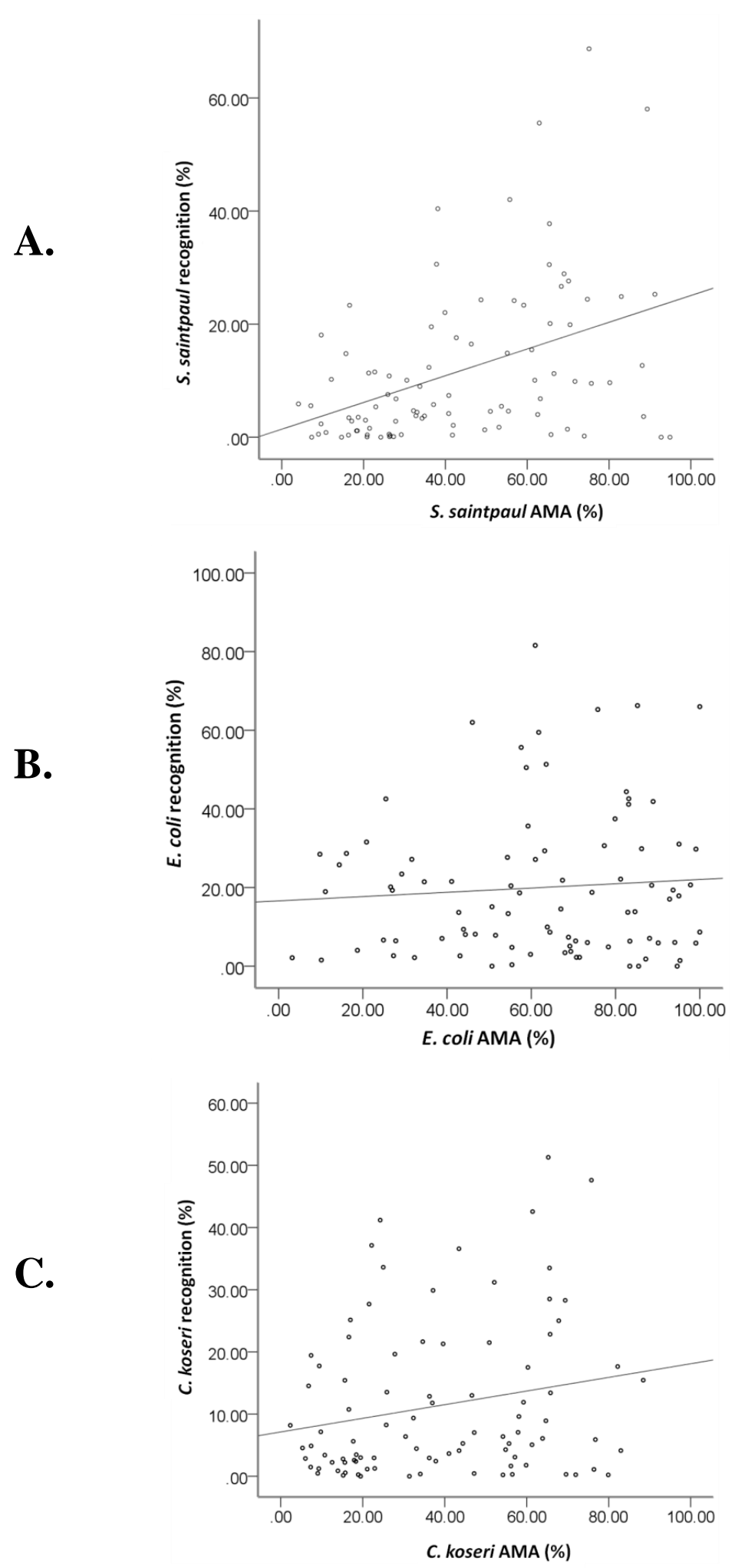

Figure 4.9: Antigen recognition as a function of anti-microbial activity in those individual captive and wild tuatara that were tested for both. A slight but significant correlation between antigen recognition and anti-microbial activity was seen for $S$. Saintpaul $\left(\mathrm{R}^{2}=0.173, P<0.001\right)$ and $C$. koseri $\left(\mathrm{R}^{2}=0.042, P=0.049\right)$, but not $E$. coli $\left(\mathrm{R}^{2}=0.006, P=0.481\right)$. 


\subsection{Discussion}

Tuatara seldom exhibit detrimental health conditions due to bacterial infections with common gastrointestinal pathogens such as those tested in this study. However, they are known to be in contact with opportunistic pathogens such as Salmonella.

Salmonella is often found in native skinks living in close proximity to tuatara (Middleton et al. 2010) and has been isolated from soil collected from inside the burrows of many of the tuatara tested in this study (Chapter Two). Despite this finding, there has only been one reported case of Salmonella isolation (from a deceased tuatara) and no gastrointestinal carriage has been detected in over 600 cloacal swabs collected from both wild and captive tuatara (Chapter Two; Gartrell et al. 2006; Gartrell et al. 2007). While tuatara are not completely immune to microbial infections, they do exhibit a remarkable ability to resist microbial colonisation. The results from this study provide the first evidence that tuatara have active peptide-mediated innate immunity.

In this study I have shown that tuatara can respond to S. Saintpaul, E. coli and C. koseri infection, and effectively inhibit the growth of these organisms in vitro. However, the efficacy of this response varies significantly among species of bacterium. Tuatara show much higher AMA against $E$. coli than $S$. Saintpaul and they have the least activity against $C$. koseri. Increased immune effectiveness towards certain organisms is likely to arise due to interactions between the innate and adaptive immune responses.

The AMA of tuatara sera was not limited by moderate heat-treatment $\left(55^{\circ} \mathrm{C}\right.$, 30minutes), indicating that tuatara AMA is likely to be peptide mediated. Antimicrobial peptides are generally considered to be heat stable in contrast to the complement system which demonstrates decreased AMA when exposed to moderate heat treatment (Diamond et al., 2009). This result is further supported by the finding that serum filtered with a $10 \mathrm{kDa}$ filter still contains significant anti-microbial activity. Anti-microbial peptides are typically less than $10 \mathrm{kDa}$ (Reddy et al. 2004) in contrast to antibodies which are normally larger than 100kDa (Djourmerska et al. 2005). Although the absolute level of activity was reduced by filtration, this difference did not reach statistical significance compared to heated or untreated sera. This finding may suggest that while most activity seen in tuatara is peptide-mediated a small portion may still be 
attributed to antibodies or other heat stable serum proteins. Anti-microbial peptides have been isolated from a broad variety of phylogenetically diverse organisms (Ganz, 2003) and can also be found in the gut, lungs and skin. Anti-microbial peptides belonging to three families have been isolated from the gastrointestinal tracts of many animals and humans and have been shown to play an important role in preventing infection (Mahida et al. 1997). Further research is therefore warranted on the presence and importance of mucosal and epithelial anti-microbial peptides in tuatara.

My results show substantial and significant variation in the AMA of five different animal species against the three test bacteria. I found that the AMA of tuatara serum was similar to the other two reptilian species tested: the coastal bearded dragon and the Australian water dragon, but it was significantly more effective at killing all three bacterial species than was donkey or mouse sera. Similar work has demonstrated striking differences in the capacity of human and alligator (Alligator mississippiensis) serum to control E. coli (Merchant et al. 2003), and the antibacterial activity of five species of tropical bird against $E$. coli has also been demonstrated to vary significantly among species (Matson et al. 2006). This variation suggests that different species employ this particular branch of the immune system to differing degrees for preventing and controlling bacterial infections. It should also be noted that both the donkey and mouse sera used in this study were collected from laboratory-raised animals. Therefore, if previous exposure to pathogens plays a significant role in the AMA of these species, my results are likely to under-represent the AMA of donkey and mouse sera. Lack of exposure is likely to be particularly important for lab-bred animals which are unlikely to have come into contact with $S$. Saintpaul or C. koseri.

The AMA of mouse and donkey sera was also heat stable, indicating that the activity in these species is in part peptide mediated. In contrast, the AMA of coastal bearded dragon and Australian water dragon sera was significantly inhibited by moderate heattreatment. I therefore suggest that the activity seen in these two reptilian species is largely or entirely complement-mediated. Complement-mediated anti-microbial activity is common in reptiles and many species of crocodilian show very high AMA, but this activity is significantly prohibited by heat-treatment. For example, sera from saltwater (Crocodylus porosus) and freshwater (Crocodylus johnstoni) crocodiles have been demonstrated to lyse approximately $90 \%$ of sheep red blood cells (SRBCs) in vitro. 
However, the ability of the sera to disrupt these cells is severely limited when sera is heated (approx. 5\% lysis) (Merchant and Britton, 2006). While complement-mediated activity is common in reptiles, AMPs have also been described in the sera of other species including the Siamese crocodile (Crocodylus siamensis) and European pond turtles (Emys orbicularis) (Preecharram et al., 2008; Stegemann et al., 2009).

Much research has been conducted on the effects of global warming on vector-borne diseases (i.e. pathogens with an invertebrate host) (Charron 2002) and the Intergovernmental Panel on Climate Change (IPCC) recognises vector-borne disease as one of the variables most likely to alter as a result of global climate change. However, the disease ecology of non-vector-borne pathogens is also unlikely to escape the effects of a global change in temperature. Changes in climate and water availability may result in changes in available habitat of both host and pathogen, in turn increasing the likelihood that hosts will be exposed to new pathogens. Warmer climates may result in shorter and less severe winters, thereby prolonging the transmission season for many diseases and allowing previously exotic diseases that enter New Zealand to establish when they may otherwise have perished. Prolonged periods of increased temperature or decreased water availability are likely to result in compromised immunity among vertebrate species. Tuatara can maintain normal body function at temperatures as low as $7^{\circ} \mathrm{C}$ and their optimal temperature range is $16-21^{\circ} \mathrm{C}$ (Saint Girons, 1980). It is unclear how an increase in mean temperature may affect the immune response of this cool-adapted reptile.

The model which best represented the data included the variables season, sex, location and condition; however AMA of tuatara serum against $S$. Saintpaul and E. coli was not linked to any of these factors. Season was found to affect AMA of tuatara serum against $C$. koseri, with samples obtained in winter having higher activity than those obtained in other seasons. There are likely to be other factors that affect innate immunity which are not included in my model. Individual genetic diversity of the host, previous exposure to pathogens and changes in pathogen pressure are examples of factors which could affect AMA. Infectious disease prevalence can vary as a result of a variety of factors, including changes in weather, fluctuations in vector populations and changes in host behaviour (Altizer et al. 2006). In poikilotherms, pathogen prevalence can be affected by temperature-induced fluctuations in host-physiology as well as direct 
temperature effects on the pathogen life cycle (Jackson and Tinsley 2002). Investment in immunity is energetically costly and therefore a greater investment in immunity among individuals that are exposed to larger numbers of pathogens might be expected (Read and Allen 2000). However, the impact of pathogen prevalence on reptile immunity is unknown and further study is warranted.

I have compared anti-microbial activity with antigen recognition data (Chapter Three) in serum from individual tuatara tested in both assays. This analysis provides a comparison of measures of innate (AMA) and adaptive (antigen recognition) immunity in tuatara. No correlation was seen between these immune measures for any of the three bacteria (S. Saintpaul, E. coli or C. koseri) investigated. Blount et al. (2003) found the relative scale of host investment in immune defence differed between measures of innate and acquired immunity and there was no correlation between aspects of cell-mediated and humoral responses. Brazilian free-tailed bats (Tadarida brasiliensis) have been shown to have a weak but significant negative correlation between T-cell responses and anti-microbial activity (Allen et al. 2009). The results from these studies and the present one suggest that individuals may not be able to maximally activate several aspects of immunity simultaneously, perhaps due to competing energetic costs. It also further supports the suggestion made by a number of authors that in order to characterise and understand vertebrate immune systems several immune parameters should be measured as a single measure of specific immune response may not accurately reflect the overall immune strategy of the species of interest (Birkhead et al. 1998, Blount et al. 2003, Allen et al. 2009).

A number of different Salmonella serovars have been isolated from wildlife in New Zealand including $S$. Saintpaul, $S$. Bousso and $S$. Warragul from native lizards, and $S$. Typhimurium and S. Brandenburg from birds (Clark 2001, Clark et al. 2002, Middleton et al. 2010). Some serovars such as $S$. Saintpaul and $S$. Typhimurium appear to be fairly ubiquitous throughout New Zealand, while other serovars, i.e. $S$. Warragul and $S$. Mana, are commonly isolated from only one or two areas (Clark et al. 2002; Middleton et al. 2010). There is therefore concern that management practices such as translocations may increase the spread of previously isolated serovars. Management practices also increase the likelihood that species will be introduced to pathogens that they had previously been unexposed to at their release sites (Woodford and Rossiter 
1994). I have demonstrated that tuatara have innate immune mechanisms which may help to prevent or reduce the severity of infection from common enteric pathogens and are therefore likely to be capable of limiting the incidence and severity of systemic bacterial infections by Salmonella, E. coli and C. koseri. I have not investigated the ability of these peptides to prevent gastrointestinal colonisation by Salmonella because it remains untested whether these peptides are secreted into the gastrointestinal tract. In mammals, secreted antibodies, such as defensins, play a very important role in preventing gastrointestinal colonisation by pathogenic bacteria (Bevins 1999). Future studies could therefore be focussed into whether the anti-microbial peptides identified in this study are secreted in tuatara.

I describe potent and broad spectrum antibacterial activities in the serum of tuatara, and to my knowledge this is the first description of the peptide-mediated innate immune response within this species. The majority of AMA in tuatara appears to be due to the presence of anti-microbial peptides, in contrast to the complement based AMA of the other reptiles tested. My results suggest that season, sex and body condition do influence the immune response of tuatara but that other factors not examined in this study may be more important in explaining the differences in AMA activity of tuatara serum. This study has gone someway in explaining the lack of detectable Salmonella carriage in tuatara, however the fact that exotic reptiles known to be shedders of Salmonella exhibited similar or higher levels of AMA activity against Salmonella than tuatara suggests that AMA activity may only be partly responsible for the lack of shedding seen in the latter. More work is therefore required in order to explain the low to zero gastrointestinal carriage of Salmonella in tuatara. Further research is also needed to determine how these immune responses may be affected by climate change and their modulation of immunity of tuatara against novel pathogens. 


\section{CHAPTER FIVE}

\section{The population structure of Salmonella isolates from skinks and soil in New Zealand}

\section{$5.1 \quad$ Abstract}

Knowledge of the population structure of bacterial pathogens is vital to our understanding of their epidemiology both at a national and international level. Therefore, studies which incorporate both immunological and molecular typing methods can be used to answer a wide range of questions regarding pathogen transmission and distribution. Serotyping is currently the predominant method of Salmonella identification, and although it is a valuable technique allowing tracing of outbreaks of disease and historical trends in population dynamics, it lacks discriminatory power and does not reveal the genetic relationships of strains within the same or different serotypes.

The importance of population parameters such as recombination $(\rho)$, mutation $(\theta)$, and adaptive selection are of great interest and importance in the study of microbial population genetics. I have employed explicit statistical (evolutionary) models that describe the effect of these parameters on gene sequences to estimate the relative contributions of recombination, mutation and drift on the evolution of Salmonella in New Zealand wildlife in an island ecosystem. I estimated $\rho$ and $\theta$ using a coalescent approach in Salmonella sequences obtained from skinks and soil samples on Stephens Island, New Zealand. I analysed a total of 38 Salmonella isolates corresponding to 18 skinks and 20 soil samples. The 38 isolates corresponded to two serovars of Salmonella, $S$. Mississippi and S. Saintpaul.

Three genes, sucA, dnaN, and thrA were amplified using a multi-locus sequence typing scheme in order to investigate their phylogenetic relationships. I found that allele type 
and serovar were directly comparable, with just two allele types found in each gene and only one allele type found per serotype. The two Salmonella serovars also separated into their own clades in the phylogenetic trees. The Salmonella isolates investigated in this study showed low clonality and were found to be under purifying selection.

Despite its importance as a disease agent in humans, domestic animals and other wildlife, very little is known about the population structure of Salmonella in New Zealand, but also at an international level. However, the changing epidemiology of Salmonella infections of humans, livestock and wildlife make it imperative to understand the contribution of these selection pressures on Salmonella in New Zealand. I have undertaken the first study of Salmonella population structure in New Zealand in order to begin to answer questions regarding the evolution and transmission of this pathogen in native fauna.

\subsection{Introduction}

Bacterial species will adapt and respond to their environments in a number of ways, and this response can be measured by assessing such factors as the genetic diversity within and among populations, the impact of natural selection in shaping that diversity, and the importance of recombination in distributing the diversity within and among populations (Perez-Losada et al. 2006). Pathogenic bacteria are typically identified by the proteins displayed on their outer cell surface, but variance in their virulence and pathogenicity may occur as a result of their underlying genetic code and lineage (Maiden 2008). Therefore, studies which integrate population genetics, evolutionary insights and epidemiology can provide important insights into the origins and spread of bacterial disease (Musser 1996, Spratt and Maiden 1999). These studies are pivotal in helping us understand the causes of microbial disease and in helping to design effective public and wildlife health management strategies (Spratt and Maiden 1999). For example, outbreaks of campylobacteriosis within and among households in Scotland were investigated and it was determined that $89 \%$ of these putative household outbreaks were molecularly related (Rotariu et al. 2010). Multi-locus sequence typing schemes have also been used in the epidemiological surveillance of Neisseria meningitidis isolates 
throughout England, Wales and Northern Ireland. The study played an important role in the public health management of meningococcal disease by enabling monitoring of outbreaks of disease caused by the same isolates, establishing clustering of isolates within schools and regions and enhanced surveillance and tracing of new serotypes (Birtles et al. 2005).

Salmonella enterica is a Gram-negative pathogen of significant zoonotic concern (Chiodini and Sundberg 1981), with an estimated 1.4 million cases of non-typhoidal human salmonellosis occurring in the United States annually (Mead et al. 1999). Salmonella serovars have a widespread distribution being carried both symptomatically and asymptomatically in reptiles, birds, humans and other mammals on almost every continent in the world (Chiodini and Sundberg 1981). In many cases individuals will act as asymptomatic carriers of the disease (Bäumler et al. 1998), but when clinical signs of infection develop they usually present as gastroenteritis, bacteraemia and septicaemia (Coburn et al. 2007).

The genus Salmonella is divided into two species: S. enterica and S. bongori (Brenner et al. 2000). S. enterica is further divided into six subspecies (I, II, IIIa, IIIb, IV and VI) on the basis of chromosomal DNA hybridisation and variation in certain phenotypic characteristics (Beltran et al. 1988). Members of subspecies I (Salmonella enterica subsp. enterica) comprise the majority of serovars $(\sim 60 \%)$ and are responsible for the vast majority ( $90 \%)$ of salmonellosis in endothermic animals (Chan et al. 2003), whilst subspecies II, IIIa, IIIb, IV and VI are generally associated with ectothermic vertebrates (Bäumler et al. 1998, Porwollik and McClelland 2003). At present, characterisation of Salmonella enterica isolates from all sources is based on serotyping according to the Kauffmann-White scheme. Assignment of a particular serovar is based on the immunological classification of three cell surface antigens; the lipopolysaccharide moieties ( $\mathrm{O}$ antigen), the flagellar protein ( $\mathrm{H}$ antigen) and capsular polysaccharide (Vi antigen). Under the Kauffmann-White scheme, $26 \mathrm{O}$ antigens and $114 \mathrm{H}$ antigens are recognised, resulting in 2523 characterised serotypes (Edwards et al. 2002, Popoff et al. 2003). However, only a small proportion of serotypes are regularly isolated from humans or animals (Mermin et al. 2004). 
Despite sharing more than $90 \%$ of their DNA content, serotypes vary widely in their host range and in the type and severity of disease they cause (Crosa et al. 1973, Porwollik and McClelland 2003). Based on these parameters they can be divided into host-specific, host-restricted and generalist serotypes (Uzzau et al. 2000, Hoelzer et al. 2011). Generalist serotypes, such as S. enterica subspecies I serovar Typhimurium, infect a wide range of hosts including humans, other mammals, reptiles and birds (Davies and Wray 1996, Aballay et al. 2000, Alley et al. 2002). In contrast, hostrestricted serotypes are adapted to only a few species, for example, $S$. Cholaraesuis is restricted primarily to swine but occasionally causes disease in other mammalian hosts including humans (Gray et al. 1996, Saphra and Wassermann 1954). Host-specific serovars infect only a single host species, for example, $S$. Typhi will infect only humans (Parkhill et al. 2001). Infection with generalist serotypes will often result in high morbidity but low mortality; in contrast, host-specific or host-restricted serotypes are often associated with low morbidity and high mortality (Hoelzer et al. 2011).

Serotyping remains the predominant method used to differentiate Salmonella subtypes globally. Serotyping is a reliable method which provides valuable information on hostassociated subtypes, the emergence of new subtypes, and historical trends in the association of specific Salmonella serovars with different host species. However, it lacks discriminatory power and does not reveal the genetic relationships of strains within the same or different serotypes (Selander et al. 1990, Alcaine et al. 2006). It also remains unclear as to what degree the different serotypes or antigenic profiles correspond with genetic diversity within Salmonella enterica. It has been suggested that the population structure of Salmonella is clonal (Beltran et al. 1988), in which case it becomes important to question whether serovar identity correlates with clonal identity. Beltran et al. (1988) demonstrated that for most serotypes investigated, one predominant worldwide clone existed, but it was also associated with a cluster of genotypically similar clones differing at only one or a few loci. The minor clones are most likely relatively recent mutant derivatives of the predominant clone (Beltran et al. 1988). Other authors have found that the Salmonella genome is influenced by very high levels of recombination and therefore exhibit a low level of clonality (Liu et al. 2009, Didelot et al. 2011). The high levels of recombination seen in many subspecies of Salmonella can make resolving the phylogenetic relationships among isolates difficult. Octavia and Lan (2006) investigated the phylogenetic relationships and 
population structure of Salmonella subspecies I isolates using four genes ( $m g l A, p r o V$, tor $($ and $s p e C$ ). They found that these genes had undergone frequent recombination which suggested a low level of clonality within subspecies I isolates. However, this frequent recombination also meant that they were unable to resolve the phylogenetic relationships among many of the isolates. Measuring the contribution of recombination in bacterial populations is important not only as a means to determine clonality and phylogeny of the population. It is also important for our wider understanding of the epidemiology of the pathogen. Clearly, in non-clonal populations where lineages diversify quickly, isolates recovered in one decade may be completely different to those recovered in the next. Therefore the epidemiological questions which can sensibly be asked of clonal and non-clonal populations will differ (Spratt and Maiden 1999).

With increased availability of automated DNA sequencing technology, DNA sequencebased subtyping methods such as multi-locus sequence typing (MLST) are becoming an increasingly valuable technique for studying pathogen evolution and the relative contributions of mutation, selection and drift on pathogen diversity. Multi-locus sequence typing (MLST) is a nucleotide sequence-based approach which determines the sequences of full or partial house-keeping genes for the characterisation of bacterial strains (Maiden et al. 1998, Aanensen and Spratt 2005). The sequences of each fragment are compared with all previously identified sequences (alleles) at the locus. The allelic profile of the bacterial strain at the seven loci is then assigned to a sequence type (ST), which is used to describe the strain (Aanensen and Spratt 2005). MLST methods have been used to successfully subtype and explore the evolutionary relationships of a variety of bacterial pathogens, including Campylobacter jejuni, Vibrio cholerae, Listeria monocytogenes, Streptococcus agalactiae and Salmonella enterica (Dingle et al. 2001, Jones et al. 2003, Kotetishvili et al. 2003, Salcedo et al. 2003, Sukhnanand et al. 2005).

Salmonella has been isolated from a variety of New Zealand wildlife species including birds, reptiles and mammals and has on occasion been linked to widespread fatalities within species of native and introduced passerines (Alley et al. 2002, Ewen et al. 2007). A number of Salmonella serotypes have been isolated from New Zealand species, including $S$. Saintpaul and $S$. Mississippi from native lizards (de Hamel and McInnes 
1971, Middleton et al. 2010) and $S$. Typhimurium in hihi and introduced passerines (Alley et al. 2002, Ewen et al. 2007). Likewise, many serovars have been isolated from domestic animal species in New Zealand such as $S$. Brandenburg from sheep (Kerslake and Perkins 2006). However, despite its importance as a disease agent in native fauna and domestic species, very little is known about the population structure of Salmonella in New Zealand. The changing epidemiology of Salmonella infections of humans, livestock and wildlife make it imperative to understand the contribution of selection pressures on Salmonella in New Zealand.

In Chapter Two, I investigated the spatio-temporal dynamics of Salmonella within an island ecosystem, and using serotyping methods, I identified two serovars of Salmonella, S. Saintpaul in skinks and soil samples, and S. Mississippi in skink samples only. In this chapter, I aimed to use multi-locus sequencing typing to determine whether serotype diversity corresponded with molecular diversity, and to obtain insights into the population structure of Salmonella on Stephens Island. This is a preliminary investigation to obtain baseline knowledge on contributions of recombination, mutation and selection and the population structure of Salmonella which can be used to implement management strategies aimed at preventing widespread disease in humans, domestic animals and wildlife by contributing to an understanding of historical source populations. To the best of my knowledge I have undertaken not only the first study of Salmonella population structure by MLST in New Zealand, but also one of the first studies to combine epidemiological findings from traditional immunological typing with molecular population structure. This foundation knowledge will contribute to further research to understand both short- and long-term epidemiological questions, contributing to our understanding of how isolates vary within and among geographical regions, whether there are species differences in subtypes of Salmonella and how the population structure of Salmonella varies over time. 


\subsection{Methods}

Salmonella isolates were obtained from New Zealand native skinks $(\mathrm{n}=18)$ and soil samples collected from inside tuatara burrows $(n=20)$ on Stephens Island, New Zealand during two years from October 2009 to October 2011 (Chapter Two). The 38 isolates represented two serotypes, $S$. Saintpaul and S. Mississippi (Table 5.1). Salmonella serotyping was performed by Environmental Science and Research (ESR, Porirua, New Zealand).

Bacteria were grown overnight in $\mathrm{LB}$ media at $37^{\circ} \mathrm{C}$ on a shaking incubator and DNA was extracted using the DNeasy blood and tissue kit (Qiagen, Valencia, CA, USA) according to the manufacturer's instructions. Three house-keeping genes were selected from the genome on the basis that they are scattered around the chromosome and flanked by genes of known function. Typically, MLST consists of a seven-gene amplification scheme; however, I experienced difficulties amplifying the remaining four genes to a standard high enough to achieve clear sequencing. The genes used are dnaN (DNA polymerase III beta subunit), sucA (alpha ketoglutarate dehydrogenase) and thrA (aspartokinase + hemoserine dehydrogenase) (Table 5.2). The selection of these genes allowed for comparison to an existing Salmonella MLST database (http://mlst.ucc.ie/mlst/dbs/Senterica/).

Amplifications for all genes were carried out using approximately $0.2 \mu \mathrm{g}$ DNA template, $250 \mu \mathrm{M}$ (each) deoxynucleoside triphosphates (dNTPs), $2.5 \mathrm{mM} \mathrm{MgCl}_{2}, 25 \mathrm{pmol}$ of primers and 1 U Thermus aquaticus (Taq) DNA polymerase (Bioline, London, England) in accordance with manufacturer's instructions. PCR cycling conditions used for all three genes were a 3 minute hold at $94^{\circ} \mathrm{C}$, followed by 35 cycles of $94^{\circ} \mathrm{C}$ for 45 seconds, $50^{\circ} \mathrm{C}$ for 45 seconds and $72^{\circ} \mathrm{C}$ for 1 minute, and a final extension of $72^{\circ} \mathrm{C}$ for 5 minutes. Products of $501 \mathrm{bp}$ in size were separated by $1.5 \%$ agarose gel electrophoresis and visualised with ethidium bromide staining and UV illumination with a gel documentation system (Gel Doc 2000; Bio-Rad, Hercules, CA). 
Table 5.1: Origin and characterisation of Salmonella isolates used in this study. The serotype, host, location and time of sampling are shown. Sequences were assigned allele types, from the MLST database, for each of three genes and these corresponded directly with serotype.

\begin{tabular}{|c|c|c|c|c|c|c|c|c|}
\hline ID & Serotype & Host & location & month & year & $\begin{array}{l}\text { ThrA } \\
\text { allele }\end{array}$ & $\begin{array}{l}\text { dnaN } \\
\text { allele }\end{array}$ & $\begin{array}{l}\text { SucA } \\
\text { allele }\end{array}$ \\
\hline 1 & S. Saintpaul & soil & Paddock 2 & June & 2010 & 115 & 406 & 7 \\
\hline 2 & S. Saintpaul & soil & Forest & January & 2011 & 115 & 406 & 7 \\
\hline 3 & S. Mississippi & skink & Forest & January & 2011 & 118 & 356 & 119 \\
\hline 4 & S. Saintpaul & soil & Paddock 2 & January & 2011 & 115 & 406 & 7 \\
\hline 5 & S. Saintpaul & soil & Paddock 2 & June & 2010 & 115 & 406 & 7 \\
\hline 6 & S. Saintpaul & skink & Paddock 2 & March & 2011 & 115 & 406 & 7 \\
\hline 7 & S. Saintpaul & skink & Forest & January & 2011 & 115 & 406 & 7 \\
\hline 8 & S. Saintpaul & skink & Paddock 2 & March & 2011 & 115 & 406 & 7 \\
\hline 9 & S. Saintpaul & soil & Paddock 1 & January & 2011 & 115 & 406 & 7 \\
\hline 10 & S. Saintpaul & skink & Paddock 2 & March & 2011 & 115 & 406 & 7 \\
\hline 11 & S. Saintpaul & skink & Forest & January & 2011 & 115 & 406 & 7 \\
\hline 12 & S. Saintpaul & soil & Paddock 2 & March & 2010 & 115 & 406 & 7 \\
\hline 13 & S. Saintpaul & soil & Paddock 2 & March & 2011 & 115 & 406 & 7 \\
\hline 14 & $S$. Mississippi & skink & Forest & March & 2010 & 118 & 356 & 119 \\
\hline 15 & S. Saintpaul & soil & Forest & January & 2011 & 115 & 406 & 7 \\
\hline 16 & S. Saintpaul & soil & Paddock 1 & June & 2010 & 115 & 406 & 7 \\
\hline 17 & S. Saintpaul & soil & Paddock 2 & March & 2011 & 115 & 406 & 7 \\
\hline 18 & S. Saintpaul & soil & Forest & June & 2011 & 115 & 406 & 7 \\
\hline 19 & S. Saintpaul & soil & Forest & January & 2011 & 115 & 406 & 7 \\
\hline 20 & S. Saintpaul & soil & Forest & March & 2010 & 115 & 406 & 7 \\
\hline 21 & S. Saintpaul & skink & Paddock 2 & March & 2010 & 115 & 406 & 7 \\
\hline 22 & S. Saintpaul & soil & Paddock 2 & March & 2010 & 115 & 406 & 7 \\
\hline 23 & S. Mississippi & skink & Paddock 1 & March & 2010 & 118 & 356 & 119 \\
\hline 24 & $S$. Mississippi & skink & Forest & January & 2011 & 118 & 356 & 119 \\
\hline 25 & S. Mississippi & skink & Paddock 2 & January & 2011 & 118 & 356 & 119 \\
\hline 26 & S. Saintpaul & soil & Paddock 1 & March & 2010 & 115 & 406 & 7 \\
\hline 27 & S. Saintpaul & skink & Paddock 2 & January & 2011 & 115 & 406 & 7 \\
\hline
\end{tabular}


Table 5.1 continued

\begin{tabular}{lllllllll}
\hline 28 & S. Saintpaul & soil & Forest & June & 2011 & 115 & 406 & 7 \\
29 & S. Saintpaul & soil & Paddock 1 & June & 2010 & 115 & 406 & 7 \\
30 & S. Saintpaul & skink & Paddock 2 & March & 2011 & 115 & 406 & 7 \\
31 & S. Saintpaul & soil & Paddock 2 & June & 2010 & 115 & 406 & 7 \\
32 & S. Saintpaul & soil & Forest & January & 2011 & 115 & 406 & 7 \\
33 & S. Saintpaul & soil & Paddock 1 & June & 2010 & 115 & 406 & 7 \\
34 & S. Saintpaul & skink & Paddock 1 & January & 2011 & 115 & 406 & 7 \\
35 & S. Saintpaul & skink & Paddock 1 & January & 2011 & 115 & 406 & 7 \\
36 & S. Saintpaul & skink & Paddock 1 & January & 2011 & 115 & 406 & 7 \\
37 & S. Saintpaul & skink & Paddock 2 & March & 2011 & 115 & 406 & 7 \\
38 & S. Saintpaul & skink & Paddock 2 & March & 2010 & 115 & 406 & 7 \\
\hline
\end{tabular}

PCR products were purified and sequenced by Macrogen Inc (Seoul, Korea) using forward and reverse PCR primers. Sequences were edited, and aligned using Geneious Pro version 5.4 (Drummond et al. 2011) (Biomatters Ltd, Auckland, New Zealand) and a concatenated sequence was obtained by combining the three genes in the order thrA, dnaN and sucA. The sequences were submitted to the MLST database website (http://mlst.ucc.ie/mlst/dbs/Senterica/) and assigned existing or novel allele type numbers defined by the database. This database defines a novel allele type if it contains one or more nucleotide changes from existing allele sequences. Composite sequence types (STs) are then usually assigned based on the set of allele types derived from the seven loci; however, I have only investigated three genes and therefore do not have sequence types. 
Table 5.2: Primers used to amplify the Salmonella genes dnaN, sucA and thrA by multilocus sequence typing. The forward and reverse primer sequences and the size of product (bp) are shown.

\begin{tabular}{llll}
\hline Gene & Primer & Primer sequence 5'-3' & Size (bp) \\
\hline dnaN & dnaNsF & CCGATTCTCGGTAACCTGCT & 501 \\
& dnaNsR & CCATCCACCAGCTTCGAGGT & \\
sucA & sucAsF & AGCACCGAAGAGAAACGCTG & 501 \\
& sucAsR & GGTTGTTGATAACGATACGTAC & \\
thrA & thrAsF & ATCCCGGCCGATCACATGAT & 501 \\
& thrAsR & CTCCAGCAGCCCCTCTTTCAG & \\
\hline
\end{tabular}

A number of parameters including population recombination $(\rho)$, population mutation $(\theta)$ and the probability of directional selection (Tajima's D) were estimated independently for each gene and also for the concatenated sequence. A standard likelihood coalescent approach within the package LDhat version 2.2 (McVean et al. 2002) was implemented to determine $\rho$ within each gene and in the concatenated sequence. Within this framework, $\rho$ is expressed as $2 N_{e} r$, where $N_{e}$ is the inbreeding effective population size and $r$ is the recombination rate per locus. LDhat uses a powerful permutation test (LPT) to test the hypothesis of no recombination (i.e. $\rho=0$ ). LDhat was also used to provide an estimate of $\theta$, defined as $\theta=2 N_{e} \mu$, where $\mu$ is the mutation rate per locus per generation. Tajima's D statistic, which determines the likelihood of genes being under neutral or random selection as opposed to directional or balancing selection, was also calculated (Tajima 1989). A negative Tajima's D is associated with an excess of low frequency polymorphisms relative to expectation, indicating purifying selection. In contrast, a positive Tajima's D indicates balancing or directional selection (Akey et al. 2004).

Using the CMS module of the programme hyphy (Pond et al. 2005), I determined the Markov model of DNA sequence evolution which was the best fit to the concatenated sequence. Hyphy analyses a total of 201 evolutionary models and assigns the best fitting model to the data using $\mathrm{AIC}_{\mathrm{c}}$ (Delport et al. 2010). The module GARD within the programme hyphy was used to find all the recombination breakpoints within the 
concatenated sequence (Pond et al. 2006), and the module SLAC was used to estimate the $\mathrm{dN} / \mathrm{dS}$ (also known as $\omega$ ) ratio at every codon in the alignment. The substitution rate $\mathrm{dN} / \mathrm{dS}$ measures the selective pressure at the protein level, with rates of $=1$ indicating neutral mutations, $<1$ purifying selection and $>1$ diversifying positive selection. Recombination breakpoints are accounted for by SLAC and nonrecombinant regions are identified, thereby allowing each region to have its own phylogenetic tree (Pond and Frost 2005).

Phylogenetic relationships among Salmonella on Stephens Island were investigated by the construction of phylogenetic trees using maximum parsimony (MP), maximum likelihood (ML) and Bayesian inference (BI) methods. Tree construction was performed using the best-fit model as predicted by hyphy. The phylogenetic signal in the data partitions was estimated by a maximum likelihood method (Strimmer and von Haeseler 1997) using TREE-PUZZLE version 5.2 (Schmidt et al. 2002). TREEPUZZLE randomly selects groups of four sequences (quartets) and analyses them using the ML method. Three possible un-rooted topologies exist for a quartet of sequences. A likelihood value is calculated for each of the potential topologies and mapped as a dot in an equilateral triangle. The value of each likelihood is represented as the proportional length of the perpendicular from the dot to the side opposite to the corner representing the resolved topology. The tree-likeness of the data is therefore represented by the distribution of dots in the triangle. Dots in the corners of the triangle represent fully resolved topologies, the lateral region represent partially resolved trees and the centre unresolved trees. Consequently, high densities of dots in the lateral or centre regions indicate phylogenetic noise (Strimmer and von Haeseler 1997). Within the TREEPUZZLE framework maximum likelihood trees were made for each individual gene and the concatenated sequences using an HKY model of substitution (Hasegawa et al. 1985). Trees were viewed using FigTree version 1.3.1.

A neighbour-joining tree was made in Geneious according to the HKY model of evolution using the concatenated sequence. A Salmonella Typhi sequence ( $S$. TyphiTy2 [AE014613.1]) was used to root the tree as $S$. Typhi has been shown based on whole-genome comparisons to be highly monomorphic (Deng et al. 2003, Achtman 2008, Holt et al. 2008) and unrelated to other serovars (Holt et al. 2008, Liolios et al. 2010). Bayesian inference analysis was performed with software BEAST version 1.7.2 
(Drummond and Rambaut 2007) under an uncorrelated log-normal relaxed clock model and an HKY model of nucleotide substitutions, using the concatenated sequence. Final trees were manipulated in FigTree version 1.3.1 for display.

I used the Bayesian analysis tool Structure version 2.3.4 (Pritchard et al. 2000) to identify the number of ancestral populations which are included in the Salmonella sequences. Admixture and linkage models of structure were tested. Two independent runs were performed for each value of the number of populations $(\mathrm{K})$ ranging from one to five. Each run consisted of 50, $000 \mathrm{MCMC}$ iterations, of which 25,000 were discarded as burn-in. The optimal value of K (ancestral populations) was estimated by comparing the posterior probabilities of the data given each value of $\mathrm{K}$ from one to five, and identifying the value of $\mathrm{K}$ where the posterior probabilities plateau (Pritchard et al. 2009). Three independent runs were then performed using the estimated optimal value of $\mathrm{K}$ with 100,000 MCMC iterations and a 50,000 burn-in in order to determine the percentage of the three populations which contribute to each isolate.

Permutational MANOVAs (PERMANOVAs) were used to compare the genetic diversity within serotypes, hosts, locations, months and years. The PERMANOVA + package within the PRIMER 6 software was used to perform permanovas and multidimensional scaling analyses (Anderson and Gorley 2008).

\subsection{Results}

I investigated whether serotype could be predicted by molecular type by comparing allelic profiles of the sequences across the three genes. Two allele types were identified in each of the three genes investigated in this study and these allele types corresponded with serotype (Table 5.1). The genetic characteristics of each MLST gene are displayed in Table 5.3.The percentage of polymorphic sites ranged from $1.40 \%$ in dnaN to $5.19 \%$ in sucA. The GC content of each gene was consistent at approximately 58\% (Table 5.3). 
Table 5.3: Genetic characteristics of MLST genes, dnaN, sucA, thrA and the concatenated sequences. The size of the product, GC content and number of alleles and polymorphic sites per gene are displayed.

\begin{tabular}{lllll}
\hline Gene & $\begin{array}{l}\text { Size of product } \\
(\mathrm{bp})\end{array}$ & $\begin{array}{l}\text { G + C content } \\
(\%)\end{array}$ & $\begin{array}{l}\text { No. of alleles } \\
\end{array}$ & $\begin{array}{l}\text { No. of } \\
\text { Polymorphic } \\
\text { sites (\%) }\end{array}$ \\
\hline dnaN & 501 & 59.68 & 2 & $7(1.40)$ \\
sucA & 501 & 58.10 & 2 & $26(5.19)$ \\
thrA & 501 & 57.70 & 2 & $13(2.59)$ \\
Concatenated & 1503 & 58.50 & 2 & $46(3.06)$ \\
\hline
\end{tabular}

In order to determine clonality of Salmonella isolates on Stephens Island I investigated a number of evolutionary measures. The recombination rate of each of the three individual genes and the concatenated sequence was determined using LDhat and the results are summarised in Table 5.4. Using these analyses I have shown that the concatenated sequence and the thrA gene have high recombination levels which significantly deviated from the null hypothesis of zero recombination (LPT $=0.003$ and 0.010 respectively). Significant amounts of recombination were not seen in dnaN or sucA. The concatenated sequence and the individual sucA and thrA genes also had Tajima's D statistics of $<-0.05$ indicating that these genes are under purifying selection, the Tajima's D of dnaN was -0.039 indicating it is likely exposed to neutral selection. These results suggest that Salmonella isolates found on Stephens Island are not clonal but under the influence of moderate recombination. 
Table 5.4: Summary statistics of concatenated and individual genes of Salmonella. The number of segregating sites, measures of mutation $(\theta)$, recombination $(\rho)$ and the significance of recombination events (LPT) are shown. Recombination was found to be a significant evolutionary force in the diversity of Salmonella isolates on Stephens Island in $S u c A$ and the concatenated sequence (LPT $<0.05)$.

\begin{tabular}{lllll}
\hline & $\begin{array}{l}\text { Concatenated } \\
\text { sequence }\end{array}$ & dnaN & sucA & thrA \\
\hline $\begin{array}{l}\text { Segregating } \\
\text { sites }\end{array}$ & 46 & 7 & 26 & 13 \\
Mean pair- & 9.918 & 1.643 & 5.499 & 2.775 \\
wise distance & & & & \\
$\Theta$ & 10.948 & 1.666 & 6.188 & 3.094 \\
$\rho$ & 3.0 & 0.0 & 0.0 & 2.0 \\
Tajima D & -0.326 & -0.039 & -0.382 & -0.325 \\
LPT & 0.003 & 1.000 & 0.356 & 0.010 \\
$\mathrm{R}^{2}$ & 0.000 & 1.000 & 0.000 & 0.006 \\
\hline
\end{tabular}

A model of evolution was tested for the concatenated sequence using GARD and the best model was found to follow the F81 model (Felsenstein 1981). The F81 model is an extension of the simplest substitution model, the JC69 model (Jukes and Cantor 1969) which assumes equal base frequencies and equal mutation. The F81 model allows the frequencies of each nucleotide to differ and allows transitions and transversions to have different substitution rates. Hyphy also detected a breakpoint at nucleotide 1032 in the concatenated sequence (Figure 5.1). Figure 5.1 demonstrates evidence of varying levels of recombination throughout the Salmonella genome with the phylogenetic tree corresponding to nucleotides 1-1031 varying in the association of sequences as compared with nucleotides 1032-1503. This corresponded with an increased number of segregating sites in the SucA gene (Table 5.4). 
a.
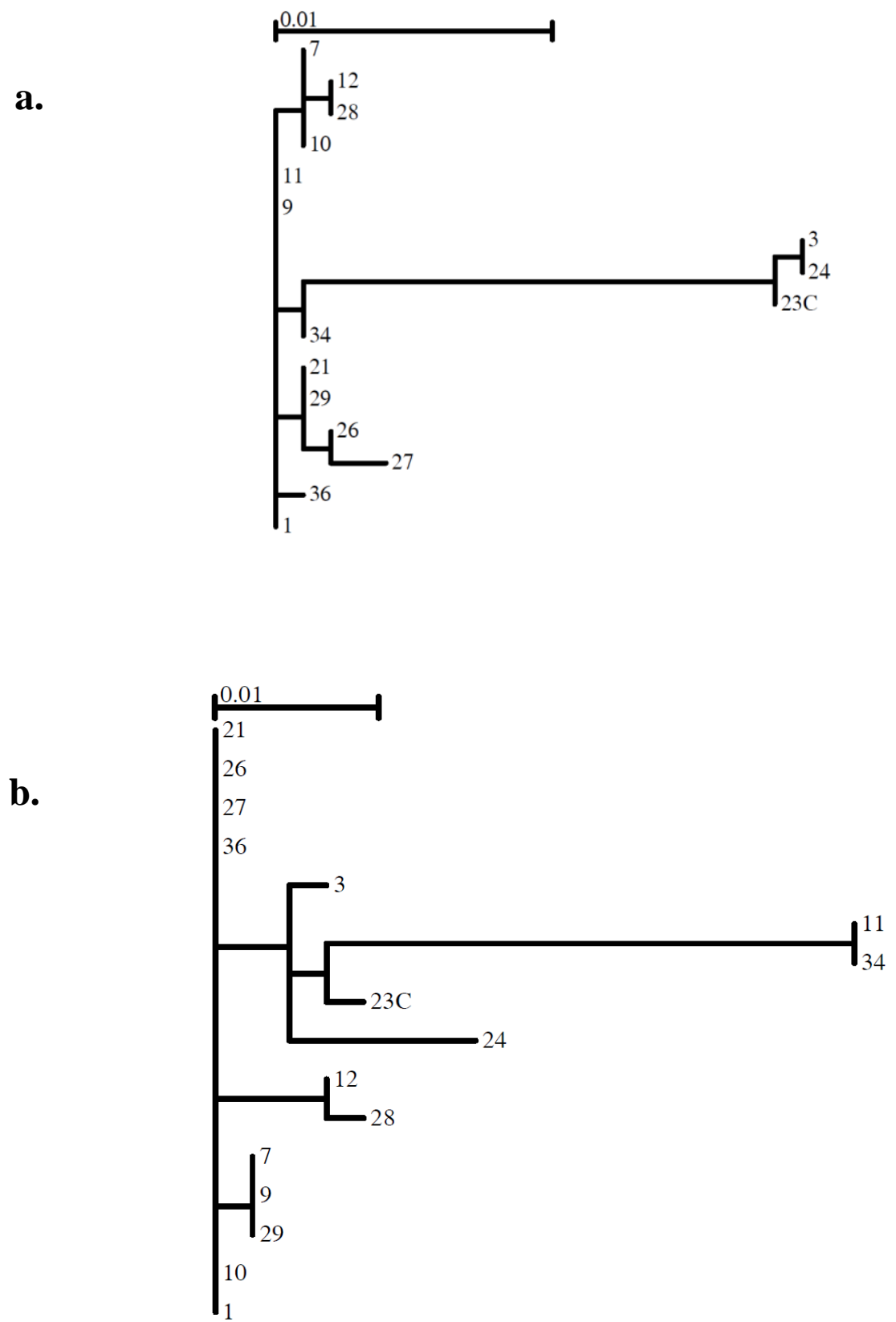

Figure 5.1: Phylogentic trees composed of nucleotides 1-1031 (a) and 1032-1503 (b), produced by determining recombination breakpoints in GARD, demonstrates evidence of recombination within the concatenated sequence as tree a varies in topology to tree $b$. 
Using this maximum likelihood phylogenetic framework, I measured the nonsynonymous/synonymous substitution rate of the concatenated sequence $\left(\mathrm{d}_{\mathrm{N}} / \mathrm{d}_{\mathrm{S}}\right)$. The mean $d_{N} / d_{S}$ ratio for the concatenated sequence in this study was 0.544 , further supporting the finding that the Salmonella sequences investigated are under purifying selection.

A likelihood mapping analysis was performed on the aligned concatenated sequences (Figure 5.2). The majority of quartets (53.8\%) were unresolved or only partially resolved indicating a large amount of phylogenetic noise in the sequences investigated. Consequently, all following phylogenetic trees must be interpreted with caution.

Three phylogenetic trees of the concatenated sequence, a neighbour joining tree, a maximum likelihood tree and a Bayesian inference tree, were compared to determine phylogenetic relationships among the Salmonella samples investigated. A neighbour joining tree, based on a concatenated sequence of the three MLST genes, showed a monophyletic lineage for serotype $S$. Mississippi (Figure 5.3). A similar pattern is seen in the maximum likelihood tree of the concatenated sequence (Figure 5.4), and in both the NJ and ML trees there is no other obvious clustering of isolates by location or host. The monophyletic lineage of $S$. Mississippi is supported by high tree-puzzling quartet support (91\%) (Figure 5.4). The deep branches of the ML tree receive very poor treepuzzling quartet support $(<70 \%)$, further supporting the findings from the likelihood mapping analysis that there is a lot of phylogenetic noise which means phylogenetic relationships must be interpreted with caution. 


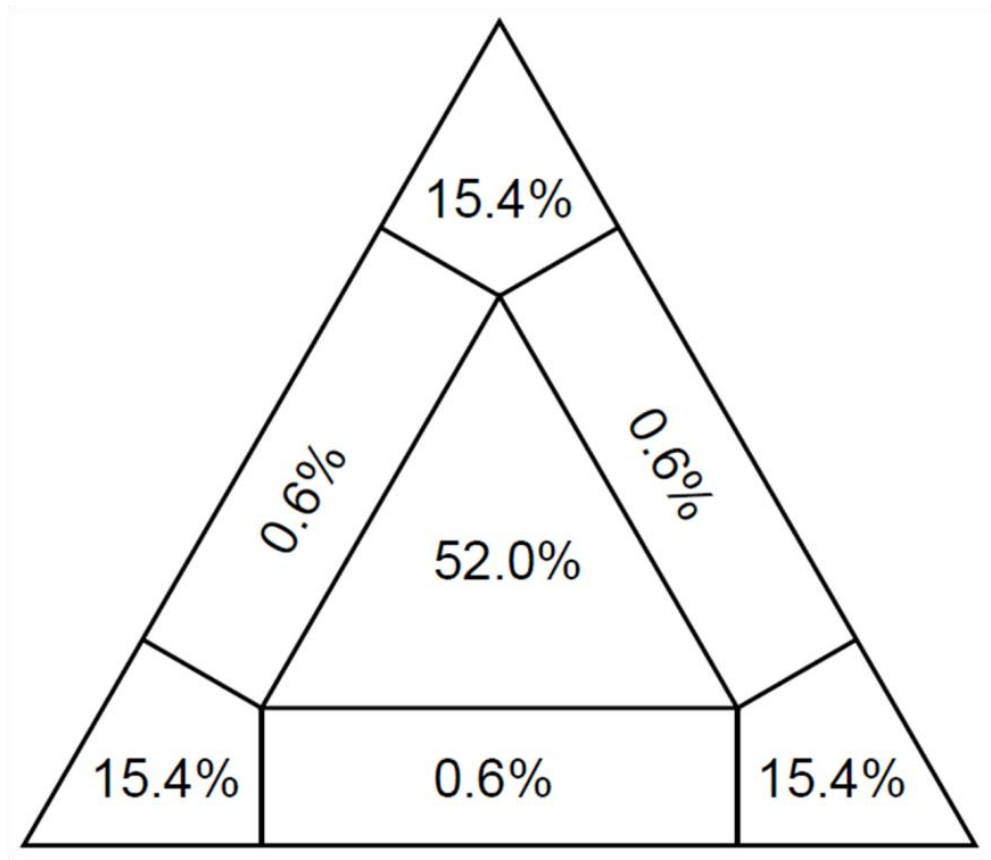

Figure 5.2: Likelihood mapping analysis of the sequence alignments of Salmonella present on Stephens Island. The regions of the corners of the triangles correspond to the three possible topologies of a quartet; the lateral regions to partly resolved trees and the central region to unresolved trees. The numbers indicate the percentage of quartets falling within each region. $52 \%$ of the trees in this study could not be resolved.

Bayesian phylogenetic analysis of concatenated $\operatorname{dnaN}$, sucA and thrA sequences also showed that $S$. Mississippi represents a monophyletic lineage (Figure 5.5). Once again this lineage was well supported with a high (1.0) posterior probability. Bayesian inference also found low support for deep branches of the tree with posterior probabilities of less than 0.3 (Figure 5.5). No monophyletic lineages were found for hosts, locations, months or years of Salmonella isolates. My analyses only identified one other lineage which was supported by posterior probabilities larger than 0.90 , which included isolates $11,34,35,37$ and 38. This lineage was identified by NJ, ML and BI trees. All of these isolates were obtained from skinks, but were found in all locations and in January and March of 2011, suggesting that there is no location or temporal influence on genetic structure of this lineage. I also compared sequences of isolates found within 1 metre of each other (from skinks and soil) and I found no clustering of sequences in this analysis. 
Individual gene trees for $\operatorname{naN} \operatorname{sucA}$ and $t h r A$ were also produced using the maximum likelihood method (Appendix C). The individual gene trees resembled one another in their topology and a large amount of similarity was observed in the clustering of strains within each gene. This provided further confirmation of the topology of the concatenated sequence.

Using the PERMANOVA package I found significant differences in the genetic structure of Salmonella among skinks and soil (PERMANOVA F=10.934, $P=0.0003$ ) and among serotypes (PERMANOVA F=87.669, $P=0.0003$ ). No similar genetic structure was found at the location (PERMANOVA F=1.100, $P=0.340$ ), month (PERMANOVA F=0.492, $P=0.717$ ) or year (PERMANOVA F=0.295, $P=0.735$ ) levels (Figure 5.6). There is also a pattern to the genetic diversity within hosts, as soil samples are found to belong to only one cluster, in contrast skink samples can be found in three different clusters (Figure 5.6).

In order to investigate the number of ancestral populations which contribute to the genetic diversity with the Salmonella samples, I applied the admixture and linkage models of Structure (Pritchard et al. 2000, Falush et al. 2003) to my data. The posterior probabilities varied across all values of $\mathrm{K}$ in the linkage model (Figure 5.7a), so I subsequently settled on an admixture model. The admixture model identified $\mathrm{K}=3$ ancestral populations in the sample (Figure 5.7b). 


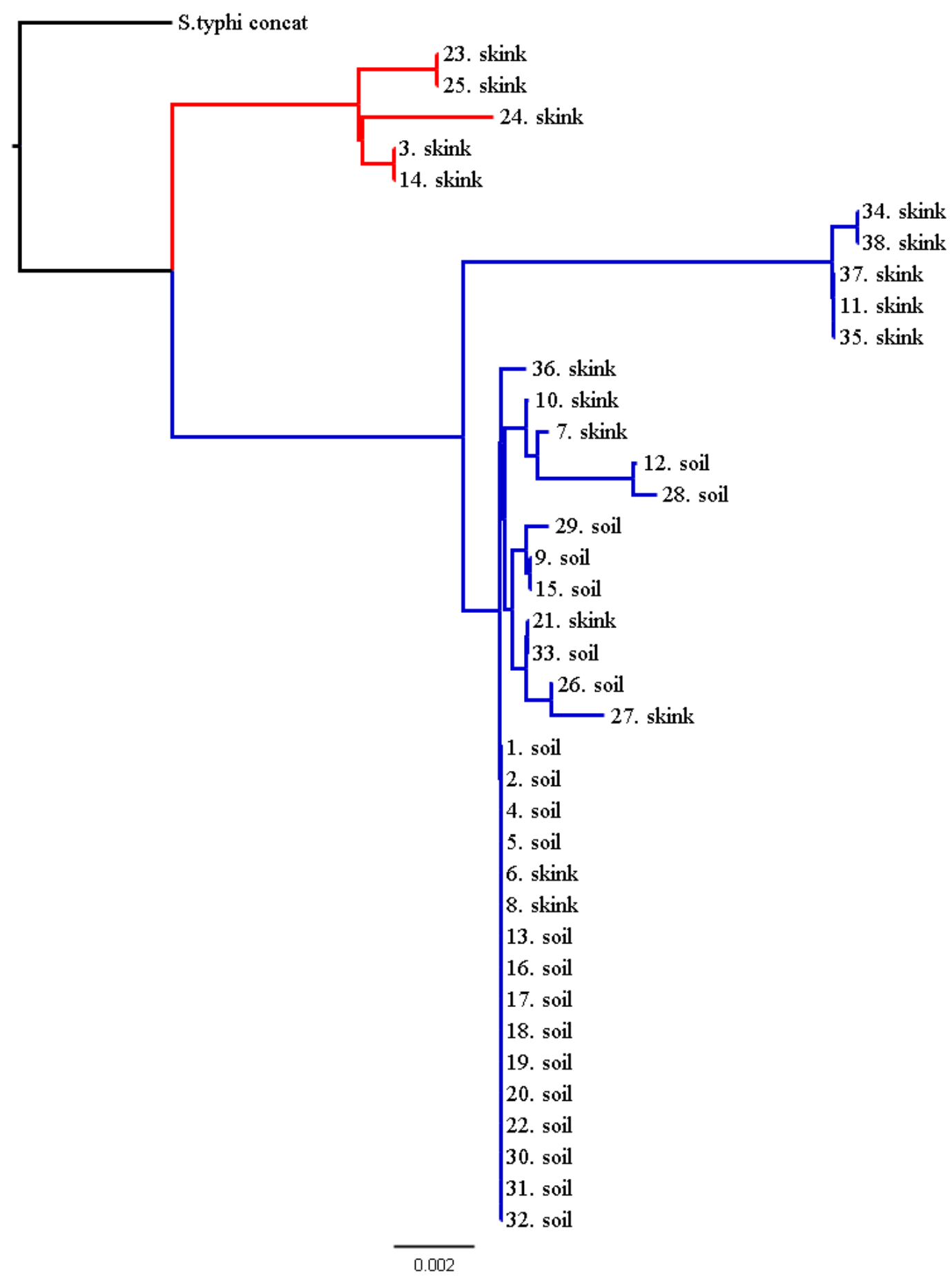

Figure 5.3: A neighbour-joining, bootstrapped tree of Salmonella samples from

Stephens Island. The sample ID and whether the isolate came from skinks or soil are shown. The tree shows that $S$. Mississippi isolates (red) are in a different clade to $S$. Saintpaul (blue). The horizontal scale represents distances among strains, a scale of 0.002 means that the strains possess $99.8 \%$ nucleotide identity. The tree is rooted using $S$. Typhi as the out-group. 


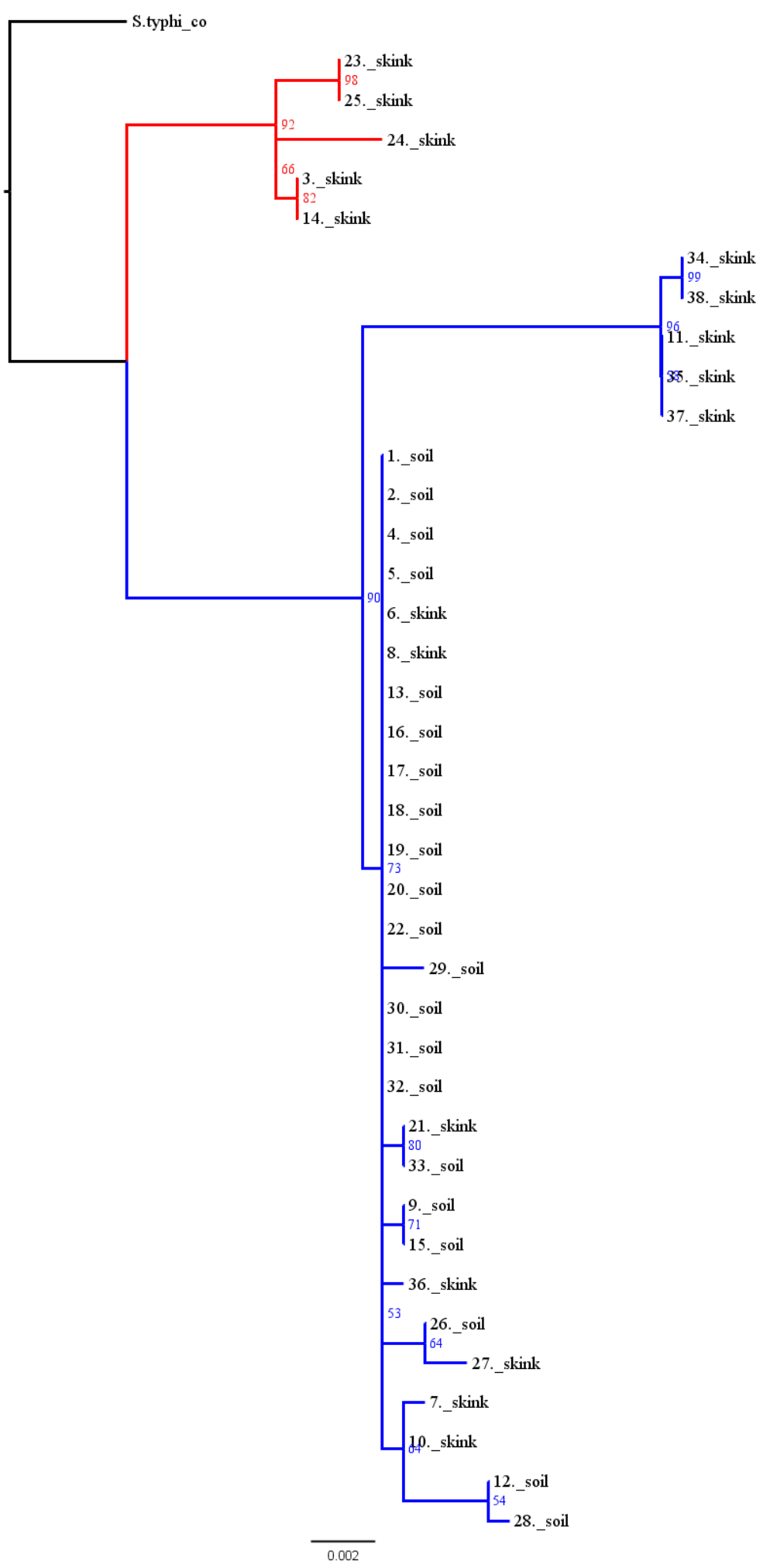

Figure 5.4: Maximum likelihood tree of Salmonella concatenated sequences. Treepuzzling quartet support is shown at the nodes of each branch. Deep branches receive very low support. Isolates serotyped as $S$. Mississippi (red) are found in a different clade to $S$. Saintpaul (blue). The horizontal scale represents distances among strains. The tree is rooted using $S$. Typhi as the out group. 


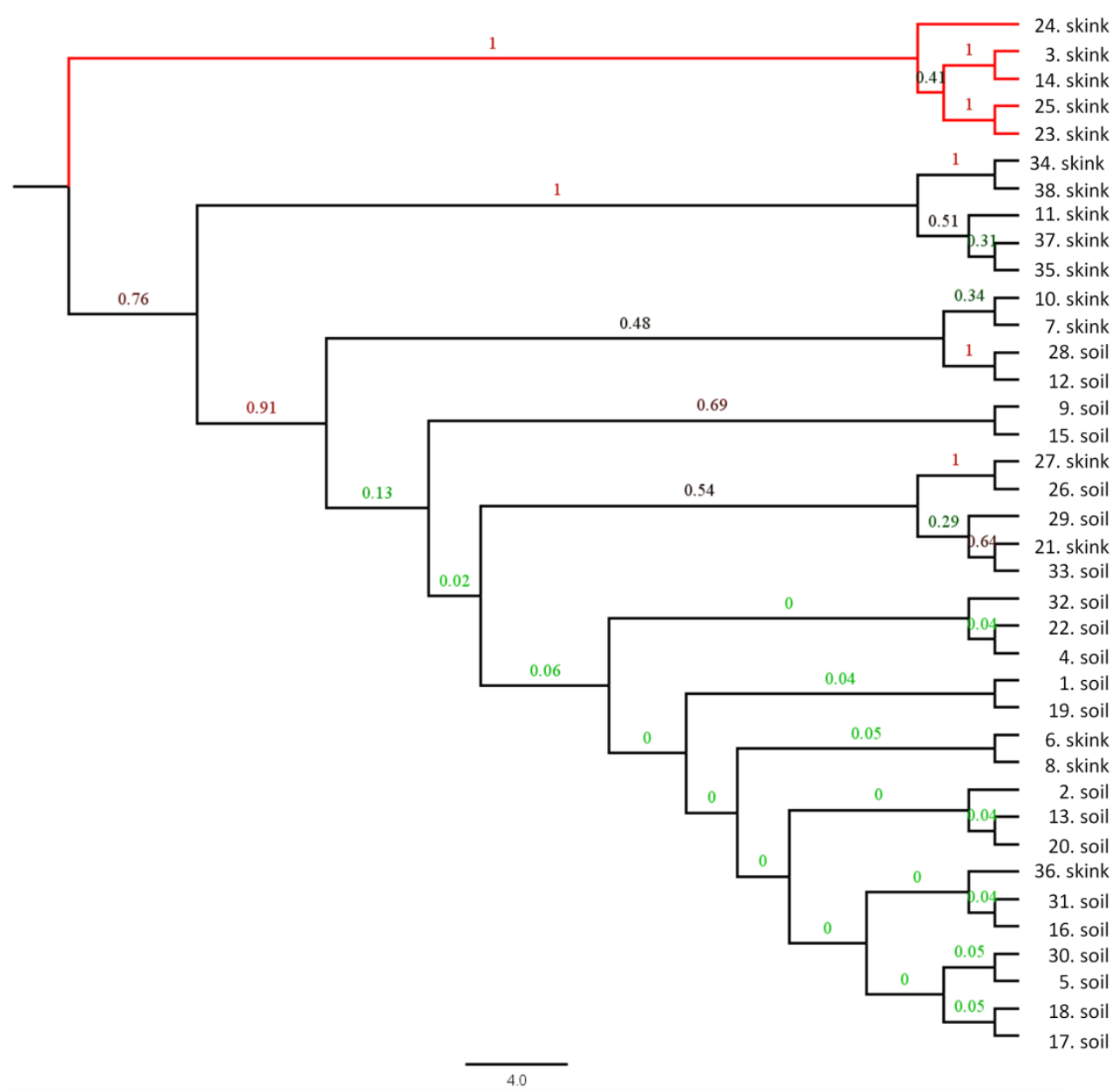

Figure 5.5: A Bayesian inference phylogenetic tree for all sequence types found among 38 Salmonella isolates based on sequencing of three genes. The phylogenetic tree was built using a Bayesian model using a concatenated alignment ThrA, dnaN and sucA. Posterior probabilities are shown above the branches and coloured from green (low support) to red (high support). The scale bar indicates relative sequence distance. Sequence ID (Table 5.1) is given at the end of branches, with isolates identified as $S$. Mississippi coloured red and S. Saintpaul blue. 


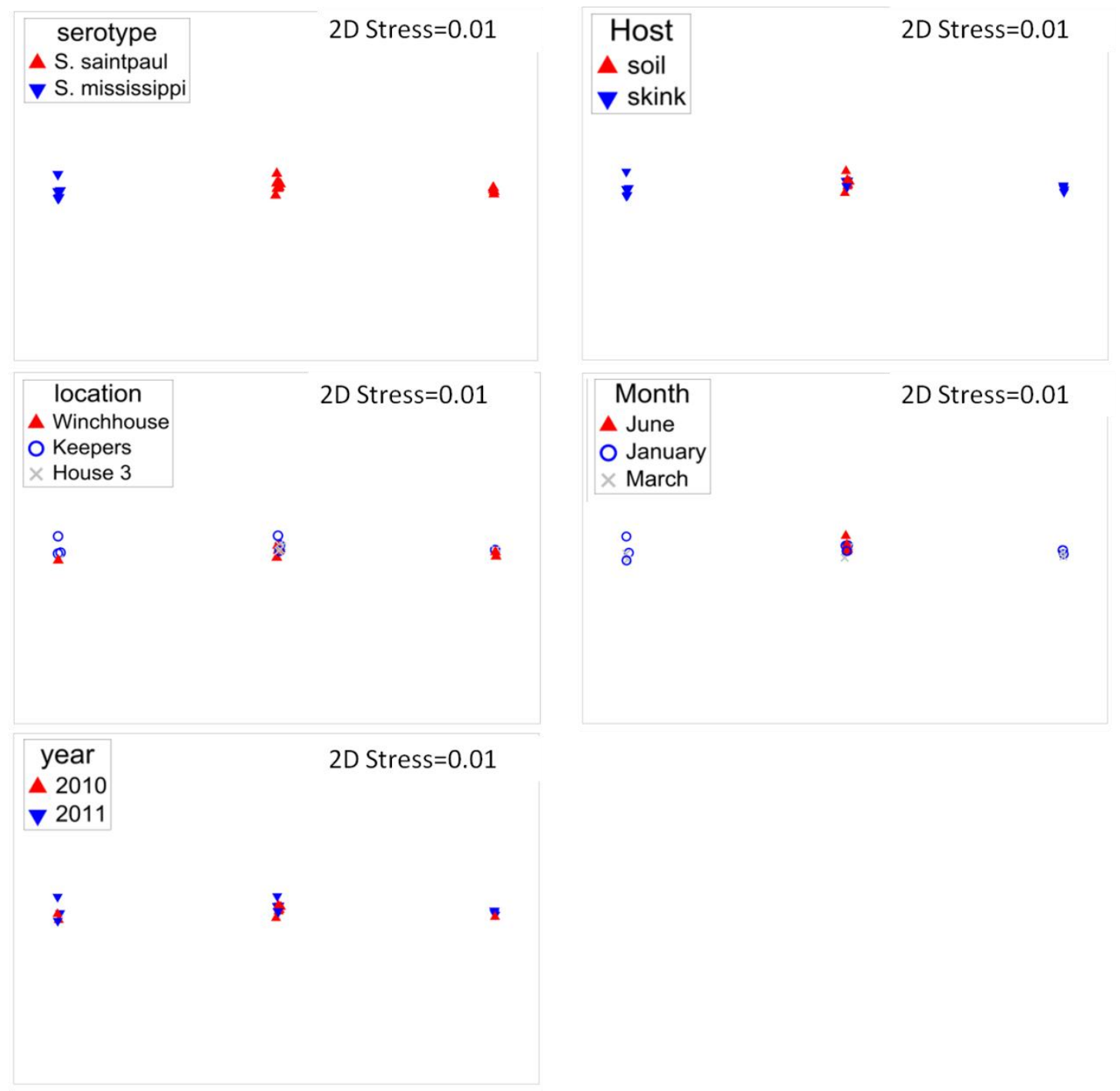

Figure 5.6: Non-metric multidimensional scaling (MDS) ordination of 38 isolates of

Salmonella by serotype, host, location, month and year shows that serotype and host are the only factors significant in explaining diversity within the sequences. The figure shows the distribution isolates between the three ancestral populations. For example, $S$. Mississippi isolates are from one predominant population, in contrast the diversity within S. Saintpaul isolates arises from two main ancestral populations. 


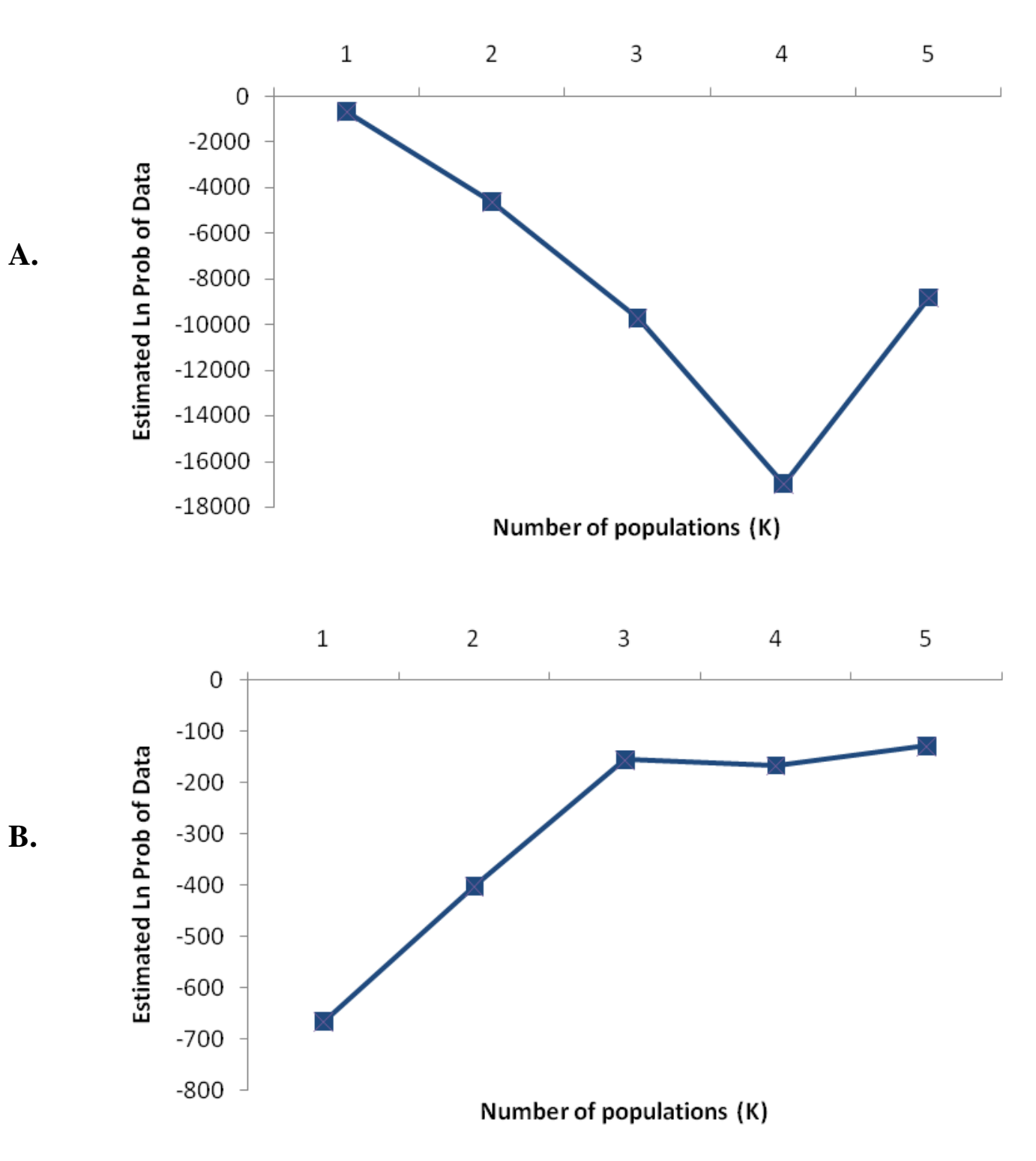

Figure 5.7: The posterior probabilities of the number of populations in Structure for admixture (A) and linkage models (B). The most likely value of $\mathrm{K}$ for the admixture model is 3 . The posterior probabilities vary over all values of $\mathrm{K}$ for the linkage model and therefore this model was discarded in further analyses. 


\subsection{Discussion}

Multi-locus sequence typing is a highly discriminatory method of determining molecular relationships among isolates. I have investigated the population structure of Salmonella in native fauna within an island ecosystem using a three-gene MLST scheme. MLST typically uses seven-genes to achieve a high discriminatory power, but other studies have shown that a three-gene sequence typing scheme may have sufficient discriminatory power to allow serotype prediction and lineage discrimination within Salmonella (Sukhnanand et al. 2005). This is the first investigation into the population structure of Salmonella in New Zealand by MLST.

Allele types were assigned for each of the three genes, dnaN, sucA and thrA, to all of the 38 isolates investigated. Only two allele types were identified for each gene and these corresponded directly with the serotype of the Salmonella isolate, confirming findings from other studies that three-gene MLST typing methods can provide a reliable method of serotype prediction (Sukhnanand et al. 2005). In standard seven-gene sequence typing methods the seven allele types would be combined to provide a unique ST number for each sequence. The relationships among these ST numbers can then be further investigated using the eBurst programme. As I was only able to amplify three genes for the isolates obtained in this study, I was unable to determine ST numbers for each sequence. However, the three gene scheme provided more discriminatory power allowing a basic investigation into phylogenetic histories that is not possible with serotyping alone.

Bacterial populations reproduce asexually by binary fission, so in principle the populations are clonal in structure, with each daughter cell containing an identical chromosome to the mother cell. In reality however, gene mutations and lateral gene transfers (recombination) mean that bacterial populations are rarely strictly clonal (Spratt and Maiden 1999). Bacterial species and populations vary in their level of clonality based on the amount of recombination and mutation that exists in their genome. I investigated the clonality of Salmonella isolates obtained from skinks and soil on Stephens Island using a concatenated sequence of all three genes. I found evidence of high levels of recombination in the thrA and concatenated sequences. Several studies have also found evidence of recombination and a low level of clonality 
within Salmonella enteric subspecies I serovars (Octavia and Lan 2006, Didelot et al. 2011). However, other studies have found limited evidence of recombination and suggest a clonal population structure (Beltran et al. 1988, Boyd et al. 1996, Sukhnanand et al. 2005). Other bacterial species such as H. pylori, N. gonorrhoeae, N. meningitides and S. pneumonia are also known to have low levels of clonality (Perez-Losada et al. 2006). The difference in measured recombination may be due to different algorithms or because different populations of Salmonella may exhibit varying degrees of clonality.

Evidence of purifying selection was found using both LDhat and $d_{N} / d_{S}$ rates. Purifying selection acts to eliminate selectively deleterious mutations, which could severely impact the function of genes. It is therefore not surprising that house-keeping genes which are essential for the maintenance of basic cellular functions would be under this type of selection. House-keeping genes in a variety of species have been shown to also be under purifying selection (Duret and Mouchiroud 2000, Viscidi and Demma 2003, Zhang and Li 2005).

The evolutionary consequences of recombination, mutation and selection discussed above can be described using combinations of three phylogenetic models: bifurcating trees, bundles and nets (Maynard Smith 1989). The bifurcating tree has for a long time been the predominant method for the reconstruction and visualisation of phylogenetic history. Under this model each member of a population is assumed to be related by a series of direct antecedents. Although this model can be appropriate for reconstructing the phylogenies of clonal populations, the more recombination there is in a population, the less useful it becomes, as any given member of a population may have acquired genetic material from a variety of other members of the species or even from closely related species (Spratt and Maiden 1999). I investigated how well my data were suited to phylogenetic analyses by bifurcating trees by investigating the percentage of topologies which could be resolved using likelihood mapping. The majority of topologies $(52 \%)$ in this study were unresolved (fell in the central part of the triangle). A quartet-puzzling tree is thought to be not completely resolved when the frequency of unresolved topologies is greater than $15 \%$, and a high percentage of unresolved or partially resolved quartets generally indicates that the data are poorly suited to phylogenetic analyses (Strimmer and von Haeseler 1996). Consequently, I have shown that Salmonella samples on Stephens Island undergo recombination at a moderate rate, 
which means that investigating phylogenies by bifurcating trees alone will not accurately depict the true phylogenetic relationships within the population.

In many bacterial species, house-keeping loci accumulate genetic variation by recombination as frequently, or more frequently, than by point mutations (Feil et al. 2003, Feil et al. 2004). In order to accommodate the recombination within a phylogeny, networks or bundles (star phylogenies) must be investigated. In practice these nets and bundles can become very complex, and can only be reconstructed for small parts of the genome over a relatively short period of time (Spratt and Maiden 1999). The eBurst (based upon related sequence types) algorithm can help to display phylogenies obtained by MLST, which have undergone frequent recombination (Feil et al. 2004). According to this algorithm sequences are assigned allele numbers at each of the seven loci. A sequence type (ST) is then assigned to each sequence based on its allelic profile. Clonal complexes (closely related genotypes) are then investigated and the founding genotype of each clonal complex is mapped (Feil et al. 2004). With seven genes, this technique would have allowed me to visualise the net or bundle phylogenies within my dataset. Future research should aim to amplify the full complement of genes so that this valuable algorithm can be performed.

Although I have shown that the Salmonella isolates in the Stephens Island population are influenced by recombination, it is still useful to investigate phylogenies using phylogenetic trees since most populations of bacteria cannot be described using just one of any of the three phylogenetic networks described as different parts of the genome are likely to be influenced by different phylogenetic networks (Spratt and Maiden 1999). The three types of tree investigated in this study, neighbour joining (NJ), maximum likelihood (ML) and Bayesian inference (BI), all found very similar phylogenetic relationships among the Salmonella isolates investigated. S. Mississippi consistently separated out into its own clade, but I found no other phylogenetic relationships at the host, location, month or year level (Table 5.1 and Chapter Two). I also considered the relatedness of isolates found less than $1 \mathrm{~m}$ apart from each other and did not find any phylogenetic relationships, that is, soil and skink samples in close proximity were not found to have closely related nucleotide sequences. Internal branch support was estimated for the maximum likelihood tree using quartet puzzling (QP). Those branches which have QP support of $>90 \%$ are considered to have very strong support. 
Branches with $<70 \%$ QP are poorly supported. The ML tree of the concatenated Salmonella sequence had very low support at deep branches $(<60 \%)$, which further supports the finding of substantial phylogenetic noise identified in the likelihood mapping analysis. Testing the full complement of seven house-keeping genes may help to reduce noise. However, other studies have found that they were still unable to determine the phylogenetic relationships among Salmonella based on the results of their seven-gene MLST schemes, particularly where they found a low level of clonality (Octavia and Lan 2006). High recombination levels have been shown to abolish genome-wide phylogenetic signals (Feil et al. 2001, Hiller et al. 2010).

Given the popularity of MLST subtyping methods for other bacteria, there are surprisingly few studies on Salmonella which utilise this technique in the primary literature. MLST offers the advantage of being able to trace phylogenetic histories and determine source populations of outbreaks, and once set up it is easily replicated between laboratories, but other methods such as MLEE, phage-typing and PFGE have been demonstrated to have higher within-serotype discriminatory power (Sukhnanand et al. 2005). Another challenge facing researchers utilising the MLST scheme is the design of appropriate primers that will allow for PCR amplification and sequencing of isolates representing the majority of the more than 2500 serotypes. For example, panB and icdA primers used in other studies have not allowed for amplification of the respective genes in $S$. Schwarzengrund isolates (Sukhnanand et al. 2005). Other studies have reported that the primers $m a n B, p d u F$ and $g l u A$ were only successful in amplifying the respective genes in $75 \%$ to $94 \%$ of the Salmonella isolates tested (Kotetishvili et al. 2002). It is possible that the failure to amplify the remaining MLST genes, purE, hisD. aroC. and hemD in my study may also be associated with primer design. Future investigation could involve the design of new universal primers for these genes based on whole genome sequences of various Salmonella serotypes (Porwollik and McClelland 2003, Sukhnanand et al. 2005).

I have provided important baseline information on relative contributions of recombination, selection and mutation on the genetic diversity of Salmonella in New Zealand native fauna. The isolates of Salmonella from skinks and soil on Stephens Island were found to exhibit moderate levels of recombination, but were under purifying selection, therefore limiting the number of deleterious mutations. 
Determining the amount of recombination that occurs in a population provides an important contribution to our understanding of the epidemiology and pathogenicity of this organism. Recombination increases the risk of new highly pathogenic strains of bacteria emerging, and understanding the contribution of recombination to genetic diversity provides direction to epidemiological investigations.

I have also obtained the first insights into the population structure of Salmonella in New Zealand, and demonstrated that more loci need to be amplified in order to fully visualise the complex network of phylogeny of Salmonella. I found that serotype corresponds to phylogeny in the case of $S$. Saintpaul and $S$. Mississippi, with each serotype separating into its own clade, and confirmed that isolates on Stephens Island arise from three source populations. Obtaining information on Salmonella isolates from both New Zealand and overseas would help identify source origins for the three ancestral populations, and contribute to risk analyses for prevention of future introductions of Salmonella to native fauna. 


\section{CHAPTER SIX}

\section{Understanding the ecological and immunological}

\section{relationships between Salmonella and tuatara}

\subsection{Introduction}

The number of emerging infectious diseases of both humans and animals is increasing (Jones et al. 2008). A large proportion of these diseases are zoonotic, and the consequences of this increase in infectious disease for wildlife, both as potential reservoirs of disease and in their susceptibility to disease, are a growing source of interest (Daszak et al. 2000, Daszak et al. 2001, Jones et al. 2008). Consequently, there is critical need for investigations which integrate and clarify both the epidemiological aspects of disease distribution and spread with the immunological responses of wildlife to common and widespread pathogens.

Salmonella is a zoonotic pathogen known to infect animals across a broad taxonomic spectrum including cattle, reptiles, birds and mammals (Woodward et al. 1997, Mermin et al. 2004, Carlson et al. 2011). Reptiles have often been implicated as carriers and transmitters of Salmonella, and reptile-associated salmonellosis has been linked to disease in humans, domestic animals and other wildlife (Johnson - Delaney 1996, Woodward et al. 1997, Burnham et al. 1998, Mermin et al. 2004, Mader 2006). Although the occurrence of Salmonella infections in humans, domestic animals and animal reservoirs has been monitored overseas, few studies have examined the prevalence of this pathogen in New Zealand wildlife (Gartrell et al. 2006, OrtizCatedral et al. 2009, Middleton et al. 2010). Knowledge of the abundance, distribution and dynamics of Salmonella ecology is essential to understanding the ecological role of this pathogen in host populations and in measuring the threat of Salmonella to native fauna. 
I examined the prevalence of Salmonella in an island ecosystem and selected one species, the tuatara, for in-depth immunological analyses. Tuatara are reptiles, and the only extant members of their order Rhynchocephalia. Approximately 230 million years ago tuatara diverged from their closest living relatives, the squamates (Holdaway and Worthy 1997). As ectotherms that are active primarily at night in a temperate climate, several environmental factors such as habitat and season, together with individual characteristics such as sex, parasite load and body condition can affect the dynamics of disease within this species (Burnham et al. 2005;2006, La Flamme et al. 2010). Using ecological, immunological and genetic analyses provided the most complete picture of the tuatara-Salmonella relationship to date. Investigation of the abundance and distribution of Salmonella in an island ecosystem has provided important baseline information on the prevalence and serovars of Salmonella in New Zealand native fauna while research on the innate and adaptive immune responses of tuatara to Salmonella provides important information on the exposure and susceptibility of tuatara to this pathogen.

The study of the ecological and immunological relationships between Salmonella and tuatara contributes to a broader understanding of disease ecology and the effects of translocations that alter pathogen transmission pathways within and between species. Understanding the spatio-temporal dynamics of disease and susceptibility of individuals to common pathogens is fundamental in successful management of wildlife populations, consequently the findings of this thesis addressed key questions for conservation. Further, these results can be used to improve disease monitoring and to develop further research into how climatic change may influence future disease dynamics.

Key questions addressed were:

-What is the prevalence and distribution of Salmonella in an island ecosystem?

- Do tuatara have antibodies against Salmonella?

- Does tuatara serum exhibit anti-microbial activity against Salmonella?

- How are tuatara immune responses affected by season?

- What is the genetic population structure of Salmonella in skinks and soil on Stephens Island? 


\subsection{Summary of major findings}

The major findings are briefly summarised as follows:

\section{1) Chapter Two - The abundance and spatio-temporal dynamics of Salmonella in an island ecosystem}

In order to determine the prevalence and seasonal distribution of Salmonella on Stephens Island cloacal swabs or faecal samples were collected from tuatara, fairy prions, skinks and weta and tested for Salmonella carriage. Soil samples collected from inside tuatara and/or fairy prion burrows were also investigated. Two serovars of Salmonella, S. Saintpaul and S. Mississippi, were isolated from skinks and soil samples from Stephens Island. S. Mississippi was isolated only from skinks and $S$. Saintpaul was found in both skink and soil samples. Both serotypes were found in the three study sites investigated and across all seasons. Salmonella was found in skinks on Stephens Island at a prevalence of $6.5 \%$ and an estimated true prevalence of $10 \%$. Soil samples collected from inside tuatara burrows had a Salmonella prevalence of $8.4 \%$ and an estimated true prevalence of $12.5 \%$. No Salmonella was identified in 620 tuatara, 190 fairy prions or 200 tree weta sampled. Salmonella was not isolated from any species investigated in this study during either of the two October sampling periods. Therefore, there may be a seasonal or temperature aspect to Salmonella distribution and transmission on Stephens Island. Salmonella appears to be a persistent pathogen on Stephens Island, but not all species on the island are carriers of the serovars isolated in this study. Tuatara, fairy prions and weta have the potential to be exposed to Salmonella through environmental contamination and consumption of infected prey but it is highly unlikely that they are carriers of the bacterium on Stephens Island. The two serovars of Salmonella found in this study, $S$. Saintpaul and $S$. Mississippi, are generalist serotypes which are found in a variety of animal species throughout the world. Therefore host adaption to the skinks is not the cause of the lack of Salmonella detection in tuatara, fairy prions or weta. Immunity is therefore a potential cause of the lack of Salmonella detection. 


\section{2) Chapter Three - Presence of antibodies to Salmonella in tuatara sera}

In Chapter Two I demonstrated that tuatara are likely to be exposed to Salmonella through contact with soil in their burrows and infected skinks sharing habitats with tuatara. In Chapter Three I aimed to determine whether tuatara had antibodies against Salmonella and how much of the antigen recognition could be attributed to cross-reactivity. Tuatara have antibodies which recognise both lysed and live Salmonella cells. Much of this recognition can be attributed to cross-reactivity with the closely related bacteria, Escherichia coli and Citrobacter koseri. However, there is 5-10\% of Salmonella recognition which cannot be attributed to cross-reactivity with $E$. coli or $C$. koseri. This suggests that tuatara may have mounted a specific immune response against $S$. Saintpaul, further supporting the hypothesis that they are exposed to this pathogen. However, I only tested for cross-reactivity against two closely related pathogens. The remaining antibodies may be due to cross-reactivity with other bacteria not investigated in this study. Antibody recognition of a potential pathogen, whether specific to that antigen or crossreactive with other antigens, will result in the initiation of the adaptive immune response and may aid in preventing or reducing a systemic infection. The importance of these antibodies in preventing bacterial colonisation remains unclear, as without controlled experiments exposing tuatara to Salmonella we cannot be sure of the reason for the lack of detection of Salmonella in tuatara or the route of prevention of colonisation. The strength of the antibody response to $S$. Saintpaul and C. koseri was strongly influenced by season with a much greater amount of recognition occurring in samples obtained from tuatara during summer. This corresponds with an increased prevalence of Salmonella on the island in summer as compared to October when I found no Salmonella in either skinks or soil. 


\section{3) Chapter Four-Anti-microbial activity of tuatara sera}

In Chapter Four I aimed to determine whether tuatara sera has anti-microbial activity against Salmonella and to compare this activity with that found in other reptile species. Innate immunity plays an important role in defence against microorganisms in most vertebrate species. Tuatara sera effectively inhibits the growth of $S$. Saintpaul, as well as E. coli and C. koseri. The anti-microbial activity of tuatara serum against $S$. Saintpaul was similar to two other reptilian species investigated; Australian water dragons and coastal bearded dragons, but it was significantly more effective at killing all three bacterial species than donkey or mouse sera. The anti-microbial activity of tuatara sera was not limited by moderate heat treatment $\left(55^{\circ} \mathrm{C}\right)$ or significantly reduced by size exclusion of proteins $>10 \mathrm{kDa}$, indicating that the anti-microbial activity seen in tuatara is peptide rather than complement-mediated. In contrast the antimicrobial activity of Australian water dragons and coastal bearded dragons was largely complement-mediated.

\section{4) Chapter Five-The population structure of Salmonella from skinks and soil} in New Zealand

The members of bacterial populations vary in a multitude of different ways and by integrating a variety of different methods including genetic, evolutionary and epidemiological studies, the origins and transmission of bacterial diseases can be better understood (Spratt and Maiden 1999). In Chapter Two, I used traditional immunological typing methods (serotyping) to investigate the spatiotemporal dynamics of Salmonella in an island ecosystem. In Chapter Five, I investigated the same isolates of Salmonella using a multi-locus sequence typing (MLST) scheme, which allowed me to investigate the population structure at the molecular level. MLST schemes can be used to answer questions such as what are the relative contributions of recombination, mutation and selection on the population structure of Salmonella as these factors can cause rapid evolution in bacterial species and result in increased pathogenicity and multi-drug resistance in recombined isolates (Perron et al. 2011). Also, understanding molecular 
signals may help us understand transmission pathways and establish risk analyses.

Using the primers and genes suggested on the Salmonella MLST database, I experienced significant difficulties amplifying genes to a standard which would allow clear sequencing, and consequently only three of the potential seven MLST genes were investigated. Although I only used a three gene scheme, I found that this had substantial discriminatory power and was able to differentiate the two serovars of Salmonella and confirm identities of serotypes found in Chapter Two. Each isolate was assigned an allele type for each of the three genes via the MLST website. I found only two allele types in each gene and these corresponded directly with the serotype. There was a significant amount of phylogenetic noise in the data which obscured the phylogenetic relationships between many of the isolates. However, $S$. Mississippi did separate into a monophyletic clade which received strong support in both the maximum likelihood and Bayesian inference trees by tree-puzzling quartet and posterior probability.

In summary, I used a classical MLST scheme to elucidate the population structure of Salmonella at the molecular level and adapted methods which will aid our understanding of the epidemiology, pathogenicity and transmission of Salmonella within native fauna.

\subsection{Ecological and immunological relationships between Salmonella and tuatara}

I aimed to understand the ecological and immunological relationships between Salmonella and tuatara. I demonstrated that tuatara are probably exposed to Salmonella through contact with infected skinks and soil in their environment. Salmonella was not isolated from fairy prions despite other species of seabirds being common carriers of Salmonella both overseas and in New Zealand (Clark 2001, Tizard 2004, Pennycott et al. 2006). I also have shown that tree weta are unlikely carriers of Salmonella on 
Stephens Island. This is the first study which has investigated the prevalence of Salmonella in invertebrate hosts in New Zealand. There have been studies overseas on the importance of invertebrates as reservoirs of Salmonella and Salmonella has been isolated from a variety of invertebrate hosts including ants, flies, cockroaches, mealworms and mosquitoes (reviewed in Hoelzer et al. 2011). Insects have been shown to play a pivotal role in the persistence of Salmonella by transmitting Salmonella between chickens on poultry farms and flies have been implicated as important vectors of $S$. Typhi in military camps (Hoezler et al. 2011).

Given the potential for tuatara to be exposed to Salmonella in their environment, I used antibodies to investigate Salmonella exposure and immunity within wild and captive tuatara. I was not successful in determining seroprevalence of Salmonella in tuatara using the techniques utilised in this study due to the high antigenic cross-reactivity between Salmonella and closely-related bacterial species that are normal colonisers of tuatara. However, I have shown that tuatara serum contains antibodies which recognise and bind whole Salmonella bacteria and these antibodies are found in captive and wild tuatara. While this antibody may have been induced by prior exposure to another bacterium, it still binds Salmonella and thus, has the potential to mediate protective immunity. Further research is needed to verify the importance of these antibodies in preventing salmonellosis in tuatara.

Expanding on the immune responses of tuatara to Salmonella, I investigated one aspect of innate immunity, anti-microbial activity by serum factors. Anti-microbial activity has been demonstrated to be an important part of the immune response in many species of alligator and crocodile and an important mode of defence in reptiles in general (Merchant and Britton 2006, Merchant et al. 2006a, Merchant et al. 2006b, Siroski et al. 2010). I have demonstrated that tuatara sera has anti-microbial activity against all of the bacteria tested, S. Saintpaul, E. coli and C. koseri. This finding provides some evidence of a defence against systemic Salmonella and other bacterial infections in tuatara.

Anti-microbial activity can arise as a result of complement-mediated immunity or antimicrobial peptides. Through heat-inactivation and size exclusion of proteins $>10 \mathrm{kDa}$ in tuatara sera, I demonstrated that the anti-microbial activity seen in tuatara is largely 
peptide-mediated. In contrast, much of the anti-microbial activity seen in alligators and crocodiles is complement-mediated, suggesting different modes of immunity among these species of reptile (Merchant and Britton 2006, Merchant et al. 2003). I have investigated serum anti-microbial peptides which have been shown in other species to effectively reduce and prevent systemic infections by bacterial pathogens (Hancock and Scott 2000). In mammals serum anti-microbial peptides such as defensins, have been shown to be secreted into areas such as the gastrointestinal tract and greatly reduce the likelihood of bacterial colonisation (Bevins 1999). In contrast, complement-dependent anti-microbial activity is likely to be less effective against bacterial colonisation, depending upon the presence of complement at the mucosal surface. Therefore, tuatara may in fact be better able to prevent gastrointestinal colonisation by Salmonella, E. coli and $C$. koseri than crocodiles and other species with predominantly complementmediated anti-microbial activity. This may also help to explain why Australian water dragons and coastal bearded dragons which had higher anti-microbial activity than tuatara are also known shedders of Salmonella.

It is interesting that tuatara have not been shown to be shedders of Salmonella in this or other studies (Gartrell et al. 2006;2007) but native geckos and skinks which share the same habitat and therefore experience the same annual temperature cycles and potential for infection are known shedders (Middleton et al. 2010). The evolutionary implications of this should be considered in future studies. There are several possible explanations for the lack of Salmonella in tuatara. Firstly, the apparent immunity could be lineage specific, a trait which has evolved in and is restricted to the Rhynchocephalians. Alternatively, the lack of colonisation may be due to a physiological trait of the tuatara, for example their lower body temperature. Besson and Cree (2011) showed that tuatara do not have lower preferred body temperatures than McCann's skinks. This may first appear to rule out temperature as a potential factor influencing Salmonella colonisation. However, more investigation is required to understand immune functions at different temperatures in different species of reptile. If the tuatara immune response is more effective at lower temperatures than the immune responses of other reptiles then this coupled with the slower growth rates of Salmonella at low temperatures could explain the lack of colonisation in tuatara. 


\subsection{Conservation implications}

Translocations are a very commonly utilised tool in conservation management both in New Zealand and overseas. Large numbers of animals have been moved throughout New Zealand in an attempt to restore wildlife to their pre-human ranges, with more than 260 translocations of 66 animal species occurring between 1960 and 2000 (Craig et al. 2000). Translocations aimed at restoring tuatara to parts of their former range have also occurred since the mid-90s (Mitchell et al. 2008). The presence and possible spread of disease is an important consideration when translocating wildlife. Animals born and bred in a captive breeding facility or captured from a wild population will have acquired local infections and may be symptomless carriers of disease. If these animals are translocated to new areas they may introduce pathogens to animals existing in the area. This could have a severe impact on the wild and domestic animals found around the release site (Woodford and Rossiter 1994). For example, captive-bred Mojave Desert tortoises (Xerobates agassizii) sourced from pet shops in California were released back into the Mojave Desert and these reptiles are believed to have infected the wild tortoises with a fatal respiratory disease probably acquired in the pet shop (Jacobson et al. 1991). It is not just the possibility that translocated animals will carry diseases endemic to the area in which they were born that is of concern, but also that they will inevitably lack the acquired immunity to infections present at the release site (Woodford and Rossiter 1994). Arabian oryx (Oryx leucoryx) that were bred in captivity in the US succumbed to botulism when they were released in Oman. Botulism is enzootic among sheep and goats of Oman and the Arabian oryx lacked acquired immunity, as they were naïve to botulism (Stanley Price 1989). Having baseline knowledge of the distribution and spatio-temporal dynamics of Salmonella in the New Zealand environment and in native animal hosts is therefore important when making decisions about appropriate sites and timings of native fauna translocations and movements among captive facilities.

In addition to understanding the spatial and species distribution of Salmonella in New Zealand native wildlife, knowledge of the seasonal distribution of Salmonella and obtaining the first insights into the genetic population structure of Salmonella in New Zealand may also be important for translocations and wildlife management. All animals should be screened for disease before being introduced to a new population; but due to lack of funds screening is rarely carried out as intensively as is necessary due to 
the difficulty in easily detecting these intermittently shed bacteria (Gartrell et al. 2006). The high level of recombination seen in the Salmonella found in this study, further highlights the potential for novel serovars or molecular types to originate through lateral gene transfer, moving serovars throughout New Zealand is likely to increase this risk. Screening for bacteria in seasons when Salmonella is most abundant in the environment and in animal hosts maximises the opportunity to identify Salmonella carriage and evaluate risks of distribution among sites.

Salmonella prevalence was found to vary seasonally in this study (Chapter Two) with no Salmonella detected in either skinks or soil during October, suggesting that bacteria are able to enter a viable but not culturable state during colder winter months, or that the bacteria is reintroduced to the island during the warmer months of spring and summer. Antibody recognition of $S$. Saintpaul and $C$. koseri by tuatara serum was also found to be highest during summer. This might suggest that the tuatara immune response is optimised to most effectively prevent bacterial colonisation during periods where bacteria numbers are high, or it may correspond with increased exposure of the tuatara to Salmonella during summer. In reality, the increased antibody response seen in tuatara is likely to have arisen as a result of both of these mechanisms. I found no similar increase in the innate immune response (i.e. anti-microbial activity) during summer (Chapter Four). In Chapters Three and Four of thesis I have investigated serum samples collected from wild tuatara during March 2010 and 2011 and January 2011 only. Ideally I would have investigated the immune response of wild tuatara in all seasons, however a previous study showed that tuatara on Stephens Island are difficult to catch during winter, with only six individuals caught during June (Godfrey et al. 2008). Captive tuatara were therefore included into the study in order to maximise the opportunity for detecting Salmonella and allow for repeated sampling in all seasons. Unfortunately, there are some limitations associated with testing captive tuatara; firstly there is a limited number of tuatara available at each location and secondly it was not always possible to sample or obtain enough serum from each tuatara in every season. Consequently, any seasonal patterns observed throughout this thesis could not be tested independently of tuatara sex and the possibility that these two factors are correlated should not be ignored. Innate, humoral and cell-mediated immunity are known to vary in their activation and responses, consequently several immune responses should be measured as we may not have enough information to accurately reflect the overall 
immune strategy of tuatara, and determine the importance of season on the ability of tuatara to prevent infection (Birkhead et al. 1998, Blount et al. 2003, Allen et al. 2009).

The spatio-temporal dynamics of disease and the ability of species to cope with invading pathogens are central themes in disease ecology and eco-immunology (Learmonth 1988, Demas and Randy 2012). This thesis contributed to these fields by integrating the spatio-temporal dynamics and genetic analyses of Salmonella in New Zealand native wildlife with the immune responses of tuatara. In summary, I have demonstrated that tuatara are probably exposed to Salmonella in their environment and have investigated some of the potential routes of immunity within this species. While this thesis has answered many questions regarding Salmonella distribution and tuatara immunology, many other questions have arisen throughout the course of this research. The groundwork has now been laid for more complex, advanced questions that may expand on the work presented here.

\subsection{Directions for future research}

6.4.1 What role do passerines play in the introduction of Salmonella to island ecosystems?

To understand whether Salmonella is persistent on Stephens Island it would be useful to investigate Salmonella prevalence in native and introduced passerines which visit and are resident on the island. Salmonella may be a persistent pathogen on Stephens Island; cycling between skinks and soil and entering a viable but not culturable state in colder winter months and recovering in the warmer summer months. Alternatively, species not investigated in this study may act as reservoirs of Salmonella periodically reintroducing the bacteria to the island. Knowledge of the species which act as reservoirs of Salmonella in New Zealand and their role in distribution of disease throughout populations is important in the management of wild populations of native species. 
6.4.2 How do climate and temperature affect the persistence of Salmonella in an island ecosystem?

The optimum temperature for the growth of Salmonella has been demonstrated to be between $35-37^{\circ} \mathrm{C}$, with growth rates greatly reduced at temperatures below $15^{\circ} \mathrm{C}$ (Zhang et al. 2010). Salmonella will also multiply within a host at rates directly proportional to the ambient temperature (at temperature range $7.5^{\circ} \mathrm{C}-37^{\circ} \mathrm{C}$ ), which often results in increased Salmonella reproduction throughout the food web during warmer months (Lake et al. 2009). Increased Salmonella reproduction in cattle and poultry has been associated with increased disease severity in humans ingesting the infected meat (Heyndrickx et al. 2002, Lake et al. 2009, Lal et al. 2012). Areas with prolonged increased temperatures or increased degree days may therefore have an increased incidence of Salmonella prevalence in the environment and animal hosts, and increased disease expression and severity in wildlife. My research on spatio-temporal dynamics and prevalence of Salmonella in island ecosystems was focussed entirely on Stephens Island. Investigating the distribution and dynamics of Salmonella on islands throughout New Zealand would further elucidate the importance of temperature and climate on the spread of this bacterium. With current rates of climate change (Ministryfor-the-Environment 2011) and the associated predicted droughts and temperature fluctuations, water and temperature may become important factors affecting the growth of Salmonella. Having a baseline understanding of the importance of water availability and temperature on Salmonella distribution in New Zealand may help to predict future impacts of this pathogen on native wildlife. Obtaining knowledge on the prevalence and distribution of Salmonella within tuatara and other native wildlife throughout New Zealand's temperature gradient would provide important information for the conservation and management of wild and captive populations of native fauna. For example, understanding the spread and distribution of Salmonella in New Zealand can provide valuable information on the importance of disease screening prior to translocations and on areas and times when translocations can be most safely performed.

Tuatara are cool-adapted reptiles that remain active at temperatures as low as $5.2^{\circ} \mathrm{C}$ (Thompson et al. 1996) and tuatara on Stephens Island have been found to reach body temperatures as low as $4.5^{\circ} \mathrm{C}$ with average body temperatures ranging from $11.5^{\circ} \mathrm{C}$ to $15.9^{\circ} \mathrm{C}$ depending on the season (Corkery 2012). Given that the growth of Salmonella 
has been shown to be greatly reduced at temperatures below $15^{\circ} \mathrm{C}$ (Zhang et al. 2010), it is possible that the lack of Salmonella colonisation observed in tuatara on Stephens Island is due to the Salmonella not reproducing within the animal. Tuatara on New Zealand's northern islands are exposed to higher average temperatures and prolonged periods of increased temperature as compared with Stephens Island tuatara. Consequently, it would be interesting to survey these populations for Salmonella to see if the increased periods of warmth may allow for greater Salmonella reproduction. If this is the case I might expect tuatara in New Zealand's northern islands to be gastrointestinal shedders of Salmonella.

In addition to performing surveys of tuatara at different temperature clines the importance of temperature in inhibiting Salmonella growth in tuatara could be tested experimentally. The anti-microbial activity of tuatara sera should be investigated at a range of incubation temperatures as well as the $27^{\circ} \mathrm{C}$ investigated in this thesis. If tuatara anti-microbial peptides are demonstrated to be more effective at preventing Salmonella growth at lower temperatures, then I might expect that this coupled with the lower growth rate of Salmonella at lower temperatures may effectively prevent colonisation. Understanding the importance of body temperature on the prevention of bacterial colonisation of tuatara will provide valuable information on the predicted impacts of a global change in temperature on tuatara and potentially other ectothermic vertebrates.

\subsubsection{What is the structure and functionality of the serum anti-microbial peptide of} tuatara?

I have shown that tuatara have active peptide-mediated innate immunity that is efficient in preventing the growth of S. Saintpaul, E. coli and C. koseri. Anti-microbial peptides are widespread throughout the animal and plant kingdoms (Zasloff 2002). The arsenal of anti-microbial peptides differs from species to species (Ganz 2003). Some peptides are found commonly in many different species, such as the defensins, which are found in very high concentrations in human and other mammalian epithelial cells (Ganz 2003). In contrast, each species of amphibian appears to produce unique anti-microbial skin peptides with activity against a broad range of microbes (Barra and Simmaco 1995). The diversity of anti-microbial peptides can be crudely categorised by grouping the 
peptides into families based on limited structural similarity (Goraya et al. 2000, Conlon et al. 2004). However, virtually no single peptide from one species has an identical amino acid sequence in another (Bevier et al. 2004). Thus, the molecular forms and primary structures of anti-microbial peptides have the ability to act as markers in the study of the evolution of immunity. Knowledge of the structure and functionality of the anti-microbial peptides in tuatara would provide a greater understanding of its importance in the prevention of Salmonella colonisation and systemic infection in tuatara.

The continued emergence of multi-drug resistant pathogens underscores the need to identify new and novel anti-microbial agents. A number of authors have suggested that naturally occurring peptides with anti-microbial properties may represent a new therapeutic modality (Shaharabany et al. 1999, Merchant et al. 2006a). Previous studies have found peptides with in-vitro activities against microorganisms resistant to conventional antibiotics (Hancock and Lehrer 1998). Therefore, further investigating the activity of tuatara anti-microbial peptides against Gram-negative and Gram-positive bacteria, and in particular multi-resistant strains may provide important information on the clinical potential of tuatara anti-microbial peptides.

\subsubsection{What roles do the antibodies and peptide-mediated immunity identified in this} study play in the prevention of gastrointestinal colonisation of tuatara by Salmonella?

I have shown that tuatara have antibodies and anti-microbial peptides with effective activity against Salmonella, but it remains unclear what role these play in the prevention of gastrointestinal colonisation of tuatara with Salmonella. Serum peptides and antibodies are likely to effectively inhibit systemic infections but their role in preventing gastrointestinal colonisation is unclear. The structure and function of reptile antibodies has only recently begun to be investigated in depth. In humans and other mammals the secretory antibody, immunoglobulin A (IgA) plays an important role in mucosal immunity including prevention of bacterial proliferation in the gastrointestinal tract (Coico et al. 2003, Zimmerman et al. 2010). IgA-like immunoglobulin has been identified in the reptile Eublepharis macularius and appears to be a secreted antibody (Gambón Deza et al. 2007). However, little more is known about the presence of secretory antibodies in reptiles. More research is required into the structure and 
functionality of antibodies found in tuatara to determine the roles they play in preventing colonisation of mucosal surfaces, such as the gastrointestinal tract, and in preventing systemic infections.

Serum anti-microbial peptides are also likely to be involved in the prevention of systemic bacterial infections but may be less important in preventing gastrointestinal colonisation. Anti-microbial peptides can be found in a range of surfaces including the skin, oral cavity and gastrointestinal tract (Barra and Simmaco 1995, Reddy et al. 2004, Diamond et al. 2009). The importance of non-serum anti-microbial peptides has been widely investigated in amphibians (Barra and Simmaco 1995, Goraya et al. 2000, Bevier et al. 2004), however considerably less is known about their presence and importance in reptiles (Zimmerman et al. 2010). Future research should consider the importance of mucosal and epithelial anti-microbial peptides in the tuatara immune response.

Establishing a greater understanding of the role these immune responses play in preventing gastrointestinal colonisation of tuatara with Salmonella may play a vital role in the formation of guidelines for successful translocations. Disease screening is a costly part of wildlife management and in particular translocations, and is consequently often not performed as intensively as is necessary to identify potential pathogens in wildlife (Gartrell et al. 2006). Understanding the immune status of tuatara to Salmonella would inform decisions regarding the potential importance of this pathogen in tuatara and consequently allow correct apportioning of finances during disease monitoring.

6.4.5 How could experimental approaches be used to further explore the tuatara immune response to Salmonella?

Tuatara are a protected species in New Zealand and this coupled with the fact this was the first in-depth analysis of the immunological response of tuatara to Salmonella led me to choose and develop non-invasive and non-fatal techniques for assessing the immune response. However, a number of experimental approaches could in principle be taken to explore how tuatara respond when exposed to Salmonella. Tuatara could be exposed to live Salmonella through oral infection with a known infective dose. This 
technique would enable investigation for any clinical signs of infection and provide a clear indication of whether tuatara are immune to Salmonella. Alternatively, tuatara could be infected via an intraperitoneal injection with an outer cell surface antigen, thereby providing a method for measuring the strength and kinetics of the adaptive immune response. For instance, Marchalonis et al. (1969) investigated the immune response of tuatara following exposure to $S$. Adellaide flagellin. The tuatara were bled at regular intervals post-infection and the antibody activity was measured (Marchalonis et al. 1969). Only one of the two tuatara were killed at day 252 after initial infection (Marchalonis et al. 1969).

Experimental infection of tuatara with Salmonella would also have provided a valuable positive control against which the flow cytometry and Western blot techniques developed in this study could be optimised. In the absence of a known tuatara positive control I used exotic reptiles which were shedders of Salmonella to optimise my techniques. Using tuatara as a positive control would prevent any possible variation which may have occurred because of the different physiologies of the tuatara and exotic reptiles.

Future studies might consider experimentally infecting tuatara with Salmonella in order to develop a greater understanding of immune factors involved in the humoral immune response of tuatara. For example knowing the classes of antibody produced when tuatara are exposed to Salmonella may help to further elucidate the evolution of the immune response in vertebrates.

\subsubsection{Can a seven-gene MLST scheme further elucidate the phylogenetic relationships} between Salmonella samples on Stephens Island?

Phylogenies and information on genetic history are often used as the framework on which other characteristics such as pathogenicity, serology, host specificity and the presence of virulence genes can be mapped (Spratt and Maiden 1999). Consequently, a clearer understanding of these phylogenies can provide valuable insights into ancestral populations, the origins of virulence and may be helpful in designing effective public and wildlife health control strategies. In this study I have only investigated three of the seven genes suggested for MLST typing. I found that allele types of the sequences for 
all three genes corresponded with the serovar of Salmonella, but without a full complement of seven genes I was unable to obtain ST types and therefore perform an eBurst analysis (Feil et al. 2004). Bacterial population structures can be described using three different methods: bifurcating trees, bundles and nets (Maynard Smith 1989). Bifurcating trees have been the traditional means of visualising phylogenies and whilst they are an adequate model for clonal populations, they assume that each member of a population is related by a series of direct antecedents. Consequently, bifurcating trees are not appropriate if there has been any degree of horizontal gene transfer, as a given member of the population may have genetic material acquired from a variety of other members of the species, or even from members of related species (Spratt and Maiden 1999). EBurst is a web-based algorithm which allows investigation of MLST data sets from clonal bacterial populations. This technique is particularly useful in the case of bacterial pathogens which undergo frequent recombination or recombination over a long-time span such that it would normally overwhelm a traditional phylogenetic signal (Feil et al. 2004). I found a significant amount of recombination within the sequences obscuring phylogenetic signals. Consequently, a seven-gene scheme analysed using eBurst may help in identifying phylogenetic relationships among Salmonella isolates on Stephens Island.

Using the primers suggested on the Salmonella MLST database (http://www.mlst.ucc.ie/mlst/dbs/Senterica/), I was unable to obtain a clean and strong enough amplification of the genes purE, hisD, aroC and hemD to obtain a clear sequence. Other researchers have found similar problems with amplifying the more than 2500 Salmonella serovars which exist (Kotetishvili et al. 2002, Sukhnanand et al. 2005). Future studies might therefore benefit from designing new primers to these genes using whole genome sequences which are likely to produce more universal primer sets.

6.4.7 How does the population structure of Salmonella isolates on Stephens Island compare with isolates from throughout New Zealand and Australia?

To the best of my knowledge this is the first investigation into the population structure of Salmonella utilising the MLST method in New Zealand. There is potential for this technique to expand beyond an island investigation to a national and international study. 
MLST schemes can answer global epidemiological questions regarding the transmission pathways, risks of transmission, source populations and potential virulence of bacterial species (Spratt and Maiden 1999). Consequently, if this study was extended to include isolates obtained from a variety of species throughout New Zealand, valuable information regarding the transmission of Salmonella in New Zealand, such as what are the primary hosts, how many ancestral populations contribute to the current population of Salmonella, and what are the risks of further Salmonella spread to our native populations could be obtained. A further expansion of the study might include sequences from Salmonella in Australia and the South Pacific, elucidating the risks of transmission from these sites. An international study would also allow predictions regarding the likely sources of Salmonella in New Zealand and would therefore be helpful in designing management strategies which could avoid future introductions of novel serovars or molecular types. Finally, comparisons of Salmonella sequences at an international level would aid predictions of the potential impacts new or introduced Salmonellas may have on native fauna. 


\section{REFERENCES}

Aanensen, D. M., and B. G. Spratt. 2005. The multilocus sequence typing network: mlst.net. Nucleic Acids Research 33:W728-W733.

Aballay, A., P. Yorgey, and F. M. Ausubel. 2000. Salmonella typhimurium ${ }^{1}$ proliferates and establishes a persistent infection in the intestine of Caenorhabditis elegans. Current Biology 10:1539-1542.

Abbas, A. K., K. M. Murphy, and A. Sher. 1996. Functional diversity of helper T lymphocytes. Nature 383:787-793.

Achtman, M. 2008. Evolution, population structure, and phylogeography of genetically monomorphic bacterial pathogens. Pages 53-70 in Annual Review of Microbiology.

Adelman, M. K., S. F. Schluter, and J. J. Marchalonis. 2004. The natural antibody repertoire of sharks and humans recognizes the potential universe of antigens. The Protein Journal 23:103-118.

Akaike, H. 1978. A Bayesian analysis of the minimum AIC procedure. Annals of the Institute of Statistical mathematics 30:9-14.

Akey, J. M., M. A. Eberle, M. J. Rieder, C. S. Carlson, M. D. Shriver, D. A. Nickerson, and L. Kruglyak. 2004. Population history and natural selection shape patterns of genetic variation in 132 genes. PLoS Biol 2:e286.

Alcaine, S. D., Y. Soyer, L. D. Warnick, W.-L. Su, S. Sukhnanand, J. Richards, E. D. Fortes, P. McDonough, T. P. Root, N. B. Dumas, Y. Gröhn, and M. Wiedmann. 2006. Multilocus sequence typing supports the hypothesis that cow- and humanassociated Salmonella isolates represent distinct and overlapping populations. Applied and Environmental Microbiology 72:7575-7585.

Allen L. C., A.S. Turmelle, M.T. Mendonça, K.J. Navara, T. H. Kunz, and G.F. McCraken. 2009. Roosting ecology and variation in adaptive and innate immune systems function in the Brazilian free-tailed bat (Tadarida brasiliensis). Journal of Comparative Physiology B: Biochemical, Systemic and Environmental Physiology 179:315-323.

\footnotetext{
${ }^{1}$ Due to frequent changes in Salmonella nomenclature the nomenclature throughout the references does not always correspond with the nomenclature I have chosen to use throughout this thesis.
} 
Alley, M. R., I. Castro, and J. E. B. Hunter. 1999. Aspergillosis in hihi (Notiomystis cincta) on Mokoia Island. New Zealand Veterinary Journal 47:88-91.

Alley, M. R., J. H. Connolly, S. G. Fenwick, G. F. Mackereth, M. J. Leyland, L. E. Rogers, M. Haycock, C. Nicol, and C. E. M. Reed. 2002. An epidemic of salmonellosis caused by Salmonella Typhimurium DT160 in wild birds and humans in New Zealand. New Zealand Veterinary Journal 50:170-176.

Altizer, S., A. Dobson, P. Hosseini, P. Hudson, M. Pascual, and P. Rohani. 2006. Seasonality and the dynamics of infectious diseases. Ecology Letters 9:467-484.

Álvarez-Barrientos, A., J. Arroyo, R. Cantón, C. Nombela, and M. Sánchez-Pérez. 2000. Applications of flow cytometry to clinical microbiology. Clinical Microbiology Reviews 13:167-195.

Amo, L., P. Lopez, and J. Martin. 2007. Habitat deterioration affects antipredatory behavior, body condition, and parasite load of female Psammodromus algirus lizards. Canadian Journal of Zoology-Revue Canadienne De Zoologie 85:743751.

Anderson, D., K. Burnham, and G. White. 1998. Comparison of Akaike information criterion and consistent Akaike information criterion for model selection and statistical inference from capture-recapture studies. Journal of Applied Statistics 25:263-282.

Anderson, M. J., and R. N. Gorley. 2008. PERMANOVA + for PRIMER: guide to software and statistical methods. PRIMER-E, Plymouth, UK.

Anderson, R. M., and R. M. May. 1979. Population biology of infectious diseases 1. Nature 280:361-367.

Anonymous. 2010. Enteric Reference Laboratory Surveillance Reports. in http://www.surv.esr.cri.nz/enteric_reference/enteric_reference.php. Environmental Science and Research, Auckland.

Apanius, V., N. Yorinks, E. Bermingham, and R. E. Ricklefs. 2000. Island and taxon effects in parasitism and resistance of Lesser Anillean birds. Ecology 81:19591969.

Arakawa, H., J. Hauschild, and J.-M. Buerstedde. 2002. Requirement of the activationinduced deaminase (AID) gene for immunoglobulin gene conversion. Science 295:1301-1306.

Araújo, F. M. G., M. T. Bahia, N. M. Magalhães, O. A. Martins-Filho, V. M. Veloso, C. M. Carneiro, W. L. Tafuri, and M. Lana. 2002. Follow-up of experimental 
chronic Chagas' disease in dogs: use of polymerase chain reaction (PCR) compared with parasitological and serological methods. Acta Tropica 81:21-31.

Aschfalk, A., L. Folkow, H. Rud, and N. Denzin. 2002. Apparent seroprevalence of Salmonella spp. in harp seals in the Greenland sea as determined by enzymelined immunosorbent assay. Veterinary Research Communications 26:523-530.

Aschfalk, A., K. J. Hundertmak, H. R. Bendiksen, J. M. Arnemo, and N. Denzin. 2003. Serosurvey for antibodies against Salmonella species in free-ranging moose (Alces alces) from Norway. Berl Munch Tierarztl Wochenschr. 116:417-420.

Ashbolt, R., and M.D. Kirk. 2006. Salmonella Mississippi infection in Tasmania: the role of native Australian animals and untreated drinking water. Epidemiology and Infection 134:1257-1265.

Bager, F., and J. Petersen. 1991. Sensitivity and specificity of different methods for the isolation of Salmonella from pigs. Acta Veterinaria Scandinavica 32:473-481.

Barra, D., and M. Simmaco. 1995. Amphibian skin: A promising resource for antimicrobial peptides. Trends in Biotechnology 13:205-209.

Barrow, P. A., M. B. Huggins, and M. A. Lovell. 1994. Host specificity of Salmonella infection in chickens and mice is expressed in vivo primarily at the level of the reticuloendothelial system. Infection and Immunity 62:4602-4610.

Barwick, R. E. 1982. Observations on active thermoregulation in the tuatara, Sphenodon punctatus (Reptilia: Rhynchocephalia). In: NEWMAN, D. G. (ed.) New Zealand Herpetology. Wellington: New Zealand Wildlife Service.

Batchelor, J. R., and B. A. Chapman. 1965. Influence of sex upon antibody response to an incompatibile tumour. Immunology 9:553-564.

Baumgarth, N., J. W. Tung, and L. A. Herzenberg. 2005. Inherent specificities in natural antibodies: a key to immune defense against pathogen invasion. Springer Seminars in Immunopathology 26:347-362.

Bäumler, A. J., R. M. Tsolis, T. A. Ficht, and L. G. Adams. 1998. Evolution of host adaptation in Salmonella enterica. Infection and Immunity 66:4579-4587.

Beck, G., and G. S. Habicht. 1996. Immunity and the invertebrates. Scientific American 275:60-71.

Beltran, P., J. M. Musser, R. Helmuth, J. J. Farmer, W. M. Frerichs, I. K. Wachsmuth, K. Ferris, A. C. McWhorter, J. G. Wells, and A. Cravioto. 1988. Toward a population genetic analysis of Salmonella: genetic diversity and relationships among strains of serotypes $S$. choleraesuis, S. derby, S. dublin, S. enteritidis, $S$. 
heidelberg, S. infantis, S. newport, and S. typhimurium. Proceedings of the National Academy of Sciences 85:7753-7757.

Bensch, S., and A. Akesson. 2003. Temporal and spatial variation of hematozoans in Scandinavian willow warblers. Journal of Parasitology 89:388-391.

Benton, M. J. 2000. Vertebrate Paleantology. Blackwell Science, London, England.

Besson A.A., and A. Cree. 2011. Integrating physiology into conservation: an approach to help guide translocations of a rare reptile in a warming environment. Animal Conservation 14:2 8-37

Bergey, D. H., D. R. Boone, R. W. Castenholz, and G. M. Garrity. 2001. Bergey's manual of systematic bacteriology. 2nd edition. Volume 2.Springer, New York.

Beutler, B. 2004. Innate immunity: an overview. Molecular Immunology 40:845-859.

Bevier, C. R., A. Sonnevend, J. Kolodziejek, N. Nowotny, P. F. Nielsen, and J. Michael Conlon. 2004. Purification and characterization of antimicrobial peptides from the skin secretions of the mink frog (Rana septentrionalis). Comparative Biochemistry and Physiology Part C: Toxicology \& Pharmacology 139:31-38.

Bevins, C.L. 1999. Defensins and innate host defence of the gastrointestinal tract. Gut 45:011-915.

Birkhead, T. R., F. Fletcher, and E. J. Pellatt. 1998. Sexual selection in the zebra finch Taeniopygia guttata: condition, sex traits and immune capacity. Behavioral Ecology and Sociobiology 44:179-191.

Birtles, A., K. Hardy, S. J. Gray, S. Handford, E. B. Kaczmarski, V. Edwards-Jones, and A. J. Fox. 2005. Multilocus sequence typing of Neisseria meningitidis directly from clinical samples and application of the method to the investigation of meningococcal disease case clusters. Journal of Clinical Microbiology 43:6007-6014.

Blazkovec, A. A., and M. W. Orsini. 1976. Ontogenetic aspects of sexual dimorphism and primary immune-response to sheep erythrocytes in hamsters from perpuberty through senescence. International Archives of Allergy and Applied Immunology 50:55-67.

Blount, J.D., D.C. Houston, A.P. Moller, and J. Wright. 2003. Do individual branches of the immune defence correlate? A comparative study of scavenging and nonscavenging birds. Oikos 102:340-350. 
Boggs, J. F., S. T. McMurry, D. M. Leslie, D. M. Engle, and R. L. Lochmiller. 1990. Influence of habitat modification on the intestinal helminth community ecology of cottontail rabbit populations. Journal of Wildlife Diseases 26:157-169.

Boyd, E. F., F. S. Wang, T. S. Whittam, and R. K. Selander. 1996. Molecular genetic relationships of the salmonellae. Applied and Environmental Microbiology 62:804-808.

Brenner, F. W., R. G. Villar, F. J. Angulo, R. Tauxe, and B. Swaminathan. 2000. Salmonella nomenclature. Journal of Clinical Microbiology 38:2465-2467.

Brown, D. 2000. Stephens Island ark of the light. Cloudy Bay Publishing, Blenheim, New Zealand.

Bugla-Płoskońska, G., A. Kiersnowski, B. Futoma-Kołoch, and W. Doroszkiewicz. 2009. Killing of Gram-negative bacteria with normal human serum and normal bovine serum: use of lysozome and complement proteins in the death of Salmonella strains O48. Microbial Ecology 58:276-289.

Burnham, B. R., D. H. Atchley, R. P. DeFusco, K. E. Ferris, J. C. Zicarelli, J. H. Lee, and F. J. Angulo. 1998. Prevalence of fecal shedding of Salmonella organisms among captive green iguanas and potential health implications. Journal of the American Veterinary Medicine Association 213:48-50.

Burnham, D. K., S. N. Keall, N. J. Nelson, and C. H. Daugherty. 2005. T cell function in tuatara (Sphenodon punctatus). Comparative Immunology Microbiology and Infectious Diseases 28:213-222. 2006. Effects of sampling date, gender, and tick burden on peripheral blood cells of captive and wild tuatara (Sphenodon punctatus). New Zealand Journal of Zoology 33:241-248.

Burnham, K. P., and D. R. Anderson. 2002. Model selection and multimodel inference: A practical information-theoretic approach. Second edition. Springer-Verlag, New York.

Campbell, R. D., S.K.A. Law, K.B.M. Reid and R. B. Sim. 1988. Structure, organization, and regulation of the serum complement genes. Annual Review of Immunology 6:161-195.

Carlson, J. C., A. B. Franklin, D. R. Hyatt, S. E. Pettit, and G. M. Linz. 2011. The role of starlings in the spread of Salmonella within concentrated animal feeding operations. Journal of Applied Ecology 48:479-486. 
Carroll, S. F., and R. J. Martinez. 1981. Antibacterial peptide from normal rabbit serum. 1. Isolation from whole serum, activity, and microbicidal spectrum. Biochemistry 20:5973-5981.

Castro, M. S., and W. Fontes. 2005. Plant defense and antimicrobial peptides. Protein and Peptide Letters 12:13-18.

CDC. 2001. Salmonella surveillance:annual summary 2000. Atlanta, GA: US Department of Health and Human Services.

Chambers, D.L., and A.C. Hulse. 2006. Salmonella serovars in the herpetofauna of Indiana county. Applied and Environmental Microbiology 72:3771-3773

Chan, K., S. Baker, C. C. Kim, C. S. Detweiler, G. Dougan, and S. Falkow. 2003. Genomic comparison of Salmonella enterica serovars and Salmonella bongori by use of an S. enterica serovar Typhimurium DNA microarray. Journal of Bacteriology 185:553-563.

Charron, D. F. 2002. Potential impacts of global warming and climate change on the epidemiology of zoonotic diseases in Canada. Canadian Journal of Public Health-Revue Canadienne De Sante Publique 93:334-335.

Chattopadhyay, S., N. K. Sinha, S. Banerjee, D. Roy, D. Chattopadhyay, and S. Roy. 2006. Small cationic protein from a marine turtle has $\beta$-defensin-like fold and antibacterial and antiviral activity. Proteins: Structure, Function, and Bioinformatics 64:524-531.

Chiodini, R. J., and J. P. Sundberg. 1981. Salmonellosis in reptiles - a review. American Journal of Epidemiology 113:494-499.

Chmielewski, R. A. N., and J. F. Frank. 1995. Formation of viable but nonculturable Salmonella during starvation in chemically-defined solutions. Letters in Applied Microbiology 20:380-384.

Clark, R. G. 2001. Black-backed gulls (Larus dominicanus) and their role in the spread of Salmonella Brandenburg. Proceedings of the New Zealand Society of Animal Production 61:71-73.

Clark, R. G., S. G. Fenwick, C. M. Nicol, R. M. Marchant, S. Swanney, J. M. Gill, J. D. Holmes, M. Leyland, and P. R. Davies. 2004. Salmonella Brandenburg emergence of a new strain affecting stock and humans in the South Island of New Zealand. New Zealand Veterinary Journal 52:26-36. 
Clark, R. G., R. A. Robinson, M. R. Alley, C. M. Nicol, S. C. Hathaway, and R. M. Marchant. 2002. Salmonella in animals in New Zealand: the past to the future. New Zealand Veterinary Journal 50:57-60.

Coburn, B., G. A. Grassl, and B. B. Finlay. 2007. Salmonella, the host and disease: a brief review. Immunology and Cell Biology 85:112-118.

Coico, R., G. Sunshine, E. Bejamini. 2003. Immunology: a short course. Wiley-Liss Publications, Hoboken, New Jersey.

Conlon, J. M., J. Kolodziejek, and N. Nowotny. 2004. Antimicrobial peptides from ranid frogs: taxonomic and phylogenetic markers and a potential source of new therapeutic agents. Biochimica et Biophysica Acta (BBA) - Proteins \& Proteomics 1696:1-14.

Connolly, J. H., M. R. Alley, G. J. Dutton, and L. E. Rogers. 2006. Infectivity and persistence of an outbreak strain of Salmonella enterica serotype Typhimurium DT160 for house sparrows (Passer domesticus) in New Zealand. New Zealand Veterinary Journal 54:329-332.

Cordeiro, F. D., O. A. Martins-Filho, M. O. Da Costa Rocha, S. J. Adad, R. CorrêaOliveira, and A. J. Romanha. 2001. Anti-Trypanosoma cruzi immunoglobulin G1 can be a useful tool for diagnosis and prognosis of human Chagas' disease. Clinical and Diagnostic Laboratory Immunology 8:112-118.

Corkery, I. 2012. Interspecific interactions: a case study using the tuatara-fairy prion association. $\mathrm{PhD}$ thesis, Victoria Universiton of Wellington.

Cosgrove, C. L., M. J. Wood, K. P. Day, and B. C. Sheldon. 2008. Seasonal variation in Plasmodium prevalence in a population of blue tits Cyanistes caeruleus. Journal of Animal Ecology 77:540-548.

Craig, J., S. Anderson, M. Clout, B. Creese, N. Mitchell, J. Ogden, M. Roberts, and G. Ussher. 2000. Conservation issues in New Zealand. Annual Review of Ecology and Systematics 31:61-78.

Crawley, M. J. 2002. Statistical computing: an introduction to data analysis using Splus. Wiley, Chichester, U.K.

Cree, A., and D. Butler. 1993. Tuatara Recovery Plan (Sphenodon spp.). Threatened species recovery plan series 9. Department of Conservation, Wellington, New Zealand. 
Cree, A., C. H. Daugherty, S. F. Schafer, and D. Brown. 1991. Nesting and clutch size of tuatara (Sphenodon guntheri) on North Brother Island, Cook Strait. Tuatara 31:9-16.

Crosa, J. H., D. J. Brenner, W. H. Ewing, and S. Falkow. 1973. Molecular relationships among the Salmonelleae. Journal of Bacteriology 115:307-315.

Daoust, P. Y., D. G. Busby, L. Ferns, J. Goltz, S. McBurney, C. Poppe, and H. Whitney. 2000. Salmonellosis in songbirds in the Canadian Atlantic provinces during winter-summer 1997-98. Canadian Veterinary Journal-Revue Veterinaire Canadienne 41:54-59.

Daszak, P., A. A. Cunningham, and A. D. Hyatt. 2000. Emerging infectious diseases of wildlife-- threats to biodiversity and human health. Science 287:443-449.

Daszak, P., A. A. Cunningham, and A. D. Hyatt. 2001. Anthropogenic environmental change and the emergence of infectious diseases in wildlife. Acta Tropica 78:103-116.

Davies, R. H., and C. Wray. 1996. Seasonal variations in the isolation of Salmonella typhimurium, Salmonella enteritidis, Bacillus cereus and Clostridium perfringens from environmental samples. Journal of Veterinary Medicine, Series B 43:119-127.

Dawbin, W. H. 1982. The tuatara Sphenodon punctatus: aspects of life history, growth and longevity. Pages 237-250 in New Zealand herpetology. Occassional publication 2. New Zealand Wildlife Service, Wellington.

Dawson, W.R. 1975. On the preferred body temperatures of reptiles. In D. M. Gates, and B.S. Rudolf, editors. Perspectives of biophysical ecology. Springer-verlag, New York. pp. 443-475.

Demas, G. E., and N. J. Randy. 2012. Introduction to Ecoimmunology. in G. E. Demas, andN. J. Randy, editors. Ecoimmunology. Oxford University Press, New York.

de Hamel, F. A., and H. M. McInnes. 1971. Lizards as vectors of human salmonellosis. Journal of Hygiene 69:247-253.

Delport, W., K. Scheffler, G. Botha, M. B. Gravenor, S. V. Muse, and S. L. Kosakovsky Pond. 2010. CodonTest: modeling amino acid substitution preferences in coding sequences. PLoS Comput Biol 6:e1000885.

Deng, W., S. R. Liou, G. Plunkett, G. F. Mayhew, D. J. Rose, V. Burland, V. Kodoyianni, D. C. Schwartz, and F. R. Blattner. 2003. Comparative genomics of 
Salmonella enterica serovar typhi strains Ty2 and CT18. Journal of Bacteriology 185:2330-2337.

de Sousa, M.A., C. Bartzavali, I. Spiliopoulou, I.S. Sanches, M.T. Chrisostomo, and H. de Lencastre. 2003. Two international methicillin-resistant Staphylococcus aureus clones endemic in a university hosptial. Journal of Clinical Microbiology 41:2027-2032.

Desser, S. S. 1978. Morphological, cytochemical and biochemical observations on blood of the tuatara, Sphenodon punctatus. New Zealand Journal of Zoology 5:503-508.

Diamond, G., N. Beckloff, A. Weinberg, and K. O. Kisich. 2009. The roles of antimicrobial peptides in innate host defense. Current Pharmaceutical Design 15:2377-2392.

Dicuonzo, G., G. Gherardi, R.E. Gertz, F. D’Ambrosio, A. Goglio, G. Lorino, S. Recchia, A. Pantosti, and B. Beall. 2002. Genotypes of invasive pneumococcal isolates recently recovered from Italian patients. Journal of Clinical Microbiology 40:3565-3571.

Didelot, X., R. Bowden, T. Street, T. Golubchik, C. Spencer, G. McVean, V. Sangal, M. F. Anjum, M. Achtman, D. Falush, and P. Donnelly. 2011. Recombination and population structure in Salmonella enterica. PLoS Genet 7:e1002191.

Dingle, K. E., F. M. Colles, D. R. A. Wareing, R. Ure, A. J. Fox, F. E. Bolton, H. J. Bootsma, R. J. L. Willems, R. Urwin, and M. C. J. Maiden. 2001. Multilocus sequence typing system for Campylobacter jejuni. Journal of Clinical Microbiology 39:14-23.

Doran, T. I. 1999. The role of Citrobacter in clinical disease of children: review. Clinical Infectious Diseases 28:384-394.

Drummond, A. J., B. Ashton, S. Buxton, M. Cheung, A. Cooper, C. Duran, M. Field, J. Heled, and M. Kearse. 2011. Available from http://www.geneious.com.

Drummond, A. J., and A. Rambaut. 2007. BEAST: Bayesian evolutionary analysis by sampling trees. Bmc Evolutionary Biology 7.

Duckworth, R. A., M. T. Mendonça, and G. E. Hill. 2001. A condition dependent link between testosterone and disease resistance in the house finch. Proceedings of the Royal Society of London. Series B: Biological Sciences 268:2467-2472. 
Duret, L., and D. Mouchiroud. 2000. Determinants of substitution rates in mammalian genes: expression pattern affects selection intensity but not mutation rate. Molecular Biology and Evolution 17:68-70.

East, K. T., M. R. East, and C. H. Daugherty. 1995. Ecological restoration and habitat relationships of reptiles on Stephens Island, New Zealand. New Zealand Journal of Zoology 22:249-261.

Edwards, R. A., G. J. Olsen, and S. R. Maloy. 2002. Comparative genomics of closely related salmonellae. Trends in Microbiology 10:94-99.

Eidinger, D., and T. J. Garrett. 1972. Studies of the regulatory effects of the sex hormones on antibody formation and stem cell differentiation. The Journal of Experimental Medicine 136:1098-1116.

Enright, M.C., B.G. Spratt. 1998. A multilocus sequence typing scheme for Streptococcus pneumoniae: identification of clones associated with serious invasive disease. Microbiology 144: 3049-3060.

Ewen, J. G., R. Thorogood, C. Nicol, D. P. Armstrong, and M. Alley. 2007. Salmonella typhimurium in hihi, New Zealand. Emerging Infectious Diseases 13:788-790.

Falla, R. A., R.B. Sibson, and E.G. Turbott. 1993. Collins field guide to the birds of New Zealand. Auckland: Harper Collins.

Fallon, S. M., R. E. Ricklefs, S. C. Latta, and E. Bermingham. 2004. Temporal stability of insular avian malarial parasite communities. Proceedings of the Royal Society of London. Series B: Biological Sciences 271:493-500.

Falush, D., M. Stephens, and J. K. Pritchard. 2003. Inference of population structure using multilocus genotype data: linked loci and correlated allele frequencies. Genetics 164:1567-1587.

Farfan-Ale, J. A., B. J. Blitvich, N. L. Marlenee, M. A. Loroño-Pino, F. PuertoManzano, J. E. García-Rejón, E. P. Rosado-Paredes, L. F. Flores-Flores, A. Ortega-Salazar, J. Chávez-Medina, J. C. Cremieux-Grimaldi, F. Correa-Morales, G. Hernández-Gaona, J. F. Méndez-Galván, and B. J. Beaty. 2006. Antibodies to West Nile virus in asymptomatic mammals, birds, and reptiles in the Yucutan Peninsula of Mexico. The American Journal of Tropical Medicine and Hygiene 74:908-914.

Feil, E. J., J. E. Cooper, H. Grundmann, D. A. Robinson, M. C. Enright, T. Berendt, S. J. Peacock, J. M. Smith, M. Murphy, B. G. Spratt, C. E. Moore, and N. P. J. Day. 
2003. How clonal is Staphylococcus aureus? Journal of Bacteriology 185:33073316.

Feil, E. J., E. C. Holmes, D. E. Bessen, M.-S. Chan, N. P. J. Day, M. C. Enright, R. Goldstein, D. W. Hood, A. Kalia, C. E. Moore, J. Zhou, and B. G. Spratt. 2001. Recombination within natural populations of pathogenic bacteria: Short-term empirical estimates and long-term phylogenetic consequences. Proceedings of the National Academy of Sciences 98:182-187.

Feil, E. J., B. C. Li, D. M. Aanensen, W. P. Hanage, and B. G. Spratt. 2004. eBURST: Inferring patterns of evolutionary descent among clusters of related bacterial genotypes from multilocus sequence typing data. Journal of Bacteriology 186:1518-1530.

Felsenstein, J. 1981. Evolutionary trees from DNA-sequences - a maximum-likelihood approach. Journal of Molecular Evolution 17:368-376.

Ferrari, N., I. M. Cattadori, J. Nespereira, A. Rizzoli, and P. J. Hudson. 2004. The role of host sex in parasite dynamics: field experiments on the yellow-necked mouse Apodemus flavicollis. Ecology Letters 7:88-94.

Ferronato, B. O., M. E. Merchant, T. S. Marques, and L. M. Verdade. 2009. Characterization of innate immune activity in Phrynops geoffroanus (Testudines: Chelidae). Zoologia 26:747-752.

Fisher, M., and A. Muth. 1989. A technique for permanently marking lizards. Herpetological Review 20:45-46.

Forest, C. G., E. Ferraro, S. C. Sabbagh, and F. Daigle. 2010. Intracellular survival of Salmonellaenterica serovar Typhi in human macrophages is independent of Salmonella pathogenicity island (SPI)-2. Microbiology 156:3689-3698.

Franco, A., R. S. Hendriksen, S. Lorenzetti, R. Onorati, G. Gentile, G. Dell'Omo, F. M. Aarestrup, and A. Battisti. 2011. Characterization of Salmonella occurring at high prevalence in a population of the land iguana Conolophus subcristatus in Galápagos Islands, Ecuador. PLoS ONE 6:e23147.

Friedman, C. R., C. Torigian, P. J. Shillam, R. E. Hoffman, D. Heltzel, J. L. Beebe, G. Malcolm, W. E. DeWitt, L. Hutwagner, and P. M. Griffin. 1998. An outbreak of salmonellosis among children attending a reptile exhibit at a zoo. Journal of Pediatrics 132:802-807. 
Gambón Deza, F., C. Sánchez Espinel, and J. Valdueza Beneitez. 2007. A novel IgAlike immunoglobulin in the reptile Eublepharis macularius. Developmental \& Comparative Immunology 31:596-605.

Ganz, T. 2003. The role of antimicrobial peptides in innate immunity. Integrative and Comparative Biology 43:300-304.

Gartrell, B. D., E. Jillings, B. A. Adlington, H. Mack, and N. J. Nelson. 2006. Health screening for a translocation of captive-reared tuatara (Sphenodon punctatus) to an island refuge. New Zealand Veterinary Journal 54:344-349.

Gartrell, B. D., J. M. Youl, C. M. King, I. Bolotovski, W. L. McDonald, and N. J. Nelson. 2007. Failure to detect Salmonella species in a population of wild tuatara (Sphenodon punctatus). New Zealand Veterinary Journal 55:134-136.

Gauthier, J. A., R. Estes, and K. Queiroz. 1988. A phylogenetic analysis of the Lepidosauromorpha. Pages 15-98 in R. Estes, and G. Pregill, editors. Phylogenetic relationships of the lizard families: essays commemorating Charles L. Camp. Stanford University Press, Stanford, CA.

Gaze, P. 2001. Tuatara recovery plan 2001-2011. Department of Conservation.

Gillingham, J. C., C. Carmichael, and T. Miller. 1995. Social behaviour of the tuatara, Sphenodon punctatus. Herpetological Monographs 9:5-16.

Godfrey, S. S., C. M. Bull, and N. J. Nelson. 2008. Seasonal and spatial dynamics of ectoparasite infestation of a threatened reptile, the tuatara (Sphenodon punctatus). Medical and Veterinary Entomology 22:374-385.

Godfrey, S. S., J. A. Moore, N. J. Nelson, and C. M. Bull. 2010. Social network structure and parasite infection patterns in a territorial reptile, the tuatara (Sphenodon punctatus). International Journal for Parasitology 40:1575-1585.

Godoy, D., G. Randle, A.J. Simpson, D.M. Aanensen, T.L. Pitt, R. Kinoshita and B.G. Spratt. 2003. Multilocus sequence tying and evolutionary relationships among the causative agents of melioidosis and glanders, Burkholderia pseudomallei and Burkholderia mallei. Journal of Clinical Microbiology 41: 2068-2079.

Goff, M. L., R. B. Loomis, and R. Ainsworth. 1987. Redescription of Neotrombicula naultini (Dumbleton, 1947) and descriptions of two new species of chiggers from New Zealanda (Acari: Trombiculidae). New Zealand Journal of Zoology 14:385-390.

Goldsby, R. A., T. J. Kindt, B. A. Osborne, and J. Kuby. 2003. Immunology. $5^{\text {th }}$ edition. W.H. Freeman and company, New York, USA. 
Gopee, N., A. Adesiyun, and K. Caesar. 2000. Retrospective and longitudinal study of salmonellosis in captive wildlife in Trinidad. Journal of Wildlife Diseases 36:284-293.

Goraya, J., Y. Wang, Z. Li, M. O'Flaherty, F. C. Knoop, J. E. Platz, and J. M. Conlon. 2000. Peptides with antimicrobial activity from four different families isolated from the skins of the North American frogs Rana luteiventris, Rana berlandieri and Rana pipiens. European Journal of Biochemistry 267:894-900.

Gray, J. T., P. J. FedorkaCray, T. J. Stabel, and T. T. Kramer. 1996. Natural transmission of Salmonella choleraesuis in swine. Applied and Environmental Microbiology 62:141-146.

Guentzel MN. 1996. Escherichia, Klebsiella, Enterobacter, Serratia, Citrobacter, and Proteus. In: Baron S, editor. Medical Microbiology. 4th edition. Galveston (TX): University of Texas Medical Branch at Galveston; Chapter 26. Available from: http://www.ncbi.nlm.nih.gov/books/NBK8035/

Gupta, S., M.C.J. Maiden. 2001. Exploring the evolution of diversity in pathogen populations. Trends in Microbiology 9:181-185.

Grey, H. M. 1963. Phylogeny of the immune response. The Journal of Immunology 91:819-825.

Guerin, M. T., S. W. Martin, G. A. Darlington, and A. Rajic. 2005. A temporal study of Salmonella serovars in animals in Alberta between 1990 and 2001. Canadian Journal of Veterinary Research 69:88-99.

Gulland, F. M. D. 1995. The impact of infectious diseases on wild animal populations A review. Cambridge University Press, The Pitt Building, Trumpington Street, Cambridge CB2 1RP, England 40 W. 20th Street, New York, New York 100114211, USA.

Habrun, B., E. Listes, S. Spicic, Z. Cvetnic, D. Lukacevic, L. Jemersic, M. Lojkic, and G. Kompes. 2006. An outbreak of Salmonella Abortusovis abortions in sheep in South Croatia. Journal of Veterinary Medicine, Series B 53:286-290.

Hall, A. J., and E. K. Saito. 2008. Avian wildlife mortality events due to salmonellosis in the United States, 1985-2004. Journal of Wildlife Diseases 44:585-593.

Hamel, F. A. D., and H. M. McInnes. 1971. Lizards as vectors of human salmonellosis. Journal of Hygiene-Cambridge 69:247-253.

Hancock, R. E. W., and R. Lehrer. 1998. Cationic peptides: a new source of antibiotics. Trends in Biotechnology 16:82-88. 
Hancock, R.E.W., and M.G. Scott. 2000. The role of antimicrobial peptides in animal defenses. Proceedings of the National Academy of Science 97:8856-8861.

Handeland, K., T. Refsum, B. S. Johansen, G. Holstad, G. Knutsen, I. Solberg, J. Schulze, and G. Kapperud. 2002. Prevalence of Salmonella Typhimurium infection in Norwegian hedgehog populations associated with two human disease outbreaks. Epidemiology and Infection 128:523-527.

Haraga, A., M. B. Ohlson, and S. I. Miller. 2008. Salmonellae interplay with host cells. Nature Reviews Microbiology 6:53-66.

Harper, P. 1985. Fairy prion. in Complete book of New Zealand birds. Reed Methuen, Auckland.

Harris, J. R., D. Bergmire-Sweat, J. H. Schlegel, K. A. Winpisinger, R. F. Klos, C. Perry, R. V. Tauxe, and M. J. Sotir. 2009. Multistate outbreak of Salmonella infections associated with small turtle exposure, 2007-2008. Pediatrics 124:1388-1394.

Hartl, D. L., and D. E. Dykhuizen. 1984. The population genetics of Escherichia coli. Annual Review of Genetics 18:31-68.

Hasegawa, M., H. Kishino, and T. A. Yano. 1985. Dating of the human-ape splitting by a molecular clock of mitochondrial DNA. Journal of Molecular Evolution 22:160-174.

Heyndrickx, M., D. Vandekerchove, L. Herman, I. Rollier, K. Grijspeerdt, and L. d. Zutter. 2002. Routes for Salmonella contamination of poultry meat: epidemiological study from hatchery to slaughterhouse. Epidemiology and Infection 129:253-265.

Heyndrickx, M., F. Pasmans, R. Ducatelle, A. Decostere, and F. Haeebrouck. 2005. Recent changes in Salmonella nomenclature: the need for clarification. The Veterinary Journal 170:275-277.

Hiller, N. L., A. Ahmed, E. Powell, D. P. Martin, R. Eutsey, J. Earl, B. Janto, R. J. Boissy, J. Hogg, K. Barbadora, R. Sampath, S. Lonergan, J. C. Post, F. Z. Hu, and G. D. Ehrlich. 2010. Generation of genic diversity among Streptococcus pneumoniae strains via horizontal gene transfer during a chronic polyclonal pediatric infection. PLoS Pathogen:e1001108.

Hoelzer, K., A. I. M. Switt, and M. Wiedmann. 2011. Animal contact as a source of human non-typhoidal salmonellosis. Veterinary Research 42:1-28. 
Holdaway, R. N., and T. H. Worthy. 1997. A reappraisal of the late quaternary fossil vertebrates of Pyramid Valley Swamp, North Canterbury, New Zealand. New Zealand Journal of Zoology 24:69-121.

Holt, K. E., J. Parkhill, C. J. Mazzoni, P. Roumagnac, F. X. Weill, I. Goodhead, R. Rance, S. Baker, D. J. Maskell, J. Wain, C. Dolecek, M. Achtman, and G. Dougan. 2008. High-throughput sequencing provides insights into genome variation and evolution in Salmonella Typhi. Nature Genetics 40:987-993.

Hosseini, P. R., A. A. Dhondt, and A. Dobson. 2004. Seasonality and wildlife disease: how seasonal birth, aggregation and variation in immunity affect the dynamics of Mycoplasma gallisepticum in house finches. Proceedings of the Royal Society of London. Series B: Biological Sciences 271:2569-2577.

Hultmark, D., H. Steiner, T. Rasmuson, and H. G. Boman. 1980. Insect immunitypurification and properties of three inducible bactericidal proteins from the hemolymph of immunized pupae of Hyalophora cecropia. European Journal of Biochemistry 106:7-16.

Hsu, E. 1998. Mutation, selection, and memory in B lymphocytes of exothermic vertebrates. Immunological Review 162:25-36.

Humphrey, T. J., and A. Bygrave. 1988. Abortion in a cow associated with Salmonella infection in badgers. Veterinary Record 123:160-160.

Hunter Jr, K. W., S. A. duPré, T. Sharp, F. C. Sandmeier, and C. R. Tracy. 2008. Western blot can distinguish natural and acquired antibodies to Mycoplasma agassizii in the desert tortoise (Gopherus agassizii). Journal of Microbiological Methods 75:464-471.

Hussein, M. F., N. Badir, R. El Ridi, and S. El Deeb. 1979. Effect of seasonal variation on immune system of the lizard, Scincus scincus. Journal of Experimental Zoology 209:91-96.

Ingram, G. A., and D. H. Molyneux. 1983. The humoral immune response of the spinytailed agamid lizard (Agama caudospinosum) to injection with Leishmania agamae promastigotes. Veterinary Immunology and Immunopathology 4:479491.

Jacobson, E. R., J. M. Gaskin, M. B. Brown, R. K. Harris, C. H. Gardiner, J. L. Lapointe, H. P. Adams, and C. Reggiardo. 1991. Chronic upper respiratory-tract disease of free-ranging desert tortoises (Xerobates agassizii). Journal of Wildlife Diseases 27:296-316. 
Janeway, C. A., and R. Medzhitov. 2002. Innate immune recognition. Annual Review of Immunology 20:197-216.

Johnson - Delaney, C. A. 1996. Reptile zoonoses and threats to public health. Pages 2032 in D. R. Mader, editor. Reptile Medicine and Surgery. WB Saunders, Philadelphia, USA.

Johnson, C.N., W.H. Benjamin, S.A. Moser, S.K. Hollingshead, X.T. Zheng, M.J. Crain, M.H. Nahm, and K.B. Waites. 2003. Genetic relatedness of Levofloxacinnonsusceptible Streptococcus pneumoniae isolates from North America. Journal of Clinical Microbiology 41:2458-2464.

Johnson, P. T. J., D. E. Stanton, E. R. Preu, K. J. Forshay, and S. R. Carpenter. 2006. Dining on disease: how interactions between infection and environment affect predation risk. Ecology 87:1973-1980.

Jones, K. E., N. G. Patel, M. A. Levy, A. Storeygard, D. Balk, J. L. Gittleman, and P. Daszak. 2008. Global trends in emerging infectious diseases. Nature 451:990993.

Jones, N., J. F. Bohnsack, S. Takahashi, K. A. Oliver, M.-S. Chan, F. Kunst, P. Glaser, C. Rusniok, D. W. M. Crook, R. M. Harding, N. Bisharat, and B. G. Spratt. 2003. Multilocus sequence typing system for group B Streptococcus. Journal of Clinical Microbiology 41:2530-2536.

Jukes, T. H., and C. R. Cantor. 1969. Evolution of Protein Molecules. Academic Press, New York.

Julenius, K., and A.G. Pederson. 2006. Protein evolution is faster outside the cell. Molecular Biology and Evolution 23:2039-2045.

Keleti, J., O. Lüderitz, D. Mlynaršék, and J. Sedlák. 1971. Immunochemical studies on Citrobacter $\mathrm{O}$ antigens (Lipopolysaccharides). European Journal of Biochemistry 20:237-244.

Kerslake, J. I., and N. R. Perkins. 2006. Salmonella brandenburg: Case-control survey in sheep in New Zealand. New Zealand Veterinary Journal 54:125-131.

Kikillus, K. H., B. D. Gartrell, and E. Motion. 2011. Prevalence of Salmonella spp., and serovars isolated from captive exotic reptiles in New Zealand. New Zealand Veterinary Journal 59:174-178.

Klein, S.L. 2000. Hormones and mating system affect sex and species difference in immune function among vertebrates. Behavioural Processes 51: 149-166. 
Koch, A. L., B. R. Robertson, and D. K. Button. 1996. Deduction of the cell volume and mass from forward scatter intensity of bacteria analyzed by flow cytometry. Journal of Microbiological Methods 27:49-61.

Kohler, H., J. Bayry, A. Nicoletti, and S. V. Kaveri. 2003. Natural autoantibodies as tools to predict the outcome of immune response? Scandinavian Journal of Immunology 58:285-289.

Kotetishvili, M., O. C. Stine, Y. Chen, A. Kreger, A. Sulakvelidze, S. Sozhamannan, and J. Morris, J. Glenn. 2003. Multilocus sequence typing has better discriminatory ability for typing Vibrio cholerae than does pulsed-field gel electrophoresis and provides a measure of phylogenetic relatedness. Journal of Clinical Microbiology 41:2191-2196.

Kotetishvili, M., O. C. Stine, A. Kreger, J. G. Morris, and A. Sulakvelidze. 2002. Multilocus sequence typing for characterization of clinical and environmental Salmonella strains. Journal of Clinical Microbiology 40:1626-1635.

La Flamme, A. C., D. de Thierry, S. O'Neill, and H. Miller. 2010. Toll-like receptor responses in tuatara. New Zealand Journal of Zoology 37:235-242.

Lake, I. R., I. A. Gillespie, G. Bentham, G. L. Nichols, C. Lane, G. K. Adak, and E. J. Threlfall. 2009. A re-evaluation of the impact of temperature and climate change on foodborne illness. Epidemiology and Infection 137:1538-1547.

Lal, A., S. Hales, N. French, and M. G. Baker. 2012. Seasonality in human zoonotic enteric diseases: a systematic review. PLoS ONE 7.

Learmonth, A. 1988. Disease ecology: and introduction continued. Basil Blackwell Ltd, Oxford, UK.

Lemaitre, B., and J. Hoffmann. 2007. The host defense of Drosophila melanogaster. Pages 697-743 in Annual Review of Immunology.

Letellier, A., S. Messier, J. Pare, J. Menard, and S. Quessy. 1999. Distribution of Salmonella in swine herds in Quebec. Veterinary Microbiology 67:299-306.

Liolios, K., I. M. A. Chen, K. Mavromatis, N. Tavernarakis, P. Hugenholtz, V. M. Markowitz, and N. C. Kyrpides. 2010. The genomes on line database (GOLD) in 2009: status of genomic and metagenomic projects and their associated metadata. Nucleic Acids Research 38:D346-D354..

Litman, G. W., M. K. Anderson, and J. P. Rast. 1999. Evolution of antigen binding receptors. Annual Review of Immunology 17:109-147. 
Liu, W.-Q., Y. Feng, Y. Wang, Q.-H. Zou, F. Chen, J.-T. Guo, Y.-H. Peng, Y. Jin, Y.-G. Li, S.-N. Hu, R. N. Johnston, G.-R. Liu, and S.-L. Liu. 2009. Salmonella paratyphi C: genetic divergence from Salmonella choleraesuis and pathogenic convergence with Salmonella typhi. PLoS ONE 4:e4510

Maciel, B. M., R. C. Argôlo Filho, S. S. C. Nogueira, J. C. T. Dias, and R. P. Rezende. 2010. High prevalence of Salmonella in Tegu Lizards (Tupinambis merianae), and susceptibility of the serotypes to antibiotics. Zoonoses and Public Health 57:e26-e32.

Mader, D. R. 2006. Reptile Medicine and Surgery. 2nd edition. Saunders Elsevier Philadelphia.

Mahida, Y.R., F. Rose, and W.C. Chan. 1997. Antimicrobial peptides in the gastrointestinal tract. Gut 40: 161-163.Maiden, M. C. J. 2008. Population genomics: diversity and virulence in the Neisseria. Current Opinion in Microbiology 11:467-471.

Maiden, M. C. J., J. A. Bygraves, E. Feil, G. Morelli, J. E. Russell, R. Urwin, Q. Zhang, J. J. Zhou, K. Zurth, D. A. Caugant, I. M. Feavers, M. Achtman, and B. G. Spratt. 1998. Multilocus sequence typing: A portable approach to the identification of clones within populations of pathogenic microorganisms. Proceedings of the National Academy of Sciences of the United States of America 95:3140-3145.

Major, S. R., C. L. Fontenot, J. A. Pojman, and M. E. Merchant. 2011. Serum complement activity in the three-toed amphiuma (Amphiuma tridactylum). Comparative Immunology Microbiology and Infectious Diseases 34:115-121.

Majowicz, S. E., J. Musto, E. Scallan, F. J. Angulo, M. Kirk, S. J. O'Brien, T. F. Jones, A. Fazil, and R. M. Hoekstra. 2010. The global burden of nontyphoidal Salmonella gastroenteritis. Clinical Infectious Diseases 50:882-889.

Manickasundari, M., P. Selvaraj, and R. M. Pitchappan. 1984. Studies on T cells of the lizard, Calotes versicolor: adherent and non-adherent populations of the spleen. Developmental \& Comparative Immunology 8:367-374.

Manolis, S. C., G. J. W. Webb, D. Pinch, L. Melville, and G. Hollis. 1991. Salmonella in captive crocodiles (Crocodylus johnstoni and C. porosus) Australian Veterinary Journal 68:102-105. 
Marchalonis, J. J., E. H. M. Ealey, and E. Diener. 1969. Immune response of the tuatara, Sphenodon punctatum. Australian Journal of Experimental Biology and Medical Science 47:367-380.

Markwell, T. J. 1998. Relationship between tuatara Sphenodon punctatus and fairy prion Pachyptila turtur densities in different habitats on Takapourewa (Stephens Island), Cook Strait, New Zealand.Marine Ornithology 26:81-83.

Matson, K. D., B. I. Tieleman, and K. C. Klasing. 2006. Capture stress and the bactericidal competence of blood and plasma in five species of tropical birds. Physiological and Biochemical Zoology 79:556-564.

Maynard Smith, J. 1989. Trees, bundles or nets. Trends in Ecology and Evolution 4:302-304.

McCurdy, D. G., D. Shutler, A. Mullie, and M. R. Forbes. 1998. Sex-biased parasitism of avian hosts: relations to blood parasite taxon and mating system. Oikos 82:303-312.

McInnes, H. 1971. Salmonella saintpaul infection of sheep with lizards as possible reservoirs. New Zealand Veterinary Journal 19:163-164.

McVean, G., P. Awadalla, and P. Fearnhead. 2002. A coalescent-based method for detecting and estimating recombination from gene sequences. Genetics 160:1231-1241.

Mead, P. S., L. Slutsker, V. Dietz, L. F. McCaig, J. S. Bresee, C. Shapiro, P. M. Griffin, and R. V. Tauxe. 1999. Food-related illness and death in the United States. Emerging Infectious Diseases 5:607-625.

Medzhitov, R., and C. Janeway. 2000. Innate immunity. New England Journal of Medicine 343:338-344.

Melville, J., and J.A. Schulte II. 2001. Correlates of active body temperatures and microhabitat occupation in nine species of central Australian agamid lizards. Austral Ecology 26: 660-669.

Merchant, M., and A. Britton. 2006. Characterization of serum complement activity of saltwater (Crocodylus porosus) and freshwater (Crocodylus johnstoni) crocodiles. Comparative Biochemistry and Physiology Part A-Molecular \& Integrative Physiology 143:488-493.

Merchant, M., D. Thibodeaux, K. Loubser, and R. M. Elsey. 2004. Amoebacidal effects of serum from the American alligator (Alligator mississippiensis). Journal of Parasitology 90:1480-1483. 
Merchant, M. E., K. Mills, N. Leger, E. Jenkins, K. A. Vliet, and N. McDaniel. 2006. Comparisons of innate immune activity of all known living crocodylian species. Comparative Biochemistry and Physiology B-Biochemistry \& Molecular Biology 143:133-137.

Merchant, M. E., M. Pallansch, R. L. Paulman, J. B. Wells, A. Nalca, and R. Ptak. 2005. Antiviral activity of serum from the American alligator (Alligator mississippiensis). Antiviral Research 66:35-38.

Merchant, M. E., C. Roche, R. M. Elsey, and J. Prudhomme. 2003. Antibacterial properties of serum from the American alligator (Alligator mississippiensis). Comparative Biochemistry and Physiology B-Biochemistry \& Molecular Biology 136:505-513.

Mermin, J., L. Hutwagner, D. Vugia, S. Shallow, P. Daily, J. Bender, J. Koehler, R. Marcus, F. J. Angulo, and the Emerging Infections Program. 2004. Reptiles, amphibians, and human Salmonella infection: A population-based, case-control study. Clinical Infectious Diseases 38:S253-S261.

Middleton, D., E. O. Minot, and B. D. Gartrell. 2010. Salmonella enterica serovars in lizards of New Zealand's offshore islands. New Zealand Journal of Ecology 34:247-252.

Ministry-for-the-Environment. 2011. Climate change information. inwww.climatechange.govt.nz/physical-impacts-and-adaptation.

Mitchell, M. A., and S. M. Shane. 2001. Salmonella in reptiles. Seminars in Avian and Exotic Pet Medicine 10:25-35.

Mitchell, N. J., M. R. Kearney, N. J. Nelson, and W. P. Porter. 2008. Predicting the fate of a living fossil: how will global warming affect sex determination and hatching phenology in tuatara? Proceedings of the Royal Society B: Biological Sciences 275:2185-2193.

Mills, S. D., and B. B. Finlay. 1994. Comparison of Salmonella typhi and Salmonella typhimurium invasion, intracellular growth and localization in cultured human epithelial cells. Microbial Pathogenesis 17:409-423.

Moller, A. P., and J. T. Nielsen. 2007. Malaria and risk of predation: a comparative study of birds. Ecology 88:871-881.

Moller, A.P., G. Sorci, and J. Erritzoe. 1998. Sexual dimorphism in immune defense. American Naturalist 152: 605-619. 
Moller, H. 1985. Tree wetas (Hemideina crassicruris) (Orthoptera: Stenopelmatidae) of Stephens Island, Cook Strait. New Zealand Journal of Zoology 12:55-69.

Moore, J. A., C. H. Daugherty, and N. J. Nelson. 2009. Large male advantage: phenotypic and genetic correlates of territoriality in tuatara. Journal of Herpetology 43:570-578.

Moore, J. A., J. M. Hoare, C. H. Daugherty, and N. J. Nelson. 2007. Waiting reveals waning weight: monitoring over 54 years shows a decline in body condition of a long-lived reptile (tuatara, Sphenodon punctatus). Biological Conservation 135:181-188.

Moore, S.L., and K. Wilson. 2002. Parasites as a viability cost of sexual selection in natural populations of mammals. Science 297: 2015-2018.

Moro, C. V., C. J. De Luna, A. Tod, J. H. Guy, O. A. E. Sparagano, and L. Zenner. 2009. The poultry red mite (Dermanyssus gallinae): a potential vector of pathogenic agents. Experimental and Applied Acarology 48:93-104.

Mougeot, F. C. O., and S. M. Redpath. 2004. Sexual ornamentation relates to immune function in male red grouse Lagopus lagopus scoticus. Journal of Avian Biology $35: 425-433$.

Musser, J. M. 1996. Molecular population genetic analysis of emerged bacterial pathogens: Selected insights. Emerging Infectious Diseases 2:1-17.

Nachum, R., S. W. Watson, J. D. Sullivan, and S. E. Siegel. 1979. Anti-microbial defense mechanisms in the horseshoe crab (Limulus polyphemus) - preliminary observations with heat derived extracts of Limulus amoebocyte lysate. Journal of Invertebrate Pathology 33:290-299.

Nelson, R. J., and G. E. Demas. 2004. Seasonal patterns of stress, disease, and sickness responses. Current Directions in Psychological Science 13:198-201.

Newman, D. G. 1982. Tuatara, Sphenodon punctatus, and burrows, Stephens Island. in D. G. Newman, editor. New Zealand Herpetology. New Zealand Wildlife Service, Victoria University of Wellington, Wellington.

Newman, D. G. 1987. Burrow use and population-densities of tuatara (Sphenodon punctatus) and how they are influenced by fairy prions (Pachyptila turtur) on Stephens Island, New Zealand. Herpetologica 43:336-344.

Ochsenbein, A. F., and R. M. Zinkernagel. 2000. Natural antibodies and complement link innate and acquired immunity. Immunology Today 21:624-630. 
Octavia, S., and R. T. Lan. 2006. Frequent recombination and low level of clonality within Salmonella enterica subspecies I. Microbiology 152:1099-1108.

Olsen, A. R., and T. S. Hammack. 2000. Isolation of Salmonella spp. from the housefly, Musca domestica L., and the dump fly, Hydrotaea aenescens (Wiedemann) (Diptera : Muscidae), at caged-layer houses. Journal of Food Protection 63:958960.

Olsen, S. J., R. Bishop, F. W. Brenner, T. H. Roels, N. Bean, R. V. Tauxe, and L. Slutsker. 2001. The changing epidemiology of Salmonella: Trends in serotypes isolated from humans in the United States, 1987-1997. Journal of Infectious Diseases 183:753-761.

Origgi, F. C., P. A. Klein, K. Mathes, S. Blahak, R. E. Marschang, S. J. Tucker, and E. R. Jacobson. 2001. Enzyme-linked immunosorbent assay for detecting herpesvirus exposure in Mediterranean tortoises (spur-thighed tortoise [Testudo graeca] and Hermann's tortoise [Testudo hermanni]). Journal of Clinical Microbiology 39:3156-3163.

Ortiz-Catedral, L., S. M. H. Ismar, K. Baird, J. G. Ewen, M. E. Hauber, and D. H. Brunton. 2009. No evidence of Campylobacter, Salmonella and Yersinia in freeliving populations of the red-crowned parakeet (Cyanoramphus novaezelandiae). New Zealand Journal of Zoology 36:379-383.

Otokunefor, T. V., B. I. Kindzeka, I. O. Ibiteye, G. U. Osuji, F. O. Obi, and A. W. K. Jack. 2003. Salmonella in gut and droppings of three pest lizards in Nigeria. World Journal of Microbiology \& Biotechnology 19:545-548.

Parkhill, J., G. Dougan, K. D. James, N. R. Thomson, D. Pickard, J. Wain, C. Churcher, K. L. Mungall, S. D. Bentley, M. T. G. Holden, M. Sebaihia, S. Baker, D. Basham, K. Brooks, T. Chillingworth, P. Connerton, A. Cronin, P. Davis, R. M. Davies, L. Dowd, N. White, J. Farrar, T. Feltwell, N. Hamlin, A. Haque, T. T. Hien, S. Holroyd, K. Jagels, A. Krogh, T. S. Larsen, S. Leather, S. Moule, P. O'Gaora, C. Parry, M. Quail, K. Rutherford, M. Simmonds, J. Skelton, K. Stevens, S. Whitehead, and B. G. Barrell. 2001. Complete genome sequence of a multiple drug resistant Salmonella enterica serovar Typhi CT18. Nature 413:848-852.

Parsons, S. K., C. M. Bull, and D. M. Gordon. 2010. Low prevalence of Salmonella enterica in Australian wildlife. Environmental Microbiology Reports 2:657-659. 
Pasmans, F., S. Blahak, A. Martel, and N. Pantchev. 2008. Introducing reptiles into a captive collection: the role of the veterinarian. The Veterinary Journal 175:5368.

Pata, S., N. Yaraksa, S. Daduang, Y. Temsiripong, J. Svasti, T. Araki, and S. Thammasirirak. 2011. Characterization of the novel antibacterial peptide Leucrocin from crocodile (Crocodylus siamensis) white blood cell extracts. Developmental and Comparative Immunology 35:545-553.

Pennycott, T. W., A. Park, and H. A. Mather. 2006. Isolation of different serovars of Salmonella enterica from wild birds in Great Britain between 1995 and 2003. Veterinary Record 158:817-820.

Perez-Losada, M., E. B. Browne, A. Madsen, T. Wirth, R. P. Viscidi, and K. A. Crandall. 2006. Population genetics of microbial pathogens estimated from multilocus sequence typing (MLST) data. Infection Genetics and Evolution 6:97-112.

Perron, G. G., A. E. G. Lee, Y. Wang, W. E. Huang, and T. G. Barraclough. 2011. Bacterial recombination promotes the evolution of multi-drug-resistance in functionally diverse populations. Proceedings of the Royal Society B: Biological Sciences.

Pfleger, S., G. Benyr, R. Sommer, and A. Hassl. 2003. Pattern of Salmonella excretion in amphibians and reptiles in a vivarium. International Journal of Hygiene and Environmental Health 206:53-59.

Pollari, F., and C. Powers. 1998. Canadian Integrated Surveillance Report for 1995 on Salmonella, Campylobacter and Pathogenic Escherichia coli. inhttp://www.hcsc.gc.ca/pphb-dgspsp/publicat/ccdr-rmtc/98vol24/24s5/index.html.

Pond, S. L. K., and S. D. W. Frost. 2005. Not so different after all: a comparison of methods for detecting amino acid sites under selection. Molecular Biology and Evolution 22:1208-1222.

Pond, S. L. K., S. D. W. Frost, and S. V. Muse. 2005. HyPhy: hypothesis testing using phylogenies. Bioinformatics 21:676-679.

Pond, S. L. K., D. Posada, M. B. Gravenor, C. H. Woelk, and S. D. W. Frost. 2006. Automated phylogenetic detection of recombination using a genetic algorithm. Molecular Biology and Evolution 23:1891-1901.

Popoff, M. Y., J. Bockemühl, and L. L. Gheesling. 2003. Supplement 2001 (no. 45) to the Kauffmann-White scheme. Research in Microbiology 154:173-174. 
Porwollik, S., and M. McClelland. 2003. Lateral gene transfer in Salmonella. Microbes and Infection 5:977-989.

Preecharram, S., S. Daduang, W. Bunyatratchata, T. Araki, and S. Thammasirirak. 2008. Antibacterial activity from Siamese crocodile (Crocodylus siamensis) serum. African Journal of Biotechnology 7:3121-3128.

Pritchard, J. K., M. Stephens, and P. Donnelly. 2000. Inference of population structure using multilocus genotype data. Genetics 155:945-959.

Pritchard, J. K., X. Wena, and D. Falush. 2009. Documentation for structure software: version 2.3. inhttp://pritch.bed.uchicago.edu/structure.html.

Pye, G. W., D. R. Brown, M. F. Nogueira, K. A. Vliet, T. R. Schoeb, E. R. Jacobson, and R. A. Bennett. 2001. Experimental inoculation of broad-nosed caimans (Caiman latirostris) and Siamese crocodiles (Crocodylus siamensis) with Mycoplasma alligatoris. Journal of Zoo and Wildlife Medicine 32:196-201.

Quinn, P. J., M. E. Carter, B. Markey, and G. R. Carter. 1994. Clinical Veterinary Microbiology. Wolfe Publishing, London.

Ravel, J., I. T. Knight, C. E. Monahan, R. T. Hill, and R. R. Colwell. 1995. Temperature-induced recovery of Vibrio cholerae from the viable but nonculturable state: growth or resuscitation? Microbiology 141:377-383.

Readel, A. M., C. A. Phillips, and T. L. Goldberg. 2010. Prevalence of Salmonella in intestinal mucosal samples from free-ranging red-eared sliders (Trachemys scripta elegans) in IllinoisHerpetological Conservation and Biology 5:207-213.

Reddy, K. V. R., R. D. Yedery, and C. Aranha. 2004. Antimicrobial peptides: premises and promises. International Journal of Antimicrobial Agents 24:536-547.

Rest, J. S., J. C. Ast, C. C. Austin, P. J. Waddell, E. A. Tibbetts, J. M. Hay, and D. P. Mindell. 2003. Molecular systematics of primary reptilian lineages and the tuatara mitochondrial genome. Molecular Phylogenetics and Evolution 29:289297.

Richards, J. M., J. D. Brown, T. R. Kelly, A. L. Fountain, and J. M. Sleeman. 2004. Absence of detectable Salmonella cloacal shedding in free-living reptiles on admission to the wildlife center of Virginia. Journal of Zoo and Wildlife Medicine 35:562-563.

Robinson, R. A., and M. J. Daniel. 1968. The significance of Salmonella isolations from wild birds and rats in New Zealand. New Zealand Veterinary Journal 16:53-55. 
Roitt, I., J. Brostoff, and D. Male. 2001. Immunology. Sixth edition. Mosby, London. Rotariu, O., A. Smith-Palmer, J. Cowden, P. R. Bessell, G. T. Innocent, S. W. J. Reid, L. Matthews, J. Dallas, I. D. Ogden, K. J. Forbes, and N. J. C. Strachan. 2010. Putative household outbreaks of campylobacteriosis typically comprise single MLST genotypes. Epidemiology and Infection 138:1744-1747.

Rozen, Y., and S. Belkin. 2001. Survival of enteric bacteria in seawater. FEMS Microbiology Reviews 25:513-529.

Saad, A.H., and W. Ali. 1992. Seasonal-changes in humoral immunity and blood thyroxine levels in the toad, Buforegularis. Zoological Science 9: 349-356.

Saint Girons, H. 1980. Thermoregulation in reptiles with special reference to the tuatara and its ecophysiology. Tuatara 24:59-80.

Salcedo, C., L. Arreaza, B. Alcalá, L. de la Fuente, and J. A. Vázquez. 2003. Development of a multilocus sequence typing method for analysis of Listeria monocytogenes clones. Journal of Clinical Microbiology 41:757-762.

Saphra, I., and M. Wassermann. 1954. Salmonella Cholerae suis. A clinical and epidemiological evaluation of 329 infections identified between 1940 and 1954 in the New York Salmonella center. The American Journal of the Medical Sciences 228:525-533.

Scantlebury, M., M.M. McWilliams, N.J. Marks, J.T.A. Dick, H. Edgar, H. Lutermann. 2010. Effects of life-history traits on parasite load in grey squirrels. Journal of Zoology 282:246-255.

Schmidt, H. A., K. Strimmer, M. Vingron, and A. von Haeseler. 2002. TREE-PUZZLE: maximum likelihood phylogenetic analysis using quartets and parallel computing. Bioinformatics 18:502-504.

Schwanz, L. 2008. Chronic parasitic infection alters reproductive output in deer mice. Behavioral Ecology and Sociobiology 62:1351-1358.

Selander, R. K., P. Beltran, N. H. Smith, R. Helmuth, F. A. Rubin, D. J. Kopecko, K. Ferris, B. D. Tall, A. Cravioto, and J. M. Musser. 1990. Evolutionary genetic relationships of clones of Salmonella serovars that cause human typhoid and other enteric fevers. Infection and Immunity 58:2262-2275.

Shadomy, S. V., S. C. Waring, and C. L. Chappell. 2004. Combined use of enzymelinked immunosorbent assay and flow cytometry to detect antibodies to Trypanosoma cruzi in domestic canines in Texas. Clinical and Diagnostic Laboratory Immunology 11:313-319. 
Shaharabany, M., N. Gollop, S. Ravin, E. Golomb, L. DeMarco, P. C. Ferreira, W. L. Boson, and E. Friedman. 1999. Naturally occurring antibacterial activities of avian and crocodile tissues. Journal of Antimicrobial Chemotherapy 44:416-418.

Sinegani, A. A. S., and J. Maghsoudi. 2011. The effect of soil water potential on survival of fecal coliforms in soil treated with organic wastes under laboratory conditions. African Journal of Microbiology Research 5:229-240.

Sinyakov, M. S., M. Dror, H. M. Zhevelev, S. Margel, and R. R. Avtalion. 2002. Natural antibodies and their significance in active immunization and protection against a defined pathogen in fish. Vaccine 20:3668-3674.

Siroski, P. A., M. Merchant, M. V. P. Marco, C. I. Pina, and H. H. Ortega. 2010. Characterization of the Serum Complement Activity of the Broad-Snouted Caiman Caiman latirostris (Crocodilia: Alligatoridae). Zoological Studies 49:64-70.

Smith, J. J., J. P. Howington, and G. A. McFeters. 1994. Survival, physiological response and recovery of enteric bacteria exposed to a polar marine environment. Applied and Environmental Microbiology 60:2977-2984.

Spratt, B. G., and M. C. J. Maiden. 1999. Bacterial population genetics, evolution and epidemiology. Philosophical Transactions of the Royal Society B-Biological Sciences 354:701-710.

Spurgin, L., J. Illera, D. Padilla, and D. Richardson. 2012. Biogeographical patterns and co-occurrence of pathogenic infection across island populations of Berthelot's pipit (Anthus berthelotii). Oecologia 168:691-701.

Stanley-Price, M.R. 1989. Individual oryx in their natural environment in. Animal Reintroductions: the arabian oryx in Oman. Cambridge University Press, Cambridge.

Steen, H. B. 2000. Flow cytometry of bacteria: glimpses from the past with a view to the future. Journal of Microbiological Methods 42:65-74.

Stegemann, C., A. Kolobov, Y. F. Leonova, D. Knappe, O. Shamova, T. V. Ovchinnikova, V. N. Kokryakov, and R. Hoffmann. 2009. Isolation, purification and de novo sequencing of TBD-1, the first beta-defensin from leukocytes of reptiles. Proteomics 9:1364-1373.

Stephens, C. 2007. Plant succession, ecological restoration and the skinks of Stephens Island/Takapourewa. Victoria University of Wellington, Wellington. 
Strimmer, K., and A. von Haeseler. 1996. Quartet puzzling: A quartet maximumlikelihood method for reconstructing tree topologies. Molecular Biology and Evolution 13:964-969. 1997. Likelihood-mapping: A simple method to visualize phylogenetic content of a sequence alignment. Proceedings of the National Academy of Sciences of the United States of America 94:6815-6819.

Sukhnanand, S., S. Alcaine, L. D. Warnick, W.-L. Su, J. Hof, M. P. J. Craver, P. McDonough, K. J. Boor, and M. Wiedmann. 2005. DNA sequence-based subtyping and evolutionary analysis of selected Salmonella enterica serotypes. Journal of Clinical Microbiology 43:3688-3698.

Sunyer, J.O. and J.D. Lambris. 1998. Evolution and diversity of the complement system of poikilothermic vertebrates. Immunological Review 166: 39-57.

Tajima, F. 1989. Statistical method for testing the neutral mutation hypothesis by DNA polymorphism. Genetics 123:585-595.

Tartakovsky, B., P. D. Baetselier, M. Feldman, and S. Segal. 1981. Sex-associated differences in the immune response against fetal major histocompatibility antigens. Transplantation 32:395-397.

Taylor, E., J. Kastner, and D. Renter. 2010. Challenges involved in the Salmonella Saintpaul outbreak and lessons learned. Journal of Public Health Management and Practice 16:221-231.

Team, R. D. C. 2010. R: A Language and Environment for Statistical Computing. R Foundation for Statistical Computing, Vienna, Austria. Available at: http://www.R-project.org/.

Thompson, M. B., G. C. Packard, M. J. Packard, and B. Rose. 1996. Analysis of the nest environment of tuatara Sphenodon punctatus. Journal of Zoology 238:239251.

Thrusfield, M. V. 2005. Describing disease occurrence. Pages Pp 46-74 in Veterinary Epidemiology. Blackwell Science, Oxford, UK.

Tizard, I. 2004. Salmonellosis in wild birds. Seminars in Avian and Exotic Pet Medicine 13:50-66.

Treffers, C., L. Y. Chen, R. C. Anderson, and P. L. Yu. 2005. Isolation and characterisation of antimicrobial peptides from deer neutrophils. International Journal of Antimicrobial Agents 26:165-169. 
Turchin, A., and E. Hsu. 1996. The generation of antibody diversity in the turtle. The Journal of Immunology 156:3797-3805.

Twentyman, C. 1999. Diseases in New Zealand reptiles. Surveillance 26: 3-5.

Uhart, M., H. Ferreyra, R. Mattiello, M. I. Caffer, R. Terragno, A. Schettino, and W. Prado. 2011. Isolation of Salmonella spp. from Yacare caiman (Caiman yacare) and broad-snouted caiman (Caiman latirostris) from the Argenitine Chaco. Journal of Wildlife Diseases 47:271-277.

Une, Y., A. Sanbe, S. Suzuki, T. Niwa, K. Kawakami, R. Kurosawa, H. Izumiya, H. Watanabe, and Y. Kato. 2008. Salmonella enterica serotype typhimurium infection causing mortality in Eurasian tree sparrows (Passer montanus) in Hokkaido. Japanese Journal of Infectious Diseases 61:166-167.

Urwin, T., M.C.J. Maiden. 2003. Multi-locus sequence typing: a tood for global epidemiology. Trends in Microbiology 11: 479-487.

Uzzau, S., D. J. Brown, T. Wallis, S. Rubino, G. Leori, S. Bernard, J. Casadesus, D. J. Platt, and J. E. Olsen. 2000. Host adapted serotypes of Salmonella enterica. Epidemiology and Infection 125:229-255.

van Dijk, A., E. J. A. Veldhuizen, and H. P. Haagsman. 2008. Avian defensins. Veterinary Immunology and Immunopathology 124:1-18.

Vicente, J., L. Leon-Vizcaino, C. Gortazar, M. Jose Cubero, M. Gonzalez, and P. Martin-Atance. 2002. Antibodies to selected viral and bacterial pathogens in European wild boars from southcentral Spain. Journal of Wildlife Diseases 38:649-652.

Viscidi, R. P., and J. C. Demma. 2003. Genetic diversity of Neisseria gonorrhoeae housekeeping genes. Journal of Clinical Microbiology 41:197-204.

Vogel, C.W., and H.J. Müller-Eberhard. 1985a. The cobra complement system:I. The alternative pathway of activation. Developmental and Comparative Immunology 9: 311-325.

Vogel, C.W., and H.J. Müller-Eberhard. 1985b. The cobra complement system: II. The membrane attack complex. Developmental and Comparative Immunology 9: 327-333.

Vyas, J. M., A. G. Van der Veen, and H. L. Ploegh. 2008. The known unknowns of antigen processing and presentation. Nat Rev Immunol 8:607-618.

Walls, G. Y. 1981. Feeding ecology of the tuatara (Sphenodon puncatus) on Stephens Island, Cook Strait. New Zealand Journal of Ecology 4:89-97. 
Whiteman, N. K., K. D. Matson, J. L. Bollmer, and P. G. Parker. 2006. Disease ecology in the Galápagos Hawk (Buteo galapagoensis): host genetic diversity, parasite load and natural antibodies. Proceedings of the Royal Society B: Biological Sciences 273:797-804.

Wilson, K. J., and A. K. Lee. 1970. Changes in oxygen consumption and heart-rate with activity and body temperature in tuatara, Sphenodon-Punctatum. Comparative Biochemistry and Physiology 33:311-322.

Winfield, M. D., and E. A. Groisman. 2003. Role of nonhost environments in the lifestyles of Salmonella and Escherichia coli. Applied and Environmental Microbiology 69:3687-3694.

Wirz-Dittus, S., L. Belloy, D. Hussy, A. S. Waldvogel, and M. G. Doherr. 2010. Seroprevalence survey for Salmonella Abortusovis infection in Swiss sheep flocks. Preventive Veterinary Medicine 97:126-130.

Wiuff, C., B.-M. Thorberg, A. Engvall, and P. Lind. 2002. Immunochemical analyses of serum antibodies from pig herds in a Salmonella non-endemic region. Veterinary Microbiology 85:69-82.

Woodford, M. H., and P. B. Rossiter. 1994. Disease risks associated with wildlife translocation projects. in P. J. S. Olney, G. M. Mace, andA. T. C. Feistner, editors. Creative Conservation: interactive management of wild and captive animals. Chapman and Hall, London.

Woodward, D. L., R. Khakhria, and W. M. Johnson. 1997. Human salmonellosis associated with exotic pets. Journal of Clinical Microbiology 35:2786-2790.

Work, T. M., G. H. Balazs, R. A. Rameyer, S. P. Chang, and J. Berestecky. 2000. Assessing humoral and cell-mediated immune response in Hawaiian green turtles, Chelonia mydas. Veterinary Immunology and Immunopathology 74:179-194.

Yitzhaki, S., A. Barnea, A. Keysary, and E. Zahavy. 2004. New approach for serological testing for Leptospirosis by using detection of Leptospira agglutination by flow cytometry light scatter analysis. Journal of Clinical Microbiology 42:1680-1685.

Zasloff, M. 2002. Antimicrobial peptides of multicellular organisms. Nature 415:389395.

Zhang, L., and W.-H. Li. 2005. Human SNPs reveal no evidence of frequent positive selection. Molecular Biology and Evolution 22:2504-2507. 
Zhang, Y., P. Bi, and J. E. Hiller. 2010. Climate variations and Salmonella infection in Australian subtropical and tropical regions. Science of the Total Environment 408:524-530.

Zimmerman, L. M., R. T. Paitz, L. A. Vogel, and R. M. Bowden. 2010a. Variation in the seasonal patterns of innate and adaptive immunity in the red-eared slider (Trachemys scripta). Journal of Experimental Biology 213:1477-1483.

Zimmerman, L. M., L. A. Vogel, and R. M. Bowden. 2010b. Understanding the vertebrate immune system: insights from the reptilian perspective. Journal of Experimental Biology 213:661-671.

Zuk, M. 1996. Disease, endocrine-immune interactions, and sexual selection. Ecology 77: 1037-1042.

Zuk, M., and K. A. McKean. 1996. Sex differences in parasite infections: patterns and processes. International Journal for Parasitology 26:1009-1024. 


\section{APPENDIX A}

\section{AIA calculations of tuatara sera antigen recognition}

Table A1: Outcomes of wild tuatara serum candidate models for: (A) S. Saintpaul, (B) E. coli and (C) C. koseri. The variables included in each model, number of parameters (K), $\mathrm{AIC}_{\mathrm{c}}$ values, $\mathrm{AIC}_{\mathrm{c}}$ differences $\left(\Delta \mathrm{AIC} \mathrm{C}_{\mathrm{c}}\right)$, and Akaike weight $\left(\omega_{\mathrm{i}}\right)$ are shown for each species of bacteria tested ( $S$. Saintpaul, E. coli and C. koseri). Models are ranked from the smallest to largest $\mathrm{AIC}_{\mathrm{c}}$ value with the best supported models $\left(\Delta \mathrm{AIC}_{\mathrm{c}}<3.0\right)$ shown in bold.

\begin{tabular}{lllll}
\hline Aariables included & K & AICc & $\Delta$ AICc & W \\
\hline sex+season+location+(1|tuatara) & $\mathbf{6}$ & $\mathbf{4 2 9 . 5 3}$ & $\mathbf{0 . 0 0}$ & $\mathbf{0 . 5 2}$ \\
location+sex+(1|tuatara) & $\mathbf{5}$ & $\mathbf{4 3 1 . 5 8}$ & $\mathbf{2 . 0 5}$ & $\mathbf{0 . 1 9}$ \\
season+location+(1|tuatara) & 5 & 433.18 & 3.65 & 0.08 \\
season+sex+(1|tuatara) & 5 & 433.18 & 3.65 & 0.08 \\
season+location+sex+ticks+(1|tuatara) & 7 & 435.09 & 5.56 & 0.03 \\
sex+(1|tuatara) & 4 & 435.43 & 5.90 & 0.03 \\
location+(1|tuatara) & 4 & 435.43 & 5.90 & 0.03 \\
location+sex+ticks+(1|tuatara) & 6 & 437.13 & 7.60 & 0.01 \\
season+(1|tuatara) & 4 & 436.53 & 7.00 & 0.02 \\
ticks+season+location+(1|tuatara) & 6 & 438.63 & 9.10 & 0.01 \\
season+sex+ticks+(1|tuatara) & 6 & 439.43 & 9.90 & 0.00 \\
(1|tuatara) & 3 & 438.79 & 9.26 & 0.01 \\
location+ticks+(1|tuatara) & 5 & 440.68 & 11.15 & 0.00 \\
sex+ticks+(1|tuatara) & 5 & 441.58 & 12.05 & 0.00 \\
location+sex+mites+(1|tuatara) & 6 & 442.93 & 13.40 & 0.00 \\
season+ticks+(1|tuatara) & 5 & 442.58 & 13.05 & 0.00 \\
mites+season+location+(1|tuatara) & 6 & 444.43 & 14.90 & 0.00 \\
season+sex+mites+(1|tuatara) & 6 & 444.83 & 15.30 & 0.00 \\
\hline
\end{tabular}




\begin{tabular}{lllll}
\hline season+location+sex+mites+ticks+(1|tuatara) & 8 & 446.67 & 17.14 & 0.00 \\
ticks+(1|tuatara) & 4 & 444.73 & 15.20 & 0.00 \\
location+mites+(1|tuatara) & 5 & 446.48 & 16.95 & 0.00 \\
sex+mites+(1|tuatara) & 5 & 446.98 & 17.45 & 0.00 \\
location+sex+mites+ticks+(1|tuatara) & 7 & 448.59 & 19.06 & 0.00 \\
season+mites+(1|tuatara) & 5 & 447.98 & 18.45 & 0.00 \\
season+location+mites+ticks+(1| tuatara) & 7 & 449.99 & 20.46 & 0.00 \\
mites+(1|tuatara) & 4 & 450.23 & 20.70 & 0.00 \\
location+mites+ticks+(1|tuatara) & 6 & 451.93 & 22.40 & 0.00 \\
sex+mites+ticks+(1| tuatara) & 6 & 453.23 & 23.70 & 0.00 \\
season+mites+ticks+(1|tuatara) & 6 & 454.13 & 24.60 & 0.00 \\
mites+ticks+(1|tuatara) & 5 & 456.28 & 26.75 & 0.00 \\
\hline
\end{tabular}


B.

\begin{tabular}{|c|c|c|c|c|}
\hline Variables included & K & AICc & $\triangle \mathrm{AICc}$ & $\omega$ \\
\hline sex+season+location+(1| tuatara) & 6 & 453.93 & 0.00 & 0.00 \\
\hline location+sex+(1| tuatara) & 5 & 456.58 & 2.65 & 0.01 \\
\hline season+sex+(1| tuatara) & 5 & 456.78 & 2.85 & 0.01 \\
\hline season+location+(1 | tuatara) & 5 & 456.88 & 2.95 & 0.01 \\
\hline season+location+sex+ticks+(1| tuatara) & 7 & 459.19 & 5.26 & 0.02 \\
\hline sex+(1|tuatara) & 4 & 459.43 & 5.50 & 0.02 \\
\hline location+(1|tuatara) & 4 & 459.63 & 5.70 & 0.02 \\
\hline season+(1| tuatara) & 4 & 459.73 & 5.80 & 0.02 \\
\hline location+sex+ticks+(1| tuatara) & 6 & 461.73 & 7.80 & 0.02 \\
\hline season+sex+ticks+(1|tuatara) & 6 & 462.03 & 8.10 & 0.02 \\
\hline ticks+season+location+(1| tuatara) & 6 & 462.13 & 8.20 & 0.02 \\
\hline (1| tuatara) & 3 & 462.59 & 8.66 & 0.02 \\
\hline location+ticks+(1|tuatara) & 5 & 464.68 & 10.75 & 0.03 \\
\hline sex+ticks+(1|tuatara) & 5 & 464.68 & 10.75 & 0.03 \\
\hline season+ticks+(1|tuatara) & 5 & 464.98 & 11.05 & 0.03 \\
\hline location+sex+mites+(1| tuatara) & 6 & 466.13 & 12.20 & 0.04 \\
\hline season+sex+mites+(1|tuatara) & 6 & 466.43 & 12.50 & 0.04 \\
\hline mites+season+location+(1| tuatara) & 6 & 466.53 & 12.60 & 0.04 \\
\hline season+location+sex+mites+ticks+(1| tuatara) & 8 & 469.07 & 15.14 & 0.04 \\
\hline ticks+(1|tuatara) & 4 & 467.73 & 13.80 & 0.04 \\
\hline sex+mites+(1| tuatara) & 5 & 469.08 & 15.15 & 0.04 \\
\hline location+mites+(1| tuatara) & 5 & 469.18 & 15.25 & 0.04 \\
\hline season+mites+(1| tuatara) & 5 & 469.38 & 15.45 & 0.04 \\
\hline location+sex+mites+ticks+(1| tuatara) & 7 & 471.49 & 17.56 & 0.05 \\
\hline season+location+mites+ticks+(1| tuatara) & 7 & 471.89 & 17.96 & 0.05 \\
\hline mites+(1|tuatara) & 4 & 472.13 & 18.20 & 0.05 \\
\hline location+mites+ticks+(1| tuatara) & 6 & 474.43 & 20.50 & 0.06 \\
\hline sex+mites+ticks+(1| tuatara) & 6 & 474.63 & 20.70 & 0.06 \\
\hline season+mites+ticks+(1| tuatara) & 6 & 474.93 & 21.00 & 0.06 \\
\hline mites+ticks+(1|tuatara) & 5 & 477.68 & 23.75 & 0.07 \\
\hline
\end{tabular}


C.

\begin{tabular}{|c|c|c|c|c|}
\hline Variables included & $\mathbf{K}$ & AICc & $\triangle \mathrm{AICc}$ & $\omega$ \\
\hline sex+season+location+(1| tuatara) & 6 & 403.13 & 0.00 & 0.36 \\
\hline location+sex+(1|tuatara) & 5 & 404.48 & 1.35 & 0.18 \\
\hline season+sex+(1|tuatara) & 5 & 405.08 & 1.95 & 0.14 \\
\hline season+location+(1| tuatara) & 5 & 405.88 & 2.75 & 0.09 \\
\hline sex+(1|tuatara) & 4 & 406.43 & 3.30 & 0.07 \\
\hline season+location+sex+ticks+(1| tuatara) & 7 & 408.39 & 5.26 & 0.03 \\
\hline location+(1| tuatara) & 4 & 407.33 & 4.20 & 0.04 \\
\hline season+(1|tuatara) & 4 & 407.83 & 4.70 & 0.03 \\
\hline location+sex+ticks+(1| tuatara) & 6 & 409.43 & 6.30 & 0.02 \\
\hline season+sex+ticks+(1|tuatara) & 6 & 410.53 & 7.40 & 0.01 \\
\hline (1|tuatara) & 3 & 409.39 & 6.26 & 0.02 \\
\hline ticks+season+location+(1| tuatara) & 6 & 411.03 & 7.90 & 0.01 \\
\hline sex+ticks+(1|tuatara) & 5 & 411.68 & 8.55 & 0.00 \\
\hline location+ticks+(1| tuatara) & 5 & 412.18 & 9.05 & 0.00 \\
\hline season+ticks+(1|tuatara) & 5 & 413.08 & 9.95 & 0.00 \\
\hline ticks+(1|tuatara) & 4 & 414.33 & 11.20 & 0.00 \\
\hline season+sex+mites+(1| tuatara) & 6 & 415.63 & 12.50 & 0.00 \\
\hline location+sex+mites+(1| tuatara) & 6 & 415.63 & 12.50 & 0.00 \\
\hline mites+season+location+(1| tuatara) & 6 & 416.33 & 13.20 & 0.00 \\
\hline season+location+sex+mites+ticks+(1| tuatara) & 8 & 418.97 & 15.84 & 0.00 \\
\hline sex+mites+(1|tuatara) & 5 & 417.58 & 14.45 & 0.00 \\
\hline season+mites+(1|tuatara) & 5 & 418.58 & 15.45 & 0.00 \\
\hline location+mites+(1| tuatara) & 5 & 418.58 & 15.45 & 0.00 \\
\hline location+sex+mites+ticks+(1| tuatara) & 7 & 420.49 & 17.36 & 0.00 \\
\hline season+location+mites+ticks+(1| tuatara) & 7 & 421.49 & 18.36 & 0.00 \\
\hline mites+(1|tuatara) & 4 & 420.73 & 17.60 & 0.00 \\
\hline sex+mites+ticks+(1|tuatara) & 6 & 422.53 & 19.40 & 0.00 \\
\hline location+mites+ticks+(1| tuatara) & 6 & 423.23 & 20.10 & 0.00 \\
\hline season+mites+ticks+(1|tuatara) & 6 & 423.43 & 20.30 & 0.00 \\
\hline mites+ticks+(1| tuatara) & 5 & 425.28 & 22.15 & 0.00 \\
\hline
\end{tabular}


Table A2: Outcomes of captive tuatara serum candidate models for: (A) S. Saintpaul, (B) E. coli and (C) C. koseri. The variables included in each model, number of parameters $(\mathrm{K}), \mathrm{AIC}_{\mathrm{c}}$ values, $\mathrm{AIC}_{\mathrm{c}}$ differences $\left(\Delta \mathrm{AIC}_{\mathrm{c}}\right)$, and Akaike weight $\left(\omega_{\mathrm{i}}\right)$ are shown for each species of bacteria tested ( $S$. Saintpaul, E. coli and $C$. koseri). Models are ranked from the smallest to largest $\mathrm{AIC}_{\mathrm{c}}$ value with the best supported models $\left(\Delta \mathrm{AIC}_{\mathrm{c}}<2.0\right)$ shown in bold.

A.

\begin{tabular}{|c|c|c|c|c|}
\hline Variables included & $\mathbf{K}$ & AICc & $\triangle \mathrm{AICc}$ & $\omega$ \\
\hline sex+season+location+year+(1 | tuatara) & 14 & 475.10 & 0.00 & 0.75 \\
\hline sex+season+location+(1|tuatara) & 13 & 477.44 & 2.34 & 0.23 \\
\hline season+location+year+(1| tuatara) & 13 & 484.34 & 9.24 & 0.01 \\
\hline season+location+(1|tuatara) & 12 & 486.50 & 11.40 & 0.00 \\
\hline location+sex+year+(1|tuatara) & 11 & 486.58 & 11.48 & 0.00 \\
\hline location+sex+(1| tuatara) & 10 & 489.07 & 13.97 & 0.00 \\
\hline location+year+(1| tuatara) & 10 & 495.77 & 20.67 & 0.00 \\
\hline season+sex+year+(1|tuatara) & 8 & 496.37 & 21.27 & 0.00 \\
\hline location+(1| tuatara) & 9 & 498.17 & 23.07 & 0.00 \\
\hline season+sex+(1|tuatara) & 7 & 497.96 & 22.86 & 0.00 \\
\hline season+year+(1|tuatara) & 7 & 504.66 & 29.56 & 0.00 \\
\hline season+(1 | tuatara) & 6 & 506.35 & 31.25 & 0.00 \\
\hline sex+year+(1|tuatara) & 5 & 508.52 & 33.42 & 0.00 \\
\hline sex+(1| tuatara) & 4 & 510.27 & 35.17 & 0.00 \\
\hline year+(1|tuatara) & 4 & 517.87 & 42.77 & 0.00 \\
\hline (1|tuatara) & 3 & 519.79 & 44.69 & 0.00 \\
\hline
\end{tabular}




\begin{tabular}{lllll}
\hline B. & K & AlCc & $\Delta$ AICc & $\boldsymbol{\omega}$ \\
\hline sex+season+location+year+(1|tuatara) & $\mathbf{1 4}$ & $\mathbf{5 0 7 . 3 0}$ & $\mathbf{0 . 0 0}$ & $\mathbf{0 . 6 7}$ \\
sex+season+location+(1|tuatara) & $\mathbf{1 3}$ & $\mathbf{5 0 9 . 2 4}$ & $\mathbf{1 . 9 4}$ & $\mathbf{0 . 2 5}$ \\
season+location+year+(1|tuatara) & 13 & 513.54 & 6.24 & 0.03 \\
season+location+(1|tuatara) & 12 & 513.00 & 5.70 & 0.04 \\
location+sex+year+(1|tuatara) & 11 & 515.98 & 8.68 & 0.01 \\
location+sex+(1|tuatara) & 10 & 517.97 & 10.67 & 0.00 \\
location+year+(1|tuatara) & 10 & 520.07 & 12.77 & 0.00 \\
location+(1|tuatara) & 9 & 522.27 & 14.97 & 0.00 \\
season+sex+year+(1|tuatara) & 8 & 530.27 & 22.97 & 0.00 \\
season+sex+(1|tuatara) & 7 & 532.36 & 25.06 & 0.00 \\
season+year+(1|tuatara) & 7 & 533.26 & 25.96 & 0.00 \\
season+(1|tuatara) & 6 & 535.55 & 28.25 & 0.00 \\
sex+year+(1|tuatara) & 5 & 539.12 & 31.82 & 0.00 \\
sex+(1|tuatara) & 4 & 541.47 & 34.17 & 0.00 \\
year+(1|tuatara) & 4 & 542.67 & 35.37 & 0.00 \\
(1|tuatara) & 3 & 545.09 & 37.79 & 0.00 \\
\hline & & & &
\end{tabular}




\begin{tabular}{lllll}
\hline Variables included & K & AICc & $\Delta$ AICc & $\boldsymbol{\omega}$ \\
\hline sex+season+location+year+(1|tuatara) & $\mathbf{1 4}$ & $\mathbf{4 7 0 . 4 0}$ & $\mathbf{0 . 0 0}$ & $\mathbf{0 . 6 2}$ \\
sex+season+location+(1| tuatara) & $\mathbf{1 3}$ & $\mathbf{4 7 1 . 6 4}$ & $\mathbf{1 . 2 4}$ & $\mathbf{0 . 3 3}$ \\
season+location+year+(1| tuatara) & 13 & 476.14 & 5.74 & 0.03 \\
season+location+(1|tuatara) & 12 & 477.5 & 7.10 & 0.02 \\
location+sex+year+(1|tuatara) & 11 & 493.28 & 22.88 & 0.00 \\
season+sex+year+(1|tuatara) & 8 & 493.37 & 22.97 & 0.00 \\
location+sex+(1|tuatara) & 10 & 495.47 & 25.07 & 0.00 \\
season+sex+(1|tuatara) & 7 & 495.66 & 25.26 & 0.00 \\
location+year+(1|tuatara) & 10 & 498.47 & 28.07 & 0.00 \\
season+year+(1|tuatara) & 7 & 498.76 & 28.36 & 0.00 \\
location+(1|tuatara) & 9 & 500.77 & 30.37 & 0.00 \\
season+(1|tuatara) & 6 & 501.35 & 30.95 & 0.00 \\
sex+year+(1|tuatara) & 5 & 516.52 & 46.12 & 0.00 \\
sex+(1|tuatara) & 4 & 518.27 & 47.87 & 0.00 \\
year+(1|tuatara) & 4 & 522.57 & 52.17 & 0.00 \\
(1|tuatara) & 3 & 524.49 & 54.09 & 0.00 \\
\hline
\end{tabular}




\title{
APPENDIX B
}

\section{Comparison of colony forming units and optical}

\author{
density for anti-microbial assays
}

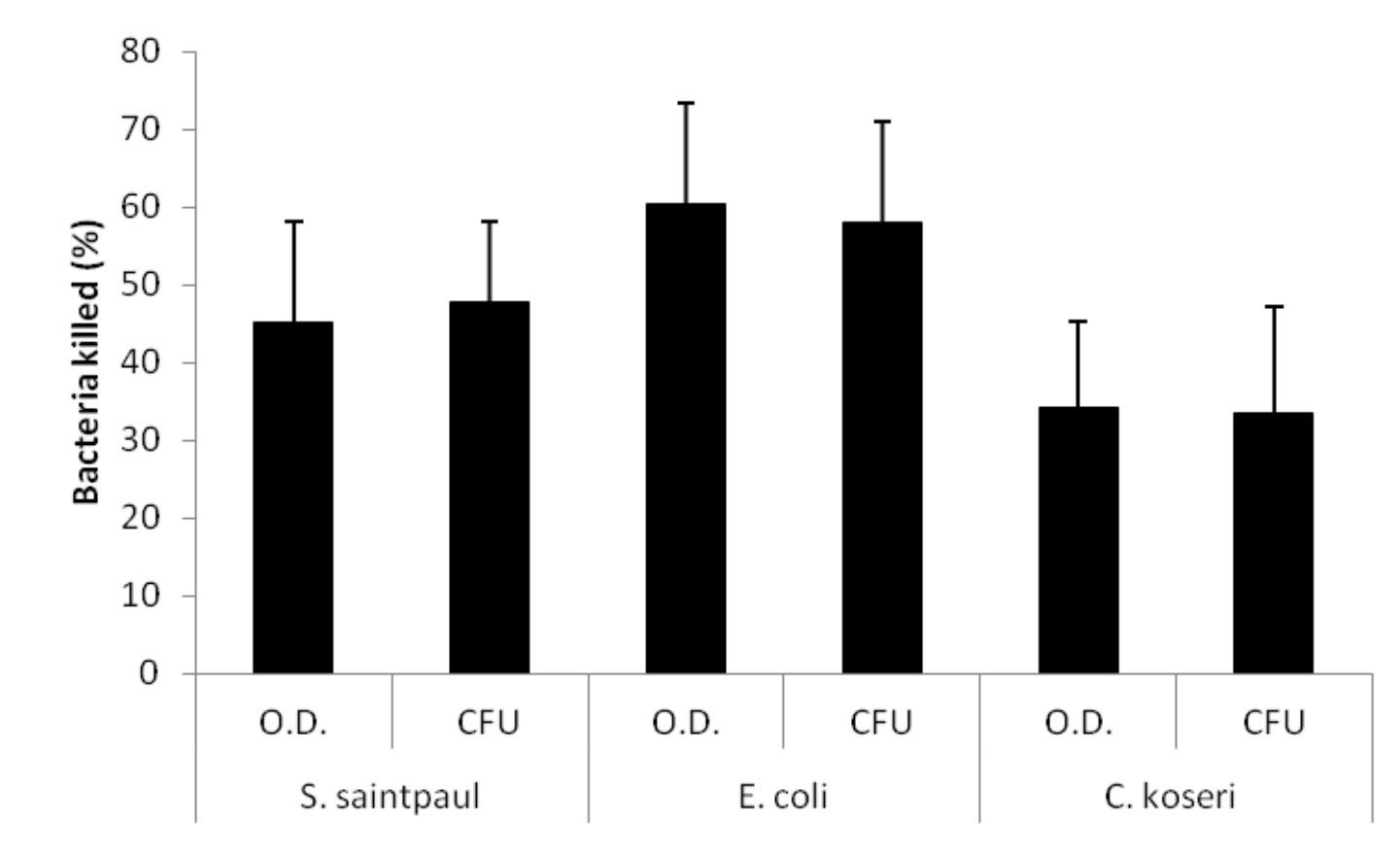

Figure A1: Anti-microbial assays were set-up using tuatara serum and three bacterial species, S. Saintpaul, E. coli and C. koseri. The percentage of bacteria killed was measured by colony forming units and optical density. There was no significant difference in the percentage of bacteria killed when measured using either method for any of the bacteria. Colony forming units is the "gold-standard" for measuring bactericidal capacity of serum samples, however it is very time consuming and consequently because no significant difference was found between the two measures I selected to use optical densities in all anti-microbial assays. 


\section{APPENDIXC}

\section{AIA calculations of tuatara sera anti-microbial activity}

Table C1: Outcomes of captive tuatara serum candidate models for: (A) S. Saintpaul, (B) E. coli and (C) C. koseri. The variables included in each model, number of parameters $(\mathrm{K}), \mathrm{AIC}_{\mathrm{c}}$ values, $\mathrm{AIC}_{\mathrm{c}}$ differences $\left(\Delta \mathrm{AIC}_{\mathrm{c}}\right)$, and Akaike weight $\left(\omega_{\mathrm{i}}\right)$ are shown for each species of bacteria tested (S. Saintpaul, E. coli and C. koseri). Models are ranked from the smallest to largest $\mathrm{AIC}_{\mathrm{c}}$ value with the best supported models $\left(\Delta \mathrm{AIC}_{\mathrm{c}}<3.0\right)$ shown in bold.

\begin{tabular}{llrrr}
\hline Variables included & K & AICc & $\Delta$ AICc & $\boldsymbol{\omega}$ \\
\hline season+location+sex+condition+(1|tuatara) & $\mathbf{1 5}$ & $\mathbf{5 6 3 . 4 1}$ & $\mathbf{0 . 0 0}$ & $\mathbf{0 . 9 6}$ \\
sex+season+location+(1|tuatara) & 14 & 570.88 & 7.48 & 0.02 \\
condition+season+location+(1|tuatara) & 13 & 572.57 & 9.17 & 0.01 \\
season+location+sex+svl+(1|tuatara) & 15 & 575.71 & 12.31 & 0.00 \\
location+sex+condition+(1|tuatara) & 12 & 579.78 & 16.38 & 0.00 \\
season+location+(1|tuatara) & 12 & 579.98 & 16.58 & 0.00 \\
svl+season+location+(1|tuatara) & 13 & 584.67 & 21.27 & 0.00 \\
location+sex+(1|tuatara) & 11 & 587.40 & 24.00 & 0.00 \\
location+condition+(1|tuatara) & 10 & 589.33 & 25.93 & 0.00 \\
location+sex+svl+(1|tuatara) & 12 & 591.98 & 28.58 & 0.00 \\
season+sex+condition+(1|tuatara) & 9 & 590.06 & 26.66 & 0.00 \\
location+(1|tuatara) & 9 & 596.96 & 33.56 & 0.00 \\
season+sex+(1|tuatara) & 8 & 598.28 & 34.88 & 0.00 \\
season+condition+(1|tuatara) & 7 & 599.20 & 35.80 & 0.00 \\
location+svl+(1|tuatara) & 10 & 601.43 & 38.03 & 0.00 \\
season+sex+svl+(1|tuatara) & 9 & 601.76 & 38.36 & 0.00 \\
sex+condition+(1|tuatara) & 6 & 607.70 & 44.30 & 0.00 \\
season+(1|tuatara) & 6 & 608.00 & 44.60 & 0.00 \\
season+svl+(1|tuatara) & 7 & 610.80 & 47.40 & 0.00 \\
\hline
\end{tabular}




\begin{tabular}{lllll}
\hline sex+(1|tuatara) & 5 & 616.08 & 52.68 & 0.00 \\
condition+(1|tuatara) & 4 & 617.25 & 53.85 & 0.00 \\
sex+svl+(1|tuatara) & 6 & 619.40 & 56.00 & 0.00 \\
svl+(1|tuatara) & 4 & 628.95 & 65.55 & 0.00 \\
$(1 \mid$ tuatara $)$ & 3 & 626.18 & 62.78 & 0.00 \\
\hline
\end{tabular}




\begin{tabular}{lrrrr}
\hline Variables included & K & AICc & $\Delta$ AICc & $\mathbf{\omega}$ \\
\hline season+location+sex+condition+(1|tuatara) & $\mathbf{1 5}$ & $\mathbf{5 0 3 . 5 1}$ & $\mathbf{0 . 0 0}$ & $\mathbf{0 . 9 7}$ \\
sex+season+location+(1|tuatara) & 14 & 511.78 & 8.27 & 0.02 \\
season+location+sex+svl+(1|tuatara) & 15 & 514.31 & 10.80 & 0.00 \\
condition+season+location+(1|tuatara) & 13 & 513.27 & 9.76 & 0.01 \\
location+sex+condition+(1|tuatara) & 12 & 514.98 & 11.47 & 0.00 \\
season+location+(1|tuatara) & 12 & 520.78 & 17.27 & 0.00 \\
svl+season+location+(1|tuatara) & 13 & 524.97 & 21.46 & 0.00 \\
location+sex+(1|tuatara) & 11 & 524.10 & 20.59 & 0.00 \\
location+sex+svl+(1|tuatara) & 12 & 525.98 & 22.47 & 0.00 \\
location+condition+(1|tuatara) & 10 & 525.43 & 21.92 & 0.00 \\
location+(1|tuatara) & 9 & 533.46 & 29.95 & 0.00 \\
season+sex+condition+(1|tuatara) & 9 & 534.46 & 30.95 & 0.00 \\
location+svl+(1|tuatara) & 10 & 537.13 & 33.62 & 0.00 \\
season+sex+(1|tuatara) & 8 & 542.18 & 38.67 & 0.00 \\
season+sex+svl+(1|tuatara) & 9 & 546.36 & 42.85 & 0.00 \\
season+condition+(1|tuatara) & 7 & 545.30 & 41.79 & 0.00 \\
sex+condition+(1|tuatara) & 6 & 547.00 & 43.49 & 0.00 \\
season+(1|tuatara) & 7 & 553.70 & 50.19 & 0.00 \\
sex+(1|tuatara) & 5 & 555.08 & 51.57 & 0.00 \\
season+svl+(1|tuatara) & 7 & 557.30 & 53.79 & 0.00 \\
sex+svl+(1|tuatara) & 5 & 558.80 & 55.29 & 0.00 \\
condition+(1|tuatara) & 559.25 & 55.73 & 0.00 \\
(1|tuatara) & 559.48 & 55.97 & 0.00 \\
svl+(1|tuatara) & 571.05 & 67.53 & 0.00 \\
\hline & & &
\end{tabular}




\begin{tabular}{lccrr}
\hline Variables included & K & AICc & $\Delta$ AICc & $\boldsymbol{\omega}$ \\
\hline season+location+sex+condition+(1|tuatara) & 15 & 538.41 & 0.00 & 0.97 \\
sex+season+location+(1|tuatara) & 14 & 545.98 & 7.57 & 0.02 \\
condition+season+location+(1|tuatara) & 15 & 548.31 & 9.90 & 0.01 \\
season+location+sex+svl+(1|tuatara) & 15 & 551.21 & 12.80 & 0.00 \\
season+location+(1|tuatara) & 12 & 553.98 & 15.57 & 0.00 \\
svl+season+location+(1|tuatara) & 13 & 558.87 & 20.46 & 0.00 \\
location+sex+condition+(1|tuatara) & 12 & 560.58 & 22.17 & 0.00 \\
location+sex+(1|tuatara) & 11 & 568.90 & 30.49 & 0.00 \\
location+condition+(1|tuatara) & 10 & 568.03 & 29.62 & 0.00 \\
season+sex+condition+(1|tuatara) & 9 & 568.46 & 30.05 & 0.00 \\
location+sex+svl+(1|tuatara) & 12 & 573.08 & 34.67 & 0.00 \\
location+(1|tuatara) & 9 & 577.36 & 38.95 & 0.00 \\
season+sex+(1|tuatara) & 8 & 576.78 & 38.37 & 0.00 \\
season+condition+(1|tuatara) & 7 & 576.80 & 38.39 & 0.00 \\
location+svl+(1|tuatara) & 10 & 580.73 & 42.32 & 0.00 \\
season+sex+svl+(1|tuatara) & 9 & 581.06 & 42.65 & 0.00 \\
season+(1|tuatara) & 6 & 585.70 & 47.29 & 0.00 \\
season+svl+(1|tuatara) & 7 & 589.50 & 51.09 & 0.00 \\
sex+condition+(1|tuatara) & 6 & 590.50 & 52.09 & 0.00 \\
sex+(1|tuatara) & 5 & 598.28 & 59.87 & 0.00 \\
condition+(1|tuatara) & 4 & 599.05 & 60.63 & 0.00 \\
sex+svl+(1|tuatara) & 6 & 602.50 & 64.09 & 0.00 \\
(1|tuatara) & 3 & 607.48 & 69.07 & 0.00 \\
svl+(1|tuatara) & 611.05 & 72.63 & 0.00 \\
\hline
\end{tabular}


Table C2: Outcomes of wild tuatara serum candidate models for: (A) S. Saintpaul, (B) E. coli and (C) C. koseri. The variables included in each model, number of parameters (K), $\mathrm{AIC}_{\mathrm{c}}$ values, $\mathrm{AIC}_{\mathrm{c}}$ differences $\left(\Delta \mathrm{AIC}_{\mathrm{c}}\right)$, and Akaike weight $\left(\omega_{\mathrm{i}}\right)$ are shown for each species of bacteria tested ( $S$. Saintpaul, E. coli and C. koseri). Models are ranked from the smallest to largest $\mathrm{AIC}_{\mathrm{c}}$ value with the best supported models $\left(\Delta \mathrm{AIC}_{\mathrm{c}}<3.0\right)$ shown in bold.

\begin{tabular}{|c|c|c|c|c|}
\hline \multirow[t]{2}{*}{ Variables included } & \multirow[t]{2}{*}{$\mathbf{K}$} & \multirow[t]{2}{*}{ AICc } & $\Delta$ & $\omega$ \\
\hline & & & \multicolumn{2}{|l|}{$\mathrm{AICc}$} \\
\hline season+location+sex+condition+(1|tuatara) & 7 & 413.10 & $\mathbf{0 . 0 0}$ & 0.48 \\
\hline season+location+sex+condition+ticks+(1|tuatara) & 8 & 414.63 & 1.52 & 0.22 \\
\hline location+sex+condition+(1|tuatara) & 6 & 416.51 & 3.40 & 0.09 \\
\hline location+sex+condition+ticks+(1|tuatara) & 7 & 417.60 & 4.50 & 0.05 \\
\hline condition+season+location+(1|tuatara) & 6 & 417.31 & 4.20 & 0.06 \\
\hline season+sex+condition+(1|tuatara) & 6 & 418.41 & 5.30 & 0.03 \\
\hline sex+season+location+(1|tuatara) & 6 & 419.41 & 6.30 & 0.02 \\
\hline season+location+sex+ticks+(1|tuatara) & 7 & 420.70 & 7.60 & 0.01 \\
\hline location+condition+(1|tuatara) & 5 & 420.83 & 7.73 & 0.01 \\
\hline season+location+sex+condition+mites $+(1 \mid$ tuatara $)$ & 8 & 423.83 & 10.72 & 0.00 \\
\hline sex + condition $+(1 \mid$ tuatara $)$ & 5 & 421.83 & 8.73 & 0.01 \\
\hline season+location+sex+condition+mites+ticks+(1|tuatara $)$ & 9 & 425.29 & 12.19 & 0.00 \\
\hline season+condition+(1|tuatara) & 5 & 422.63 & 9.53 & 0.00 \\
\hline location+sex+(1|tuatara) & 5 & 422.83 & 9.73 & 0.00 \\
\hline location+sex+ticks+(1|tuatara) & 6 & 423.81 & 10.70 & 0.00 \\
\hline location+condition+ticks+(1|tuatara) & 6 & 424.11 & 11.00 & 0.00 \\
\hline season+location+(1|tuatara) & 5 & 423.73 & 10.63 & 0.00 \\
\hline season+sex+ticks+(1|tuatara) & 6 & 425.21 & 12.10 & 0.00 \\
\hline season+sex+(1|tuatara) & 5 & 424.73 & 11.63 & 0.00 \\
\hline season+condition+ticks+(1|tuatara) & 6 & 425.41 & 12.30 & 0.00 \\
\hline location + sex + condition + mites $+(1 \mid$ tuatara $)$ & 7 & 427.00 & 13.90 & 0.00 \\
\hline location+sex+condition+mites+ticks+(1|tuatara) & 8 & 428.23 & 15.12 & 0.00 \\
\hline condition+(1|tuatara) & 4 & 426.27 & 13.16 & 0.00 \\
\hline ticks+season+location+(1|tuatara) & 6 & 427.41 & 14.30 & 0.00 \\
\hline
\end{tabular}




\begin{tabular}{|c|c|c|c|c|}
\hline season+sex+condition+mites+ticks+(1|tuatara) & 8 & 429.93 & 16.82 & 0.00 \\
\hline location+(1|tuatara) & 4 & 427.37 & 14.26 & 0.00 \\
\hline sex+ticks+(1|tuatara) & 5 & 428.43 & 15.33 & 0.00 \\
\hline $\operatorname{sex}+(1 \mid$ tuatara $)$ & 4 & 428.27 & 15.16 & 0.00 \\
\hline condition+ticks+(1|tuatara) & 5 & 428.93 & 15.83 & 0.00 \\
\hline season+location+condition+mites+ticks+(1|tuatara) & 8 & 431.13 & 18.02 & 0.00 \\
\hline season+location+sex+mites+ticks+(1|tuatara) & 8 & 431.33 & 18.22 & 0.00 \\
\hline season+(1|tuatara) & 4 & 428.97 & 15.86 & 0.00 \\
\hline location+condition+mites $+(1 \mid$ tuatara $)$ & 6 & 431.21 & 18.10 & 0.00 \\
\hline location+ticks+(1|tuatara) & 5 & 430.93 & 17.83 & 0.00 \\
\hline sex+condition+mites+ticks+(1|tuatara) & 7 & 433.00 & 19.90 & 0.00 \\
\hline sex + condition + mites $+(1 \mid$ tuatara $)$ & 6 & 432.41 & 19.30 & 0.00 \\
\hline season+ticks+(1|tuatara) & 5 & 432.03 & 18.93 & 0.00 \\
\hline season+condition+mites+(1|tuatara $)$ & 6 & 433.21 & 20.10 & 0.00 \\
\hline location+sex+mites+(1|tuatara) & 6 & 433.31 & 20.20 & 0.00 \\
\hline location+sex+mites+ticks+(1|tuatara) & 7 & 434.30 & 21.20 & 0.00 \\
\hline location+condition + mites + ticks $+(1 \mid$ tuatara $)$ & 7 & 434.30 & 21.20 & 0.00 \\
\hline mites+season+location+(1|tuatara) & 6 & 434.11 & 21.00 & 0.00 \\
\hline (1|tuatara) & 3 & 432.81 & 19.71 & 0.00 \\
\hline season+sex+mites+(1|tuatara) & 6 & 435.31 & 22.20 & 0.00 \\
\hline season+condition+mites+ticks+(1|tuatara) & 7 & 436.10 & 23.00 & 0.00 \\
\hline ticks+(1|tuatara) & 4 & 435.57 & 22.46 & 0.00 \\
\hline season+location+mites+ticks+(1|tuatara $)$ & 7 & 437.60 & 24.50 & 0.00 \\
\hline condition+mites $+(1 \mid$ tuatara $)$ & 5 & 436.73 & 23.63 & 0.00 \\
\hline sex + mites + ticks $+(1 \mid$ tuatara $)$ & 6 & 439.11 & 26.00 & 0.00 \\
\hline sex+mites+(1|tuatara $)$ & 5 & 438.73 & 25.63 & 0.00 \\
\hline condition+mites+ticks+(1|tuatara) & 6 & 439.51 & 26.40 & 0.00 \\
\hline season+mites+(1|tuatara) & 5 & 439.53 & 26.43 & 0.00 \\
\hline location+mites+ticks+(1|tuatara) & 6 & 441.01 & 27.90 & 0.00 \\
\hline season+mites+ticks+(1|tuatara) & 6 & 442.61 & 29.50 & 0.00 \\
\hline mites $+(1 \mid$ tuatara $)$ & 4 & 443.17 & 30.06 & 0.00 \\
\hline mites+ticks+(1|tuatara) & 5 & 446.03 & 32.93 & 0.00 \\
\hline location+condition+(1|tuatara) & 5 & 464.63 & 51.53 & 0.00 \\
\hline
\end{tabular}




\begin{tabular}{|c|c|c|c|c|}
\hline Variables included & $\mathbf{K}$ & AICc & $\Delta \mathrm{AICc}$ & $\omega$ \\
\hline season+location+sex+condition+(1|tuatara) & 7 & 413.80 & 0.00 & 0.68 \\
\hline condition+season+location+(1|tuatara) & 6 & 417.31 & 3.50 & 0.12 \\
\hline season+location+sex+condition+ticks+(1|tuatara) & 8 & 419.43 & 5.62 & 0.04 \\
\hline season+sex+condition+(1|tuatara) & 6 & 418.71 & 4.90 & 0.06 \\
\hline location+sex+condition+(1|tuatara) & 6 & 419.41 & 5.60 & 0.04 \\
\hline sex+season+location+(1|tuatara) & 6 & 420.51 & 6.70 & 0.02 \\
\hline season+location+sex+condition+mites $+(1 \mid$ tuatara $)$ & 8 & 424.43 & 10.62 & 0.00 \\
\hline season+condition+(1|tuatara) & 5 & 422.43 & 8.63 & 0.01 \\
\hline location+condition+(1|tuatara) & 5 & 423.23 & 9.43 & 0.01 \\
\hline location+sex+condition+ticks+(1|tuatara) & 7 & 425.00 & 11.20 & 0.00 \\
\hline season+location+(1|tuatara) & 5 & 423.93 & 10.13 & 0.00 \\
\hline sex+condition+(1|tuatara) & 5 & 424.33 & 10.53 & 0.00 \\
\hline season+location+sex+ticks+(1|tuatara) & 7 & 426.10 & 12.30 & 0.00 \\
\hline season+sex+(1|tuatara) & 5 & 425.33 & 11.53 & 0.00 \\
\hline location+sex+(1|tuatara) & 5 & 426.33 & 12.53 & 0.00 \\
\hline season+condition+ticks+(1|tuatara) & 6 & 427.41 & 13.60 & 0.00 \\
\hline season+location+sex+condition + mites + ticks $+(1 \mid$ tuatara $)$ & 9 & 430.09 & 16.29 & 0.00 \\
\hline location+condition+ticks+(1|tuatara) & 6 & 428.61 & 14.80 & 0.00 \\
\hline location+sex+condition+mites $+(1 \mid$ tuatara $)$ & 7 & 429.80 & 16.00 & 0.00 \\
\hline condition+(1|tuatara) & 4 & 428.37 & 14.56 & 0.00 \\
\hline ticks+season+location+(1|tuatara) & 6 & 429.61 & 15.80 & 0.00 \\
\hline season+(1|tuatara) & 4 & 428.87 & 15.06 & 0.00 \\
\hline season+sex+ticks+(1|tuatara) & 6 & 430.51 & 16.70 & 0.00 \\
\hline location+(1|tuatara) & 4 & 430.07 & 16.26 & 0.00 \\
\hline season+location+condition+mites+ticks+(1|tuatara) & 8 & 433.33 & 19.52 & 0.00 \\
\hline location+sex+ticks+(1|tuatara) & 6 & 432.01 & 18.20 & 0.00 \\
\hline $\operatorname{sex}+(1 \mid$ tuatara $)$ & 4 & 431.17 & 17.36 & 0.00 \\
\hline season+condition+mites+(1|tuatara) & 6 & 432.91 & 19.10 & 0.00 \\
\hline season+sex+condition+mites+ticks+(1|tuatara) & 8 & 434.63 & 20.82 & 0.00 \\
\hline location+condition+mites+(1|tuatara) & 6 & 433.71 & 19.90 & 0.00 \\
\hline condition+ticks+(1|tuatara) & 5 & 433.33 & 19.53 & 0.00 \\
\hline
\end{tabular}




\begin{tabular}{|c|c|c|c|c|}
\hline location+sex+condition+mites+ticks+(1|tuatara) & 8 & 435.53 & 21.72 & 0.00 \\
\hline mites+season+location+(1|tuatara) & 6 & 434.41 & 20.60 & 0.00 \\
\hline season+ticks+(1|tuatara) & 5 & 434.03 & 20.23 & 0.00 \\
\hline sex + condition + mites $+(1 \mid$ tuatara $)$ & 6 & 434.81 & 21.00 & 0.00 \\
\hline season+location+sex+mites+ticks+(1|tuatara) & 8 & 436.73 & 22.92 & 0.00 \\
\hline season+sex+mites $+(1 \mid$ tuatara $)$ & 6 & 435.81 & 22.00 & 0.00 \\
\hline location+ticks+(1|tuatara) & 5 & 435.63 & 21.83 & 0.00 \\
\hline (1|tuatara) & 3 & 435.11 & 21.31 & 0.00 \\
\hline location + sex + mites $+(1 \mid$ tuatara $)$ & 6 & 436.71 & 22.90 & 0.00 \\
\hline sex+ticks+(1|tuatara $)$ & 5 & 436.53 & 22.73 & 0.00 \\
\hline season+condition+mites+ticks+(1|tuatara) & 7 & 438.00 & 24.20 & 0.00 \\
\hline location+condition+mites+ticks+(1|tuatara) & 7 & 439.00 & 25.20 & 0.00 \\
\hline condition+mites $+(1 \mid$ tuatara $)$ & 5 & 438.63 & 24.83 & 0.00 \\
\hline season+location+mites+ticks+(1|tuatara) & 7 & 440.10 & 26.30 & 0.00 \\
\hline sex+condition+mites+ticks+(1|tuatara $)$ & 7 & 440.20 & 26.40 & 0.00 \\
\hline season+mites+(1|tuatara) & 5 & 439.33 & 25.53 & 0.00 \\
\hline location+condition+(1|tuatara) & 5 & 440.33 & 26.53 & 0.00 \\
\hline ticks+(1|tuatara) & 4 & 440.17 & 26.36 & 0.00 \\
\hline location+sex+mites+ticks+(1|tuatara) & 7 & 442.50 & 28.70 & 0.00 \\
\hline sex+mites $+(1 \mid$ tuatara $)$ & 5 & 441.53 & 27.73 & 0.00 \\
\hline condition+mites+ticks+(1|tuatara) & 6 & 443.81 & 30.00 & 0.00 \\
\hline season+mites+ticks+(1|tuatara) & 6 & 444.71 & 30.90 & 0.00 \\
\hline location+mites+ticks+(1|tuatara) & 6 & 446.01 & 32.20 & 0.00 \\
\hline mites+(1|tuatara) & 4 & 445.27 & 31.46 & 0.00 \\
\hline sex+mites+ticks+(1|tuatara $)$ & 6 & 447.01 & 33.20 & 0.00 \\
\hline mites+ticks+(1|tuatara) & 5 & 450.63 & 36.83 & 0.00 \\
\hline
\end{tabular}




\begin{tabular}{|c|c|c|c|c|}
\hline Variables included & $\mathbf{K}$ & AICc & $\Delta$ AICc & $\omega$ \\
\hline season+location+sex+condition+(1|tuatara) & 7 & 399.10 & $\mathbf{0 . 0 0}$ & 0.51 \\
\hline location+sex+condition+(1|tuatara) & 6 & 401.41 & 2.30 & 0.16 \\
\hline condition+season+location+(1|tuatara) & 6 & 402.41 & 3.30 & 0.10 \\
\hline season+sex+condition+(1|tuatara) & 6 & 402.61 & 3.50 & 0.09 \\
\hline season+location+sex+condition+ticks+(1|tuatara) & 8 & 406.23 & 7.12 & 0.01 \\
\hline sex+season+location+(1|tuatara) & 6 & 405.01 & 5.90 & 0.03 \\
\hline location+condition+(1|tuatara) & 5 & 404.83 & 5.73 & 0.03 \\
\hline sex+condition+(1|tuatara) & 5 & 405.03 & 5.93 & 0.03 \\
\hline season+condition+(1|tuatara) & 5 & 406.03 & 6.93 & 0.02 \\
\hline location+sex+condition+ticks+(1|tuatara) & 6 & 407.71 & 8.60 & 0.01 \\
\hline location+sex+(1|tuatara) & 5 & 407.43 & 8.33 & 0.01 \\
\hline season+location+sex+condition+mites+(1|tuatara) & 8 & 410.03 & 10.92 & 0.00 \\
\hline season+location+(1|tuatara) & 5 & 408.43 & 9.33 & 0.00 \\
\hline season+sex+(1|tuatara) & 5 & 408.63 & 9.53 & 0.00 \\
\hline condition+(1|tuatara) & 4 & 408.57 & 9.46 & 0.00 \\
\hline season+location+sex+ticks+(1|tuatara) & 7 & 412.10 & 13.00 & 0.00 \\
\hline location+sex + condition + mites $+(1 \mid$ tuatara $)$ & 7 & 412.30 & 13.20 & 0.00 \\
\hline location+condition+ticks+(1|tuatara) & 6 & 411.91 & 12.80 & 0.00 \\
\hline location+(1|tuatara) & 4 & 410.97 & 11.86 & 0.00 \\
\hline $\operatorname{sex}+(1 \mid$ tuatara $)$ & 4 & 411.17 & 12.06 & 0.00 \\
\hline season+condition+ticks+(1|tuatara) & 6 & 413.11 & 14.00 & 0.00 \\
\hline season+(1|tuatara) & 4 & 412.07 & 12.96 & 0.00 \\
\hline location+sex+ticks+(1|tuatara) & 6 & 414.41 & 15.30 & 0.00 \\
\hline season+location+sex+condition+mites+ticks+(1|tuatara) & 9 & 417.29 & 18.19 & 0.00 \\
\hline ticks+season+location+(1|tuatara) & 6 & 415.61 & 16.50 & 0.00 \\
\hline season+sex+ticks+(1|tuatara) & 6 & 415.61 & 16.50 & 0.00 \\
\hline location+condition+mites+(1|tuatara) & 6 & 415.71 & 16.60 & 0.00 \\
\hline sex + condition + mites $+(1 \mid$ tuatara $)$ & 6 & 416.01 & 16.90 & 0.00 \\
\hline condition+ticks+(1|tuatara) & 5 & 415.53 & 16.43 & 0.00 \\
\hline (1|tuatara) & 3 & 414.71 & 15.61 & 0.00 \\
\hline season+condition+mites+(1|tuatara) & 6 & 417.01 & 17.90 & 0.00 \\
\hline location+sex+condition+mites+ticks+(1|tuatara) & 6 & 418.01 & 18.90 & 0.00 \\
\hline
\end{tabular}




\begin{tabular}{lllll}
\hline location+sex+mites+(1|tuatara) & 6 & 418.31 & 19.20 & 0.00 \\
location+ticks+(1|tuatara) & 5 & 417.93 & 18.83 & 0.00 \\
sex+ticks+(1|tuatara) & 5 & 418.03 & 18.93 & 0.00 \\
season+location+condition+mites+ticks+(1|tuatara) & 8 & 420.53 & 21.42 & 0.00 \\
mites+season+location+(1|tuatara) & 6 & 419.11 & 20.00 & 0.00 \\
season+sex+condition+mites+ticks+(1|tuatara) & 8 & 420.73 & 21.62 & 0.00 \\
season+sex+mites+(1|tuatara) & 6 & 419.61 & 20.50 & 0.00 \\
season+ticks+(1|tuatara) & 5 & 419.13 & 20.03 & 0.00 \\
condition+mites+(1|tuatara) & 5 & 419.43 & 20.33 & 0.00 \\
season+location+sex+mites+ticks+(1|tuatara) & 8 & 423.03 & 23.92 & 0.00 \\
location+condition+mites+ticks+(1|tuatara) & 7 & 422.90 & 23.80 & 0.00 \\
location+condition+(1|tuatara) & 5 & 421.73 & 22.63 & 0.00 \\
sex+condition+mites+ticks+(1|tuatara) & 7 & 423.10 & 24.00 & 0.00 \\
sex+mites+(1|tuatara) & 5 & 422.03 & 22.93 & 0.00 \\
ticks+(1|tuatara) & 4 & 421.67 & 22.56 & 0.00 \\
season+condition+mites+ticks+(1|tuatara) & 7 & 424.10 & 25.00 & 0.00 \\
season+mites+(1|tuatara) & 5 & 422.93 & 23.83 & 0.00 \\
location+sex+mites+ticks+(1|tuatara) & 7 & 425.40 & 26.30 & 0.00 \\
season+location+mites+ticks+(1|tuatara) & 7 & 426.30 & 27.20 & 0.00 \\
condition+mites+ticks+(1|tuatara) & 6 & 426.51 & 27.40 & 0.00 \\
mites+(1|tuatara) & 4 & 425.57 & 26.46 & 0.00 \\
location+mites+ticks+(1|tuatara) & 6 & 428.81 & 29.70 & 0.00 \\
sex+mites+ticks+(1|tuatara) & 6 & 429.01 & 29.90 & 0.00 \\
season+mites+ticks+(1|tuatara) & 6 & 430.01 & 30.90 & 0.00 \\
mites+ticks+(1|tuatara) & 5 & 432.53 & 33.43 & 0.00 \\
\hline
\end{tabular}




\section{APPENDIX D}

\section{Individual maximum likelihood gene trees assigned by}

\section{MLST}

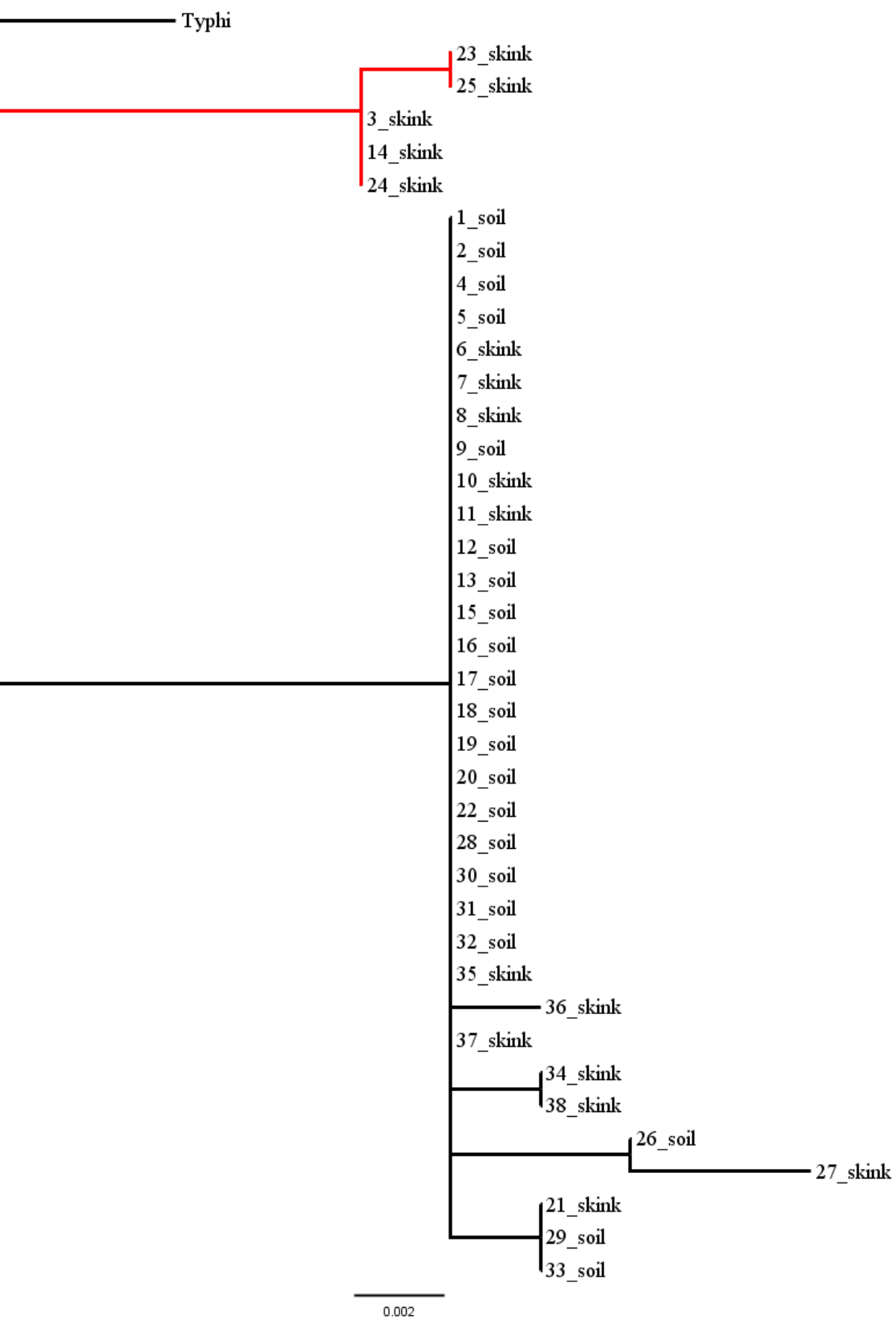

Figure D1: Maximum likelihood of ThrA sequences. Isolates serotyped as $S$.

Mississippi (red) and S. Saintpaul (black). Tree is rooted using S. Typhi as the outgroup. 


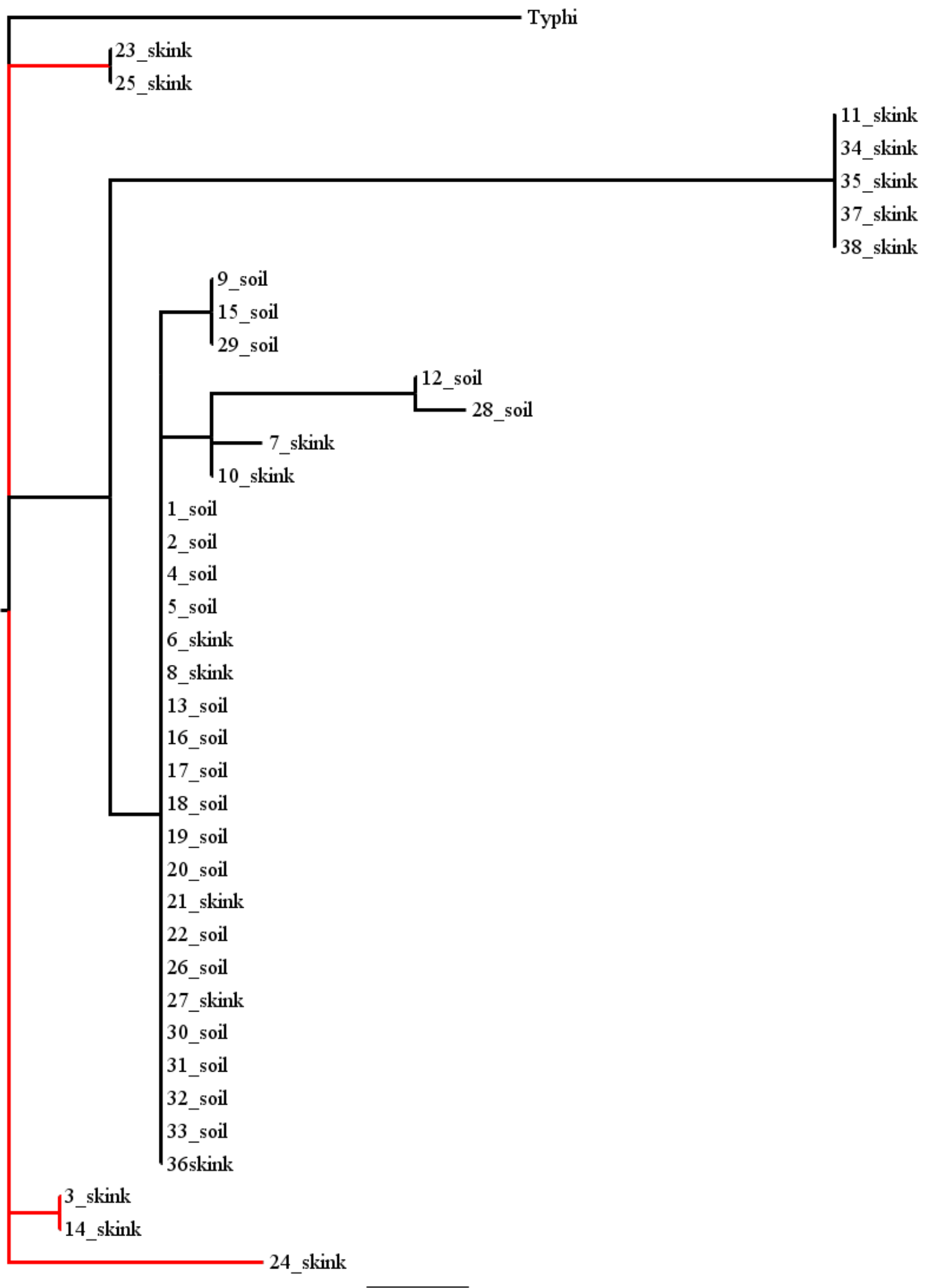

Figure D2: Maximum likelihood of SucA sequences. Isolates serotyped as $S$.

Mississippi (red) and S. Saintpaul (black). Tree is rooted using S. Typhi as the outgroup. 


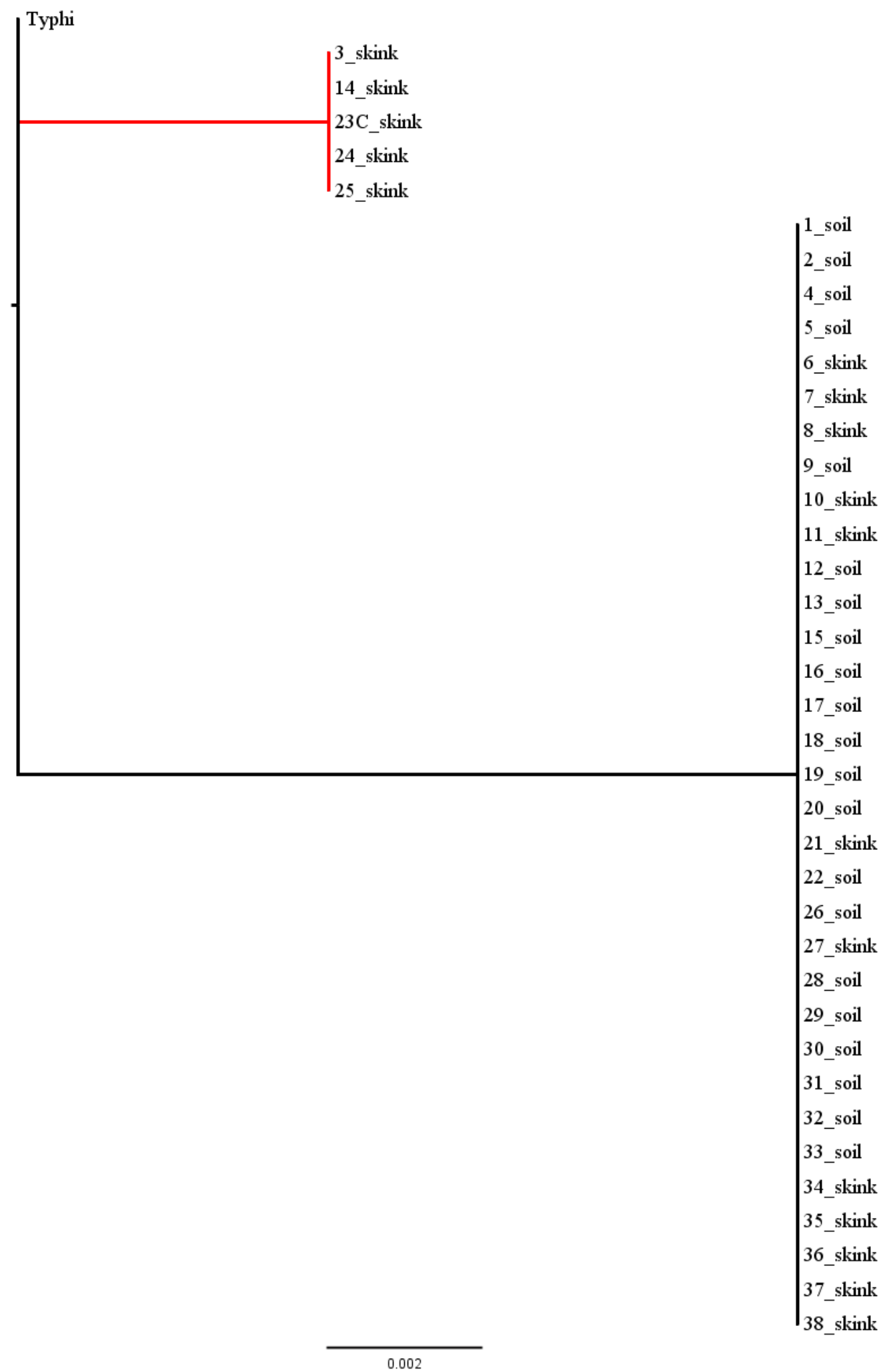

Figure D3: Maximum likelihood of dnaN sequences. Isolates serotyped as $S$.

Mississippi (red) and S. Saintpaul (black). Tree is rooted using S. Typhi as the outgroup. 
